International Journal of Financial Studies

\title{
Topics in Sports Finance
}

Edited by

Duane Rockerbie and Angel Barajas Printed Edition of the Special Issue Published in International Journal of Financial Studies 
Topics in Sports Finance 



\section{Topics in Sports Finance}

Special Issue Editors

Duane Rockerbie

Angel Barajas 
Special Issue Editors

Duane Rockerbie

Angel Barajas

University of Lethbridge

HSE University

Canada

Russia

Editorial Office

MDPI

St. Alban-Anlage 66

4052 Basel, Switzerland

This is a reprint of articles from the Special Issue published online in the open access journal International Journal of Financial Studies (ISSN 2227-7072) from 2018 to 2019 (available at: https:// www.mdpi.com/journal/ijfs/special_issues/sports_finance)

For citation purposes, cite each article independently as indicated on the article page online and as indicated below:

LastName, A.A.; LastName, B.B.; LastName, C.C. Article Title. Journal Name Year, Article Number, Page Range.

ISBN 978-3-03921-066-4 (Pbk)

ISBN 978-3-03921-067-1 (PDF)

(C) 2019 by the authors. Articles in this book are Open Access and distributed under the Creative Commons Attribution (CC BY) license, which allows users to download, copy and build upon published articles, as long as the author and publisher are properly credited, which ensures maximum dissemination and a wider impact of our publications.

The book as a whole is distributed by MDPI under the terms and conditions of the Creative Commons license CC BY-NC-ND. 


\section{Contents}

About the Special Issue Editors $\ldots \ldots \ldots \ldots \ldots \ldots \ldots$ vii

Preface to "Topics in Sports Finance" $\ldots \ldots \ldots \ldots \ldots \ldots \ldots \ldots$ ix

Panagiotis E. Dimitropoulos and Konstantinos Koronios

Earnings Persistence of European Football Clubs under UEFA's FFP

Reprinted from: Int. J. Financial Stud. 2018, 6, 43, doi:10.3390/ijfs6020043 . . . . . . . . . . . . 1

Egon Franck

European Club Football after "Five Treatments" with Financial Fair Play-Time for an Assessment

Reprinted from: Int. J. Financial Stud. 2018, 6, 97, doi:10.3390/ijfs6040097 . . . . . . . . . . . . 16

Mercedes Mareque, Angel Barajas and Francisco Lopez-Corrales

The Impact of Union of European Football Associations (UEFA) Financial Fair Play Regulation on Audit Fees: Evidence from Spanish Football

Reprinted from: Int. J. Financial Stud. 2018, 6, 92, doi:10.3390/ijfs6040092 . . . . . . . . . . . . 35

Wladimir Andreff

Financial and Sporting Performance in French Football Ligue 1: Influence on the Players' Market

Reprinted from: Int. J. Financial Stud. 2018, 6, 91, doi:10.3390/ijfs6040091 . . . . . . . . . . . . 55

\section{Duane Rockerbie and Stephen Easton}

Revenue Sharing in Major League Baseball: The Moments That Meant so Much

Reprinted from: Int. J. Financial Stud. 2018, 6, 71, doi:10.3390/ijfs6030071 . . . . . . . . . . . . 72

Rodney Paul, Andrew Weinbach and Nick Riccardi

Attendance in the Canadian Hockey League: The Impact of Winning, Fighting, Uncertainty of Outcome, and Weather on Junior Hockey Attendance

Reprinted from: Int. J. Financial Stud. 2019, 7, 12, doi:10.3390/ijfs7010012 . . . . . . . . . . . 88

Benjamin Baumer and Andrew Zimbalist

The Impact of College Athletic Success on Donations and Applicant Quality

Reprinted from: Int. J. Financial Stud. 2019, 7, 19, doi:10.3390/ijfs7020019 . . . . . . . . . . . . 99

Aju J. Fenn, Lucas Gerdes and Samuel Rothstein

Country of Origin Effects on the Average Annual Values of NHL Player Contracts

Reprinted from: Int. J. Financial Stud. 2019, 7, 24, doi:10.3390/ijfs7020024 . . . . . . . . . . . . 122

Daniel Plumley, Rob Wilson, Robbie Millar and Simon Shibli

Howzat? The Financial Health of English Cricket: Not Out, Yet

Reprinted from: Int. J. Financial Stud. 2019, 7, 11, doi:10.3390/ijfs7010011 . . . . . . . . . . . . 133

\section{Paul Gift}

Performance Bonuses and Effort: Evidence from Fight Night Awards in Mixed Martial Arts

Reprinted from: Int. J. Financial Stud. 2019, 7, 13, doi:10.3390/ijfs7010013 . . . . . . . . . . . . 150 



\section{About the Special Issue Editors}

Duane Rockerbie, Professor of Economics, has published extensively in the field of sports economics in Journal of Sports Economics and International Journal of Sport Finance, among others, as well as authored chapters in sports economics for various volumes. He is a past Vice President of the North American Association of Sports Economists and has taught an undergraduate course in sports economics for the last 20 years. Dr. Rockerbie is also a member of the Editorial Board for the Journal of Sports Economics. His other research interests include international finance and the economics of higher education.

Angel Barajas is Professor of Finance and Head of the Department of Finance at the St Petersburg School of Economics of Management (NRU Higher School of Economics). Moreover, he is the Academic Supervisor of the International Laboratory of Intangible-Driven Economy (NRU Higher School of Economics-Perm Campus). Dr. Barajas has been a Visiting Lecturer at Universities in Germany, Spain, and UK. He was Director of the MBA in Sport at University of Vigo in 2012-2016. His research interests include investment valuation, intellectual capital, and finance of sports. 



\section{Preface to "Topics in Sports Finance"}

Sports economics is a relatively new field of research that is experiencing rapid growth in the economics literature. The importance of the sports industry to economies, coupled with the availability of financial and productivity data, have made the study of sports economics a useful avenue for exploring research questions that have eluded mainstream economics fields. The main goal of this Special Issue, "Topics in Sports Finance", is to encourage theoretical and applied research in sports economics that is of interest to both academics and practitioners. This Special Issue is a collection representing the 10 research papers published in the International Journal of Financial Studies under the issue "Sports Finance 2018".

The Special Issue "Topics in Sports Finance" begins with four articles that examine the financial health of European football in recent decades. The UEFA Financial Fair Play (FFP) regulations were developed in response to the deteriorating financial situation of football clubs in Europe. Many clubs have operated with annual operating losses and been in negative equity positions. The fear of long-established football clubs entering into receivership was becoming a looming reality.

The FFP regulations were adopted for the 2011-12 European football league season. At the broadest level, the regulations require the submission of independently audited annual financial statements to UEFA, the banning of overdue payments on player transfers and owed taxes, a break-even requirement over the sum of three consecutive reporting years, and the disallowing of a negative equity position that worsens over two consecutive years. Failure to meet these regulations can result in penalties of warnings, fines, withholding of prize money and transfer bans, as well as additional penalties that can be imposed by the national associations. The goals of the FFP regulations were two-fold: 1) to promote financial stability of UEFA clubs and to improve the overall level of profitability by limiting expenses, and 2) to reduce the competitive gap between the financially large and small clubs.

Dimitropoulos and Koronios (DK) focus on the stability of reportable revenues (as defined in the FFP regulations) and whether the FFP regulations have improved revenue stability. Stability is defined as the ability to predict next season's revenue from the current season's revenue. Using a large sample of 109 European clubs, DK find favorable results that support the FFP objectives, more so for financially smaller clubs. This is an important result since increased financially stability can reduce borrowing costs for capital (lower risk premiums) and make the clubs more attractive to shareholders (if they are held by shareholders).

The focus on club revenues in response to the FFP regulations is continued by Frank. Using summary financial data garnered from UEFA reports, Frank notes that reportable club revenues have improved since 2011-12, and attributes this growth to more responsible financial decisions by club management, knowing that the FFP regulations prohibit moral hazard type behavior that relies on ex post "bailouts" by club sponsors or owners. Financial parity has become more elusive under the FFP regulations, and Frank attributes this to the greater ability of larger clubs to finance higher payrolls by generating higher revenues, while the smaller revenue-generating ability of smaller clubs limits their payroll growth. The FFP regulations do not directly address this issue, and Frank suggests some possible solutions.

The FFP regulations could result in unexpected increases in the expenses of football clubs that are not associated with payrolls and player acquisitions. Mareque, Barajas, and Lopez-Corrales (MBLC) examine the effects on auditing fees for clubs in the Spanish First Division. It could be the case that 
audit fees increased post-FFP due to the increased scrutiny the financial statements would receive from UEFA. MBLC found significantly higher audit fees using a regression model that uses a number of independent variables to explain audit fees. This could put clubs at a financial disadvantage post-FFP, however, MBLC note that the higher expected future revenues- - that seem to be result from the FFP regulations—could more than offset the higher fees.

Despite the intentions of the FFP regulations to improve club profitability, Andreff notes that the majority of clubs in French League 1 still operate with annual losses, largely due to high payroll costs that have not translated into Champions League or Europa League prize monies. Clubs may have the ability to absorb these losses by securing lucrative sponsorship deals or by having owners who can subsidize losses through other business ventures. Andreff uses this logic to formalize a "soft budget constraint" that encourages profit-maximizing clubs to overspend on payrolls and player transfers.

The next four papers in this Special Issue focus on North American sports leagues and ask a great diversity of questions. Revenue sharing is an accepted business practice in the four major North American sports Leagues (NFL, MLB, NBA, and NHL). Contributing a share of club revenues into a central fund and then distributing the fund back to the clubs (equally in the NFL and MLB, and not equally in the NBA and NHL) is argued to support small-market clubs and improve parity. Recent theoretical and empirical research suggests that parity worsens with revenue sharing. Rockerbie and Easton (RE) suggest an alternative, but complementary, argument for revenue sharing: that revenue sharing reduces the variance of revenues and provides a welfare gain to club owners by diversifying their revenues. After developing a measure of welfare gain, RE estimate significant welfare gains for MLB clubs over the last two decades.

Ice hockey is a fast, physical game with frequent contact and minor confrontations. The professional NHL and the semi-pro Canadian Hockey League (CHL) do not condone fighting but recognize that fighting is allowable by imposing lighter penalties than other sports leagues. Paul, Weinbach, and Riccardi (PWR) estimate the effect of fighting on game attendance in the CHL using a regression model that controls for other factors that could affect attendance. They also contribute to the mounting evidence that suggests that the uncertainty of outcome is not a factor in attendance demand, an important result for theoretical models that incorporate outcome uncertainty in demand functions.

Although not formally a sports league, the NCAA is certainly moving in that direction by adopting similar business practices (revenue sharing, a playoff system, and a centralized business model). American football is the most lucrative revenue source for NCAA schools that does not arise from tuition, donors, or governments. Baumer and Zimbalist (BZ) note that most of the athletic departments in a large sample of NCAA schools incur operating deficits, although determining what costs should be included in the calculation is not without controversy. BZ test the assertion that a successful athletic program confers other benefits that might justify running the program in a deficit, such as more applications, better quality students, and more donations and government funding. Their regression model is robust, and the results convincingly support the previous literature. The upshot is that without any significant benefits, college athletic departments are simply win-maximizers.

European and Russian players comprised only 43 out of 210 players (20.5\%) in the ten-round NHL draft in 1990. This figure increased to 79 out of 184 players (42.9\%) in the seven-round 2018 NHL draft. European and Russian players are much more prevalent in the NHL than in the past, but they are still a minority in comparison to Canadian and American players. These foreign players 
might come at a higher price than in the past due to the increased competition for players from the Continental Hockey League (KHL) in Russia and the Swedish Hockey League (SHL). Fenn, Gerdes, and Rothstein (FGR) test this assertion by estimating a salary regression model that holds constant player performance variables and contract status. The results suggest that Russian and European players are paid a premium, perhaps suggesting that Canadian and American NHL players have fewer alternative employment possibilities.

The two papers that round out the Special Issue provide glimpses into rather underappreciated, yet growing, sports in the sports economics literature: English cricket and mixed martial arts (MMA) fighting. In recent years, cricket has become a lucrative sport with the advent of the Twenty20 format. This format limits the length of test matches to three hours or so, making for much better viewing for spectators, television, and internet audiences. Financial success has largely been limited to the Indian Premier League, Australia's Big Bash, and international test matches. Plumley, Wilson, Millar, and Shibli (PWMS) examine the extent to which this success has filtered through the English Cricket Board (ECB) to the UK County Championship. They ask the question of whether the clubs in the Championship can survive due to ongoing concerns regarding the absence of monies granted to them, by the ECB, from international matches. PWMS provide convincing evidence using data gleaned from club financial statements.

MMA has garnered large television and internet audiences since its organization in 2001 as the Ultimate Fighting Championship (UFC). Fighters have always received financial compensation for showing up for fights and winning fights, however, 2006 saw the introduction of bonus awards for the best knockout of the night, best submission, best overall match, and others. These bonus awards are a substantial portion of the possible earnings a fighter can take home for the night. Gift tests, statistically, whether the sizes of these bonus monies affect the performance of the contestants using an extensive dataset reaching back to 2001. Though economics suggests that the incentive effects could be strong, Gift finds no significant effect based on fight metrics.

Duane Rockerbie, Angel Barajas

Special Issue Editors 

Article

\title{
Earnings Persistence of European Football Clubs under UEFA's FFP
}

\author{
Panagiotis E. Dimitropoulos * and Konstantinos Koronios \\ Department of Sport Organization and Management, University of Peloponnese, Sparta 23100, Greece; \\ konskoron@hotmail.com \\ * Correspondence: dimitrop@uop.gr; Tel.: +30-273-108-9677
}

Received: 4 March 2018; Accepted: 13 April 2018; Published: 17 April 2018

\begin{abstract}
The goal of this study was to examine the predictability and persistence of earnings of the European football clubs and whether the new Union of European Football Associations (UEFA) Financial Fair Play (FFP) licensing regulation has forced clubs to produce a more predictable earnings stream. We utilized a sample of 109 European top-tier clubs over the period 2008-2016, summing up to 844 firm-year observations. Empirical evidence indicated that the cash flow component of earnings is more relevant in predicting one-year ahead earnings than accruals. This positive impact of cash flows for predicting earnings is more significant after the FFP regulation since earnings predictability has increased during that period. Moreover, the abovementioned finding is more significant for the smaller league clubs rather than the Big-5 league clubs. This finding is attributed to the fact that smaller league clubs are more in need of UEFA prize money relative to Big-5 league clubs, thus they are more incentivized to produce a more predictable earnings stream.
\end{abstract}

Keywords: earnings persistence; accruals; earnings predictability; European football clubs; financial fair play

JEL Classification: M41; G32; G34

\section{Introduction and Theoretical Background}

The professionalization of European football has been considered by academics, practitioners and regulators for several years now, especially since clubs have been transformed to well establish corporations with separate ownership and control (Andreff 2007) and some of them have been floated on the stock exchange. Clubs have managed to attract significant amounts of revenues from several sources, not only the classic match day receipts, but also from sponsoring, advertising, merchandising, broadcasting contracts, league prizes, etc. Nevertheless, the financial viability of the majority of European clubs has been deteriorating significantly for several years leading to accumulated debt and losses, despite the increased revenue streams and amounts invested on behalf of the shareholders (Dermit-Richard et al. 2017).

These are the symptoms of clubs' financial instability yet the actual culprit lies within the operational framework of the clubs and their relation to their fans and other stakeholders. Dimitropoulos et al. (2016) argud that clubs establish close relationship with their fans and in several instances fans affect managers' decisions. Fans cannot be considered as customers since they are emotionally attached to the club and even intervene to assist clubs when financial troubles knock at their door. Moreover, fans exert significant pressure on managers to enhance athletic success, and, therefore, to achieve higher on-field performance, managers are willing to pay exorbitant salaries and transfer fees for improving club's roster competitiveness. Thus, a club's relation with fans is one source of financial irrationality but is not the only one faced by clubs. Furthermore, Mourao (2012) verified the abovementioned arguments suggesting that clubs in Europe face a triangle of behavioral forces 
that does not let them escape from indebtedness. The triangle is formed by the pressure of athletic success, football players' increased wages (attributed to the pressure for on-field success) and media coverage which exerts the biggest portion of revenues. Football player wages have increased over the years such that more than 50-60 percent of clubs' revenues are channeled to cover player wages (Nicoliello and Zampatti 2016). This wage inflation trend is exacerbated by the majority of leagues in the European continent. According to Rohde and Breuer (2016), the pursuit of higher on-field performance is achieved via paying increasing player transfer fees and wage contracts and on-field success contributes to higher revenues from league prizes and media coverage. However, the goal of athletic success is not always achieved, bestowing on the investment in player transfers high risk, leading to a deterioration of soccer quality and an increase in costs and debt levels.

The issue of financial vulnerability and indebtedness has been on the agenda of the UEFA and the issuance of the financial fair play regulation (FFP) aimed at the rationalization of club finances. The financial principles of the FFP are not distant from the common logic of financial sustainability: (a) debt must be kept within manageable levels and paid on time; and (b) expenditure must be kept within the parameters of each club's ability to pay based on their revenues (Cordery et al. 2013). Practically, UEFA introduced profitability as the most important financial characteristic of the new licensing regulation since clubs have to prove that they will honor their debt obligations (no overdue payables). According to Nicoliello and Zampatti (2016), clubs need to reduce the cost side of the equation (player and staff wages) or increase revenues to achieve profitability. Moreover, several clubs in both major and minor European Leagues are operating in the "red" since descriptive evidence from the sample of the current study indicate that the average shareholder's funds are negative and up to -5.9 percent of total assets, over the period 2008-2016. Practically, 30 percent of our observations have negative equity and this fact corroborates previous arguments in the above-mentioned literature regarding the insolvency of European football clubs.

Within this framework, the current study aimed to examine whether the new FFP regulation has impacted on clubs' motives to produce a more reliable and sustainable earnings stream to achieve future profitability and adhere to the new regulatory guidelines. Earnings persistence is a crucial characteristic of earnings quality since, according to Kang et al. (2012), the role of financial reporting is to provide useful information to investors for assessing future cash flows and earnings, thus is a very useful attribute for financial decision making. Practically, earnings persistence expresses the extent that present profits may be maintained in the future. This was estimated by a regression of future earnings on current earnings. The closer the regression coefficient was to unity (1), the higher was the earnings persistence. Studies by Sloan (1996), Richardson et al. (2005), and Oei et al. (2008) in samples of American and Australian firms estimated an earnings persistence coefficient ranging from 0.609 in Australia to 0.84 in the US. This is interpreted as, if a company earns $\$ 1$ of earnings during year $t$, then $\$ 0.84$ would be expected to persist in the following year $t+1$. In other words, earnings figures of firms with higher earnings persistence are more predictable (thus those firms are associated with lower information uncertainty) and is consequently easier for investors and regulators to assess the future status of the firm.

The consensus among financial economists is that the improved quality of financial numbers produces advantages such as better allocation of resources, higher liquidity to the markets and firms, a reduction of cost of capital, and lower information asymmetry (Kothari et al. 2009). Those findings suggest that earnings that map closely into cash are more favorable, are more persistent and can help investors to predict future earnings. Since investors are relying on earnings to make investment decisions to a higher extent than cash flows and dividends, if earnings are of poor quality, they will reduce the coordination between firms and their stakeholders, creating information risk. This in turn will lead investors to demand a higher risk premium for their investments, contributing to increased cost of capital (Francis et al. 2004). This fact was corroborated by Rascher et al. (2012) in the NFL. They argued that clubs with volatile or unpredictable revenues face increased cost of debt, since the desired uncertainty in sport outcomes has the consequence of reducing the predictability of revenue streams, 
leading to more information asymmetry and thus to increased cost of capital. Nevertheless, investment in new stadia reduces this information asymmetry and leads to more predictable revenue streams. Even though the study of Rascher et al. (2012) focused on revenues and not profits, it provided a useful example of the positive impact of persistence on corporate attributes such as financial risk.

Earnings persistence is even more important for economic sectors that face significant regulatory changes (Kang et al. 2012). Altamuro and Beatty (2010) and LaFond and You (2010) provided analyses of regulatory change in the US banking industry (the FDICIA internal control regulation) arguing that, when regulation is formatted out of a crisis and this regulation reforms and enhances corporate supervision and imposes stricter financial reporting requirements, it impacts on the predictability and persistence of firm earnings. Especially in the US banking industry, this new regulatory intervention increased the predictability of banks' cash flows and earnings persistence, and reduced income smoothing for those banks that were obliged to comply with the new regulation. The football industry and the new FFP regulation share several common characteristics with the abovementioned study. UEFA introduced more strict criteria (not only financial but also strong merit is attributed to financial criteria) for granting licenses to prestigious leagues (Champions League and Europa League). Moreover, the Club Financial Control Body (CFCB) was established as an additional mechanism for examining the reliability of clubs' financial reports and assessing the effectiveness of clubs achieving the FFP criteria and whether they comply with the designated regulation. Overall, the new FFP regulation increased scrutiny placed on football clubs and undoubtedly increased club monitoring and oversight.

To examine whether the FFP regulation has improved clubs' earnings persistence, we utilized a sample of 109 European top-tier clubs over the period 2008-2016. Empirical evidence indicated that the cash flow component of earnings is more relevant in predicting future earnings than accruals. This positive impact of cash flows for predicting earnings is more significant after the FFP regulation since earnings predictability increased during that period. Moreover, the abovementioned finding is more significant for the smaller league clubs rather than the Big-5 league clubs. This finding is attributed to the fact that smaller league clubs are more in need of UEFA prize money relative to Big-5 league clubs (Menary 2016) because UEFA prize money constitutes a larger part of their annual revenues. Thus, they are more incentivized to produce a more predictable earnings stream.

This study adds to a growing literature on earnings persistence within an industry facing severe financial problems. A recent study by Dermit-Richard et al. (2017) showed that, in France, clubs' budget is targeting towards funding losses (by 74 percent) instead of investments. This fact accords with the issue that shareholders' contributions do not suffice to cover losses (for the majority of top-tier clubs), leading clubs to disinvest or downsize business activities, creating a volatile economic environment. FFP regulation aims to mitigate these problems by forcing clubs to live on their own resources and sustain their viability. Thus, this study provided ample evidence of the impact of the new regulation on the tendency of football clubs to focus on a medium to long term policy towards profitability, thus enhancing their financial reporting quality as a way to sustain their participation in UEFA's lucrative championships.

The rest of the paper is organized as follows: Section 2 is devoted to the literature review and the formation of the research hypotheses. Section 3 presents the data selection procedure and the research design. Section 4 discusses the empirical results of the study and related sensitivity analysis. Section 5 concludes the paper, offering useful policy implications for clubs and regulators and potential avenues for future research.

\section{Related Literature and Research Hypotheses}

As previously mentioned, a crucial role of the financial accounting reporting system is to serve as a mechanism to signal firms' future performance to the public and also to discipline managerial behavior (Kang et al. 2012). Nevertheless, financial accounting follows the accrual principle for 
recognizing revenues and expenses ${ }^{1}$, a fact that helps portray more effectively firms' actual financial condition, yet it has the disadvantage of greater subjectivity on the estimation of several accounting figures (provisions, depreciation, inventories, etc.). As Richardson et al. (2005) mentioned, if accrual accounting were not in effect, the only asset or liability that would appear on a firm's balance sheet would be the cash asset amount. Put differently, all other assets and liabilities on the balance sheet are the outcome of the accrual accounting process (Oei et al. 2008).

Under this framework, previous studies on the issue of accruals persistence indicated that accruals are less persistent than cash flows due to the increased subjectivity of accruals relative to cash flows and also because accruals can easily be manipulated with less material impact on the firms' fundamentals, relative to cash flows (Sloan 1996). The reduced persistence of accruals is also attributed to their lower reliability because accruals require judgments for the estimation of the relative figures, and even in the case of no manipulation of those figures, they definitely contain errors that will be corrected in accruals recorded in future periods. Earnings persistence (as a measure of earnings informativeness) does not suffer from the potential measurement errors inherent in accrual models and is characterized as an important feature of financial reporting integrity and firm value (Kormendi and Lipe 1987; Kang et al. 2012).

These types of errors could be the estimating outcome of future economic effects of current or past transactions which are measured with error (Oei et al. 2008). For example, the provision or allowance for doubtful debt will never be completely accurate. In addition, in the European football industry, UEFA's (2015) FFP regulation declares that, for the estimation of the clubs' relevant revenues (for those clubs which follow the capitalization and amortization method), the profit from disposal of player registration rights is calculated by deducting the net book value at the time of the transfer from the net disposal proceeds received or receivable. This means that clubs generate large accrual accounting from player registration rights which are not always received in total due to other arrangements ${ }^{2}$, creating errors in the estimation.

Furthermore, Dermit-Richard et al. (2017) argued that several determinant figures of the relevant revenues and expenses which come from related parties must be adjusted to reflect the fair value of such transactions. For instance, sponsorship deals must be evaluated at fair values yet those might not be comparable to other respective deals for other clubs, so they are inherent to enhanced subjectivity by managers. The main issue here is the input information that clubs use to estimate those fair values. If the information come from verifiable sources, then subjectivity is diminished (not eliminated), but, if information is derived from non-verifiable sources and includes more judgment on behalf of the club management, then accruals are definitely estimated with error. Consequently, following the previous discussion, due to the measurement error in accruals, the persistence coefficient on the accrual component should be smaller than the persistent coefficient on the cash flow component of earnings due to less or no error in tis measurement. Thus, the first research hypothesis is stated as follows:

H1: Accruals will be less persistent than cash flows.

Previous studies on the impact of regulatory intervention on earnings persistence provided ample but contradictory evidence. For instance, Kang et al. (2012) indicated that the abolition of the 20-F reconciliation requirement for firms cross-listing in the US was not improved for all firms but only for those that were originating from weak investor protection countries. This fact was explained as 20-F reconciliation playing a signaling role for the financial statement users and its elimination led to an increase in firms' incentives to improve the reporting quality voluntarily. Additionally, LaFond and You (2010) argued that the introduction of the Federal Deposit Insurance Corporation Improvement Act (FDICIA) as a response of the US government to the 2007-2008 financial crisis, imposed stricter

1 Revenues and expenses are recognized when they are materialized, irrespectively of the time of payment.

2 For example, several clubs re-arrange those deals by lending players to each other for a short-period, a fact which does not affect cash assets. 
reporting requirements such as the disclosure of the fair market values of bank assets. This legislation increased the supervision of banks imposing annual on-site inspections on banks and the formation of an independent audit committee. Relative interventions were imposed on those banks that failed to meet the respective requirements of the law. Practically, the new regulation forced management to report their responsibilities for preparing financial statements, sustaining an adequate internal control structure and conform to laws and regulations. According to Altamuro and Beatty (2010), this regulation increased banks earnings persistence and earnings predictability due to increased monitoring and oversight, which contributed to less reporting discretion. This reduced managerial discretion increased the association between current reported accruals and future cash flows.

The financial fair play (FFP) regulation in European football shares several common features relative to the above-mentioned cases. The new UEFA regulation increased the amount of financial information that clubs have to publish, introduced greater scrutiny on clubs' finances via the financial oversight board, and dictated that national football federations must exercise additional control on clubs' operations. Failure of clubs to adhere to the new regulations would lead to sanctions, in the form of transfer restrictions, refusing to grant licenses, cash fines, withholding prizes and several other measures. This new environment impacts clubs' financial reporting decisions since the failure to conform to the new regulation definitely impacts clubs' future athletic success and financial performance. Thus, clubs are more incentivized to report earnings that are more stable and predictable in the future. Therefore, the second hypothesis is stated as follows:

\section{H2: Earnings persistence has increased after the FFP regulation implementation.}

Moreover, regulatory changes are expected to have a different impact on earnings persistence between smaller and larger firms, belonging to different size markets. LaFond and You (2010) indicated that, after the FDICIA regulation in the US banking industry, smaller banks experienced larger increases in earnings persistence and predictability, a result attributed to the increased motivation by managers of smaller banks to signal their financial statement quality in the market and mainly because any negative outcome regarding non-compliance with the new regulation would result in severe or unaffordable implications relative to larger banks. In addition, Kang et al. (2012) documented that the level of investor protection mechanisms in a market directly impacts the reporting incentives. For example, in a market where there is more regulation on the reporting system and decisions are more transparent (thus protecting the interests of shareholders and various stakeholders), there is less incentive for those firms to enhance their earnings predictability due to the smaller marginal benefit that they receive from this behavior. On the contrary, firms in countries with smaller firms and markets (and less investor protection mechanisms) are more incentivized to voluntarily improve their reporting quality to gain access to financing.

Following the above-mentioned reasonin,g the size of the leagues and hence the teams is expected to have an effect on the persistence of earnings. Specifically, smaller clubs gain a significant percentage of their annual budget (and revenues) from UEFA prizes. According to Solberg and Haugen (2010), Swedish clubs increased their revenues by almost 80 percent in the case that they were qualified to the first round of Europa League or Champions League. The same situation stands for other small European Leagues (Cyprus, Bulgaria, Greece, etc.) where, according to Menary (2016), the adherence of small clubs to the FFP can yield significant revenues able to finance the club's budget and even achieve club's sustainability. On the contrary, clubs from larger leagues (such as the Top-5 championships) are not so dependent on UEFA prizes since they present a balance between revenues from their national league and UEFA tournaments (Menary 2016). Consequently, based on the above discussion, clubs from smaller leagues are expected to report more persistent earnings figures to enhance their reliability towards the financial control body and also their chances to adhere to the new regulatory requirements, relative to clubs from larger leagues. However, the opposite reasoning can also be true since larger clubs might lose more if they fail to conform to FFP regulation, since they are more likly to advance their presence in the prestigious UEFA tournaments and gain more revenues. Thus, due to 
the conflicting arguments mentioned above, the third and final hypothesis is formed in the null form as follows:

H3: There will be a difference on the earnings persistence between smaller and larger league clubs.

\section{Data Selection and Research Design}

The sample selection procedure included the selection of financial accounting data, namely net profit, operating cash flows and total assets from the annual financial statement from clubs in European countries (Belgium, Finland, France, Greece, Italy, Netherlands, Norway, Spain, and United Kingdom) that had at least two football clubs with available financial data for more than two fiscal years over the period 2008-2016. The sample selection started by collecting data from 117 football clubs which fit the legal form of a corporation, however we had to delete six clubs due to data unavailability. Moreover, to reduce the impact of outliers and thus eliminate potential biases in the estimation of the variables, we removed the upper and lower 1 percent of the data distribution of earnings and cash flows. Consequently, the final unbalanced sample includes 109 football clubs and 869 firm year observations. Table 1 presents the distribution of our sample clubs per country. The majority of the sample observations originated from the Big-4 championships, namely United Kingdom, Italy, France, and Spain. Greece presented a significant portion of the sample observations followed by Belgium. The fact that Big-4 leagues constituted the majority of our sample observations warranted the examination of earnings persistence between Big-4 and Non-Big-4 leagues, as discussed in Section 4.

Table 1. Observations distribution per country and year.

\begin{tabular}{ccccccccccc}
\hline Countries & $\mathbf{2 0 0 8}$ & $\mathbf{2 0 0 9}$ & $\mathbf{2 0 1 0}$ & $\mathbf{2 0 1 1}$ & $\mathbf{2 0 1 2}$ & $\mathbf{2 0 1 3}$ & $\mathbf{2 0 1 4}$ & $\mathbf{2 0 1 5}$ & $\mathbf{2 0 1 6}$ & Total \\
\hline Belgium & 7 & 7 & 6 & 7 & 6 & 6 & 5 & 7 & 7 & 58 \\
Finland & 2 & 1 & 1 & 2 & 2 & 1 & 2 & 2 & 2 & 15 \\
France & 11 & 11 & 11 & 11 & 11 & 11 & 10 & 11 & 11 & 98 \\
Greece & 10 & 10 & 9 & 10 & 10 & 10 & 10 & 10 & 10 & 89 \\
Italy & 20 & 19 & 18 & 20 & 20 & 20 & 20 & 20 & 20 & 177 \\
Netherlands & 3 & 3 & 3 & 3 & 3 & 3 & 3 & 3 & 3 & 27 \\
Norway & 2 & 2 & 2 & 2 & 2 & 2 & 1 & 1 & 1 & 15 \\
Spain & 6 & 7 & 7 & 7 & 7 & 7 & 7 & 7 & 7 & 62 \\
United & 37 & 37 & 37 & 37 & 37 & 37 & 29 & 43 & 43 & 328 \\
Kingdom & 98 & 97 & 92 & 97 & 96 & 94 & 87 & 104 & 104 & 869 \\
Total & 98 & & & & & & & & &
\end{tabular}

The final sample exclusively included football clubs that participate in the top division of their country's official league (as in Dimitropoulos et al. 2016) for two main reasons: those clubs competing in the top division of the national league are more likely to participate in UEFA championships and therefore are more inclined to conform to the criteria set by the FFP regulation. Thus, we expect that they are more motivated to report more persistent earnings figure to improve their chances to adhere to the new regulation's financial criteria.

Our research design required dividing the sample into two sub-periods: the pre-FFP implementation period (including fiscal years ending in June 2008-2011) and the post-FFP period (fiscal years ending in June 2012-2016). The reason for selecting 2012 as the beginning of the FFP-period (even though the regulation was first published in 2010) is because the 2011-2012 football season (and fiscal year) is the first during which the FFP regulation was in full force. Practically, the implementation of the FFP regulation was not in full effect during (and before) the fiscal year ending June 2011, since several exemptions and acceptable levels of deviation were imposed from the regulation's financial criteria to assist clubs to steadily adjust to the new regulatory environment. Therefore, we considered the 2011 fiscal year belonging to the pre-FFP regulation period to draw more precise inferences regarding the impact of the new regulation on earnings persistence. 
We measured earnings persistence by regressing the future return on assets on the current return on assets following previous studies by Richardson et al. (2005) and Oei et al. (2008) according to the following model:

$$
R O A_{i t+1}=a_{0}+a_{1} R O A_{i t}+e_{i t}
$$

where ROA is the return on assets estimated as net income after tax to lagged total assets and $e$ is the regression error term. Subscripts $i$ and $t$ denote the club and the year, respectively. Model (1) was estimated including club fixed effects to capture any impact on the regression model attributed to specific club characteristics. Model (1) was estimated using the panel fixed effect estimation since panel analysis contains more information with more variability and less collinearity among the variables, leading to more efficient estimates and precise parameters of model estimation, allowing us to detect many effects that are not detectable in plain cross-sectional data analysis. In addition, we performed the Breusch-Pagan Lagrangian multiplier test for random effect, which tests the null hypothesis that the error variance is equal to zero. The test produced an insignificant value leading us not to reject the null and thus the fixed effect estimation is considered as the most appropriate estimation method. Coefficient $\mathrm{a}_{1}$ measures earnings persistence, and the closer to unity (1), the higher the earnings persistence, indicating a more stable and predictable earnings stream.

The first hypothesis states that the accrual component of earnings will be less persistent than cash flow component of earnings in the determination of future earnings. To test this hypothesis, we estimated the following equation to capture the differential persistence of the accrual components of earnings:

$$
R O A_{i t+1}=\beta_{0}+\beta_{1} R O A_{i t}+\beta_{2} T A C C_{i t}+e_{i t}
$$

where TACC denotes the club's total accruals estimated as the different between net income and operating cash flows divided by lagged total assets. The rest of the variables are defined as above.

According to Richardson et al. (2005), the accrual component of earnings is expected to be less persistent than the cash flow component of earnings, which is the difference between earnings performance and the accrual component of earnings performance. Thus, the initial functional form of Model (2) was as follows:

$$
R O A_{i t+1}=\gamma_{0}+\gamma_{1}\left(R O A_{i t}-T A C C_{i t}\right)+\gamma_{2} T A C C_{i t}+u_{i t+1}
$$

where $\gamma_{1}$ capture the persistence of cash flows and $\gamma_{2}$ captures the persistence of accruals. Thus, the modified version Model (2a) is Model (2) with earnings performance itself instead of cash flow performance. Rewriting Equation (2a) in terms of the persistence parameters produced the following:

$$
R O A_{i t+1}=\gamma_{0}+\gamma_{1} R O A_{i t}+\left(\gamma_{2}-\gamma_{1}\right) T A C C_{i t}+u_{i t+1}
$$

Thus, $\beta_{1}=\gamma_{1}$ and $\beta_{2}=\left(\gamma_{2}-\gamma_{1}\right)^{3}$. According to Richardson et al. (2005), the advantage of estimating Model (2) instead of Model (2b) is that $\beta_{2}$ provides a direct estimate of $\left(\gamma_{2}-\gamma_{1}\right)^{4}$.

Model (2) was estimated including club fixed effects to capture any impact on the regression model attributed to specific club characteristics. For example, there could be small differences in the revenues sharing process between leagues. A recent report by KPMG (2017) indicated that the Big-5 European leagues present a somehow uniform process of broadcasting revenue distribution with the majority of revenues being shared equally between clubs, and an equal percentage is distributed based on sport performance and popularity. This form of distribution is evidenced in other minor leagues as well such as Greece. The relative distribution percentages of each factor may differ from league

3 Please refer to the study by Richardson et al. (2005), Section 4.2 for the derivation of this formula.

4 We estimated Model $(2 \beta)$ as well, but untabulated results provide qualitatively similar findings compared with those on the main tables, so we discuss the results from the estimation of Model (2). 
to league so the club fixed effect aims to capture this impact. In Equation (2), coefficient $\beta_{1}$ captures the persistence of the cash flow component of earnings, while coefficient $\beta_{2}$ captures the differential persistence of the accrual component of earnings. If H1 is valid, we expect coefficient $\beta_{2}$ to be smaller in magnitude and significance relative to coefficient $\beta_{1}$.

To examine the second research hypothesis, Models (1) and (2) were reestimated during the pre (2008-2011) and post (2012-2016) FFP regulation sub-periods. If H2 is valid, we expect a highly significant and positive coefficient with larger magnitude during the post-FFP period relative to the pre-FFP period. Finally, to examine the third research hypothesis, both models were reestimated after partitioning the sample between sample clubs belonging to the top European leagues (Italy, France, Spain and UK) and clubs belonging to the other European leagues. H3 is verified if coefficient $\beta_{1}$ is larger in magnitude and significant for Non-Top-4 leagues relative to Top-4 leagues.

\section{Empirical Results}

Table 2 presents the descriptive statistics of the main variables for the whole research period, as well as during the pre- and post-FFP periods. The average total accruals are negative and cover 17 percent of total assets, indicating that net income is less than cash flows for the sample clubs, thus clubs operate with more accruals on their profit and loss account. In addition, average return on assets is negative and covers 10 percent of total assets. This result is relevant to previous studies on European football regarding the clubs' financial performance (Dimitropoulos et al. 2016). Average ROA does not present any significant change before and after the implementation of FFP regulation, while, on the contrary, TACC have been reduced after FFP initiation from -0.18 to -0.16 , indicating the tendency of clubs to report accounting earnings that are more associated with operating cash flows.

Table 2. Descriptive statistics of sample variables.

\begin{tabular}{ccc}
\hline Variables & TACC & ROA \\
\hline FULL SAMPLE & & \\
Mean & -0.169 & -0.101 \\
St.Dev. & 0.241 & 0.417 \\
Min & -1.355 & -2.859 \\
Max & 3.641 & 4.854 \\
\hline PRE-FFP & & \\
Mean & -0.180 & -0.102 \\
St.Dev. & 0.205 & 0.475 \\
Min & -1.355 & -2.859 \\
Max & 0.281 & 4.854 \\
\hline POST-FFP & & \\
Mean & -0.160 & -0.100 \\
St.Dev. & 0.267 & 0.365 \\
Min & -1.339 & -2.784 \\
Max & 3.641 & 2.090 \\
\hline
\end{tabular}

The sample period includes fiscal years from 2008 to 2016. The pre-FFP period is 2008-2011 and the post-FFP period is 2012-2016. TACC is total accruals estimated as the different between net income and operating cash flows divided by lagged total assets, and ROA is the return on assets estimated as net income after tax to lagged total assets.

Table 3 presents the estimation of regression Model (1) for the whole period under investigation as well as during the pre- and post-FFP periods. Overall, earnings persistence is 0.183 , suggesting that on average from a $€ 1$ profit during the current year 0.18 cents are expected to persist in the following year. This coefficient is far below the persistence coefficient of previous studies in the US, Australia and Korea (Richardson et al. 2005; Oei et al. 2008; Jeon et al. 2006). This result can be attributed to the increased volatility of football clubs' profits and revenues, as evidenced by Rascher et al. (2012), and the fact that several clubs in Europe do not focus on sustaining their profitability but just breaking 
even (Dermit-Richard et al. 2017). Nevertheless, the coefficient on earnings persistence is higher in magnitude and statistically significant only in the post-FFP period (0.296) indicating that almost $€ 0.30$ of current earnings will persist in the following year. The coefficient of ROA during the pre-FFP period is positive, yet not statistically significant within conventional levels. Taken together, findings in Table 2 verify $\mathrm{H} 2$ and indicate that the new UEFA regulation increased the amount of financial information that clubs have to publish, and introduced greater scrutiny on clubs finances via the financial oversight board, and this impacted clubs' financial reporting decisions, leading them to report earnings that are more persistent and predictable in the future.

Table 3. Earnings persistence results.

\begin{tabular}{|c|c|c|}
\hline Variables & Coef. & $\begin{array}{c}T \text {-Test } \\
(p \text {-Value) }\end{array}$ \\
\hline \multicolumn{3}{|c|}{ FULL SAMPLE } \\
\hline Constant & $-0.083^{* * *}$ & $\begin{array}{c}-6.44 \\
(0.001)\end{array}$ \\
\hline ROA & $0.183 * *$ & $\begin{array}{c}2.22 \\
(0.026)\end{array}$ \\
\hline $\mathrm{R}^{2}$-Adj. & \multicolumn{2}{|c|}{0.334} \\
\hline F-stat & $4.95 * *$ & $(0.024)$ \\
\hline \multicolumn{3}{|c|}{ PRE-FFP } \\
\hline Constant & $-0.107^{* * *}$ & $\begin{array}{c}-5.16 \\
(0.001)\end{array}$ \\
\hline ROA & 0.098 & $\begin{array}{c}0.93 \\
(0.520)\end{array}$ \\
\hline $\mathrm{R}^{2}$-Adj. & \multicolumn{2}{|c|}{0.115} \\
\hline F-stat & $2.87^{* *}$ & $(0.05)$ \\
\hline \multicolumn{3}{|c|}{ POST-FFP } \\
\hline Constant & $-0.059 * * *$ & $\begin{array}{l}-3.99 \\
(0.001)\end{array}$ \\
\hline ROA & $0.296^{* * *}$ & $\begin{array}{c}2.46 \\
(0.014)\end{array}$ \\
\hline $\begin{array}{c}\mathrm{R}^{2} \text {-Adj. } \\
\text { F-stat }\end{array}$ & \multicolumn{2}{|c|}{0.723} \\
\hline
\end{tabular}

$* * *$ and $* *$ indicate statistical significance at the $1 \%$ and $5 \%$ significance level, respectively. The sample period includes fiscal years 2008-2016. The pre-FFP period is 2008-2011 and the post-FFP period is 2012-2016. ROA is the return on assets estimated as net income after tax to lagged total assets. Club fixed effects are included in the estimation.

To verify this argument and provide an additional robustness check on the findings in Table 3, we examined whether earnings predictability enhanced after the FFP regulation came into act. For this reason, we followed previous studies by Kousenidis et al. (2013) and Gaio (2010) and estimated earnings predictability (EarnPredict) as the standard deviation of residuals of Model (1). EarnPredict measures the ability of earnings to be predicted in the future and thus be more persistent and have higher quality. Larger values of the standard deviation of residuals indicate less predictable earnings and vice versa. Therefore, we estimated a simple regression model including earnings predictability as the dependent variable and a dummy variable FFP_D (which designates the initiation of the FP regulation) acts as the independent variable. The results are presented in Table 4: 
Table 4. Earnings predictability during FFP regulation.

\begin{tabular}{ccc}
\hline Variables & Coef. & $\begin{array}{c}T \text {-Test } \\
(p \text {-Value })\end{array}$ \\
\hline \multirow{3}{*}{ Constant } & Dependent variable: EarnPredict & \\
& $0.081^{* * *}$ & 51.41 \\
FFP_D & $-0.016^{* * *}$ & $(0.001)$ \\
& & -9.32 \\
R & & $(0.001)$ \\
F-Adj. & 0.106 & \\
\hline
\end{tabular}

*** indicate statistical significance at the $1 \%$ significance level. The sample period includes fiscal years from 2008 to 2016. FFP_D is a dummy variable receiving unity (1) for the post-FFP period (2012-2016) and zero (0) otherwise. The dependent variable (EarnPredict) is the standard deviation of the residuals of Model (1).

The coefficient on the FFP_D variable is negative and highly significant, indicating that earnings predictability increased (the standard deviation of residuals is smaller, suggesting more predictable earnings) after the FFP implementation. The economic meaning of this coefficient is that, after the initiation of FFP regulation, the standard deviation of earnings residuals decreased by 1.6 percent suggesting enhanced earnings predictability. This finding complements the evidence in Table 3 and provides another justification for accepting $\mathrm{H} 2$.

Table 5 presents the results from the estimation of Model (2). The coefficient on the cash flow component of earnings (captured by the ROA variable) is positive and significant, while the relative coefficient of the TACC variable is insignificant, thus the cash flow component of earnings is more persistent than that of accruals, verifying H1. This finding corroborates previous evidence by Kormendi and Lipe (1987) and Kang et al. (2012) that the lower persistence of accruals is attributed to their lower reliability since accruals require judgments for the estimation of the relative figures. Moreover, the analysis during the pre- and post-FFP periods corroborates the evidence in Table 3. Specifically, the accrual component of earnings (TACC) was a significant determinant of future earnings before the FFP regulation came into act but becomes insignificant after FFP. On the contrary, the cash flow component of earnings has a positive and significant coefficient during the FFP period while the coefficient on TACC is insignificant. This evidence verifies our previously mentioned arguments about the impact of the new UEFA regulation on clubs' incentives to report more predictable earnings figures (based on cash flows) thus enhancing earnings persistence.

Table 5. Results on the persistence of accruals and cash flows.

\begin{tabular}{ccc}
\hline Variables & Coef. & $\begin{array}{c}T \text {-Test } \\
(p \text {-Value })\end{array}$ \\
\hline FULL SAMPLE & & -2.52 \\
Constant & $-0.056^{* * *}$ & $(0.012)$ \\
& & 1.93 \\
ROA & $0.162^{* *}$ & $(0.054)$ \\
TACC & 0.150 & 1.26 \\
R $^{2}$-Adj. & & $0.210)$ \\
F-stat & $3.86^{* *}$ & \\
\hline
\end{tabular}


Table 5. Cont.

\begin{tabular}{|c|c|c|}
\hline Variables & Coef. & $\begin{array}{c}T \text {-Test } \\
(p \text {-Value) }\end{array}$ \\
\hline \multicolumn{3}{|l|}{ PRE-FFP } \\
\hline Constant & $-0.1061^{* * *}$ & $\begin{array}{c}-2.48 \\
(0.013)\end{array}$ \\
\hline ROA & 0.067 & $\begin{array}{c}0.66 \\
(0.512)\end{array}$ \\
\hline TACC & $0.270^{* *}$ & $\begin{array}{c}2.25 \\
(0.025)\end{array}$ \\
\hline $\mathrm{R}^{2}$-Adj. & \multicolumn{2}{|c|}{0.266} \\
\hline F-stat & $2.73 * *$ & $(0.06)$ \\
\hline \multicolumn{3}{|l|}{ POST-FFP } \\
\hline Constant & -0.042 & $\begin{array}{c}-1.57 \\
(0.117)\end{array}$ \\
\hline ROA & $0.288^{* *}$ & $\begin{array}{c}2.20 \\
(0.028)\end{array}$ \\
\hline TACC & 0.066 & $\begin{array}{c}0.45 \\
(0.655)\end{array}$ \\
\hline $\mathrm{R}^{2}$-Adj. & \multicolumn{2}{|c|}{0.791} \\
\hline F-stat & $3.68^{* *}$ & $(0.026)$ \\
\hline
\end{tabular}

*** and ** indicate statistical significance at the $1 \%$ and $5 \%$ significance level, respectively. The sample period includes fiscal years 2008-2016. The pre-FFP period is 2008-2011 and the post-FFP period is 2012-2016. ROA is the return on assets estimated as net income after tax to lagged total assets, and TACC is total accruals estimated as the difference between net income and operating cash flows divided by lagged total assets. Club fixed effects are included in the estimation.

Furthermore, to examine the validity of the third research hypothesis, we reestimated Models (1) and (2) between clubs belonging to the top European leagues and the rest, as well as also during the preand post-FFP periods. Results are presented in Table 6A. For both models, the persistence of the cash flow component of earnings (the coefficient on the ROA variable) is higher for clubs belonging to the minor leagues relative to clubs from major European leagues. Practically, results of Model (2) indicate that smaller clubs have $€ 0.34$ of current earnings persisting in the following year, relative to $€ 0.11$ for larger clubs. This evidence combined with the fact that accruals are more significant determinants of future earnings only for larger clubs verifies the third research hypothesis and indicates that clubs from smaller leagues are expected to report more persistent earnings figures to enhance their reliability towards the financial control body and also their chances to adhere to the new regulatory requirements. Put differently, since clubs from larger leagues gain a significant percentage of their annual budget (and revenues) from UEFA prizes, they are not so dependent on this type of financing, since they already present a balance between revenues from the league and UEFA prizes (Menary 2016).

Table $6 \mathrm{~B}$ presents the results regarding the impact of FFP regulation on earnings persistence between major and minor leagues. The results seem to corroborate the findings in Table 6A and the main conclusions. Specifically, earnings persistence has decreased for the major leagues after the FFP initiation since the relative coefficient on ROA is statistically insignificant. On the one hand, the relative coefficient for clubs on the minor leagues has increased for the post-FFP period to 0.439 from 0.372 during the pre-FFP period. The same conclusion can be drawn by the estimation of Model (2) where TACC is only significant for the major league clubs but insignificant for minor leagues clubs. Overall, evidence in Table $6 \mathrm{~B}$ verifies the third research hypothesis and indicates that clubs from smaller leagues are expected to report more persistent earnings figures to enhance their reliability towards the financial control body to conform to the new regulatory requirements. 
Table 6. Results of the persistence of accruals and cash flows between major and minor European leagues and during the pre and post FFP periods. (A) Panel A: Overall estimation between major and minor leagues; (B) Panel B: Results between major and minor leagues during the pre and post FFP periods.

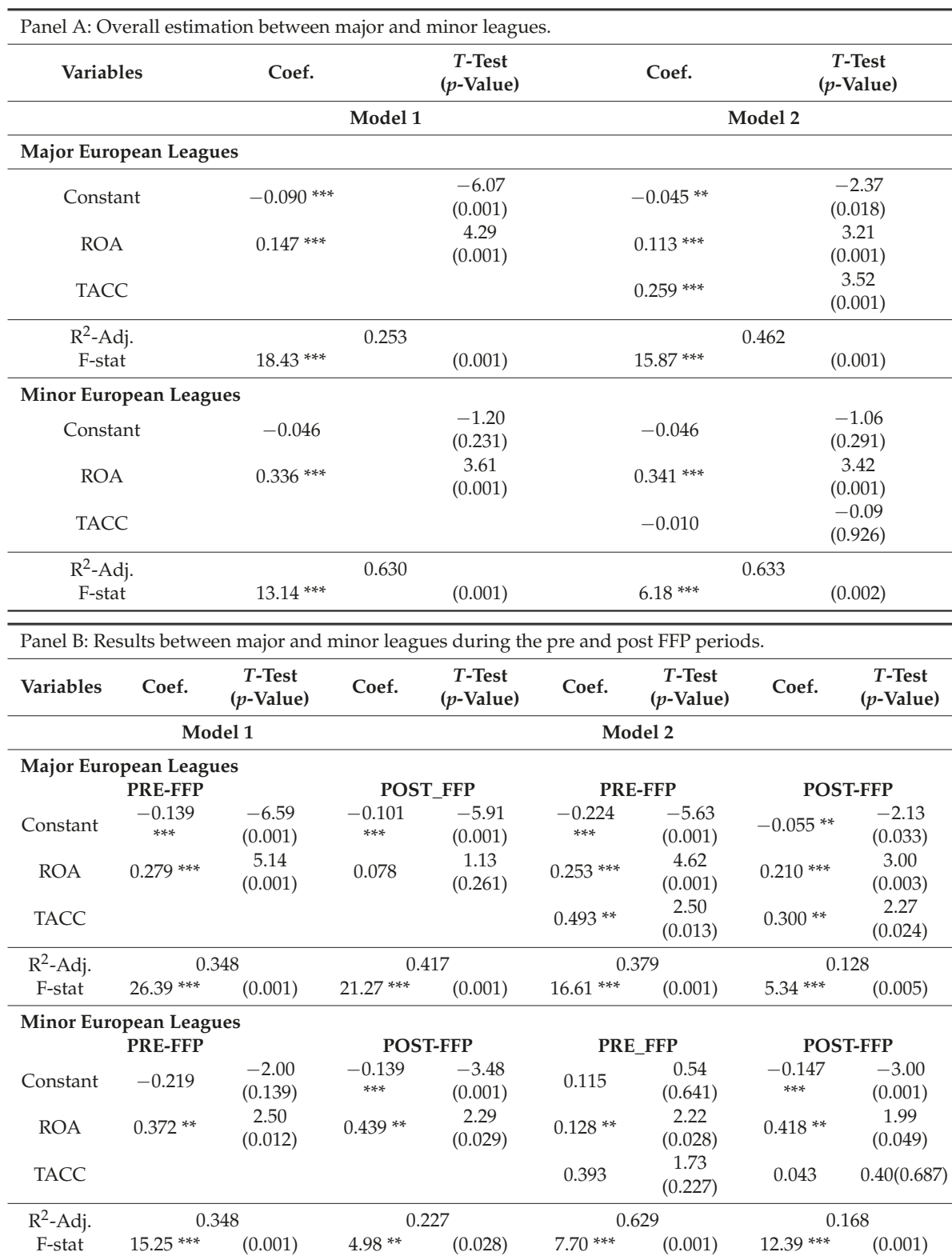

*** and ${ }^{* *}$ indicate statistical significance at the $1 \%$ and $5 \%$ significance level, respectively. ROA is the return on assets estimated as net income after tax to lagged total assets, and TACC is total accruals estimated as the difference between net income and operating cash flows divided by lagged total assets. Major European leagues include clubs from Italy, France, Spain and UK, while the rest of the clubs belong to the minor European leagues. Club fixed effects are included in the estimation. 
Finally, to check for the sensitivity of the main findings, we performed some robustness tests regarding the definition of the variables and the period under study. First, we re-estimated all models by estimating TACC based on two different definitions. The first is the difference between net income and overall cash flow (instead of operating cash flow) and the second is the balance sheet approach proposed by Ball and Shivakumar (2006) where TACC is estimated as the change in current assets minus change in current liabilities minus depreciation. Both alternative estimations yielded qualitatively similar results as those presented on Tables 3-6. In addition, all models were re-estimated by calculating ROA using net income before tax, but we observed no change in the main findings. In addition, we considered the case that, even though FFP regulation started in full effect from the 2012 fiscal year, several clubs could have been adjusting their financial reporting practices prior to that year. Thus, all models were re-estimated by defining the post-FFP period from 2011 to 2016. Empirical evidence indicated that the cash flow component of earnings was more significant than the accrual component of earnings after the FFP inauguration, thus verifying $\mathrm{H} 2$ and corroborating the robustness of our main results presented in Tables 3 and 5. Finally, we controlled for the potential impact of club's on-field success on their earnings persistence, since success on the field can be a driver of profitability. For this reason, we re-estimated both models by including their percentages of wins for every season as an additional control variable. Empirical evidence remained qualitatively unchanged from this test.

\section{Conclusions}

The present study investigated the issue of earnings persistence and predictability within a sample of European football clubs and whether the UEFA's new FFP regulation had any impact on the persistence of accruals and cash flow components of earnings. The analysis over the period 2008-2016 indicated that the cash flow component of earnings is more useful in predicting future earnings compared to accruals. This positive impact of cash flows for earnings prediction is more significant after the FFP regulation implementation because earnings predictability increased during that period. Moreover, the abovementioned finding is more significant for the smaller league clubs rather than the Top-5 league clubs. This finding is attributed to the fact that smaller league clubs are more in need of UEFA prize money relative to Big-5 league clubs (Menary 2016) because UEFA prize money constitutes a larger part of their annual revenues, thus they are more incentivized to produce a more predictable earnings stream.

In total, the empirical evidence from this study (within a services industry, i.e. football) seems to corroborate previous studies on the impact of financial regulation on the motivation of firms to improve or not the quality of their financial reporting. The examples of FDICIA, the Sarbanes-Oxley Act (SOX), and the compulsory implementation of IFRS in the European Union are characteristic cases where new regulation lead to an improvement of financial reporting (LaFond and You 2010; Barth et al. 2008; Doyle et al. 2007). The UEFA FFP regulation serves as a natural experiment on this study, since it shares several common characteristics with some of the abovementioned regulations: it forced clubs to report a larger amount of financial information, it introduced stricter control and monitoring on clubs' fundamentals and posed significant sanctions on clubs failing to fully conform to this regulation. Therefore, this paper provides an additional perspective on the debate regarding regulation and earnings persistence.

The findings of this study can provide useful implications for regulators since they indicate that, on average, football clubs report more predictable earnings streams after the new regulation initiation. Whether this is a secondary goal of the FFP (or a byproduct of the main goals of FFP regulation) is an issue for potential future exploration. As LaFond and You (2010) argued, regulation and control mechanisms in corporations cannot prevent bad decisions. Although is more difficult to make bad decisions under stricter financial regulation (due to enhanced control and strict sanctions), stricter regulation cannot prevent fraud or manipulation. Most times, regulation may lead human behavior in the opposite direction and efforts to circumvent regulation (Dimitropoulos et al. 2016). Thus, future research can extend current evidence by examining clubs' ownership and corporate 
governance structure as additional determinants of earnings persistence and how FFP regulation impacted that relation. Moreover, it would be interesting to examine the potential impact of different revenues sources (broadcasting, match day, UEFA prizes, etc.) on earnings persistence and the impact of sponsorship deals on the predictability of clubs' revenues and earnings streams. In addition, another avenue for future research is the examination of the impact of earnings persistence on clubs' cost of debt (or financing) and whether clubs with higher quality financial statements are compensated by investors.

Acknowledgments: We would like to thank the editor and two anonymous reviewers for helpful comments and suggestions that improved the paper significantly. Remaining errors and omissions are authors' responsibility. No research funding was provided to the authors by any source.

Author Contributions: Authors equally contributed to the research and writing of the paper.

Conflicts of Interest: The authors declare no conflict of interest.

\section{References}

Altamuro, Jennifer, and Anne Beatty. 2010. How does internal control regulation affect financial reporting? Journal of Accounting and Economics 49: 58-74. [CrossRef]

Andreff, Wladimir. 2007. French football: A financial crisis rooted in weak governance. Journal of Sports Economics 8: 652-61. [CrossRef]

Ball, Ray, and Lakshmanan Shivakumar. 2006. The Role of Accruals in Asymmetrically Timely Gain and Loss Recognition. Journal of Accounting Research 44: 207-42. [CrossRef]

Barth, Mary, Wayne. R. Landsman, and Mark H. Lang. 2008. International accounting standards and accounting quality. Journal of Accounting Research 46: 467-98. [CrossRef]

Cordery, Carolyn J., Dalice Sim, and Rachel F. Baskerville. 2013. Three models, one goal: Assessing financial vulnerability in New Zealand amateur sports clubs. Sport Management Review 16: 186-99. [CrossRef]

Dermit-Richard, Nadine, Nicolas Scelles, and Stephen Morrow. 2017. French DNCG management control versus UEFA Financial Fair Play: a divergent conception of financial regulation objectives. Soccer and Society. [CrossRef]

Dimitropoulos, Panagiotis, Stergios Leventis, and Emmanouil Dedoulis. 2016. Managing the European football industry: UEFA's regulatory intervention and the impact on accounting quality. European Sport Management Quarterly 16: 459-86. [CrossRef]

Doyle, Jeffrey, Weili Ge, and Sarah McVay. 2007. Determinants of weaknesses in internal control over financial reporting and the implications for earnings quality. Journal of Accounting and Economics 44: 193-223. [CrossRef]

Francis, Jennifer, Ryan LaFond, Per M. Olsson, and Katherine Schipper. 2004. Costs of equity and earnings attributes. The Accounting Review 79: 967-1010. [CrossRef]

Gaio, Cristina. 2010. The relative importance of firm and country characteristics for earnings quality around the world. European Accounting Review 19: 693-738. [CrossRef]

Jeon, Sungil, Joungman Kim, and Sangjae Lee. 2006. The persistence of abnormal earnings and systematic risk. Tourism Management 27: 867-73. [CrossRef]

Kang, Tony, Gopal V. Krishnan, Michael C. Wolfe, and Han S. Yi. 2012. The impact of eliminating the 20-F reconciliation requirement for IFRS filers on earnings persistence and information uncertainty. Accounting Horizons 26: 741-65. [CrossRef]

Kormendi, Rogen, and Robert Lipe. 1987. Earnings innovations, earnings persistence and stock returns. Journal of Business 60: 323-45. [CrossRef]

Kothari, S.P., Li Xu, and James E. Short. 2009. The effect of disclosures by management, analysts, and business press on cost of capital, return volatility, and analysts forecasts: a study using content analysis. The Accounting Review 84: 1639-70. [CrossRef]

Kousenidis, Dimitrios V., Anestic C. Ladas, and Christos I. Negakis. 2013. The effects of the European debt crisis on earnings quality. International Review of Financial Analysis 30: 351-62. [CrossRef]

KPMG. 2017. Broadcasting Revenue Distribution: Fine-Tuning the Balance. Available online: www.footballbenchmark. com/broadcasting_revenue_distribution (accessed on 27 March 2018). 
LaFond, Ryan, and Haifeng You. 2010. The federal deposit insurance corporation improvement act, bank internal controls and financial reporting quality. Journal of Accounting and Economics 49: 75-83. [CrossRef]

Menary, Steve. 2016. One rule for one: the impact of Champions League prize money and Financial Fair Play at the bottom of the European club game. Soccer and Society 17: 666-79. [CrossRef]

Mourao, Paulo. 2012. The indebtedness of Portuguese soccer teams - looking for determinants. Journal of Sports Sciences 30: 1025-35. [CrossRef] [PubMed]

Nicoliello, Mario, and Davide Zampatti. 2016. Football clubs' profitability after the Financial Fair Play regulation: Evidence from Italy. Sport, Business and Management: An International Journal 6: 460-75. [CrossRef]

Oei, Rosalyn, Alan Ramsay, and Paul Mather. 2008. Earnings persistence, accruals and managerial share ownership. Accounting and Finance 48: 475-502. [CrossRef]

Rascher, Daniel A., Matthew T. Brown, Mark S. Nagel, and Chad D. McEvoy. 2012. Financial risk management: The role of a new stadium in minimizing the variation in franchise revenues. Journal of Sports Economics 13: 431-50. [CrossRef]

Richardson, Scott A., Richard G. Sloan, Mark T. Soliman, and Irem Tuna. 2005. Accrual reliability, earnings persistence and stock returns. Journal of Accounting and Economics 39: 437-85. [CrossRef]

Rohde, Marc, and Christoph Breuer. 2016. Europe's elite football: Financial growth, sporting success, transfer investment and private majority investors. International Journal of Financial Studies 4: 12. [CrossRef]

Sloan, Richard G. 1996. Do stock prices fully reflect information in accruals and cash flows about future earnings? The Accounting Review 71: 289-315.

Solberg, Harry Arne, and Kjetil K. Haugen. 2010. European club football: Why enormous revenues are not enough? Sport in Society 13: 329-43. [CrossRef]

(c) 2018 by the authors. Licensee MDPI, Basel, Switzerland. This article is an open access article distributed under the terms and conditions of the Creative Commons Attribution (CC BY) license (http://creativecommons.org/licenses/by/4.0/). 


\title{
Article \\ European Club Football after "Five Treatments" with Financial Fair Play-Time for an Assessment
}

\section{Egon Franck}

Department of Business Administration, University of Zurich, Affolternstrasse 56, 8050 Zurich, Switzerland; egon.franck@business.uzh.ch; Tel.: +41-44-6342845

Received: 8 October 2018; Accepted: 6 December 2018; Published: 13 December 2018

\begin{abstract}
UEFA's Club Licensing and Financial Fair Play Regulations (FFP) have impacted European club football. After five distinct applications of the break-even requirement, which represents the cornerstone of these regulations, it is time for an assessment. How has the situation in European top-division football changed since the FFP regulation? The most recent financial data show that European club football is characterized by significant financial recovery and further polarization. How has the FFP regulation presumably affected this development? This article discusses plausible reasons why FFP has contributed to financial recovery but has not aggravated polarization. Understanding the drivers of polarization is essential before taking further regulatory steps.
\end{abstract}

Keywords: football; regulation; financial fair play; financial recovery; polarization

JEL Classification: L83; L49; L51

\section{Introduction}

European club football has been confronted with a major regulatory intervention, UEFA's Club Licensing and Financial Fair Play Regulations (FFP). Today, after five distinct applications of the break-even requirement, which represents the cornerstone of this intervention, it is time for an assessment: How has the situation changed since FFP first impacted European top-division football? Additionally, how has the regulatory intervention presumably affected this development?

In sum, the most recent data show that European club football is characterized by quick financial recovery and further polarization. While pre-FFP European club football was on a trajectory of ever-deepening financial distress until 2011, the data show a continuous improvement since financial year (FY) 2012, the first reporting period entering into a break-even assessment. Of course, the mere comparison of the financial indicators pre- and post-FFP does not prove that FFP is the (or the main) cause behind the financial comeback of the European football industry. Nonetheless, this article suggests a plausible economic story as to why FFP has had a significant impact on creating a more financially stable industry ${ }^{1}$.

The newest data also show that financial recovery went hand in hand with further polarization. Absolute revenue growth has been much stronger at the top of the football pyramid, thereby further entrenching the sportive dominance of the "big clubs". However, the mere coincidence of FFP and further polarization does not imply that FFP is a (or the) cause for this development. This article discusses good reasons why polarization has not been aggravated by FFP. Clearly identifying the main drivers of polarization is of fundamental importance before embarking on a new regulatory exercise beyond the scope of FFP.

1 See Franck (2014) for a detailed explanation. 
The remainder of this paper is organized as follows. Section 2 gives a short overview of the financial situation of European club football pre-FFP. Section 3 briefly explains the main pillars, the assessment periods, and the judicial process of FFP. Section 4 is devoted to the economic analysis of FFP: Where exactly does the regulation change the incentives of decision-makers in the football industry? Section 5 presents facts and figures about the financial situation of post-FFP European club football. Section 6 is devoted to the analysis of the polarization between the top-tier clubs and the rest. Section 7 provides some first reflections on the European "super league" project. Section 8 concludes.

\section{The Financial Distress of Pre-FFP European Club Football}

UEFA publishes a yearly Benchmarking report ${ }^{2}$ covering the financial situation of approximately 700 first division clubs in $55^{3}$ member associations. Figure 1 shows the aggregate "bottom line", country by country, for the FY 2011. While football operating profits focus on the contribution from core football activities, the "bottom line" gives the performance of the clubs after including transfer activity, financing and divesting results, non-operating items, and tax. The country by country result in Figure 1 sends a message of financial distress. The red columns show countries whose first division clubs had spent between $€ 1.10$ and $€ 1.20$ to gain $€ 1.00$ of revenue, whereas dark-red columns show countries where even more than $€ 1.20$ had been spent to gain $€ 1.00$ of revenue. The predominance of the red and dark-red colors indicates that, with rare exceptions, football was a largely unprofitable business in 2011.

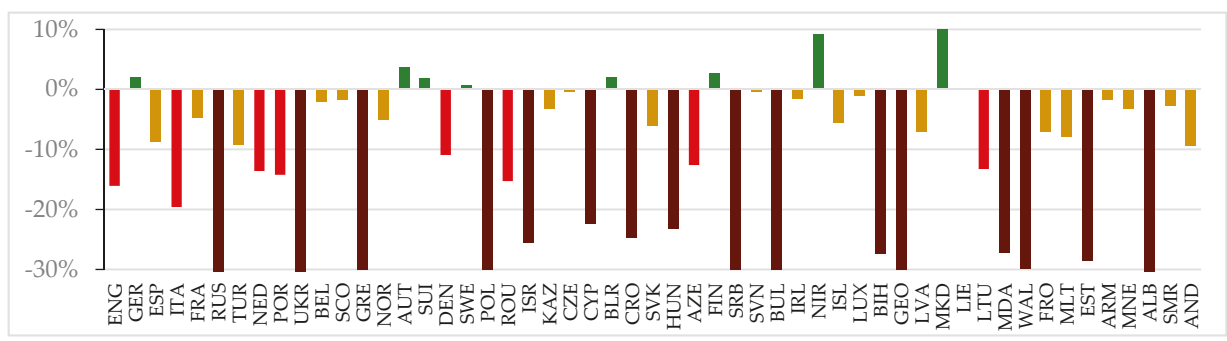

Figure 1. Aggregate "bottom line" (net profit/loss of the leagues in 2011). Source: UEFA (2013, p. 104). UEFA limited the chart at $-30 \%$. Maximum losses were significantly higher in single cases.

Figure 2 shows the development of the combined yearly net losses of all European top-division clubs from 2007 to 2011 . The losses almost tripled from $€ 0.6$ billion to $€ 1.7$ billion.

The cause of increasing financial distress was that the clubs spent everything and even more than they could reasonably afford on players. While revenues had increased at an average rate of $5.6 \%$ per year ${ }^{4}$, wages grew by $9.1 \%$ per year from 2007 to $2011 .^{5}$ The combined employee and net transfer costs to revenue ratio, which impacts bottom-line results, increased from $62 \%$ to $71 \%$, meaning that the revenue increase between FY 2007 and FY 2011 had not been enough to cover the increase in combined employee and net transfer costs. As a consequence, the financial results of the clubs competing in European competitions were worsening year after year despite the fact that football as an industry was growing. The percentage of "financial zombies", i.e., clubs with negative net equity, reached $38 \% .^{6}$ Meanwhile, in 2011, 63\% of all top-division clubs reported an operating loss and 55\% a net loss. ${ }^{7}$ The reported liabilities of the top-division clubs reached $€ 18.5$ billion in 2011 , and auditors expressed

\footnotetext{
All financial information in this section is taken from the UEFA Benchmarking Report covering the FY 2011. See UEFA (2013). This is the actual number in 2018.

See UEFA (2013, p. 78).

See UEFA (2013, p. 80).

See UEFA (2013, p. 15).

See UEFA (2013, p. 8).
} 
"going concern" doubts (i.e., doubts whether the club could still trade normally in 12 months' time) for one in every seven clubs. ${ }^{8}$

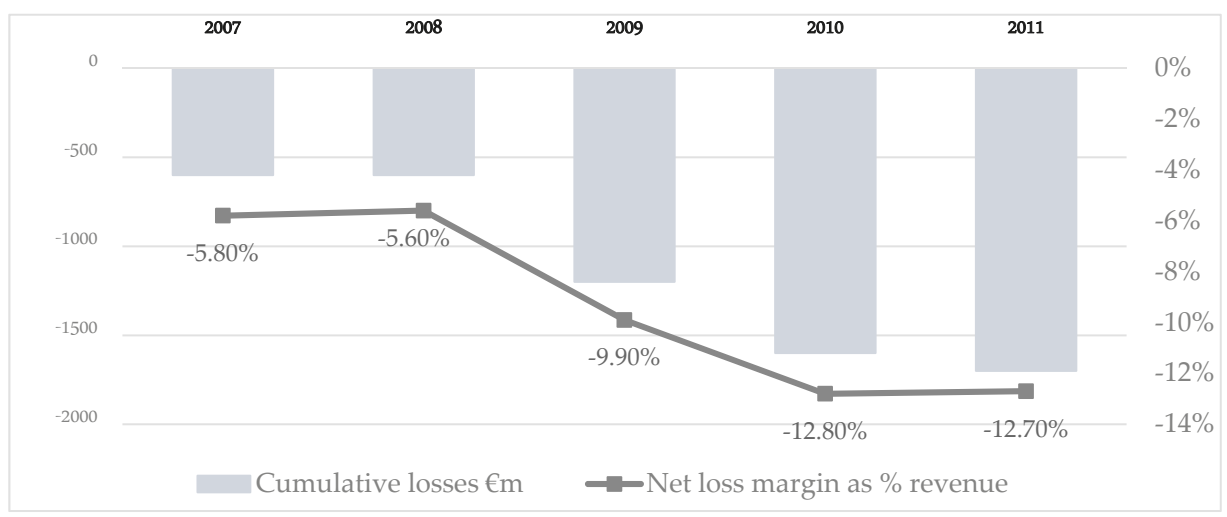

Figure 2. Combined net losses ( $€$ Millions) of the European top-division clubs, 2007 to 2011. Source: UEFA (2013, p. 82).

As a reaction to this development, stakeholders in the football industry increasingly shared the perception that the long-term viability and sustainability of the entire system was being threatened by football clubs' ever-deepening financial crisis. As clubs are strongly interconnected through their peculiar technology of producing a team output, the "championship race" ${ }^{\prime \prime}$, if some clubs go out of operation in mid-season, the credibility of the entire product of "championship" is severely harmed. Financial domino effects get triggered because bankrupt clubs cannot fulfill their obligations from transfer deals. Several factors, such as the high percentage of clubs with negative equity, the high level of overdue payables, the exit of "normal" investors ${ }^{10}$ from the industry, etc., jointly indicated that the system was "overheating"11.

Alerted by these developments, UEFA gathered internal and external experts to work on a regulation that would restabilize the football industry without entering into conflict with European Union competition law. The first version of the UEFA Club Licensing and Financial Fair Play Regulations was approved by the UEFA Executive Committee in September 2009.

\section{The Two Main Pillars, the Assessment Periods, and the Judicial Process of FFP ${ }^{12}$}

UEFA designed the new regulations as an enhancement of UEFA's established "workhorse", the club licensing system, which was introduced at the start of the 2004/2005 football season. In order to be admitted to UEFA's club competitions, the Champions League and the Europa League, each club must fulfill a series of quality standards falling into five categories: Sporting, infrastructure, personnel, legal, and financial. With the introduction of the new FFP regulations, UEFA upgraded the financial standards by introducing two important new requirements, explained below. These requirements are monitored by a newly created body of independent experts, the Club Financial Control Body (CFCB).

\footnotetext{
See UEFA (2013, p. 15).

See Neale (1964) for the initial formulation of this basic insight. Neale wrote about an "inverted joint product".

"Normal" investors expect a competitive risk-adjusted return from their engagement.

11 These and other related developments were already highlighted in the Independent European Sports Review published in 2006. See Arnaut (2006).

12 All information included in this section is based on the relevant UEFA documents: The Procedural Rules Governing the UEFA Club Financial Control Body (see UEFA 2015a) and The UEFA Club Licensing and Financial Fair Play Regulations (UEFA 2015b).
} 
The enhanced overdue payable rule, monitored from June 2011 onwards, is the first of the two new requirements. It demands that clubs playing in UEFA competitions must fulfill all their financial obligations towards other clubs, employees, and social or tax authorities punctually. While the established licensing system already assessed overdue payables, it only did so at one single date in the year, i.e., as of December 31. With the enhanced overdue payables rule, the CFCB monitors the fulfillment two more times per year, i.e., as of June 30 and September 30.

The break-even requirement, implemented in 2012 with the first assessment done during the $2013 / 2014$ season, is the second and main pillar of FFP. The idea behind this requirement is that each club achieves a sustainable balance between its income and expenses in the football market. The income earned in the football market is called "relevant income" and consists mainly of gate receipts, broadcasting, sponsoring, advertising, and commercial income. The expenses in the football market are called "relevant expenses" and consist mainly of employee benefit expenses and player transfer amortization. Balancing these two factors means that clubs must be able to perform their core football activities without owner contributions and without incurring debt. At the same time, clubs can still invest and incur debt or expend owner contributions on infrastructure, youth development, and community activities. Because such investments are for the long-term benefit of the club, the corresponding expenses are not considered as "relevant" for the purpose of the break-even calculation.

Importantly, clubs must balance "relevant income" and "relevant expenses" not in one FY, but in monitoring periods usually consisting of three FYs. Table 1 explains the concept of the applied "rolling three-year assessment". The main consequence of the rolling three-year assessment is that every FY will be part of three break-even assessments until it drops out.

Table 1. The aggregate break-even result is assessed over three reporting periods ( $T, T-1, T-2)$.

\begin{tabular}{cccc}
\hline & \multicolumn{3}{c}{ Monitoring Period } \\
\hline Assessment \# & FY $_{\mathrm{T}}$ & FY $_{\mathrm{T}-1}$ & FY $_{\mathrm{T}-2}$ \\
\hline 1 & 2013 & 2012 & N/A \\
2 & 2014 & 2013 & 2012 \\
3 & 2015 & 2014 & 2013 \\
4 & 2016 & 2015 & 2014 \\
5 & 2017 & 2016 & 2015 \\
\hline \multicolumn{4}{c}{ Source: UEFA (2015b). }
\end{tabular}

The first genuine break-even assessment took place in spring 2014. The CFCB had to wait until the clubs with a December year end closed their books for the FY 2013. In its first assessment, the CFCB assessed only the FYs 2012 and 2013 as an exception. In spring 2015, the CFCB then looked at the first complete monitoring period consisting of the FYs 2012, 2013, and 2014. The bottom box indicates the most recent assessment of the CFCB.

Due to the huge influence of sportive results on financial results-consider, for example, the financial impact of qualifying or not qualifying for the next round in the UEFA Champions League - the regulations give some flexibility to the clubs. More precisely, a break-even deficit of $€ 5$ million over three years is considered to be an "acceptable deviation". Furthermore, the rules permit an additional deficit of up to $€ 25$ million over three years, provided that it is covered through the injection of equity by the owners. This gives some flexibility to redevelop mismanaged clubs into viable businesses ${ }^{13}$.

13 Additional flexibility for new owners has been introduced through the concept of voluntary agreements. See UEFA (2015b, pp. 94-95) 
Table 2 and Figure 3 provide a brief overview of the judicial process of FFP. The CFCB comprises two chambers. The investigatory chamber conducts the investigation, determines the facts, and gathers all relevant evidence. It decides on every case, taking one of the following options:

- $\quad$ Dismiss the case;

- Impose minor disciplinary measures;

- Conclude a settlement agreement;

- $\quad$ Refer the case to the second chamber, the adjudicatory chamber.

The adjudicatory chamber takes a final decision on the case, which is either a dismissal or the instruction of disciplinary measures. As Figure 3 shows, the disciplinary measures of the adjudicatory chamber reach from a warning to the exclusion from competitions and withdrawal of titles and awards. Clubs can appeal the decisions of the adjudicatory chamber before the Court of Arbitration of Sport in Lausanne (CAS).

Table 2. The judicial process of FFP.

\begin{tabular}{|c|c|}
\hline Investigatory Chamber & Adjudicatory Chamber \\
\hline $\begin{array}{l}\text { - Conducts the investigation, } \\
\text { determines the facts, and gathers all } \\
\text { relevant evidence }\end{array}$ & $\begin{array}{l}\text { - Takes the final decision on the cases referred } \\
\text { by the CFCB investigatory chamber and } \\
\text { eventually imposes disciplinary measures }\end{array}$ \\
\hline $\begin{array}{l}\text { CFCB's Chief Investigator may } \\
\text { (in consultation with all members): }\end{array}$ & Court of Arbitration for Sport (CAS) \\
\hline $\begin{array}{l}\text { - } \quad \text { Dismiss the case } \\
\text { - } \quad \text { Impose minor disciplinary measures } \\
\text { - } \quad \text { Refer the case to the adjudicatory chamber }\end{array}$ & - $\quad$ Appeals can be lodged before the CAS \\
\hline
\end{tabular}

Source: UEFA (2015a). CFCB: Club Financial Control Body, FFP: UEFA's Club Licensing and Financial Fair Play Regulations.

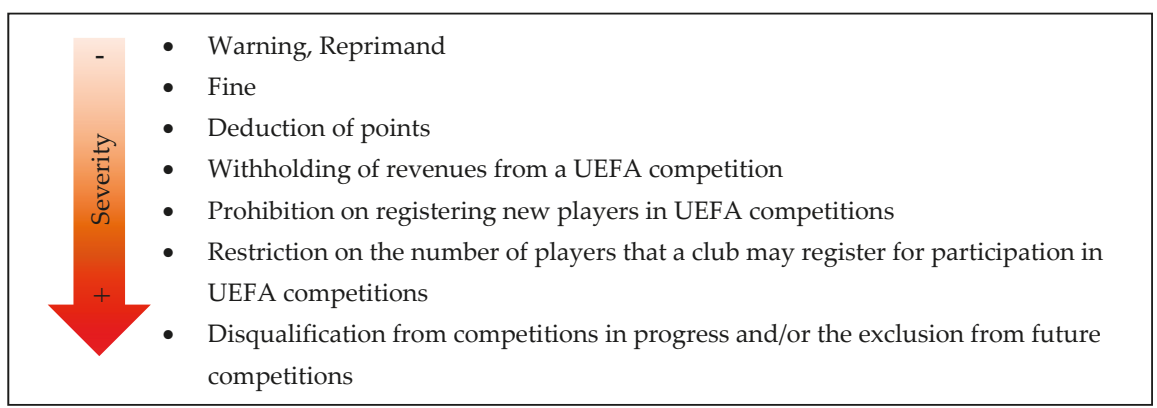

Figure 3. Disciplinary measures of the adjudicatory chamber. Source: (UEFA 2015a).

The experience of the last years clearly shows that the most important instrument in the daily practice of the CFCB is the settlement agreements concluded by the investigatory chamber with individual clubs. A significant number of clubs-28 until today, among them prominent ones, such as Paris Saint-Germain FC, Manchester City FC, Inter Milan, AS Monaco, AS Roma, FC Zenit, or FC Porto-entered into settlement agreements.

Instead of going through a lengthy judicial procedure, clubs with the clear potential to come back into compliance rather quickly sign settlement agreements voluntarily with the investigatory chamber. These agreements contain a detailed plan with annual and aggregate break-even targets that have to be reached and a set of "provisions" that, from an economic point of view, can be seen as sanctions and 
restrictions. For example, there have been very high (unconditional and conditional) withholdings of prize money, up to $€ 60$ million, and also strict limitations of player registration activities.

UEFA publishes on its website summaries of all settlement agreements and of all the decisions of the adjudicatory chamber ${ }^{14}$.

\section{The Economic Analysis of FFP ${ }^{15}$}

Football championships are examples of a certain form of economic competition, which is known as a contest in the literature. Research on contests shows that under certain circumstances, a phenomenon of overinvestment emerges. ${ }^{16}$ While this "arms race" or "rat race" effect ${ }^{17}$ explains why clubs may dissipate some resources in their attempt to achieve sporting success, it does not suffice to explain the extreme dissipation of resources in football, which transformed many clubs into "financial zombies" (i.e., a situation where the value of their liabilities exceeds the value of their assets). In other words, the concept of a "rat race" seems too weak to characterize an industry in which such a substantial part of the participants was technically bankrupt. Therefore, in this context, the concept of a "zombie race" seems more appropriate.

Obviously, a "zombie race" requires that the "normal" threat of dissolution of the club in case of insolvency is not functioning as a hard constraint. This leads to the second element of the story, i.e., to the soft budget constraints (SBCs) of many football clubs before the regulation. ${ }^{18}$ Football club managers could rationally expect that in case of a deficit, some form of "supporting organization", either the state or a private benefactor ${ }^{19}$, would step in to relieve the club from the pressure to "cover its expenditures out of its initial endowment and revenue" (Kornai et al. 2003, p. 4).

What is wrong with SBCs, though? Normally, economists would immediately discuss the differences between burning public or private money in football. However, this diverts from the main problem of bailouts in this specific context: They distort the incentives of decision-makers in football clubs.

\subsection{Runaway Demand for Talent and the Emergence of a "Salary Bubble"20}

If a club has a perfect SBC, the own price-elasticity of demand for player talent becomes zero, meaning that the demand for talent is not determined by the price but rather by other variables (Kornai 1986, p. 9). It seems rational to assume that winning is desirable for club decision-makers and that talent contributes to winning. If the supply of talent is not sufficiently elastic, the direct consequence of the SBC is the formation of excess demand for player talent. Frank and Bernanke (2004) explain why the supply of talent is inelastic by definition: "Indeed, the most important input of all—highly talented players-is in extremely limited supply. This is because the very definition of talented player is inescapably relative - simply put, such a player is one who is better than most others" (Frank and Bernanke 2004, p. 113). Thus, talent, understood as the capacity of a few players to be better than most others, is extremely scarce and its price gets bid through the roof if enough clubs have SBCs and a very low price-elasticity of demand for talent as a consequence. The more clubs operate with SBCs, the more football becomes

14 See https://www.uefa.com/insideuefa/disciplinary/club-financial-controlling-body/cases/index.html.

15 This section is not original but entirely based on my previous work. Please refer to Franck (2014, pp. 195-206) and the following Franck (2015, pp. 230-33) for the original analysis.

16 See Dietl et al. (2008) for an in-depth treatment of this issue.

17 See Akerlof (1976).

18 The concept of soft budget constraints had been introduced and initially studied by Kornai $(1980,1986)$ in the context of post-socialist economies. It has received much attention in the sports economics literature and also in the media. See e.g., Andreff (2007, 2011, 2015), Storm (2012), Storm and Nielsen (2012), Franck (2014, 2015) or Kuper (2009).

19 See the detailed discussion of this mechanism in Franck (2014, pp. 197-201).

20 This section corresponds to Franck (2015, p. 231). See Franck (2014, pp. 202-3) for a more in-depth explanation. 
a "talent shortage economy", resulting in a "salary bubble" 21 , where the wages and transfer fees of the few talented players reach levels that are unsustainable without systematic money injections.

\subsection{Managerial Moral Hazard: Too Much Risk and Too Little Care ${ }^{22}$}

Another consequence of the declining price-responsiveness of football clubs operating with SBCs is risk escalation. The emergence of managerial moral hazard behavior in environments with SBCs is a standard result that has been studied in different contexts. A prominent example is the "too big to fail" problem in the financial sector ${ }^{23}$, in which managers are inclined to take excessive risks because they can expect to be bailed out ex post. Franck and Lang (2014) analyzed money injections in football clubs based on a formal model. As soon as the option to be bailed out with a certain probability exists, club decision-makers are induced to make riskier investments.

Risk escalation is only one aspect of managerial moral hazard. In absence of what Kornai (1986, p. 12) called "'dead-serious' considerations of revenues and ultimately of supply", decision-makers do not invest enough of their own time and energy to end bad projects and develop good projects. Therefore, money "coming like manna" (Kornai 1986, p. 12) triggers waste and profuseness.

\subsection{Managerial Rent-Seeking ${ }^{24}$}

Managerial rent-seeking gives weak incentives to innovate and to develop the business, as Kornai (1986) explains: "Allocative efficiency cannot be achieved when input-output combinations do not adjust to price-signals. Within the firm there is no sufficiently strong stimulus to maximum efforts; weaker performance is tolerated. The attention of the firm's leaders is distracted from the shop floor and from the market to the offices of the bureaucracy where they may apply for help in case of financial trouble" (Kornai 1986, p. 10).

To the extent that rent-seeking behavior is systematically rewarded in SBC organizations, their managers invest less effort in developing competitive advantages by "improving quality, cutting costs, introducing new products or new processes" (Kornai 1986, p. 10). If productive efforts can easily be substituted by asking the "sugar daddy" to compensate for unfavorable developments, SBC organizations will be less innovative and their managers less entrepreneurial in a dynamic perspective. ${ }^{25}$

\subsection{Crowding Out of Incentives for "Good Management" 26}

Clubs operating with hard budget constraints find themselves victims of the "salary bubble" produced by the clubs with SBCs. Maintaining their old level of playing strength by keeping their share of "star players" would require higher expenditure in the player market. At first sight, this could generate an additional incentive to further increase efficiency through "better management" in order to remain competitive on the pitch. However, what if the margin to further increase efficiency through "better management" becomes too small compared to the magnitude of the money injections of benefactors at their competitors?

21 The terms "shortage economy" and "salary bubble" are, of course, borrowed from Kornai (1980, 1986).

22 This section largely corresponds to Franck (2015, pp. 231-32) and to Franck (2014, p. 203).

23 See e.g., Stern and Feldman (2004).

24 This section largely corresponds to Franck (2015, p. 232). See also Franck (2014, p. 203) for the initial version.

25 Numerous hearings with "clubs in trouble" in the CFCB over the last years have personally convinced me of the relevance of this piece of economic theory about managerial rent-seeking. It is striking to see how commercially underdeveloped some "big clubs" of the past are, where "sugar daddies" wrote checks year after year to bail them out. They have no own stadia, no systematic international fan development, underdeveloped sponsorship and commercial rights, excess employment, lack of professional managerial competence, huge and inefficient player portfolios, etc. It is a true challenge for their new owners to turn around these clubs and make them catch up with their former peers in terms of commercial development.

26 This section corresponds to Franck (2015, pp. 232-33). See also Franck (2014, p. 204) for the initial version. 
It seems that these clubs will have no choice but to accept sportive decline or to change sides and start gambling on success and invest more aggressively. If we consider that sportive decline generates disutility both for club decision-makers and fans, it seems plausible that the SBCs of some clubs should intensify the incentives of other clubs to overspend.

Thus, "unlimited" money injections have a tendency to crowd out business models based on "good management". More and more clubs tend to take more risk and chronically expend more than their earnings, hoping to be rescued by external money injections year after year if the gamble goes wrong. One might argue that this state of affairs had already been reached in the FY 2011, given the numbers presented in Section 2.

\subsection{The Role of FFP}

Against this background, FFP is an instrument to move from a state of affairs with SBCs to a state of affairs with harder budget constraints ${ }^{27}$. The message sent to football managers by the cornerstone of FFP, the break-even requirement, is that they should no more "hope for a bailout" when the payroll expenditures drive relevant expenses to a level that exceeds relevant income by more than the "acceptable deviation". Clubs will be sanctioned and, in extreme cases, not receive a license to play if they do not break even in the football market. Thus, the existence of benefactors that would be willing to donate additional money to cover excessive salary and transfer payments becomes irrelevant.

In theory, the FFP regulation should therefore mitigate the inefficiencies resulting from SBCs and reduce the systemic risk of a severe financial crisis in the football industry. Clubs that break even in the football market and pay their bills punctually are sustainable and do not produce any kind of negative externalities, which might bring other clubs in trouble.

\section{The Financial Situation of Post-FFP European Club Football}

"Will football revenues drop substantially post-FFP?" This "prosperity concern" was a major criticism when FFP was introduced ${ }^{28}$. "Will post-FFP football enter into a downward development if the money injections of benefactors no longer freely flow into the clubs?" The fear was that smaller money injections would lead to lower quality on the pitch, less attractive games, lower consumer interest, and lower sponsor interest, therefore driving clubs into a downward spiral.

However, Figure 4 shows that the post-FFP reality contrasted these criticisms. The post-FFP compound annual growth rate (CAGR) of revenues increased to an impressive $7.2 \%$. There are at least two good reasons for this development.

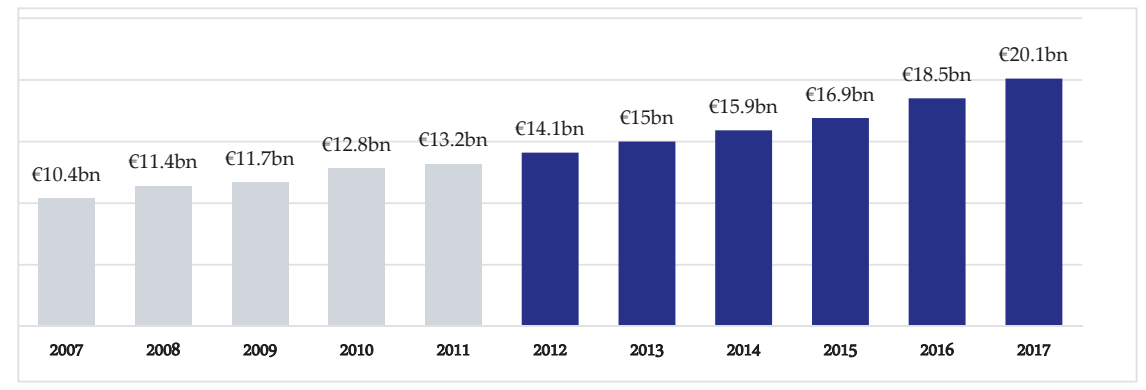

Figure 4. Long-term European club revenue growth (€ Billions). Sources: UEFA (2017, p. 56). The data for the FY 2017 have been provided by UEFA to the author in personal communication.

27 See Franck (2015, p. 229) for a similar interpretation. See Franck (2014, pp. 204-5) for a more detailed analysis.

28 See Madden (2015) for a theoretical analysis supporting the "prosperity concern". 


\subsection{First Reason ${ }^{29}$}

Critics exaggerated the "prosperity concern" because they failed to precisely study the new regulations. In that case, they would have easily found out that the payments of owners made for the absorption of losses in the past would not entirely disappear post-FFP. A substantial part of them would simply become a fair market value transaction and continue to flow into football.

As an example, consider the German chemicals corporation Bayer AG, which is the $100 \%$ owner of the Bayer 04 Leverkusen football club. The question to be answered under FFP is how much would the Bayer AG have to invest in public relations (PR) activities per year in order to achieve a similar level of brand awareness as that produced by Bayer Leverkusen? The Bayer AG can continue to absorb losses of this level at its subsidiary club under FFP by simply concluding a sponsorship agreement and paying the fair market value sponsorship fee.

The major difference to the ex-post absorption of losses common in the past, is that such sponsorship deals have to be concluded ex ante. Because managers of football clubs have complete knowledge of the sponsorship revenues, which are a component of relevant income, they have no reason to develop any kind of SBC expectations with all the associated incentive problems. All the former money injections of club owners that constitute a fair market value compensation for transacted goods or services will therefore continue to flow into football, for example, by being transformed into sponsorships. However, they enter the system without creating SBCs.

Only payments that would constitute contributions above the fair market value of goods or services exchanged between the club and the owner will not be counted as relevant income under FFP. If, for example, the Bayer AG would pay more to its subsidiary club in a sponsoring agreement than a comparable amount of exposure/image transfer costs in the free market, this "sponsoring in excess of fair market value" would not count as relevant income.

Under FFP, the club can still take this money and spend it on infrastructure, youth development, or community activities. However, the club cannot use this money to cover relevant expenses, that is, for player salaries and transfer amortizations. For owners with a longer-term perspective, investments in infrastructure, youth development, etc. outside the direct payroll may still make good sense. These owners will not reduce their money injections to a "fair market value" level, but they will simply not use the "excess" to directly inflate payrolls in the club.

Thus, it could be expected that a substantial part of the owner injections seen in the past would still flow into football as fair market value transactions, and another substantial part would continue to flow into football as investment in infrastructure, youth development, and community projects outside the fair market value adjustment.

\subsection{Second Reason}

New revenue sources would emerge in a regime with different managerial incentives. A lot more money would be generated in the football market if managers facing hard budget constraints stopped playing moral-hazard and rent-seeking games and started doing "a good job", concentrating on productive efforts, taking adequate risks, and developing the business ${ }^{30}$. Taking all these reasons together, concerns that FFP would lead to decreasing revenues and to a downward spiral seemed unfounded.

Until 2011, growing revenues went hand in hand with deteriorating club finances. After the introduction of FFP, this is no longer the case. Figure 5 shows that the post-FFP overdue payables decreased by more than $90 \%$ compared to pre-FFP.

29 See Franck (2014, pp. 205-6) for the short original treatment of this issue. See Franck (2015, pp. 236-38) for an in-depth discussion.

30 See Franck (2014, p. 206) for stressing this main effect of hard budget constraints. 


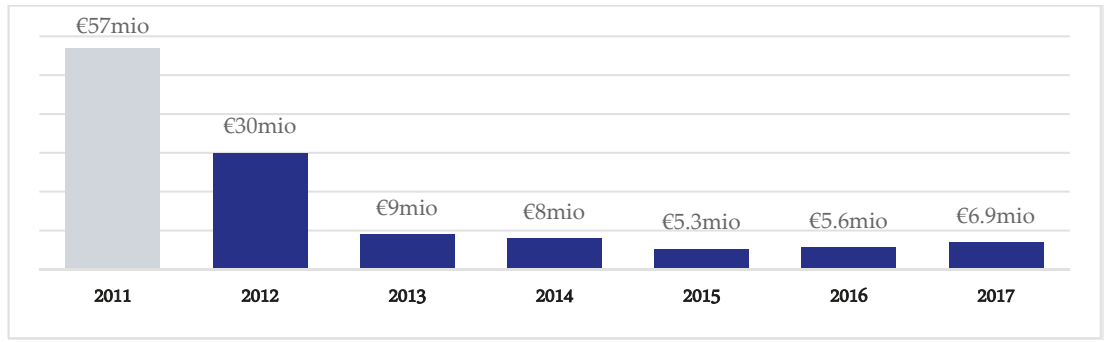

Figure 5. Overdue payables-Trend 2011 to 2017 ( $€$ Millions). Source: The data have been provided by UEFA to the author in personal communication.

Figure 6 shows the aggregate operating results for the European top division clubs. For the first time, clubs reported decreasing operating losses in 2012, the first year entering into a break-even assessment. Since 2013, top-division clubs have reported positive operating profits: They generated $€ 2.9$ billion in operating profits over the $2015-2017$ period.

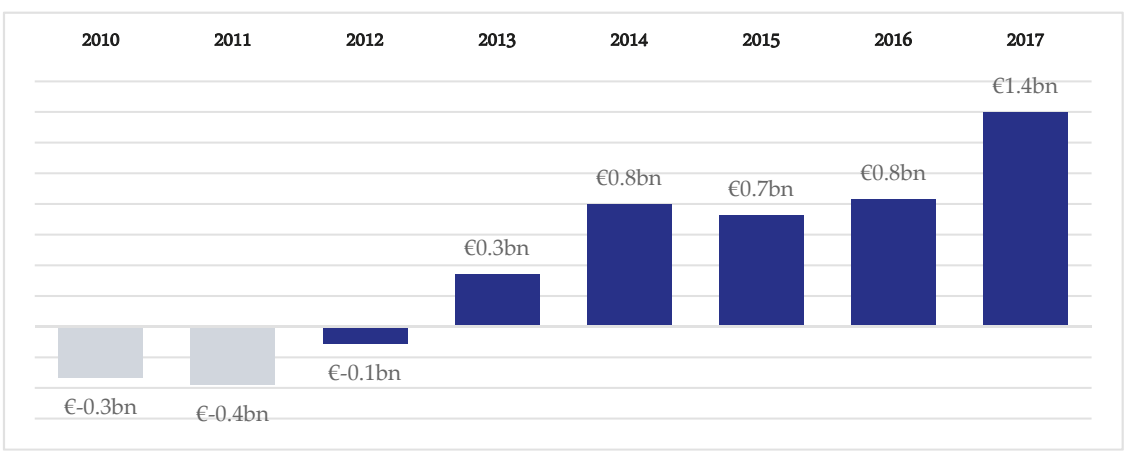

Figure 6. Aggregate European top-division operating profits. Sources: UEFA (2017, p. 101). The data for the FY 2017 have been provided by UEFA to the author in personal communication.

Figure 7 shows the aggregated net results after including transfer activity, financing, and investment/divestment and taxes. Since the FY 2012, a clear positive development in the aggregated net results is apparent. For the first time in 2017, European club football even reported an aggregate bottom line profit. This is remarkable when considering that European football clubs are generally not seen as "normal" profit-maximizing firms. Even after fixing the problem of SBCs through regulation, football remains a contest between win-maximizing participants. FFP does not force participants "to make profit", but only to break even in the football market by and large (with an acceptable deficit of somewhere between $€ 5$ and $€ 30$ million in 3 years, as long as the owner covers the difference through equity injections).

Figure 8 shows the evolution of top-division club net equity (assets less liabilities). A significant improvement of the balance sheets has taken place, meaning that the "zombie race" problem disappears. Net equity has more than tripled since the rules were approved in 2009.

The numbers presented in this section undeniably show the financial comeback of the European football industry. 


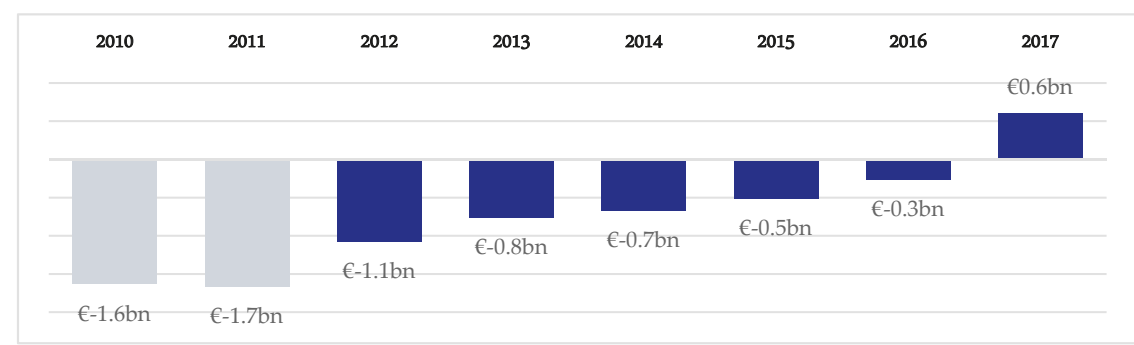

Figure 7. Aggregate European top-division net results. Sources: UEFA (2017, p. 102). The data for the FY 2017 have been provided by UEFA to the author in personal communication.

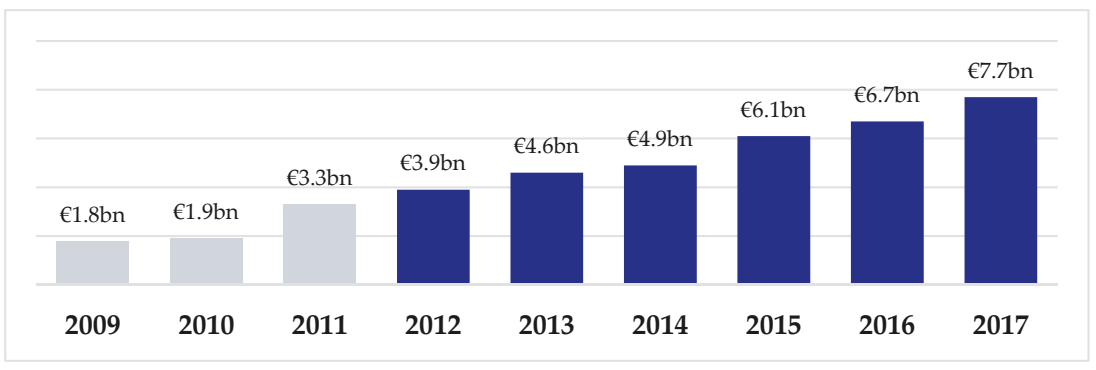

Figure 8. Evolution in European top-division club net equity (assets less liabilities) ( $€$ Billions). Sources: UEFA (2017, p. 124). The data for the FY 2017 have been provided by UEFA to the author in personal communication.

\section{Polarization: A Challenge Not Directly Addressed by FFP}

The Deloitte Football Money League, a report produced annually by the accountancy firm Deloitte, ranks European football clubs based on their revenues ${ }^{31}$. Table 3 shows that in Season 2016/2017, the top 10 clubs in this ranking had revenues of $€ 535$ million on average, while the clubs ranked 11-20 had revenues of $€ 255$ million on average. In the Season 2011/2012, the revenues were $€ 334$ million for the top 10 and $€ 150$ million for the $11-20$, whereas in the Season $2006 / 2007$, the revenues were $€ 251$ million for the top 10 and $€ 122$ million for the 11-20.

Table 3. Top 20 clubs by revenue ( $€$ Millions).

\begin{tabular}{cccc}
\hline Year & Top 1-10 Clubs & Top 11-20 Clubs & $\boldsymbol{\Delta}$ Top 10 vs. Top 11-20 \\
\hline $2016 / 2017$ & 535 & 255 & +280 \\
$2011 / 2012$ & 334 & 150 & +184 \\
$2006 / 2007$ & 251 & 122 & +129 \\
\hline \multicolumn{4}{r}{}
\end{tabular}

The last column exhibits the difference between the top 10 and the 11-20 clubs in the different seasons. The difference was $€ 129$ million in 2006/2007 and grew to $€ 184$ million in 2011/2012 and to a

31 See e.g., Deloitte (2018). 
$€ 280$ million in 2016/2017. These absolute numbers ${ }^{32}$ show that in the last five years, the clubs at the top have literally "pulled away" away from the rest.

At the same time, these "big clubs" seem to become more dominant on the pitch. In Table 4 , the top panel shows that the Bundesliga, the Serie A, and the French League 1 are dominated by one club, whereas the bottom panel shows that the final stages of the UEFA Champions League (UCL) look more and more like a closed and exclusive competition, because the number of different semifinalists decreased.

Table 4. Polarization in domestic leagues and in the UEFA CL.

\begin{tabular}{|c|c|c|c|c|c|c|c|}
\hline \multicolumn{8}{|c|}{ Champions in Domestic Leagues } \\
\hline League & $2017 / 2018$ & $2016 / 2017$ & \multicolumn{2}{|c|}{$2015 / 2016$} & $2014 / 2015$ & $2013 / 2014$ & $2012 / 2013$ \\
\hline German & Bayern & Bayern & \multicolumn{2}{|c|}{ Bayern } & Bayern & Bayern & Bayern \\
\hline Bundesliga & Munich & Munich & \multicolumn{2}{|c|}{ Munich } & Munich & Munich & Munich \\
\hline Italian & Juventus & Juventus & \multirow{2}{*}{\multicolumn{2}{|c|}{$\begin{array}{l}\text { Juventus } \\
\text { Turin }\end{array}$}} & Juventus & Juventus & Juventus \\
\hline Serie A & Turin & Turin & & & Turin & Turin & Turin \\
\hline French & Paris St. & AS & \multirow{2}{*}{\multicolumn{2}{|c|}{$\begin{array}{l}\text { Paris St. } \\
\text { Germain }\end{array}$}} & Paris St. & Paris St. & Paris St. \\
\hline Ligue 1 & Germain & Monaco & & & Germain & Germain & Germain \\
\hline \multicolumn{8}{|c|}{ UEFA CL } \\
\hline Years & \multicolumn{3}{|c|}{ Teams Reaching the Semifinals } & \multicolumn{3}{|c|}{$\begin{array}{l}\text { Country of Origin of the } \\
\text { Semifinalists }\end{array}$} & $\begin{array}{l}\text { \# Different } \\
\text { Semifinalists }\end{array}$ \\
\hline $\begin{array}{l}2011 / 2012 \text { to } \\
2017 / 2018\end{array}$ & $\begin{array}{r}\text { Atletico } \\
\text { Bayern } \\
\text { Dortmun } \\
\text { Liverpo } \\
\text { Monaco, }\end{array}$ & $\begin{array}{l}\text { drid, Barcel } \\
\text { anich, Borus } \\
\text { Chelsea, Juve } \\
\text { Manchester } \\
\text { al Madrid, R }\end{array}$ & & \multicolumn{3}{|c|}{$\begin{array}{l}\text { England, France, Germany, } \\
\text { Italy, Spain }\end{array}$} & 11 \\
\hline $\begin{array}{c}2004 / 2005 \text { to } \\
2010 / 2011\end{array}$ & $\begin{array}{r}\text { Arsenal } \\
\text { Munich, Ch } \\
\text { Milan, } \\
\text { Manchest } \\
\text { Madrid }\end{array}$ & $\begin{array}{l}\text { rcelona, Bay } \\
\text { ea, Eindhove } \\
\text { verpool, Lyo } \\
\text { nited, Milar } \\
\text { halke, Villar }\end{array}$ & Inter & \multicolumn{3}{|c|}{$\begin{array}{l}\text { England, France, Germany, } \\
\text { Italy, Netherlands, Spain }\end{array}$} & 13 \\
\hline $\begin{array}{l}1997 / 1998 \text { to } \\
2003 / 2004\end{array}$ & $\begin{array}{r}\text { Barcelona, } \\
\text { Leverkuser } \\
\text { Chelsea, } \\
\text { Milan, Juv } \\
\text { Coruña, Lee } \\
\text { United, } \\
\text { Madri }\end{array}$ & $\begin{array}{l}\text { ern Munich } \\
\text { orussia Dor } \\
\text { tamo Kiew, } \\
\text { 1s, Deportiv } \\
\text { United, Mar } \\
\text { n, Monaco, } \\
\text { orto, Valen }\end{array}$ & $\begin{array}{l}\text { ayer } \\
\text { ind, } \\
\text { er } \\
\text { e la } \\
\text { ester } \\
\text { al }\end{array}$ & \multicolumn{3}{|c|}{$\begin{array}{l}\text { England, France, Germany, } \\
\text { Italy, Portugal, Spain, Ukraine }\end{array}$} & 16 \\
\hline
\end{tabular}

In the period covering the Seasons $1997 / 1998$ to 2003/2004, 16 different clubs reached the UCL semifinals. In the period covering the Seasons 2004/2005 to 2010/2011, the number of clubs in UCL

32 One could argue that in relative terms, not so much has changed over time: The ratio between the revenues of the top 10 and the revenues of the 11-20 was always around 2 (it was 2.057 in the season 2006/2007, 2.227 in the season 2011/2012, and 2.098 in season 2016/2017). However, what matters with respect to balanced competition is the absolute difference in revenues and not the relative difference. Carreras and Garcia (2018) look at the newly signed TV deals in England and Spain. They lead to smaller relative differences in revenues. However, absolute differences in revenues go up and competitive balance worsens as a result. This can be explained by the fact that wages and talent do not have a linear relationship but an exponential one. 
semifinals decreased to 13. Finally, in the period covering the Seasons 2011/2012 to 2017/2018, only 11 different clubs entered the UCL semifinals.

In sum, the numbers suggest that a process of polarization has taken place:

- Absolute revenues have grown stronger at the "big clubs" and

- "Big clubs" have become more dominant on the pitch.

An important question is whether there is a causal relationship between FFP and polarization. Indeed, FFP has been at times attacked by pointing to the fact that it has not worked as an effective remedy against polarization. However, it is important to note that FFP was not designed as a remedy against polarization. For example, if Real Madrid and FC Basel follow the rules and balance relevant income and expenses, the consequence is not that they become equal competitors on the pitch. If "big clubs" and "small clubs" live within their own means, in line with the break-even requirement, this does not imply that they rely on equal means.

FFP has also been attacked with the argument that it contributed to further polarization ${ }^{33}$ because even the richest "sugar daddies" have to compete based on payrolls largely financed through income generated in the football market. As a consequence, they will no longer be able to challenge the "bigger clubs" by spending more money on players. The idea that FFP might therefore entrench the dominance of already "big clubs" seems plausible at first sight. However, the key question is whether a mechanism exists that systematically allocates payroll injections according to a pattern that makes "small clubs" relatively more competitive ${ }^{34}$.

First of all, FPP only caps "inflated" owner payments. A sponsoring agreement, where the owners pay a fair market price in exchange for the exposure/image transfer generated by the team for their other businesses, is in line with the regulations. In order to be affected by FFP, the owners must be willing to inject more money into payrolls than the publicity and image transfer generated through the success of their teams. In other words: Those owners that will be restrained by FFP in their "usual" spending behavior are "pure" success-seekers. "Pure" success-seekers by definition will try to spend their money where winning probabilities are the highest. As a consequence, they will systematically search for the clubs with the largest market potential available on the market.

It is widely accepted that the behavior of European football clubs is best described as "win maximization" subject to a budget constraint. Which is the likely result of a matching process between success-seeking benefactors and win-maximizing clubs? This article suggests that, in equilibrium, "money comes to money" because success-seeking benefactors look for the clubs with the largest market potential available and win-maximizing clubs by definition prefer the largest payroll injection. If unregulated, this simultaneous competition for money injections and market potential should converge to a state where the benefactors with the deepest pockets get allocated to the clubs with the largest market potential (the "favorites"), making them even more dominant.

One could argue that by preventing "pure" success-seekers from inflating payrolls, FFP is also preventing the deepest pockets from supporting clubs from the largest markets. Thus, FFP actually slows down the speed of polarization.

However, what else may be driving polarization? Polarization is likely the result of the concurrence of several factors, such as digital technologies, globalization, and the "winner-take-most" dynamic in many entertainment markets. The basic mechanism has been explained in the seminal paper of Rosen (1981).

New technology dramatically enlarges the market for producers of football entertainment. While before the advent of TV, the potential number of consumers of a football game was limited by the size of the stadium and the local population, later, with national TV rights, the national market became the

33 See for example Dupont (2013) and, for a formal academic treatment, Sass (2016).

34 See Franck (2014, pp. 209-10) for a short initial treatment of this question and Franck (2015, pp. 235-44) for a detailed discussion. 
crucial limitation. Nowadays, with new technologies, such as high-speed internet and mobile digital platforms, potentially the entire world is the relevant market.

If consumers prefer higher to lower quality, the likely outcome is a sort of "superstar" development: The attention of consumers with a preference for quality migrates to the producers of top content. During the first phase of market enlargement, from local stadium to national TV markets, national "top clubs" emerge. These producers will attract more attention. To the extent that revenues are attached to attention, these producers can further increase their quality. The larger the national TV market is, the more these "top clubs" can increase their quality and revenues. They are in a favorable position to exploit the next phase of market enlargement, the development of global entertainment demand through new technologies. Quality-sensitive consumers from the all over the world will be attracted by the "best product" offered by these "top clubs" that were able to grow and develop in their "big national markets" in the past. As a consequence, they will attract even more quality-sensitive consumers and further increase their revenues. In the end, these winners will take most of the market. As a consequence, attention and correlated revenues concentrate at the top of the producer hierarchy.

Adler (1985) has added to this theory the insight that new fans tend to attach to the clubs that already have many fans. A person interested in football derives utility not only from watching games, but also from discussing and interacting with other likeminded people. The more popular the club in question is, the lower the searching costs to find fellow fans will consequently be.

To sum up, the very skewed distribution of attention, correlated earnings, and success are the result of the following two factors:

- First, new technology has dramatically enlarged the market for producers and quality-sensitive worldwide demand has migrated to the top of the producer hierarchy (i.e., the Rosen effect).

- Second, once a club has a large "installed base" of fans, "popularity effects" kick in. New fans patronize the superstar club because of the network externalities emerging from a large fan base (i.e., the Adler effect).

In order to capture their global profile, UEFA measured the traffic on clubs' websites in September 2016. Figure 9 shows that 5 European club websites had more than 5 million visitors. The large portion of foreign online visitors (in grey) clearly suggests that these clubs are "global brands" reaching out to a worldwide audience, just as the Rosen-Adler superstar theory would predict. The extreme case is FC Barcelona: 91\% of the online traffic on the FC Barcelona website originates from outside Spain.

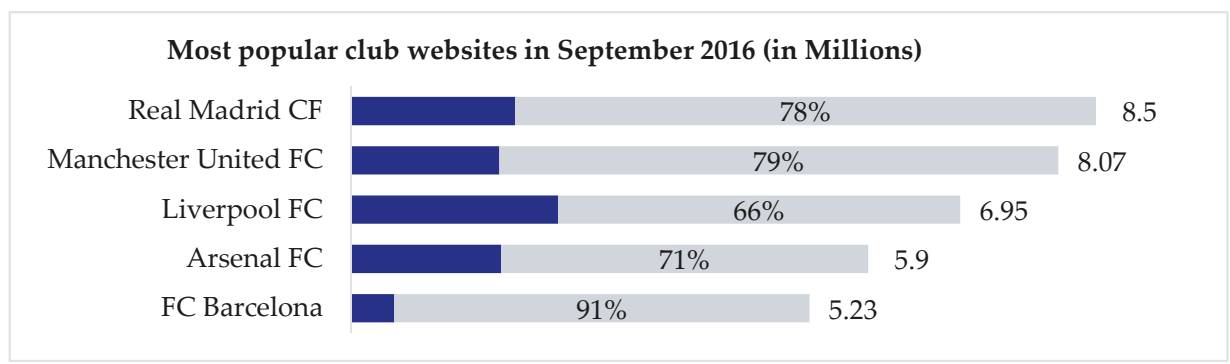

Figure 9. Global profile of largest clubs becomes clear from online traffic. Indicated in \% (and in grey) is the proportion of foreign online visitors. Only the clubs with more than 5 million visitors were extracted from the original source. Source: UEFA (2017, p. 18).

Finally, an obvious consequence of polarization is the proliferation of "unequal pairings", i.e., matches between the "big clubs" and the rest. The "big clubs" literally dominate the other teams in domestic league games and the same happens in the group phase of the Champions League, where the "big clubs" encounter teams from much smaller domestic leagues. As a consequence, one 
may ask if in the future there will be sufficient suspense left in the system to attract fans, sponsors, or commercial partners. Should the preservation of sufficient suspense be addressed by changing the format of the competition? Is the European "super league" a possible solution?

\section{Some Reflections on the Incentives of the "Big Clubs" in the European "Super League" Project}

Discussions about the creation of a closed European league of "big clubs" recently gained new momentum ${ }^{35}$. A look at the current top-level format of the competition is helpful to clarify the incentives of the "big clubs". Two main characteristics stand out:

- Overlapping competitions, i.e., the "big clubs" play in the domestic leagues and in the Champions League simultaneously;

- Openness, i.e., access to the Champions League is mainly based on sportive qualification in the domestic leagues.

The overlapping competitions at the top of the football pyramid are an anomaly when compared to all other levels of the pyramid. Second division clubs, third division clubs, etc. normally only play in their respective divisions of the domestic competitions, if we abstract from cup games. A first approach to dealing with the problem of "unequal pairings" would be to abolish this anomaly of overlapping competitions and preserve openness by creating a European "super league" with promotion and relegation on top of the domestic leagues.

This "super league" 36 would replace the current European competitions, and its participants would no longer play and earn revenues in domestic competitions simultaneously. This model would be much more effective with respect to the avoidance of "unequal pairings" than the current format ${ }^{37}$. Teams that dominate domestically get promoted to the presumably stronger European level and teams that underperform at the European level "go back" to their domestic competitions. Of course, many details of this open "super league" model would have to be worked out properly before putting it into practice. In particular, the heterogeneity of domestic competitions is difficult to tackle in this context.

However, comparable problems have been solved in the past at other levels. For example, when the German Bundesliga was created in 1963, it was introduced as the "German super league" and the new "top" of the domestic football pyramid, which previously consisted of five different regional leagues ("Oberligen"). Why should the project of an open European "super league" be less successful today than the project of an open German "super league" was in 1963? If the Rosen-Adler superstar theory holds, games between strong teams attract quality-sensitive consumers. The current European competitions already show the existence of a supranational market for football entertainment. Moreover, travel time between the big European cities has become shorter than, for example, between provincial towns in Germany, thanks to modern transportation technologies. Why then do we not see any significant attempt to embark on projects that would further develop and implement this solution of an open European "super league" with promotion and relegation?

An important reason is presumably that the "big clubs" are not interested in this model. Their strategy seems to aim in the opposite direction, namely, to preserve overlapping competitions, and, at the same time, to put pressure on UEFA in order to increasingly "close" the final stages of the Champions League:

- The number of slots in the group phase of the Champions League has been increased to currently four for each of the "big" domestic leagues. Since the "big clubs" all come from the "big" domestic

35 See e.g., https://www.independent.co.uk/sport/football/european/football-leaks-european-super-league-manchestercity-manchester-united-uefa-a8619856.html.

36 Hoehn and Szymanski (1999) and Kesenne (2007), for example, provide much more sophisticated, welfare-oriented analyses of the "super league" problem. This article focuses on the incentives of the "big clubs" and not on welfare issues.

37 The focus is on the polarization problem here. I am not suggesting that there are no other disadvantages from a welfare perspective. 
leagues, they have almost "safe access" to the Champions League. Even in less successful domestic seasons, their much more expensive squads will manage to finish on one of the first four ranks of the domestic league table;

- The group phase then systematically sorts out the "underdogs", which might win single games but cannot survive in a series of games against the star squads of the "big clubs";

- Finally, seeding ensures that the "big clubs" do not meet and sort out each-other in the first stages of the competition;

Thus, the final and most lucrative stages of the Champions League look more and more like a closed competition of the "big clubs".

Recently, the media have spread the idea that the "big clubs" intend to leave domestic competitions entirely to play only in a new hermetic self-operated European "super league". However, there is a difference between the threat, which the "big clubs" have systematically produced in the past in order to improve their own bargaining position in negotiations with UEFA, and the strategy they have pursued in reality. The threat to leave the football pyramid and the current system is a proven instrument to pressure UEFA into giving ever larger pieces of the Champions League "pie" to the "big clubs". By definition, the threat to leave "the current system" can only be the creation of a hermetic, self-operated league, because there is no other football pyramid, which the "big clubs" could target as their new "home". Therefore, the "big clubs" started to invest resources in what can be called the "perpetual hermetic super league project". This project goes back to at least the year 1998 and gained additional momentum in 2000 with the G14 initiative ${ }^{38}$.

A closer look at the incentives of the "big clubs" suggests that the credibility of their threat is rather moderate for a number of reasons.

First, if they would make real their threat and break away, they would automatically lose the advantages stemming from the current system of overlapping competitions, e.g.,:

Multiple sources of income: The current modus of overlapping competitions at the national and the European level allows the "big clubs" to earn money in their domestic competitions and in the European competitions simultaneously. The more developed and prosperous the respective domestic competitions are, the higher the incentives of "big clubs" to preserve the link and play domestically.

Multiple chances to lift trophies: A detailed inspection of a letter written by clubs such as Real Madrid, Manchester United or Bayern Munich is helpful to see the point made in this section. Half of the space on the left side of the letter typically lists the trophies these clubs have won in the past. For such "big clubs", years with only one "minor" trophy (for example, a domestic cup title) are considered as failures. Overlapping competitions create multiple chances to lift trophies.

Second, if the "big clubs" exited the current system, they would exit the football pyramid and lose the advantages related to this pyramid, e.g.,:

Multiple sources of suspense: By preserving the link to the pyramid, the "big clubs" make sure that fan interest is fueled by several open questions that generate suspense. Instead of a single potentially open question such as "which team will win the closed league?", many questions are open in a multilevel contest format, such as "which team will win the championship race in every league of the system? Which team will get promoted to the next level? Which team will be able to avoid relegation? Which team will be demoted? Which team will be able to qualify for the UCL from a domestic league? Which team will qualify for the Europa League?", etc.

Multiple sources of surprise: Entertainment demand is not only driven by suspense, but also by surprise ${ }^{39}$. The rise and unexpected performance of underdogs fascinates people and attracts new fans to the game. The current system, the football pyramid, is open to "success stories". Consider the rise of RB Leipzig from the bottom to the top of the German football leagues within only seven seasons, or FC

38 See, e.g., https://www.theguardian.com/football/2008/jan/16/newsstory.sport7.

39 See Ely et al. (2015) for a theoretical treatment of this and Bizzozero et al. (2016) for an empirical proof in the tennis industry. 
Leicester City winning the Premier League in 2016. Compared to that, the model of a closed, balanced "big club"-league leaves little room for surprise because "underdogs" are nonexistent by definition.

Third, "hermetic leagues" function according to a different logic, which would require a complete redesign of the governance and incentives systems. To make a closed league attractive, the "big clubs" would need to guarantee "openness of outcome" as long as possible in every season through revenue redistribution, salary caps, drafts systems, etc. Is it realistic to assume that the win-maximizing "big clubs" of today, which voluntarily engage in genuine arms races, will convert to an "egalitarian regime", where they share their resources and voluntarily respect "arms-control" regulations? Redesigning the governance and incentives systems would generate very substantial transaction costs, which the "big clubs" would then bear. In addition, if they really succeeded in creating such a league with 16 clubs, every club would lift a trophy only every 16 years, on average. It is hard to imagine that the owners and executives running these clubs at the moment and also their fans can really adapt to such a "trophy tax" situation.

\section{Outlook}

Football clubs are strongly interconnected because they jointly produce the championship race. If some clubs go out of operation in mid-season, the credibility of the entire championship is severely harmed through incomplete schedules. Financial domino effects get triggered because bankrupt clubs no longer fulfill their obligations from transfer deals, which brings other clubs in danger.

Clubs that manage to break even and live within the income generated in the football market are sustainable and do not produce this kind of negative externalities. In that sense, the clubs respecting the break-even requirement and the no-overdue-payables rule behave in a "financially fair" way. The FFP regulation derives its specific notion of "fairness" from this link to the overall goal of systemic financial stability. Given the numbers presented, it seems difficult to deny that the football industry has become financially much more stable since the introduction of FFP.

However, systemic financial stability is not the only concern among the stakeholders of the European football industry. Polarization raises new challenges. The "normal" solution for the problem of "unequal pairings" would be to abolish overlapping competitions and create a European "super league" with promotion and relegation on top of the domestic leagues. However, the strategy of the "big clubs" is not compatible with this model. Their "perpetual hermetic super league project" has been used as a threat to improve their bargaining power in negotiations with UEFA. So far, they succeeded to capture ever larger pieces of the Champions League "pie", while continuing to simultaneously play and earn money and lift trophies in their prosperous domestic leagues.

In conclusion, if this path continues into the future, polarization and the question of adequate regulation will presumably remain the hot topics of the coming years. Recently, UEFA has announced the reform of the Europa League and the introduction of a third level of club competitions ${ }^{40}$. In the context discussed here, this can be interpreted as a first "corrective move". Given that the "big clubs" already profit from overlapping competitions, the reform creates the chance for more football clubs in Europe to profit from simultaneous participation in domestic and European competitions, thus redirecting some revenues and attention to the lower levels of the pyramid.

Funding: This research received no external funding.

Acknowledgments: The paper is based on a keynote lecture delivered at the II. International Conference on Economics of Football in Moscow, Russia, 9-11 July 2018. We thank the participants of the II. International Conference on Economics of Football in Moscow. Thanks go to Paolo Bizzozero, Philippe Meier, and Martje Timmermann for excellent research assistance.

Conflicts of Interest: Egon Franck is Professor of Strategic Management and Business Policy at the University of Zurich. He has served as a member of UEFA's Club Financial Control Body (CFCB) since its creation in 2012.

40 https://www.theguardian.com/football/2018/dec/02/uefa-new-european-club-competition-2021. 
He also acted as a member of the predecessor of the CFCB, the Club Financial Control Panel, established in 2009, and as a member of The Independent European Sports Review Committee in 2006. The views, thoughts, and opinions expressed in the text belong solely to the author, and not necessarily to the author's employer or to UEFA.

\section{References}

Adler, Moshe. 1985. Stardom and talent. American Economic Review 75: 208-212.

Akerlof, George. 1976. The Economics of Caste and of the Rat Race and other Woeful Tales. Quarterly Journal of Economics 90: 599-617. [CrossRef]

Andreff, Wladimir. 2007. French football: A financial crisis rooted in weak governance. Journal of Sports Economics 8: 652-61. [CrossRef]

Andreff, Wladimir. 2011. Some comparative economics of the organisation of sports: Competition and regulation in North American vs. European professional team sports leagues. European Journal of Comparative Economics 8: 3-27.

Andreff, Wladimir, ed. 2015. Governance of professional team sport clubs: Agency problem and soft budget constraint. In Disequilibrium Sports Economics. London: Edward Elgar, pp. 175-227.

Arnaut, José Luis. 2006. Independent European Sport Review. Technical Report. Brussels: European Commission.

Bizzozero, Paolo, Raphael Flepp, and Egon Franck. 2016. The importance of suspense and surprise in entertainment demand: Evidence from Wimbledon. Journal of Economic Behavior \& Organization 130: 47-63.

Carreras, Miquel, and Jaume Garcia. 2018. TV rights, financial inequality and competitive balance in European Football: Evidence from the English Premier League and the Spanish LaLiga. International Journal of Sport Finance 13: 201-24.

Deloitte Football Money League. 2007. The Reign in Spain. Available online: https://www2.deloitte.com/ content/dam/Deloitte/uk/Documents/sports-business-group/deloitte-uk-deloitte-football-moneyleague-2007.pdf (accessed on 15 June 2018).

Deloitte Football Money League. 2012. Fan Power. Available online: https://www2.deloitte.com/content/dam/ Deloitte/uk/Documents/sports-business-group/deloitte-uk-deloitte-football-money-league-2012.pdf (accessed on 15 June 2018).

Deloitte Football Money League. 2018. Rising Stars. Available online: https:/ /www2.deloitte.com/content/dam/ Deloitte/uk/Documents/sports-business-group/deloitte-uk-sbg-dfml2018.pdf (accessed on 15 June 2018).

Dietl, Helmut M., Egon Franck, and Markus Lang. 2008. Overinvestment in team sports leagues: A contest theory model. Scottish Journal of Political Economy 55: 353-68. [CrossRef]

Dupont, Jean-Louis. 2013. Football's anticompetitive streak. The Wall Street Journal, March 25. Available online: http: / / online.wsj.com/news/articles/SB10001424127887324077704578357992271428024\#printMode (accessed on 15 June 2018).

Ely, Jeffrey, Alexander Frankel, and Emir Kamenica. 2015. Suspense and Surprise. Journal of Political Economy 123: 215-60. [CrossRef]

Franck, Egon. 2014. Financial Fair Play in European Club Football-What is it all about? International Journal of Sport Finance 9: 193-217. [CrossRef]

Franck, Egon. 2015. Regulation in leagues with clubs' soft budget constraints: The effect of the new UEFA Club Licensing Regulations on managerial incentives and suspense. In Disequilibrium Sports Economics. Edited by Wladimir Andreff. Cheltenham: Edward Elgar, pp. 228-49.

Franck, Egon, and Markus Lang. 2014. Theoretical analysis of the influence of money injections on risk taking in football-clubs. Scottish Journal of Political Economy 61: 430-54. [CrossRef]

Frank, Robert H., and Ben S. Bernanke. 2004. Principles of Microeconomics, 2nd ed. New York: McGraw-Hill/Irwin.

Hoehn, Thomas, and Stefan Szymanski. 1999. The Americanization of European football. Economic Policy 14: 204-40. [CrossRef]

Kesenne, Stefan. 2007. The peculiar international economics of professional football in Europe. Scottish Journal of Political Economy 54: 388-99. [CrossRef]

Kornai, János. 1980. Economics of Shortage. Amsterdam: North-Holland.

Kornai, János. 1986. The Soft Budget Constraint. Kyklos 39: 3-30. [CrossRef]

Kornai, János, Eric Maskin, and Gerard Roland. 2003. Understanding the soft budget constraint. Journal of Economic Literature 41: 1095-136. [CrossRef] 
Kuper, Simon. 2009. Football Abandons the Fantasy that it is a Business. Available online: http://www.ft.com/ $\mathrm{intl} / \mathrm{cms} / \mathrm{s} / 2$ /fd77a01c-aa07-11de-a3ce-00144feabdc0.html\#axzz2GRMmCmGD (accessed on 15 June 2018).

Madden, Paul. 2015. Welfare economics of "Financial Fair Play" in a sports league with benefactor owners. Journal of Sports Economics 16: 159-84. [CrossRef]

Neale, Walter C. 1964. The peculiar economics of professional sports: A contribution to the theory of the firm in sporting competition and in market competition. Quarterly Journal of Economics 78: 1-14. [CrossRef]

Rosen, Sherwin. 1981. The economics of superstars. American Economic Review 71: 845-58.

Sass, Markus. 2016. Glory hunters, sugar daddies, and long-term competitive balance under UEFA Financial Fair Play. Journal of Sports Economics 17: 148-58. [CrossRef]

Stern, Gary H., and Ron J. Feldman. 2004. Too Big to Fail: The Hazards of Bank Bailouts. Washington: Brookings Institution Press.

Storm, Rasmus K. 2012. The need for regulating professional soccer in Europe: A soft budget constraint argument. Sport, Business and Management: An International Journal 2: 21-38. [CrossRef]

Storm, Rasmus K., and Klaus Nielsen. 2012. Soft budget constraints in professional football. European Sport Management Quarterly 12: 183-201. [CrossRef]

UEFA. 2013. The European Club Licensing Benchmarking Report Financial Year 2011. Available online: http:/ / www.uefa.com/MultimediaFiles/Download/Tech/uefaorg/General/01/91/61/84/1916184_ DOWNLOAD.pdf (accessed on 15 June 2018).

UEFA. 2015a. Procedural Rules Governing the UEFA Club Financial Control Body, Edition 2015. Available online: http:/ / www.uefa.org/MultimediaFiles/Download/Tech/uefaorg/General/02/28/72/ 46/2287246_DOWNLOAD.pdf (accessed on 15 June 2018).

UEFA. 2015b. UEFA Club Licensing and Financial Fair Play Regulations, Edition 2015. Available online: https://www.uefa.org/MultimediaFiles/Download/Tech/uefaorg/General/02/26/77/91/2267791_ DOWNLOAD.pdf (accessed on 15 June 2018).

UEFA. 2017. The European Club Footballing Landscape. Club Licensing Benchmarking Report Financial Year 2016. Available online: https://es.uefa.com/MultimediaFiles/Download/OfficialDocument/uefaorg/ Clublicensing/02/53/00/22/2530022_DOWNLOAD.pdf (accessed on 15 June 2018).

(c) 2018 by the author. Licensee MDPI, Basel, Switzerland. This article is an open access article distributed under the terms and conditions of the Creative Commons Attribution (CC BY) license (http:/ / creativecommons.org/licenses/by/4.0/). 


\title{
The Impact of Union of European Football Associations (UEFA) Financial Fair Play Regulation on Audit Fees: Evidence from Spanish Football
}

\author{
Mercedes Mareque ${ }^{1}$, Angel Barajas ${ }^{2, *}$ and Francisco Lopez-Corrales ${ }^{3}$ \\ 1 Department of Financial Economics and Accounting, Faculty of Business and Tourism, University of Vigo, \\ Campus Universitario, s/n, 32004 Ourense, Spain; chedesmareque@uvigo.es \\ 2 Department of Finance, School of Economics and Management, \\ National Research University Higher School of Economics, 194100 St. Petersburg, Russia \\ 3 Department of Financial Economics and Accounting, Faculty of Social Sciences and Communication, \\ University of Vigo, Campus A Xunqueira, s/n, 36005 Pontevedra, Spain; corrales@uvigo.es \\ * Correspondence: balonso@hse.ru; Tel.: +7-999-115-65-98
}

Received: 19 September 2018; Accepted: 7 November 2018; Published: 13 November 2018

\begin{abstract}
This paper analyzes whether the Financial Fair Play (FFP) regulations set by Union of European Football Associations (UEFA) have influenced the auditing fees charged to football clubs. In addition, it explores the determinants of audit fees. We used a two-sample t-test with equal variances to determine whether differences are present. After this, we carried out a panel data regression with the clubs fix effect to estimate the determinants of audit fees in football clubs. Our findings revealed an increase of audit fees after the implementation of FFP regulations. On top of that, audit fees were explained by the presence of foreign investors if the audit firm was one of the Big 4 and if the auditor was a woman. The regulation change has had an impact on the audit fees charged by auditors for their services. However, this increase may be compensated over future years given the improving financial situation of clubs; therefore, the auditors' risk diminishes and subsequent audit fees may be reduced. UEFA should monitor audit fees as well as the quality of the audit reports, which have become crucial to obtaining the license to participate in UEFA competitions.
\end{abstract}

Keywords: football; audit fees; audit shopping; Financial Fair Play; UEFA; Z2; M41; M42

\section{Introduction}

Increasing debts and persistent deficits have characterized the financial situation of most of the European football clubs (Ascari and Gagnepain 2006; Barajas 2004; Barajas and Rodríguez 2010; Boscá et al. 2008; Deloitte 2014; Gammelsæter 2010; García and Rodríguez 2003; Gay 2009a, 2009b; Robinson and Simmons 2014; Storm and Nielsen 2012). Serious financial problems due to the imbalance between revenues and expenses and the subsequent increase in debt have affected European football; for this reason, some clubs are or have been on the edge of bankruptcy. Numerous clubs have been under administration. Kuper and Szymanski (2009) pointed out that 40 professional English football clubs were involved in processes of insolvency between 1992 and 2008. Beech et al. (2010) indicated that over half of the clubs in the Premier League and the English Football League Championship in season 2008-2009 had been insolvent over the last years. In Spain, at the end of 2011, 22 clubs were or had been under administration (Barajas and Rodríguez 2014).

Concerned with the financial health of the clubs, the Union of European Football Associations (UEFA) approved the Financial Fair Play (FFP) Regulations in 2010, subsequently updated in 2012 and 2015. Since 2011, all clubs taking part in competitions organized by UEFA have had to fulfill the requirements of the FFP. These regulations aim to ensure the long-term financial viability and 
the sustainability of the clubs. They should be managed in break even, avoid reporting negative equity changes, set overdue payables, and finally prove their going concern ability (Morrow 2014; UEFA 2010).

The FFP Regulation stipulates that an independent external auditor must audit clubs' financial statements. UEFA assesses the content of the auditing report and can deny the license if (i) the report has a disclaimer of opinion or an adverse opinion, (ii) the auditor's report either has an emphasis of matter or a qualified 'except for' opinion in respect of going concern, and (iii) the auditor's report has, concerning a matter other than going concern, either an emphasis of matter or a qualified 'except for' opinion, but they are significant in expressing the true and fair image of the equity and financial results of the club.

Failure of the clubs to meet the criteria established by the FFP Regulation may lead to sanctions and the denial of the license for participation in UEFA competitions. This could lead to serious losses for the sanctioned club, since competitions, such as the Champions League or the Europa League, provide clubs with significant revenues, thus potentially jeopardizing their financial viability (Dimitropoulos 2016).

Therefore, the role of auditors will become even more relevant. In many countries, when the football clubs presented their audited accounts, the opinion of the auditors had no repercussions on sporting. However, as previously explained, the implementation of the FFP has converted the opinion of the auditor into a crucial factor. In this way, auditors will increasingly become responsible for expressing their opinion. Along with this, audit efforts will have to be greater given the current financial problems of the clubs. The relevance of having an unqualified opinion can exert pressure on the auditor. Ruiz-Barbadillo (2016) asserts that an unqualified opinion for the users may generate an extra cost for the company and its managers. This fact implies pressure on the auditor to provide a positive opinion, which is a threat to the independence of the auditor. This possible attitude, on top of being fraud, could actually damage the interest of the shareholder and affect stakeholders using the financial information (De Angelo 1981; Archambeault and DeZoort 2001; Ruíz-Barbadillo and Gómez-Aguilar 2007).

On the other hand, the weak financial position of numerous football clubs-some of which have serious on-going problems-will increase the risk of the auditors and affect their work. The studies of Simunic (1980), Simunic and Stein (1996), Seetharaman et al. (2002), Choi et al. (2008), and Francis and Wang (2008) support the theory that auditors increase their effort in high risk environments. If the perception of business risk is higher, the auditors increase the audit procedures. This implies more evidence to be gathered, more time, more personnel, and consequently, higher fees (Mautz and Sharaf 1961; Davis et al. 1993; Bell et al. 2001; Bell et al. 2008; Bedard et al. 2008; Asthana et al. 2009; Redmayne et al. 2010).

Previous studies show that audit risk will be determined for the client business risk as well as for the financial reporting risk. In this regard, football clubs operate in a very competitive context. Part of their business is the transfer of players for huge amounts of money in comparison with their revenues. Moreover, those players receive extremely high salaries in order to maintain them. This leads to the fact, that, in many cases, club finances are affected by increasing debts and persistent deficits, leading to some clubs having real continuity problems (going concern problems), some of them operating on the verge of bankruptcy (Barajas and Rodríguez 2010; Dimitropoulos et al. 2016). In this environment, auditors must increase their audit procedures in order to evaluate the club's compliance with the going concern principle. They have to reduce the risk of issuing an inadequate opinion (for example, issuing a more favorable opinion than the client deserves and then the company goes bankrupt). Brumfield et al. (1983) assert that when an audit firm accepts a client with high business risk the auditor reacts to that risk increasing the time for audit work. Auditors face higher chances to be sued if their clients go into bankruptcy or if they have extremely high losses (Rittenberg et al. 2012). Bell et al. (2001) also found a positive relationship between business risk and audit fees. They sustain that the increase in the audit 
fees is solely due to the higher number of working hours needed and that the auditor will try to be on the safe side with an additional audit effort when bigger losses are expected.

When auditors carry out their work in entities experiencing financial problems, the audit risk of issuing an inappropriate opinion will increase and subsequently the litigation risk will be higher. The relationship between litigation risk and increment in audit fees has been studied by Badertscher et al. (2014), Choi et al. (2009), Venkataraman et al. (2008). Abbott et al. (Abbott et al. 2017, p. 1104) affirm that these studies obtain evidence that 'as the imposition of expected auditor losses from legal liability increases, ceteris paribus, audit fees will increase because auditors exert more effort to reduce audit firm litigation risk, charge a pure premium for bearing increased exposure to litigation risk, or both'. Seetharaman et al. (2002) and Venkataraman et al. (2008) found evidence on the relation between litigation risk and audit fees as well. In particular, they observed that auditors raise their fees when their exposure to litigation increases. Badertscher et al. (2014, p. 307) assert that auditors respond to the eventuality of litigation by increasing their fees in order to '(i) to cover the cost of increased audit production effort, (ii) to reduce the audit firm's risk of failing to detect material misstatement, or (iii) to add a risk premium for higher expected future litigation costs'.

Aware of the financial reporting risk in football clubs, UEFA has set strict financial rules in the FFP Regulations to ensure clubs' financial sustainability. These regulations affect the audit work because changes or new regulations usually imply a higher auditing effort. This is due to the additional time for learning the rules and the additional time (working hours). Subsequently, the audit fees will be affected. In this sense, previous studies, such as Griffin et al. (2009), Vieru and Shadewitz (2010), Kim et al. (2012), De George et al. (2013), De Fuentes and Sierra-Grau (2015), Higgins et al. (2016), and Lin and Yen (2016), have studied the impact of new rules or changes in regulations on audit fees in several countries from an accounting perspective. Menon and Williams (2001), Oxera Report (2006), Raghunandan and Rama (2006), Griffin and Lont (2007), Ghosh and Pawlewicz (2009), Huang et al. (2009), Salman and Carson (2009), Charles et al. (2010), and De Fuentes and Sierra-Grau (2015) have analyzed the impact of changes in auditing standards on audit fees. However, no paper has analyzed the impact of FFP Regulation implementation on audit fees charged by football club auditors. Dimitropoulos (2016) pointed out the need for future research on audit fees paid by clubs before and after FFP implementation. This paper aims to fill this gap in the literature. To this end, we have used the Spanish clubs in First Division during the period 2007 to 2016 as the sample to be tested. FFP regulation was inexistent from 2007 to 2010, the period from 2010 to 2013 was a transition period, and FFP regulation was totally implemented throughout 2014 to 2016. Additionally, this paper also studies the factors that determine audit fees.

This paper makes two main contributions; firstly, it examines one of the economic consequences of implementing FFP regulations and analyzes its effect on audit fees. Secondly, it analyzes the behavior of audit fees within a particular context, namely the football industry.

The methodology that is employed is in line with previous studies. After a t-test to determine the presence of significant changes in audit fees, we use an OLS to test the hypothesis that the change in regulation and other variables affects the audit fees. The model includes features that are related to both the auditor and the clubs.

As aforementioned, this paper analyzes the clubs in the Spanish First Division. These clubs can qualify for the UEFA competitions (Champions League and Europa League) and they would need the UEFA license to do so. The period under study began in 2007-2008 and spanned until 2015-2016. The study divides this period into three periods: Pre-FFP, the time before the regulations were set (from June 2007 to 2010); trans-FFP, a transitory period (from June 2010 to 2013); and, FFP, when the regulations fully apply (from June 2013 to 2016). Dimitropoulos (2016) and Dimitropoulos et al. (2016) have employed similar divisions. Financial data have been deflated. We have therefore worked with real (not nominal) prices. 
The results show that the new FFP rules have increased audit fees in real terms. Moreover, audit fees are explained by the presence of foreign investors if the audit firm is one of the Big 4 and if the auditor is a woman.

The remainder of this paper is organized, as follows; Section 2 provides an overview of the relevant literature and introduces the hypotheses, while the model and data are described in Section 3 and the results are presented in Section 4 . Section 5 summarizes the main findings and discusses some implications.

\section{Literature Review and Hypotheses Development}

The literature evidences that the implementation and changes in rules of both accountancy and auditing have driven to increased audit fees. Changes in account rules affect the audit fees because auditors will need to invest in acquiring the necessary knowledge on the new rules, which will subsequently increase their cost. Moreover, the inherent risk of the financial statements will increase, and in turn, the audit risk. According to De Fuentes and Sierra-Grau (2015), IFRSs implied a significant change for most European countries. Their results show that, between 2004 and 2006, audit fees increased for the group accounts of Spanish listed companies given the incremental costs that are associated with the mandatory adoption of IFRS. On the other hand, they also reflect an increase for parent audit fees in 2008 with the new domestic accounting rules.

Griffin et al. (2009) found that the audit fees increased significantly in the year prior to IFRS adoption, the year of adoption, and in subsequent years in New Zealand. Higgins et al. (2016) confirm the results of Griffin et al. (2009), indicating higher audit fees post-IFRS, but they extend the prior analysis by considering a longer sample period (2002-2012).

Vieru and Shadewitz (2010) indicate that IFRS adjustments, as a measure of the disparity between Finnish Accounting Standards (FAS) and IFRS, positively and significantly affect total audit fees paid to statutory auditors. Additionally, Kim et al. (2012) conclude that mandatory IFRS adoption leads to an increase in audit fees, which suggests that the increase in audit task complexity is the driving force behind the IFRS-related audit fee increase. In the same line, De De George et al. (2013) provide evidence of a directly observable and significant cost of IFRS adoption. Their results imply an overall increase of approximately 9 percent in the average level of audit fees in the year of IFRS adoption.

For a sample of the Shanghai and Shenzhen stock exchanges, Lin and Yen (2016) found that auditors with IFRS experience charged significantly higher audit premiums in the initial years of IFRS adoption. They also found that audit clients with IFRS experience paid significantly lower incremental fees. In the UK, the Oxera Report (2006) identified high audit fees between 2002 and 2004 due to changes in regulation and accounting rules.

Regarding auditing rules, Menon and Williams (2001) observed increased audit fees between 1980 and 1997. In particular, they noted a significant increase in 1988, when the Auditing Standards Board issued the "expectation gap" standards. Most of the research focuses on the implementation of the Sarbanes Oxley Act (Sarbanes Oxley-SOX 2002), which revealed high audit fees that were charged to customers during the post-SOX period in relation to the pre-SOX period as consequence of the increased auditing procedures, increased liability litigation, and a more highly regulated audit environment.

Thus, for the United States, Raghunandan and Rama (2006) examine the association between audit fees and internal control disclosures pursuant to section 404 of the SOX Act, which requires management and the auditor to report on internal controls over financial reporting. They found that audit fees for the firms were on average 86 percent higher for fiscal 2004 than the corresponding fees for 2003.

Huang et al. (2009) hypothesized that initial-year audit fee discounts would be less likely in the post-SOX period than in the pre-SOX period. They examined the audit fees for clients changing auditors in 2001 and 2006 and found that there was a significant initial-year audit fee discount in 2001 for clients of the Big 4 audit firms. The new clients paid, on average, about 24 percent less 
than continuing clients. In contrast, a significant premium for new Big 4 clients was present in 2006. Initial-year client premiums were, on average, 16 percent higher than those of continuing clients.

Charles et al. (2010) found a positive statistically and economically significant relationship between financial reporting risk and audit fees that were paid to Big 4 auditors. The relation between financial reporting risk and audit fees strengthened significantly in 2002 and 2003 . This is consistent with a shift in the way auditors priced risk in likely response to the events surrounding the Sarbanes-Oxley Act of 2002.

Regarding football, as mentioned in the introduction, the FFP regulations implemented by UEFA will imply a more influential role on the part of the auditors in this process. One way to see this is to consider audit fee changes. Silva et al. (2016) highlight the relevant role of independent audits in the reduction of informational asymmetry in the football industry. The perception is that a special role can bring about changes in auditor service charges. Moreover, Dimitropoulos et al. (2016) evidenced that club managers became more inclined towards aggressive Earning Management after the FFP regulation was established. They additionally found that club managers tended to move from big-4 company auditors to local auditors. Moreover, these authors consider that regulatory monitoring that is related to accounting data will inevitably lead to a deterioration in accounting quality. Nevertheless, financial statements must be audited by independent auditors and the reports must be 'clean'; new tensions are thus likely to appear and may be reflected in the audit fees. For this reason, studying audit fees sheds light on a wider debate than just auditor earnings; audit fees point to a deeper effect in the changes brought about by FFP regulation.

Therefore, according to the previous evidence, audit fees are expected to increase with the establishment of the FFP regulation given the greater auditing effort and risk with higher exposure of their responsibility when the auditors send opinion. The weak financial situation of many football clubs implies a greater audit effort due to the higher perception of auditor risk. This perception of risk usually represents more working hours and therefore higher fees. The FFP regulation emphasizes the going concern. If auditors perceive symptoms of going concern, they will modify the audit processes to investigate the impact of risk factors in depth. Consequently, we propose the following hypothesis:

Hypothesis 1 (H1). Auditors increase their audit fees after implementing Fair Play regulation.

\section{Methodology}

\subsection{Data}

The study conducts the empirical analysis for the football teams of the Spanish First Division. It uses the information included in the individual annual accounts and their corresponding audit reports. Financial Statement are reported according to Spanish GAAP, rather than using the IFRS. We have gathered this information from several sources: websites of football teams, Spanish Professional Football League (La Liga), House of Companies, and the Amadeus database. Therefore, the initial sample consists of data from 20 football teams with a nine-year follow-up for each of the seasons between $2007 / 08$ and 2015/16, that is, 180 records. We have only analyzed the first division teams as they are the ones that have the chance to qualify for UEFA competitions (Champions League and Europa League). Finally, the data for Osasuna (from 2009/10 to 2012/13), Xerez (2009/10) and Levante $(2007 / 08)$ are missing. Therefore, the database contains 174 records. None of the Spanish football clubs were listed on the stock exchange. As there is promotion and relegation, we have an unbalanced panel.

As shown in Table 1 and Figure 1, the audit fees paid by Real Madrid and Barcelona (group 1 in the graph) are much higher on average than those that are paid by the rest of the clubs (group 0 in the Figure 1). This is why Real Madrid and Barcelona have been excluded from the sample. 
Table 1. Descriptive statistics for Real Madrid (RM) and Barcelona audit fees and those of the rest of the clubs. (Data in Euros corrected for inflation).

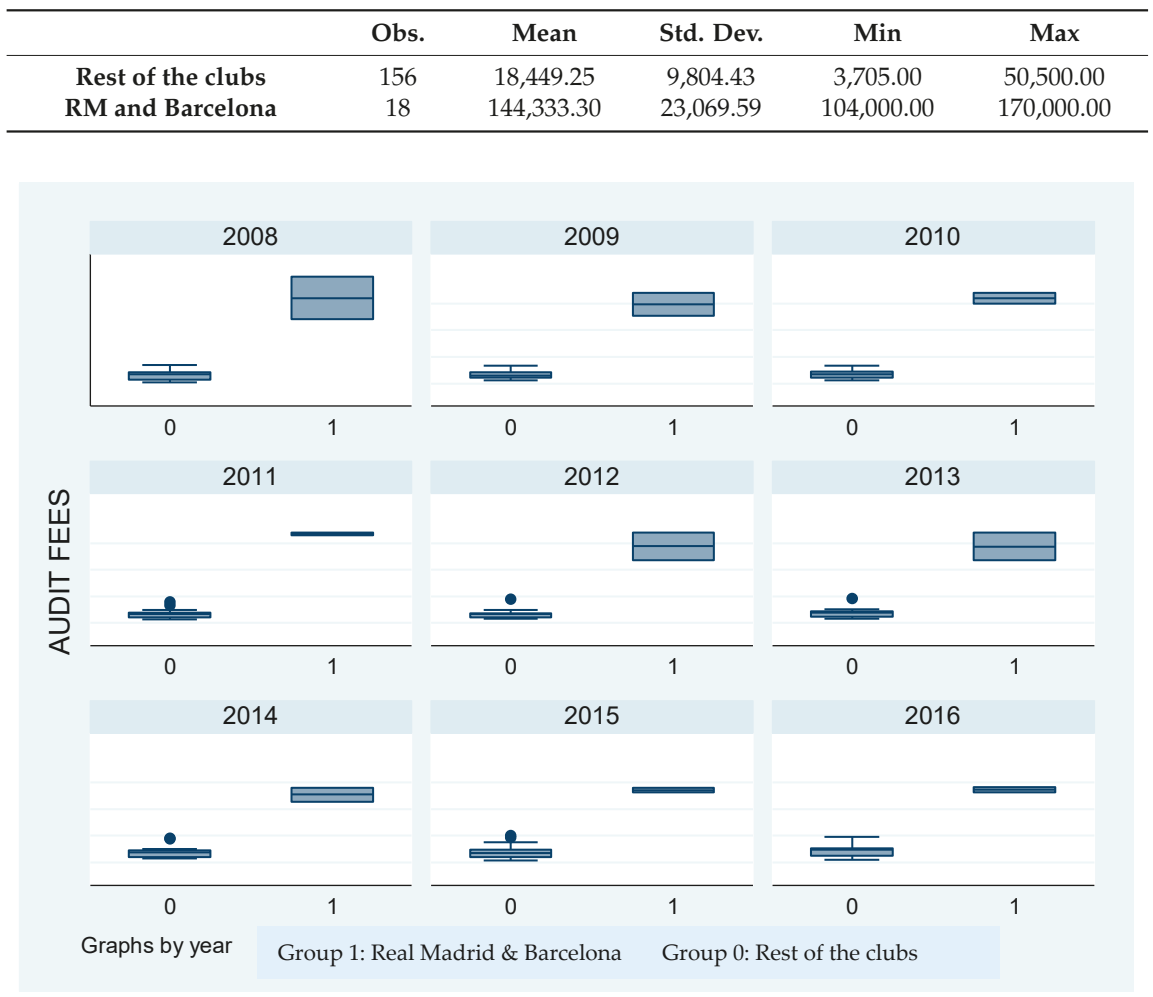

Figure 1. Differences, on average, between the Real Madrid and Barcelona audit fees and those of the rest of the clubs.

Before analyzing the factors that explain the audit fees, we conducted different $t$-tests for the two samples to detect significant differences among the three periods. First, the comparison is between each of the periods and the rest (Tables 2 and 3). We do this on the sample without Real Madrid and Barcelona and when comparing real values to avoid problems with inflation.

Table 2. Two-sample t-test with equal variances (pre-FFP).

\begin{tabular}{|c|c|c|c|c|c|c|}
\hline Group & Obs. & Mean & Std. Err. & Std. Dev. & \multicolumn{2}{|c|}{ [95\% Conf. Interval] } \\
\hline Trans-FFP + FFP & 105 & $17,499.07$ & 931.671 & 9546.787 & $15,651.54$ & $19,346.61$ \\
\hline Pre FFP & 51 & $15,329.05$ & 1016.084 & 7256.292 & $13,288.18$ & $17,369.91$ \\
\hline combined & 156 & $16,789.64$ & 712.4386 & 8898.355 & $15,382.3$ & $18,196.98$ \\
\hline diff & & 2170.025 & 1513.627 & & -820.1261 & 5160.177 \\
\hline & \multicolumn{4}{|c|}{$\mathrm{t}=1.4337$} \\
\hline & & Ho: diff $=0$ & \multicolumn{4}{|c|}{ degrees of freedom $=154$} \\
\hline \multirow{2}{*}{\multicolumn{2}{|c|}{$\begin{array}{c}\text { Ha: diff }<0 \\
\operatorname{Pr}(T<t)=0.9232\end{array}$}} & \multirow{2}{*}{\multicolumn{3}{|c|}{$\begin{aligned} \text { Ha: diff } ! & =0 \\
\operatorname{Pr}(|\mathrm{T}|>|\mathrm{t}|) & =0.1537\end{aligned}$}} & \multicolumn{2}{|c|}{ Ha: diff $>0$} \\
\hline & & & & & \multicolumn{2}{|c|}{$\operatorname{Pr}(T>t)=0.0768$} \\
\hline
\end{tabular}

The audit fees in the period before the FFP are slightly lower than the two other periods. However, the transition period showed no significant difference in audit fees. Secondly, the audit fees in the 
period of full FFP implementation are significantly higher than those of the two previous periods (Table 3).

Table 3. Two-sample t-test with equal variances (Financial Fair Play (FFP)).

\begin{tabular}{|c|c|c|c|c|c|c|}
\hline Group & Obs & Mean & Std. Err. & Std. Dev. & \multicolumn{2}{|c|}{ [95\% Conf. Interval] } \\
\hline Pre-FFP + Trans FFP & 102 & $15,673.23$ & 746.4224 & 7538.497 & $14,192.53$ & $17,153.93$ \\
\hline FFP & 54 & $18,898.43$ & 1467.803 & $10,786.1$ & $15,954.39$ & $21,842.47$ \\
\hline combined & 156 & $16,789.64$ & 712.4386 & \multirow[t]{2}{*}{8898.355} & $15,382.3$ & $18,196.98$ \\
\hline Diff & & -3225.198 & 1479.733 & & -6148.392 & -302.0034 \\
\hline \multirow{2}{*}{\multicolumn{3}{|c|}{$\begin{array}{c}\operatorname{diff}=\operatorname{mean}(0)-\text { mean }(1) \\
\text { Ho: diff }=0\end{array}$}} & \multicolumn{4}{|c|}{$\mathrm{t}=-2.1796$} \\
\hline & & & \multicolumn{4}{|c|}{ degrees of freedom $=154$} \\
\hline \multicolumn{3}{|c|}{ Ha: diff $<0$} & \multicolumn{2}{|c|}{ Ha: diff $!=0$} & \multicolumn{2}{|c|}{ Ha: diff $>0$} \\
\hline \multicolumn{2}{|c|}{$\operatorname{Pr}(\mathrm{T}<\mathrm{t})=0.0154$} & \multicolumn{3}{|c|}{$\operatorname{Pr}(|\mathrm{T}|>|\mathrm{t}|)=0.0308$} & \multicolumn{2}{|c|}{$\operatorname{Pr}(\mathrm{T}>\mathrm{t})=0.9846$} \\
\hline
\end{tabular}

As it has been said, there is no statistically significant difference between the audit fees in the transition period regarding the fees before the implementation of FFP and the fees when the FFP was fully implemented. As it could be expected that rational clubs and auditors could have used the transition period to adapt the fees, we have also compared the fees before FFP and when the regulations are fully implemented. Table 4 presents the results. The difference is significant, and clubs with the FFP Regulation implemented pay that is, on average, $€ 3569$ more in audit fees. This amount is presented in real terms.

Table 4. Two-sample t-test with equal variances (pre-FFP vs. FFP).

\begin{tabular}{|c|c|c|c|c|c|c|}
\hline Group & Obs & Mean & Std. Err. & Std. Dev. & \multicolumn{2}{|c|}{ [95\% Conf. Interval] } \\
\hline Pre-FFP & 51 & $15,329.05$ & 1016.084 & 7256.292 & $13,288.18$ & $17,369.91$ \\
\hline FFP & 54 & $18,898.43$ & 1467.803 & $10,786.1$ & $15,954.39$ & $21,842.47$ \\
\hline combined & 105 & $17,164.73$ & 914.5184 & 9371.025 & $15,351.2$ & $18,978.25$ \\
\hline Diff & & -3569.38 & 1804.694 & & -7148.562 & 9.808026 \\
\hline \multicolumn{4}{|c|}{$\operatorname{diff}=\operatorname{mean}(0)-\operatorname{mean}(1)$} & \multicolumn{3}{|c|}{$\mathrm{t}=-1.9778$} \\
\hline \multicolumn{4}{|c|}{ Ho: diff $=0$} & \multicolumn{3}{|c|}{ degrees of freedom $=103$} \\
\hline \multirow{2}{*}{\multicolumn{2}{|c|}{$\begin{array}{c}\text { Ha: diff }<0 \\
\operatorname{Pr}(\mathrm{T}<\mathrm{t})=0.0253\end{array}$}} & \multirow{2}{*}{\multicolumn{3}{|c|}{$\begin{aligned} \text { Ha: diff } ! & =0 \\
\operatorname{Pr}(|\mathrm{T}|>|\mathrm{t}|) & =0.0506\end{aligned}$}} & \multicolumn{2}{|c|}{ Ha: $\operatorname{diff}>0$} \\
\hline & & & & & \multicolumn{2}{|c|}{$\operatorname{Pr}(\mathrm{T}>\mathrm{t})=0.9747$} \\
\hline
\end{tabular}

\subsection{Regression Model and Variable Definitions}

The model proposed by Simunic (1980) is the starting point for literature on the study of fees. In this seminal work, audit fees are considered to be a cost in the client's accounting system, which clients attempt to minimize.

The research conducted so far in different countries signals a set of independent variables that are linked to the determination of audit fees for both the audited company and the auditor. The variables related to the audited company are fundamentally size, complexity and risk.

Following Simunic (1980), the model used to explain audit fees and test the stated hypothesis presents the following expression:

$$
\begin{aligned}
\text { AUDITFEES }_{i t}= & \beta_{0}+\beta_{1} \text { TRAN }_{\text {FFP }}+\beta_{2} \text { FFP }+\beta_{3} \text { NON }_{\text {AUDITFES }_{i t}}+\beta_{4} \text { TA }_{i t-1} \\
& +\beta_{5} \text { FOWND }_{i t}+\beta_{6} \text { REPORTLAG }_{i t}+\beta_{7} \text { ROA }_{i t-1} \\
& +\beta_{8} \text { LEV V }_{i t-1}+\beta_{9} L I Q_{i t-1}+\beta_{10} \text { LOSS }_{i t-1}+\beta_{11} \text { GCO }_{i t-1} \\
& +\beta_{12} \text { BIG }_{i t}+\beta_{13} \text { AUDITCHANG } \\
& +\beta_{15} \text { POINTS }_{i t-1}+\beta_{16} \text { ATTENDER DIt }_{i t}
\end{aligned}
$$

Table 5 presents the variables included in the model. The dependent variable is the amount of money paid for audit services. As well as the other financial variables, this variable has been taken in 
real terms adjusted for inflation. In the model, three dummy variables reflect the different periods that are under scrutiny in this paper. They are related directly to FFP. The seasons before the FFP (PRE_FFP) are considered as a basis. The total assets variable has been included to control for size. We have considered whether the owner of the club is a foreigner as a factor that may increase the audit fees. We have also included other variables to analyze the impact of risk, these being ROA, leverage, liquidity, whether the club had losses in the previous season, and whether the auditing report presented going concern opinion. The features of the auditor are included to analyze the effect of the auditor being one of the Big 4 and whether choosing to change the auditor and selecting an auditor of another gender affects the fees and the perception of non-audit fees by the auditor. Our work includes the report lag in the audit report to capture the potential existence of more complex audit work. Finally, we introduce the possible effect of sporting factors in the model through the points that were obtained in the previous season, the average attendance to the stadium and whether the club participated in the previous season UEFA competitions. The following subsections explain all of these variables.

Table 5. Description of the variables included in the model and expected sign (financial variables in real terms).

\begin{tabular}{|c|c|c|}
\hline Variables & Definition & Sign \\
\hline \multicolumn{3}{|c|}{ Dependent variable } \\
\hline AUDITFEES & Amount paid for auditing fees (in Euros) & \\
\hline \multicolumn{3}{|c|}{ Independent variables } \\
\hline PRE_FFP & $\begin{array}{l}1 \text { seasons when FFP regulations were not applied (2007/08, } \\
2008 / 09 \text { y 2009/10); } 0 \text { otherwise. }\end{array}$ & (base) \\
\hline TRAN_FFP & $\begin{array}{l}1 \text { seasons of transition to the full implementation of the } \\
\text { FFP }(2010 / 11,2011 / 12 \text { y 2012/13; } 0 \text { otherwise. }\end{array}$ & + \\
\hline FFP & $\begin{array}{l}1 \text { seasons when FFP regulations are fully implemented } \\
(2013 / 14,2014 / 15 \text { y 2015/16); } 0 \text { otherwise. }\end{array}$ & + \\
\hline NON_AUDITFEES & Expenses on non-audit services (in Euros) & $+/-$ \\
\hline L.TA & Total Assets in the previous fiscal year & + \\
\hline FOWND & 1 if the main owner is foreign; 0 otherwise & + \\
\hline REPORTLAG & $\begin{array}{l}\text { Days between the close of the accounts and the } \\
\text { auditing report. }\end{array}$ & + \\
\hline L.ROA & Return on Assets in previous fiscal year & - \\
\hline L.LEV & Leverage in previous fiscal year & + \\
\hline L.LIQ & $\begin{array}{l}\text { Current Assets divided by Current Liabilities in } \\
\text { previous year }\end{array}$ & - \\
\hline L.LOSS & 1 if the club had losses in previous season; 0 otherwise. & + \\
\hline L.GCO & $\begin{array}{l}1 \text { if the report in the previous year included going concern } \\
\text { opinion; } 0 \text { otherwise. }\end{array}$ & + \\
\hline BIG 4 & $\begin{array}{l}1 \text { if auditor is one of the big } 4 \text { auditing companies; } \\
0 \text { otherwise. }\end{array}$ & + \\
\hline AUDITCHANG & 1 if the auditor has changed; 0 otherwise. & - \\
\hline GENDER & $\begin{array}{l}1 \text { if the auditor who signs the report is a woman; } \\
0 \text { otherwise. }\end{array}$ & + \\
\hline L.POINTS & Points obtained by the club in the previous season & $-/+$ \\
\hline L.ATTENDANCE & Average attendance to the stadium in the previous season & - \\
\hline L.UCL_EL & $\begin{array}{l}1 \text { if the club participated in the previous season UEFA } \\
\text { competitions; } 0 \text { otherwise. }\end{array}$ & - \\
\hline
\end{tabular}


Table 6 presents the values of the sample variables. The first thing to remark is that upon using lagged variables to avoid problems of lag causality, the number of observations drops considerably. However, when using the variables of the same year, the results of the regression are similar. In that sense, we consider that it is better to maintain the lag variables. Audit fees in real terms vary notably from the fees that are paid by SD Eibar in 2015 - a promoted team with healthy ratios of liquidity (1.73), leverage (0.47), ROA (0.31) — and the fees paid by Valencia CF in 2015, a club struggling with huge financial problems (losses over 1.7 million Euros, low liquidity and high leverage). Many clubs (42.95\%) do not contract non audit services. RCD Espanyol and Valencia CF spent $€ 45,320.98$ and $€ 55,362.68$, respectably in 2016. The amount paid that year by Valencia CF was higher than the maximum amount paid for audit fees in the whole period. Two clubs-CD Osasuna and Hercules CF-had a delay of more than two years in presenting the audit report for season 2011. Some figures on financial ratios may sound odd. However, studies on the finances of Spanish football show that these values have not been very uncommon (see for example Ascari and Gagnepain 2006; Barajas and Rodríguez 2010; 2014). ROA is negative in $37.74 \%$ of the observations. In the case of Hercules CF, in 2011 its operating losses were higher than its total assets. That season, the club had returned to First Division after more 14 years and made a big effort to be competitive by hiring well-known players. However, at the end of the season the team ended second to last and was relegated. This fact meant huge losses, further relegation to Second B Division, and it is on the brink of disappearing. On the other hand, there are also cases with high ROA. Having entered under administration in 2011 and attaining its best league position in 2013 while simultaneously qualifying for the UEL (the club did not receive the UEFA license due to its financial situation), Rayo Vallecano SAD made a remarkable profit in 2014. Clubs with high values in Leverage ratio usually benefit from having been under administration. That is the case of RC Deportivo de La Coruña in 2015 and 2016 (4.5 and 3.6, respectively). It is also worth noting that the audit reports of the clubs presented ongoing concerns in $53 \%$ of the cases. Almost $40 \%$ presented losses in the previous year. This situation is improving in the period of fully implementation of FFP regulations (29.6\%). In only $9 \%$ of the cases is there a foreign owner, and the auditor is one of the Big 4 in only $3 \%$.

Table 6. Descriptive statistics (financial variables in real terms).

\begin{tabular}{cccccc}
\hline Variable & Obs. & Mean & Std. Dev. & Min & Max \\
\hline Real Audit Fees & 156 & $16,789.64$ & 8898.36 & 3362.60 & $45,833.04$ \\
Real non Audit Fees & 156 & 6397.88 & 9519.58 & 0.00 & $55,362.68$ \\
Lag. Real TA (thousands $€$ ) & 119 & $134,000.00$ & $146,000.00$ & 8532.59 & $546,000.00$ \\
Reportlag (days) & 159 & 124.01 & 79.00 & 26.00 & 758.00 \\
Lag. ROA & 119 & 0.01 & 0.23 & -1.05 & 1.16 \\
Lag. Leverage & 119 & 1.08 & 0.60 & 0.25 & 4.50 \\
Lag. Liquidity & 119 & 0.67 & 0.40 & 0.08 & 2.49 \\
Lag. Points & 120 & 51.33 & 10.66 & 35.00 & 90.00 \\
Lag. Average Attendance & 120 & $23,796.19$ & $10,724.38$ & 4727.00 & $46,532.00$ \\
UCL + EL & 161 & 0.28 & 0.45 & 0.00 & 1.00 \\
Foreign owner & 161 & 0.09 & 0.29 & 0.00 & 1.00 \\
Lag. Losses & 119 & 0.39 & 0.49 & 0.00 & 1.00 \\
Lag. GCO & 120 & 0.53 & 0.50 & 0.00 & 1.00 \\
Big 4 & 160 & 0.03 & 0.17 & 0.00 & 1.00 \\
Audit change & 159 & 0.10 & 0.30 & 0.00 & 1.00 \\
Gender & 160 & 0.11 & 0.31 & 0.00 & 1.00 \\
\hline
\end{tabular}

\subsubsection{Regulation}

As stated, Griffin et al. (2009), Vieru and Shadewitz (2010), De George et al. (2013), De Fuentes and Sierra-Grau (2015), Higgins et al. (2016), and Lin and Yen (2016) have analyzed the impact of changes in accountancy rules, or the impact of new ones on audit fees. Menon and Williams (2001), Ghosh and Lustgarten (2006), Raghunandan and Rama (2006), Griffin and Lont (2007), Ghosh and 
Pawlewicz (2009), Huang et al. (2009), Salman and Salman and Carson (2009), Charles et al. (2010), and De Fuentes and Sierra-Grau (2015) have studied the impact of changes in auditing rules. Most of these studies distinguish between two or three periods: before the application of the regulation, during the first years of implementation, and after the implementation. This paper analyzes the time before the FFP (seasons 2007-2008, 2008-2009, and 2009-2010), a transitory period (2010-2011, 2011-2012, and 2012-2013), and the period when the FFP was fully implemented (2013-2014, 2014-2015, and 2015-2016). The first period is the basis. Audit fees are expected to be higher after the transitory or full implementation periods than they were before the new rules. The complexity of the audit work will increase with a subsequent increase in auditing effort. Moreover, the responsibility of auditors will be more highly exposed when they report their opinion.

\subsubsection{Non Audit Fees}

Studies trying to conjunctly determine the fees for audit and non-audit services have observed interdependency between both fees and they have identified the presence of efficiencies deriving from the exchange of knowledge between both activities (Monterrey and Sánchez 2007). Simunic (1984) discovered a positive association between both fees. He concluded that firms hiring non-audit services from the same auditor assume cost in the audit fees that are higher than those assumed by firms that do not do so. Palmrose (1986) and Bell et al. (2001) point out that the positive coefficients that are associated among audit and non-audit fees originate in scale economies that reduce the number of required auditing hours. Nevertheless, other authors, like Stein et al. (1994) and Whisenant et al. (2003), did not find a direct relationship between both variables.

\subsubsection{Size of the Firm (the Club)}

The size of the club is a widely tested explanatory variable and, according to Hay et al. (2006) it typically explains more than $70 \%$ of the variation in audit fees. This paper uses the lagged total assets in real terms of the company to avoid endogeneity. Casterella et al. (2004), and Basioudis et al. (2008) also use total assets to control for size. We expect a positive association with audit fees.

\subsubsection{Foreign Ownership}

Wilson et al. (2013) assert that foreign ownership may help clubs to improve their accounts, make them sustainable and improve their finances. At the same time, foreign investors have more difficulties in getting information than the local ones (Beneish and Yohn 2008; He et al. 2014). To compensate for this, foreign investors will look for more qualified auditors (Dimitropoulos 2016). We therefore expect a positive relationship regarding audit fees.

\subsubsection{Delay in the Report}

The existence of problems can imply longer periods of time to finish audit reports (Knechel and Payne 2001). Stanley (2011) found a positive relationship between audit fees and the time spent until the final audit report. More complex audit work may take longer to perform and it may imply a subsequent delay in the signing of the audit report. In such case, higher fees are expected. This is why the model includes the variable REPORTLAG.

\subsubsection{Risk}

Extensive literature reveals that the audit fees are positively related to risk, as evinced in the papers by Xu et al. (2013), Zhang and Huang (2013), Alexeyeva and Tobias (2015), and Groff et al. (2017). That is, higher client risk may expose the auditor. The auditor will then apply more tests and thereby increase the time employed. Thus, fees would be higher. Several variables measure risk direct or indirectly. ROA is included because a low return on assets may be symptomatic of mismanagement. We would therefore expect a negative relationship. 
Leverage (LEV) and liquidity (LIQ) ratios, two of the proxies that are most commonly used to measure indebtedness (Hay et al. 2006; Hay 2013), reflect whether the club could have financial problems. A positive relationship between leverage and audit fees is expected (Callaghan et al. 2009; Casterella et al. 2004). On the contrary, a negative relationship is expected with the liquidity (Craswell et al. 1995; Simunic 1980).

Moreover, Casterella et al. (2004), Callaghan et al. (2009) find that firms with losses (LOSS) represent higher risk. This would imply higher audit fees as well.

\subsubsection{Additional Risk}

Football clubs have real financial difficulties in their operations (Ascari and Gagnepain 2006; Barajas and Rodríguez 2010; Beech et al. 2010; Boscá et al. 2008; Kuper and Szymanski 2009), which in some cases have led to bankruptcy. This creates an additional risk for the auditor. The auditor will have to pay special attention to these events, which can imply going concern. Audit fees are expected to be higher in the presence of a going concern opinion (Krishnan and Wang 2015; Stanley 2011; Wang and Chui 2015).

\subsubsection{BIG 4}

Previous studies indicate that the big international audit firms have a differential reputation that is derived from having a recognized brand name, and deliver audits of a higher quality than small and medium-sized audit firms (De Angelo 1981; DeFond 1992). The existence of a relationship between audit fees and an auditor's reputation has been studied by various authors with positive results. This is the case of Liu (2007), Monterrey and Sánchez (2007), and Whisenant et al. (2003). The variable BIG 4 has been included in the model as a dummy variable, making a distinction between the Big 4 (PwC, E\&Y, KPMG, or Deloitte) and the other firms. A positive relation with the audit fees variable is expected.

\subsubsection{Auditor Change}

One of the most common reasons given by clients for deciding to change auditor is that the audit fee will decrease. Lower audit fees can have their origin in the intention of audit firms of attracting new customers (lowballing). Another reason would be that the new auditor can offer a more efficient service which could reduce their fees. Regardless of the reason for the decrease in the fees, previous research suggests that the continuity of the auditor must be considered in the audit fees models. The two most common proxies that are used to include the continuity of the auditor are a dummy variable that reflects a recent change in the auditor and the actual length of the current auditor in that role (Hay et al. 2006). Hay (2013), Wang and Chui (2015), and De Fuentes and Sierra-Grau (2015) use a dummy variable that reflects the auditor change. This paper also includes this variable and expects it to be negatively related to audit fees.

\section{Auditor Features}

Gul et al. (2013), Ittonen and Peni (2012), Ittonen et al. (2013), and Sundgren and Svanström (2014) have recently studied the effect of auditor features on auditing service quality. Hardies Kris and Branson (2015) affirm that audit fees may be higher for female auditors due to greater engagement effort (i.e., more hours) by female auditors. Female auditors may demand more audit effort because of systematic differences in knowledge, skills, abilities, preferences, and behavior. Ittonen and Peni (2012) found that audits performed by women in Denmark, Sweden, and Finland were more expensive that those performed by men. These authors justify their results due to the existence of factors, such as gender differences in risk tolerance, which may affect pricing decisions by increasing the audit investment and/or increasing the audit fee risk premium. In addition, they also refer to female auditors' diligence, lower overconfidence, and higher level of preparation could also lead to an increase in audit investment, and thereby result in higher audit fees. 
Ittonen et al. (2013) refer to several papers considering cognitive psychology and behavioral economy that have found the existence of important gender differences related to information processing, diligence, conservatism, overconfidence, caution, and risk tolerance (Eckel and Grossman 2002; Nettle 2007; Schmitt et al. 2009). Other studies affirm that women are more conservative and risk adverse than men, and that their behavior is less risky when making economic and financial decisions (Barber and Odean 2001; Dwyer et al. 2002; Watson and McNaughton 2007). Our model includes a variable considering gender and we expect a positive association with audit fees.

Sporting Features

We expect those teams with better performance in the previous season to be capable of increasing their clubs' revenue and reducing financial risk. However, some clubs could overspend to achieve good sporting performance and this would make risk higher. Therefore, the sign of the coefficient could be positive or negative. After the FFP, with higher financial control, the chances of getting a negative sign could be greater.

On the other hand, we may expect reduced club risk if the average attendance to the stadium is high, because it reflects a wide fan base that would help to increase revenues. If the risk is low, the audit fees should also decrease. Therefore, the model includes variables that gather the information about points (performance measure) and average attendance in the previous season.

Finally, we have also included participation in the previous edition of UEFA competitions (Champions League and Europa League) to reflect the effect of sporting features. If a team took part in previous editions, it had to fulfill financial requirements in that season and this facilitates the fulfillment of the financial requirements of the current season. What is more, participation usually provides extra revenue to the club and it may reduce an eventual going concern situation under financial control.

\section{Results}

We have verified the Hypothesis (H1). The results are presented in Table 7. It has been demonstrated that on average auditors significantly increased their audit fees after implementing Fair Play regulation in comparison to pre-implementation fees. On average, the difference is slightly lower than $€ 3500$ in real terms.

On the other hand, some results regarding the determinants of audit fees in football clubs corroborate what was expected. However, most of the variables do not present a significant influence on audit fees. First, we find that the audit fees increased by nearly 1700 Euros (2000 in nominal terms) in the transition period as compared to the period in which FFP did not exist. That amount was practically two-fold in the period of full FFP regulation implementation. This was the expected result, even more so after the t-test.

Foreign ownership is another significant factor that explains the audit fees. In clubs with local owners, audit fees increased by nearly 4500 euros in the advent of foreign investment.

If the auditor is one of the Big 4, then audit fees are about 11,700 Euros higher than those of smaller audit firms, which falls in line with previous research. We should point out that apart from Real Madrid and Barcelona - both excluded from this analysis—only Sevilla CF and Valencia CF were audited by a Big 4 audit firm in seasons 2014-2015 and 2015-2016, in addition to Málaga CF in season 2015-2016, periods in which the FFP regulations were fully implemented. Moreover, Valencia CF and Málaga CF have foreign investors. On the other hand, only Ernst and Young and Deloitte, both of which belong to the Big 4, had audited football clubs throughout the whole period.

Another interesting result is that when the auditor is a woman, audit fees are about 3500 Euros higher than when the auditor is a man. It should be noted that only one of the female auditors works for a Big 4 (Ernst\&Young). Recent studies find similar results when considering the gender of the auditor. Ittonen and Peni (2012) introduced gender differences in risk tolerance as potential reasons to explain this effect. These authors claim that this may increase audit investment and audit fee risk premium. 
They also point out other factors, such as the diligence of female auditors, lower overconfidence, and a higher level of preparation could lead to an increased audit fees. Moreover, Ittonen et al. (2013) found that female auditors might have a constraining effect on earnings management, which may also contribute to higher audit fees. The results obtained by Hardies Kris and Branson (2015) show that firms pay higher audit fees (by about 7 percent) to female auditors. They suggest the existence of a female audit fee premium due to differences in knowledge, skills, abilities, preferences, and behavior or due to supply-side factors. Hu et al. (2014) found that female auditors charge significantly higher audit fees than their male counterparts. They explain that this is due to female auditors' preference for reducing audit risk. In the case of football clubs, the perception of risk by female auditors may also be a plausible reason.

Table 7. Outputs of the regression (real terms).

\begin{tabular}{|c|c|}
\hline VARIABLES & Audit Fees \\
\hline TRAN-FFP & $\begin{array}{l}1661 * \\
(878.3)\end{array}$ \\
\hline FFP & $\begin{array}{c}3408^{* * * *} \\
(1186)\end{array}$ \\
\hline NON_AUDITFEES & $\begin{array}{c}-0.00689 \\
(0.0518)\end{array}$ \\
\hline L.TA & $\begin{array}{c}2.49 \times 10^{-7} \\
\left(1.24 \times 10^{-5}\right)\end{array}$ \\
\hline FOWND & $\begin{array}{l}4436^{* *} \\
(2057)\end{array}$ \\
\hline REPORTLAG & $\begin{array}{l}-12.81 \\
(21.26)\end{array}$ \\
\hline L.ROA & $\begin{array}{l}-274.8 \\
(2,071)\end{array}$ \\
\hline L.LEV & $\begin{array}{l}-551.9 \\
(879.6)\end{array}$ \\
\hline L.LIQ & $\begin{array}{l}18.61 \\
(1680)\end{array}$ \\
\hline L.LOSS & $\begin{array}{l}-170.8 \\
(797.7)\end{array}$ \\
\hline L.GCO & $\begin{array}{c}1567 \\
(1238)\end{array}$ \\
\hline BIG 4 & $\begin{array}{c}11,662 * * * \\
(2244)\end{array}$ \\
\hline AUDITCHANG & $\begin{array}{c}1289 \\
(1311)\end{array}$ \\
\hline GENDER & $\begin{array}{l}3516^{*} \\
(1844)\end{array}$ \\
\hline L.POINTS & $\begin{array}{l}-8.329 \\
(56.53)\end{array}$ \\
\hline L.ATTENDANCE & $\begin{array}{c}0.00838 \\
(0.189)\end{array}$ \\
\hline L.UCL_EL & $\begin{array}{l}-1862 \\
(1179)\end{array}$ \\
\hline Constant & $\begin{array}{c}10,709 * \\
(5400)\end{array}$ \\
\hline Clubs fix effect & YES \\
\hline Observations & 115 \\
\hline Number of id & 25 \\
\hline R-squared & 0.926 \\
\hline
\end{tabular}

Standard errors in parentheses; ${ }^{* *} p<0.01,{ }^{* *} p<0.05,{ }^{*} p<0.1$. 
No evidence supports the possible influence of sporting factors on audit fees, which could possibly be explained by the absence of a relation between sports performance and economic results in Spanish football (Barajas et al. 2005). Variables that are related to risk have resulted in being non-significant as well. Increased risk for the auditor was expected to increase audit fees. In this sense, we expected that higher leverage, and the presence of losses and going concern opinion, to have an impact on higher audit fees. On the contrary, a higher return on assets and liquidity ratio resulted in lower risk and lower expected audit fees too. However, none of these variables were significant. This may be related to the real influence of the FFP regulations on club finances. In fact, as shown in Table 8, the financial situation of clubs improved on average. Throughout the period when the FFP regulations were fully implemented, the return on assets was much higher on average than it had been in the previous periods. The average of these three years was $11.5 \%$, while the average of both previous periods was negative. A similar situation arose with the other indicators. The leverage was around 1 on average in the last period; this was lower than it had been in the previous years. Liquidity clearly improved with a 0.82 average over the last three years as compared to its prior 0.6 average. The number of clubs declaring losses declined to less than a third as compared to the peak of the whole period, in which over $60 \%$ of companies had reported losses. Finally, the percentage of clubs with problems of going concern dropped notably over the last years, especially in 2016. All of this may explain the contribution of FFP regulations to improving the financial situation of the clubs, thereby reducing risk and not influencing the fees that are charged by the auditors. This may represent a problem of endogeneity, but we must recall that we used lagged variables in the regression to avoid this.

Table 8. Evolution of risk indicators.

\begin{tabular}{cccccccccc}
\hline & $\mathbf{2 0 0 8}$ & $\mathbf{2 0 0 9}$ & $\mathbf{2 0 1 0}$ & $\mathbf{2 0 1 1}$ & $\mathbf{2 0 1 2}$ & $\mathbf{2 0 1 3}$ & $\mathbf{2 0 1 4}$ & $\mathbf{2 0 1 5}$ & $\mathbf{2 0 1 6}$ \\
\hline ROA & $-12.4 \%$ & $2.9 \%$ & $5.6 \%$ & $-7.9 \%$ & $-8.9 \%$ & $9.3 \%$ & $10.1 \%$ & $8.6 \%$ & $15.9 \%$ \\
LEV & 0.88 & 1.19 & 1.23 & 1.34 & 1.17 & 1.19 & 0.99 & 1.07 & 0.98 \\
LIQ & 0.62 & 0.65 & 0.54 & 0.63 & 0.58 & 0.76 & 0.80 & 0.90 & 0.75 \\
LOSS & $41.2 \%$ & $27.8 \%$ & $41.2 \%$ & $47.1 \%$ & $61.1 \%$ & $33.3 \%$ & $27.8 \%$ & $33.3 \%$ & $27.8 \%$ \\
GCO & $52.9 \%$ & $55.6 \%$ & $64.7 \%$ & $61.1 \%$ & $55.6 \%$ & $72.2 \%$ & $44.4 \%$ & $44.4 \%$ & $29.4 \%$ \\
\hline
\end{tabular}

We have included clubs fixed effect as there are features of the clubs that remain constant throughout the period. It is interesting to observe which clubs pay more or less than the base team, which is Almeria CF in our case. The clubs that pay significantly higher audit fees are Atletico de Madrid (understandable due to its size), Athletic de Bilbao, Deportivo de la Coruña, Osasuna, Racing de Santander, Rayo Vallecano, Real Sociedad, and Zaragoza CF. Most of these clubs had faced serious financial problems. On the other hand, the clubs that pay significantly less are Eibar, Getafe, and Granada CF. All of them are 'small' clubs and Eibar had only been in First Division in the last 2 seasons, and for the first time in its history.

\section{Summary and Discussion}

As it has been proven, the audit fees have grown in real terms after the implementation of FFP regulations. Moreover, audit fees are explained by the presence of foreign investors, having one of the Big 4 as the auditing firm and having a female auditor. The fact that the Big 4 audit companies charge higher audit fees seems clear. The fact that the presence of a female auditor may increase the fees is surprising, but it is even more surprising to find that other studies have obtained results akin to ours. These studies explain the higher audit fees given female auditors' perception of risk. This may be relevant in the case of football clubs, which are 'risky businesses'.

This paper makes two main contributions. On the one hand, it analyzes the economic consequences of the implementation of FFP regulations by mainly considering their effect on audit fees. On the other hand, the behavior of audit fees is analyzed within a particular context, the football industry. It reveals no influence of sporting factors, even when they had been expected. 
With respect to the implications of the paper, it seems that the change in regulations has had an impact on audit fees charged by auditors for their services. However, this increase may be compensated over future years because the clubs' financial situation is improving, and, subsequently, the risk taken by auditors is diminishing. This facilitates the reduction in audit fees. UEFA should monitor whether the audit fees are reasonable as well as the quality of the audit reports, which have become crucial for obtaining a license to participate in UEFA competitions.

Audit fees are symptomatic of the deeper effects of the changes brought about by FFP regulation. Furthermore, the role of auditors imposed by UEFA can contribute to avoiding the problem of earning management, as pointed out by Dimitropoulos et al. (2016).

This study presents some limitations. Some of them are derived from the nature of the study and it is almost impossible to address them. One of them is the problem of the size of the sample, but only 18 clubs each year (as Real Madrid and Barcelona are excluded) are affected by these regulations. Nevertheless, Hay et al. (2006) present a summary of 148 papers on audit fees describing the sample. The size of the samples varies, but $20.3 \%$ of the papers have a sample smaller than 100 and $46.6 \%$ smaller than 200. The size of the sample is relevant when the model includes many independent variables, as these diminish the degrees of freedom. This problem is common for most of the papers on this issue. However, the results are pretty much similar upon excluding some of the non-significant variables. For that reason, we consider it best to maintain them as they could theoretically determine audit fees.

On the other hand, some variables such as other personal features of the auditors or other types of ownership could be missed, as well as other changes in audit or accountancy regulations. At this point, it is worth remarking that during the period of study some changes in audit or accountancy regulations took place. In accounting matters, the reform of the Spanish General Accounting Plan (Spanish GAAP) was approved in 2007, with the aim of accommodating the new IRFS to Spanish accounting regulations. Subsequently, in 2010, a new modification of the Spanish GAAP standards was made and the rules for the formulation of the Consolidated Annual Accounts were approved. In 2016, new amendments were incorporated into Spanish legislation to comply with the provisions of the EU Directive 34/2013. Regarding auditing, there were two amendments of the Audit Act with the purpose of adapting Spanish domestic legislation to EU Directives 43/2006 EC and 56/2014 in 2010 and in 2015, respectively. These changes overlap the period that we have taken. These kinds of variables could be used for more specific studies on the topic. Moreover, studies with companies from other industries would help to understand if the changes in general regulations affect football clubs in different ways.

The results of this study provide several future research lines. First, it would be interesting to carry out this analysis on other European leagues. Second, it would also be worth studying other possible effects of FFP regulations such as the presence of significant changes in auditor opinion. Third, seeing whether the adoption of FFP regulation would lead to an increased likelihood of clubs choosing a Big 4 accounting firm is a further line of study to be pursued.

Author Contributions: Authors equally contributed to the research and writing of the paper

Funding: This research was funded by National Research University Higher School of Economics in its Basic Research Program.

Acknowledgments: This paper is an output of a research project implemented as part of the Basic Research Program at the National Research University Higher School of Economics (HSE).

Conflicts of Interest: The authors declare no conflict of interest. The funders had no role in the design of the study; in the collection, analyses, or interpretation of data; in the writing of the manuscript, or in the decision to publish the results. 


\section{References}

Abbott, Laurence J., Katherine Gunny, and Troy Pollard. 2017. The impact of litigation risk on auditor pricing behavior: Evidence from reserve mergers. Contemporary Accounting Research 34: 1103-27. [CrossRef]

Alexeyeva, Irina, and Svanström Tobias. 2015. The impact of the global financial crisis on audit and non-audit fee. Managerial Auditing Journal 30: 302-23. [CrossRef]

Archambeault, Deborah, and Tood DeZoort. 2001. Auditor opinion shopping and the audit committee: An analysis of suspicious auditor switches. International Journal of Auditing 5: 33-52. [CrossRef]

Ascari , Guido, and Philippe Gagnepain. 2006. Spanish football. Journal of Sports Economics 7: 76-89. [CrossRef]

Asthana, Shara, Steven Balsam, and Sungsoo Kim. 2009. The effect of Enron, Andersen, and Sarbanes-Oxley on the US market for audit services. Accounting Research Journal 22: 4-26. [CrossRef]

Badertscher, Brand, Bjorn Jorgensen, Sharon P. Katz, and William Kinney. 2014. Public equity and audit pricing in the United States. Journal of Accounting Research 52: 303-39. [CrossRef]

Barajas, Angel. 2004. Modelo de Valoración de Clubes de Fútbol Basado en los Factores clave de su negocio [Valuation model for football clubs based on the key factors of their business]. MPRA Paper 13158. Munich: University Library of Munich.

Barajas, Angel, Carlos Fernández-Jardón, and Liz Crolle. 2005. Does Sports Performance Influence Revenues and Economic Results in Spanish Football? MPRA Paper 3234. Munich: University Library of Munich, Available online: https: / / papers.ssrn.com/sol3/papers.cfm?abstract_id=986365 (accessed on 1 April 2018).

Barajas, Angel, and Plácido Rodríguez. 2010. Spanish football clubs' finances: Crisis and player salaries. International Journal of Sport Finance 1: 52-66.

Barajas, Angel, and Plácido Rodríguez. 2014. Spanish football in need of financial therapy: Cut Expenses and Inject Capital. International Journal of Sport Finance 9: 73-90.

Barber, Brad M., and Terrance Odean. 2001. Boys will be boys: Gender, overconfidence, and common stock investment. Quarterly Journal of Economics 116: 261-92. [CrossRef]

Basioudis, Ilias G., Evangelos Papakonstantinou, and Marshall A. Geiger. 2008. Audit fees, non-audit fees and auditor going-concern reporting decisions in the United Kingdom. Abacus, A Journal of Accounting, Finance and Business Studies 44: 284-307. [CrossRef]

Beech, John, Simon Horsman, and Jamie Magraw. 2010. Insolvency events among English football clubs. International Journal of Sports Marketing \& Sponsorship 11: 53-6. [CrossRef]

Bedard, Jean C., Donald R. Deis, Mary B. Curtis, and J. Gregory Jenkins. 2008. Risk monitoring and control in audit firms: A research synthesis. Auditing: A Journal of Practice and Theory 27: 187-218. [CrossRef]

Bell, Timothy B., Rajib Doogar, and Ira Solomon. 2008. Audit labor usage and fees under business risk auditing. Journal of Accounting Research 46: 729-60. [CrossRef]

Bell, Timothy, Wayne R. Landsman, and Douglas A. Shackelford. 2001. Auditor's perceived business risk and audit fees: Analysis and evidence. Journal of Accounting Research 39: 35-43. [CrossRef]

Beneish, Messod D., and Teri Lombardi Yohn. 2008. Information friction and investor home bias: A perspective on the effect of global IFRS adoption on the extent of equity home bias. Journal Accounting Public Policy 27: 433-43. [CrossRef]

Boscá, José E., Vicente Liern, Aurelio Martínez, and Ramón Sala. 2008. The Spanish football crisis. European Sport Management Quarterly 8: 165-77. [CrossRef]

Brumfield, Craig A., Robert K. Elliott, and Peter D. Jacobson. 1983. Business risk and the audit process. Journal of Accountancy 155: 60-68.

Callaghan, Joseph, Mohinder Parkash, and Rajeev Singhal. 2009. Going-concern audit opinions and the provision of non-audit services: Implications for auditor independence of bankrupt firms. Auditing: A Journal of Practice \& Theory 28: 153-69. [CrossRef]

Casterella, Jeffrey R., Jere R. Francis, Barry L. Lewis, and Paul L. Walker. 2004. Auditor industry specialization, client bargaining power and audit pricing. Auditing: A Journal of Practice and Theory 23: 123-40. [CrossRef]

Charles, Shannon L., Steven M. Glover, and Nathan Y. Sharp. 2010. The association between financial reporting risk and audit fees before and after the historic events surrounding SOX. Auditing: A Journal of Practice and Theory 29: 15-39. [CrossRef] 
Choi, Jong-Hang, Jeong Bon Kim, Xiaohong Liu, and Dan A. Simunic. 2008. Audit pricing, legal liability regimes, and Big 4 premiums: theory and cross-country evidence. Contemporary Accounting Research 25: 55-99. [CrossRef]

Choi, Jong-Hang, Jeong-Bon Kim, Xiaohong Liu, and Dan A. Simunic. 2009. Cross-listing audit fee premiums: Theory and evidence. The Accounting Review 84: 1429-63. [CrossRef]

Craswell, Allen T., Jere R. Francis, and Stephen L. Taylor. 1995. Auditor brand name reputation and industry specializations. Journal of Accounting and Economics 20: 297-322. [CrossRef]

Davis, Larry R., David N. Ricchiute, and Greg Trompeter. 1993. Audit effort, audit fees, and the provision of non-audit services to audit clients. The Accounting Review 68: 135-50.

De Angelo, Linda Elizabeth. 1981. Auditor size and audit quality. Journal of Accounting and Economics 3: 183-99. [CrossRef]

De Fuentes, Cristina, and Eva Sierra-Grau. 2015. IFRS adoption and audit and non-audit fees: Empirical evidence from Spanish listed companies. Spanish Journal of Finance and Accounting 44: 387-426. [CrossRef]

De Fuentes, Cristina, and Eva Sierra-Grau. 2015. Industry specialization and audit fees: A meta-analytic approach. Academia, Revista Latinoamericana de Administración 28: 419-35. [CrossRef]

De George, Emmanuel T., Colin B. Ferguson, and Nasser A. Spear. 2013. How much does IFRS cost? IFRS adoption and audit fees. Accounting Review 88: 429-62. [CrossRef]

DeFond, Mark L. 1992. The association between changes in client company agency costs and auditor switching. Auditing: A Journal of Practice \& Theory 11: 16-31.

Deloitte. 2014. Annual Review of Football Finance 2014 Highlights, Sports Business Group. Available online: https://www2.deloitte.com/content/dam/Deloitte/uk/Documents/sports-businessgroup/deloitte-uk-annual-review-football-finance.pdf (accessed on 20 March 2018).

Dimitropoulos, Panagiotis. 2016. Audit selection in the European football industry under Union of European Football Associations Financial Fair Play. International Journal of Economics and Financial Issues 6: 901-6.

Dimitropoulos, Panagiotis, Stergios Leventis, and Emmanouil Dedoulis. 2016. Managing the European football industry: UEFA's regulatory intervention and the impact on accounting quality. European Sport Management Quarterly 16: 459-86. [CrossRef]

Dwyer, Peggy, James Gilkeson, and John List. 2002. Gender differences in revealed risk taking: Evidence from mutual fund investors. Economics Letters 76: 151-58. [CrossRef]

Eckel, Catherine C., and Philip J. Grossman. 2002. Sex differences and statistical stereotyping in attitudes toward financial risk. Evolution and Human Behavior 23: 281-95. [CrossRef]

Francis, Jerre R., and Dechun Wang. 2008. The joint effect of investor protection and Big 4 audits on earnings quality around the world. Contemporary Accounting Research 25: 157-91. [CrossRef]

Gay, José M. 2009a. Fútbol finanzas: La economía de la liga de las estrellas (I). Radiografía económica del fútbol español (temporada 2006-07) [Football finance: The economy of the league of the stars (I). Economic in-depth analysis of Spanish football (season 2006-07)]. Partida Doble 208: 62-89.

Gay, José M. 2009b. Fútbol finanzas: La economía de la liga de las estrellas (II). Radiografía económica del fútbol español (temporada 2006-07) [Football finance: The economy of the league of the stars (II). Economic in-depth analysis of Spanish football (season 2006-07).]. Partida Doble 209: 62-87.

Gammelsæter, Hallgeir. 2010. Institutional pluralism and governance in 'Commercialized' sport clubs. European Sport Management Quarterly 10: 569-94. [CrossRef]

García, Jaume, and Plácido Rodríguez. 2003. From sports clubs to stock companies: The financial structure of football in Spain 1992-2001. European Sport Management Quarterly 3: 235-69. [CrossRef]

Ghosh, Aloke, and Steven Lustgarten. 2006. Pricing of initial audit engagements by large and small audit firms. Contemporary Accounting Research 23: 333-68. [CrossRef]

Ghosh, Aloke, and Robert Pawlewicz. 2009. The impact of regulation on auditor fees: evidence from the Sarbanes-Oxley Act. Auditing: A Journal of Practice and Theory 28: 171-97. [CrossRef]

Griffin, Paul A., and David H. Lont. 2007. An analysis of audit fees following the passage of Sarbanes-Oxley. Asia-Pacific Journal of Accounting \& Economics 14: 161-92. [CrossRef]

Griffin, Paul A., David. H. Lont, and Estelle Y. Sun. 2009. Governance regulatory changes, international financial reporting standards adoption, and New Zealand audit and non-audit fees: Empirical evidence. Accounting E Finance 49: 697-724. [CrossRef] 
Groff, Maja Z., Domen Trobec, and Aleksander Igličar. 2017. Audit fees and the salience of financial crises: Evidence from Slovenia. Economic Research Ekonomska Istraživanja 30: 922-38. [CrossRef]

Gul, Ferdinand, Donghui Wu, and Zhifeng Yang. 2013. Do individual auditors affect audit quality: Evidence from archival data. The Accounting Review 88: 1993-2023. [CrossRef]

Hardies Kris, Diane Breesch, and Joël Branson. 2015. The female audit fee premium. Auditing: A Journal of Practice \& Theory 34: 171-95. [CrossRef]

Hay, David. 2013. Further evidence from meta-analysis of audit fee research. International Journal of Auditing 17: 162-76. [CrossRef]

Hay, David, W. Robert Knechel, and Norman Wong. 2006. Audit fees: A meta-analysis of the effect of supply and demand attributes. Contemporary Accounting Research 23: 141-91. [CrossRef]

He, Xianjie, Oliver Rui, Liu Zheng, and Hongjun Zhu. 2014. Foreign ownership and auditor choice. Journal of Accounting and Public Policy 33: 401-18. [CrossRef]

Higgins, Stephen, David Lont, and Tom Scott. 2016. Longer term audit costs of IFRS and the differential impact of implied auditor cost structures. Accounting and Finance 56: 165-203. [CrossRef]

Hu, Naw-wei, Wen-si Ouyang, and Ning-jiao Deng. 2014. Research on auditors' gender and audit fees. Paper presented at 2014 International Conference on Management Science Engineering (ICMSE), Nirjuli, India, May 7-8; pp. 1307-12.

Huang, Hua-Wei, Kannan Raghunandan, and Dasaratha Rama. 2009. Audit fees for initial audit engagements before and after SOX. Auditing: A Journal of Practice \& Theory 28: 171-90. [CrossRef]

Ittonen, Kim, and Emilia Peni. 2012. Auditor's gender and audit fees. International Journal of Auditing 16: 1-18. [CrossRef]

Ittonen, Kim, Emilia Vähämaa, and Sami Vähämaa. 2013. Female auditors and accruals quality. Accounting Horizons 27: 205-28. [CrossRef]

Kim, Jeong-Bong, Xiaohong Liu, and Liu Zheng. 2012. The impact of mandatory IFRS adoption on audit fees: Theory and evidence. The Accounting Review 87: 2061-94. [CrossRef]

Knechel, W. Robert, and Jeff L. Payne. 2001. Additional evidence on audit report lags. Auditing: A Journal of Practice E Theory 20: 137-46. [CrossRef]

Krishnan, Gopal V., and Changiiang Wang. 2015. The relation between managerial ability and audit fees and going concern opinions. Auditing: A Journal of Practice \& Theory 34: 139-60. [CrossRef]

Kuper, Simon, and Stefan Szymanski. 2009. Soccernomics: Why England Loses, Why Germany and Brazil Win, and Why the US, Japan, Australia, Turkey—and Even Iraq-Are Destined to Become the Kings of the World's Most Popular Sport. New York: Nation Books.

Lin, Hsiao-Lun, and Ai-Ru Yen. 2016. The effects of IFRS experience on audit fees for listed companies in China. Asian Review of Accounting 24: 43-68. [CrossRef]

Liu, Ji-Hong. 2007. On determinants of audit fee: New evidence from China. Journal of Modern Accounting and Auditing 3: 60-64.

Mautz, Robert Kuhn, and Hussein Amer Sharaf. 1961. The Philosophy of Auditing. Sarasota: American Accounting Association Monograph, No. 6.

Menon, Krishnagopal, and David D. Williams. 2001. Long term trends in audit fees. Auditing: A Journal of Practice and Theory 20: 115-36. [CrossRef]

Monterrey, Juan, and Amparo Sánchez. 2007. Un estudio empírico de los honorarios del auditor [An Empirical Study of auditor's fees]. Cuadernos de Economía y Empresa 32: 81-210. [CrossRef]

Morrow, Stephen. 2014. Financial Fair Play-Implications for Football Club Financial Reporting. The Institute of Chartered Accountants of Scotland. Available online: http://www.storre.stir.ac.uk/bitstream/1893/ 21393/1/ICAS\%20Financial\%20Fair\%20Play\%20Report\%20-\%20Stephen\%20Morrow.pdf (accessed on 10 May 2018).

Nettle, Daniel. 2007. Empathizing and systemizing: What are they, and what do they contribute to our understanding of psychological sex differences? British Journal of Psychology 98: 237-55. [CrossRef] [PubMed]

Oxera Report. 2006. Competition and Choice in the UK Audit Market. Prepared for Department of Trade and Industry and Financial Reporting Council. Oxford: Oxera Consulting Ltd.

Palmrose, Zoe-Vonna. 1986. The effect of nonaudit services on the pricing of audit services: Further evidence. Journal of Accounting Research 24: 405-41. [CrossRef] 
Raghunandan, Kannan, and Dasaratha Rama. 2006. Sox section 404 material weakness disclosures and audit fees. Auditing: A Journal of Practice \& Theory 25: 99-114. [CrossRef]

Redmayne, Nives Botica, Michael E. Bradbury, and Steven F. Cahan. 2010. The effect of political visibility on audit effort and audit pricing. Accounting and Finance 50: 921-39. [CrossRef]

Rittenberg, Larry E., Karla Johnstone, and Audrey Gramling. 2012. Auditing, 8th ed. Cincinnati: South-Western College Publishing.

Robinson, Terry, and Robert Simmons. 2014. Gate-sharing and talent distribution in the English football league. International Journal of the Economics of Business 21: 413-29. [CrossRef]

Ruiz-Barbadillo, Emiliano. 2016. Regulación frente a reputación como medio de salvaguarda de la independencia del auditor [Regulation versus reputation as a means of safeguarding the independence of the audit]. Revista de Contabilidad y Tributación 401-402: 161-98.

Ruíz-Barbadillo, Emiliano, and Nieves Gómez-Aguilar. 2007. Análisis empírico de los factores que explican la mejora de opinión de auditoría: compra de opinión y mejora en las prácticas contables de la empresa [An empirical analysis of the factors explaining the change in audit opinion: opinion shopping and accounting practices improvements in firms]. Spanish Journal of Finance and Accounting 36: 317-50. [CrossRef]

Salman, Fazlina Mohd, and Elizabeth Carson. 2009. The impact of the Sarbanes-Oxley Act on the audit fees of Australian listed firms. The International Journal of Auditing 13: 127-40. [CrossRef]

Schmitt, David, Anu Realo, Martin Voracek, and Jüri Allik. 2009. Why can't a man be more like a woman? Sex differences in big five personality traits across 55 cultures. Journal of Personality and Social Psychology 94 : 168-82. [CrossRef] [PubMed]

Seetharaman, Ananth, Ferdinand A. Gul, and Stephen G. Lynn. 2002. Litigation risk and audit fees: evidence from UK firms cross-listed on US markets. Journal of Accounting and Economics 33: 91-115. [CrossRef]

Silva, Rosana Cristina, Felipe Silva Moreira, José Emerson Firmino, Jaspe Padilha Miranda, and José Dionísio Gómez Silva. 2016. Julgamento dos Auditores Independentes sobre o Ativo Intangível: Um estudo sobre a qualidade da auditoria em clubes de futebol do Brasil [Judgment of independent auditors regarding intangible assets: A study on audit quality in Brazillian football clubs]. Revista Contabilidade e Controladoria 8: 65-88. Available online: http:/ / revistas.ufpr.br/rcc/article/view/39449 (accessed on 2 May 2018).

Simunic, Dan A. 1980. The pricing of audit services: Theory and evidence. Journal of Accounting Research 18: 161-90. [CrossRef]

Simunic, Dan A. 1984. Auditing, Consulting, and Auditor Independence. Journal of Accounting Research 22: 679-702. [CrossRef]

Simunic, Dan A., and Michael T. Stein. 1996. Impact of litigation risk on audit pricing: A review of the economics and the evidence. Auditing: A Journal of Practice and Theory 15: 119-34.

Sarbanes Oxley-SOX. 2002. Committee on Financial Services, Sarbanes-Oxley Act. Available online: http: / / www.sarbanes-oxley.com (accessed on 23 February 2018).

Stanley, Jonathan D. 2011. Is the audit fee disclosure a leading indicator of clients' business risk? Auditing: A Journal of Practice \& Theory 30: 157-79. [CrossRef]

Stein, Michael. T., Dan A. Simunic, and Terrence B. O'Keefe. 1994. Industry differences in the production of audit services. Auditing: A Journal of Practice \& Theory 13: 128-42.

Storm, Rasmus K., and Klaus Nielsen. 2012. Soft budget constraints in professional football. European Sport Management Quarterly 12: 183-201. [CrossRef]

Sundgren, Stefan, and Tobias Svanström. 2014. Auditor-in-charge characteristics and going concern reporting. Contemporary Accounting Research 31: 531-550. [CrossRef]

UEFA. 2010. UEFA Club Licensing and Financial Fair Play Regulations, Edition 2010 ed. Nyon: UEFA.

Venkataraman, Ramgopal, Joseph P. Weber, and Michael Willenborg. 2008. Litigation risk, audit quality, and audit fees: Evidence from initial public offerings. The Accounting Review 83: 1315-45. [CrossRef]

Vieru, Markku, and Hannu Shadewitz. 2010. Impact of IFRS transition on audit and non-audit fees: Evidence from small and medium-sized listed companies in Finland. The Finnish Journal of Business Economics 1: 11-41.

Wang, Yuequan, and Andy C.W. Chui. 2015. Product market competition and audit fees. Auditing: A Journal of Practice \& Theory 34: 139-56. [CrossRef]

Watson, John, and Mark McNaughton. 2007. Gender differences in risk aversion and expected retirement benefits. Financial Analysts Journal 63: 52-62. [CrossRef] 
Whisenant, Scott, Srinivasan Sankaraguruswamy, and Kannan Raghunandan. 2003. Evidence on the Joint Determination of Audit and Non-Audit Fees. Journal of Accounting Research 41: 721-44. [CrossRef]

Wilson, Robert, Daniel Plumley, and Girish Ramchandani. 2013. The relationship between ownership structure and club performance in the English Premier League. Sport, Business and Management: An International Journal 3: 19-36. [CrossRef]

Xu, Yang, Elizabeth Carson, Neil Fargher, and Liwei Jiang. 2013. Responses by Australian auditors to the global financial crisis. Accounting and Finance 53: 301-38. [CrossRef]

Zhang, Tianshu, and Jun Huang. 2013. The risk premium of audit fee: Evidence from the 2008 financial crisis. China Journal of Accounting Studies 1: 47-61. [CrossRef]

(C) 2018 by the authors. Licensee MDPI, Basel, Switzerland. This article is an open access article distributed under the terms and conditions of the Creative Commons Attribution (CC BY) license (http:/ / creativecommons.org/licenses/by/4.0/). 
Article

\title{
Financial and Sporting Performance in French Football Ligue 1: Influence on the Players' Market
}

\author{
Wladimir Andreff ${ }^{\dagger}$ \\ Scientific Council at the Observatory of the Sports Economy, French Ministry for Sports, 75013 Paris, France; \\ andreff@club-internet.fr; Tel.: +33-4-6685-2804 \\ † Emeritus Professor at the University Paris 1 Panthéon Sorbonne.
}

Received: 3 October 2018; Accepted: 3 November 2018; Published: 8 November 2018

\begin{abstract}
Despite the globalisation of European soccer, each professional league exhibits specificities. French Ligue 1 sometimes contends with the trading-off of financial performance against sporting performance of its teams in European soccer competitions, and its inner auditing body, the Direction Nationale du Contrôle de Gestion (DNCG), is in charge of controlling clubs' financial accounts. Moreover, Ligue 1 operates with one of the best competitive balances in the Big Five, which is detrimental to its clubs' success at the European level. However, the league and a number of clubs have not been able to curb payroll inflation and have not avoided being recurrently run in a deficit and accumulating debts, in particular payment arrears and player transfer overdue. Lax management occurs, since very few clubs have been sanctioned by a payment failure, even fewer by liquidation, and there has been no bankruptcy. The concept of a soft budget constraint theoretically encapsulates such empirical evidence. The novelty of the paper is to establish a link between the soft budget constraint and the players' labour market where it crucially triggers market disequilibria: an excess of demand for superstars' talents and an excess of supply for journeymen players are modelled. Data paucity about player individual wages hinders econometric testing of the aforementioned link and the model. However, a look at transfer fees that concentrates on a few of the top European soccer clubs provides a first insight into the arms race for talent that fuels an excess of demand for superstars and dips a number of clubs' finance into the red.
\end{abstract}

Keywords: sports finance; soft budget constraint; payment failure; disequilibrium modelling; segmented labour market; French soccer

JEL Classification: Z10; G30; J42

\section{Introduction}

The globalisation of European football (soccer) started up in the 1990s. The labour market for football players was fully liberalised as a result of the Bosman case (1995), a liberalisation that was extended to most developing countries by an international agreement called the Lomé Convention (2001). In 1999, following a failed attempt by Media Partners to launch a European football super league, a dramatic change in the format and financial endowment of UEFA (Union of European Football Associations) competitions completed the transformation of the economic model in a number of professional football clubs and leagues, in particular those benefiting from the new money godsend.

However, all national football leagues have kept some specificity when compared to the new global model. French professional football Ligue 1 is a case in point, namely as regards its trade-off between financial and sporting performance (Section 1), evolving financial structure, and management of deficits and debts (Section 2), payment arrears, and payment failures (Section 3). Such a recurrent situation can be conceptualised with the notion of a soft budget constraint that rules the economic model of clubs in an open league system; the soft budget constraint paves the way to a disequilibrium 
labour market for talent: players. This is in no way specific to French professional football, and can be encapsulated into more general disequilibrium modelling (Section 4) that opens up an avenue for further research and empirical testing of the relationship between lax financial disciplines on the one hand and, on the other hand, skyrocketing payroll and transfer fee inflation in the case of superstar players.

\section{Trading-Off Financial versus Sporting Performance in Ligue 1}

The economic model of top professional football in France is marked by various specificities. First, television (TV) rights revenues account for the lion's share of the league's finance (Andreff and Staudohar 2000) and, through a redistribution scheme, in club finance. Second, French football clubs attempt to cover their operating deficits by a players' transfer excess balance, sometimes without success, and a rather effective marketing strategy (Andreff and Scelles 2017). Some French football analysts are used to considering a third characteristic, according to which the French Ligue 1 (FL1) is the best-managed football league in Europe or, at least, they admit that it is one of the two best-managed leagues together with the German Bundesliga (GBL). Indeed, the experiences of auditing clubs' financial accounts before delivering them a license to participate in the Bundesliga, as well as the Direction Nationale du Contrôle de Gestion (DNCG)'s role of inner audit for the sake of the French football league (the Ligue du Football Professionnel, LFP), had been scrutinised at the UEFA level before launching the Financial Fair Play (FFP) rules in 2012, and might have had some influence on the design of this new financial regulation in European football.

However, the French model of management and financing for professional football is not actually admired, especially in those countries with the richest and highest-performing football leagues. It is sometimes an argument pushed forward by the LFP and other French football stakeholders that the price to pay for maintaining a sound financial management à la française is a relatively weak sporting performance of the French clubs in UEFA competitions (Champions League and Europa League) compared to other Big Five leagues. In a nutshell, the level of sporting achievement is lower in FL1 than in other major European football leagues, while the financial performance does not appear to be worse than in other Big Five soccer leagues on average (Andreff 2014a). As a consequence, in the UEFA rankings, France's rank dropped from fourth in 2008 to eighth in 2015, though it recovered to fifth in 2017.

A glimpse at Table 1 confirms the FL1's low sporting performance and shows that the argument applies also to some extent to the German Bundesliga; indeed, these two leagues exhibit small numbers of winners and quarter-finalists in European football competitions over 2000-2018. From such an observation it may be derived that there is a kind of trade-off between financial and sporting performance that is somewhat detrimental to the sporting performance. The opposite strategy is conducted by the English Premier League (EPL) and the Spanish La Liga (SLL), where sporting performance seems to be privileged, with some efficiency, over financial disciplines, while the Italian Serie A (ISA) is in dire financial straits and has not had many significant sporting successes over the past decade.

Table 1. The performance of major European leagues in UEFA competitions, 2000-2018.

\begin{tabular}{|c|c|c|c|c|c|}
\hline Champions League & EPL & FL1 & GBL & ISA & SLL \\
\hline Number of winners from & 2 & 0 & 1 & 3 & 11 \\
\hline Number of quarter finalists & 38 & 13 & 21 & 21 & 43 \\
\hline Europa League & English EPL & French FL1 & German BL & Italian LC & Spanish LF \\
\hline Number of winners from & 2 & 0 & 0 & 0 & 10 \\
\hline Number of quarter finalists & 14 & 9 & 19 & 12 & 31 \\
\hline Total & English EPL & French FL1 & German BL & Italian LC & Spanish LF \\
\hline Number of winners from & 4 & 0 & 1 & 3 & 21 \\
\hline Number of quarter finalists & 52 & 22 & 40 & 33 & 74 \\
\hline
\end{tabular}

EPL, English Premier League; FL1, French Ligue 1; GBL, German Bundesliga; ISA, Italian Serie A; SLL, Spanish La Liga. Source: UEFA (2000 is for the 1999-2000 season, and so on). 
The FL1's most favourable sporting dimension is often presented as being also its level of competitive balance. The most widely used measure of competitive balance over one season, the Noll-Scully index, which refers to the observed win percentage distribution to the distribution that would be theoretically expected if the league were perfectly balanced, in which all teams would have exactly a $50 \%$ win percentage, is written as:

$$
\mathrm{NS}=\sigma /(0.5 / \sqrt{ } \mathrm{N})
$$

where $\sigma=\sqrt{ } 1 / \mathrm{N} \Sigma_{\mathrm{i}}\left(v_{i}-0.5\right)^{2}$ is the actually observed standard deviation of a real league, $0.5 / \sqrt{ } \mathrm{N}$ is the standard deviation of the theoretical perfectly balanced league, $\mathrm{N}$ is the number of matches played by each team in the league, and $v_{i}$ is the win percentage of team $i$. The closer is NS to 1 , the more a championship is balanced in a season; the further it is from 1, the less the league is balanced.

With such a metric at hand, FL1 appears to have been the most balanced major European league over the 1996-2012 period on average (Table 2), followed by La Liga and Bundesliga in 1996-2008, and by Bundesliga and Serie A in 2008-2012. The general trend is that all of the Big Five leagues are becoming more imbalanced, except for Serie A in 2008-2012. Since 2012, the introduction of the UEFA FFP has not stopped imbalances from increasing in the five leagues; quite the contrary. The three leagues that benefit from the most important player transfers from abroad, i.e., the EPL, SLL, and ISA, were much more imbalanced than the two other leagues on average in 2012-2018. FL1 is no longer the most balanced league among the Big Five, since the Bundesliga exhibited a slightly lower Noll-Scully index in 2012-2018. This switch not only coincides with the UEFA FFP's enforcement, but also probably more with the aggressive talent recruitment strategy of Paris Saint-Germain, which is fuelled by Qatari funding, and, to a lesser extent, Monaco's recruitment strategy, which is benefiting from Mr. Rybolovlev's finance and recently Marseille's one after its takeover by Frank McCourt, an American billionaire and former owner of a major league baseball (MLB) franchise, the Los Angeles Dodgers.

Table 2. The competitive balance in five major European football leagues.

\begin{tabular}{|c|c|c|c|c|c|}
\hline \multicolumn{6}{|c|}{ 1997-2018 } \\
\hline \multicolumn{6}{|c|}{ A/Noll-Scully Index } \\
\hline Season & French L1 & English PL & Italian SA & Spanish LF & German BL \\
\hline 1996/1997 & 1.47 & 1.23 & 1.33 & 1.61 & 1.43 \\
\hline $1997 / 1998$ & 1.31 & 1.28 & 1.76 & 1.39 & 1.14 \\
\hline $1998 / 1999$ & 1.42 & 1.52 & 1.35 & 1.41 & 1.52 \\
\hline $1999 / 2000$ & 0.88 & 1.69 & 1.65 & 1.03 & 1.43 \\
\hline $2000 / 2001$ & 1.15 & 1.43 & 1.60 & 1.29 & 1.14 \\
\hline $2001 / 2002$ & 1.18 & 1.72 & 1.71 & 1.14 & 1.54 \\
\hline $2002 / 2003$ & 1.28 & 1.62 & 1.56 & 1.32 & 1.23 \\
\hline $2003 / 2004$ & 1.46 & 1.57 & 1.86 & 1.28 & 1.61 \\
\hline $2004 / 2005$ & 1.10 & 1.73 & 1.45 & 1.51 & 1.50 \\
\hline $2005 / 2006$ & 1.44 & 1.94 & 1.97 & 1.49 & 1.53 \\
\hline $2006 / 2007$ & 1.06 & 1.64 & 1.78 & 1.39 & 1.30 \\
\hline $2007 / 2008$ & 1.36 & 2.09 & 1.60 & 1.46 & 1.47 \\
\hline Mean 1996/2008 & 1.26 & 1.62 & 1.64 & 1.36 & 1.40 \\
\hline $2008 / 2009$ & 1.58 & 1.91 & 1.59 & 1.50 & 1.59 \\
\hline $2009 / 2010$ & 1.60 & 1.87 & 1.56 & 1.84 & 1.53 \\
\hline $2010 / 2011$ & 1.25 & 1.33 & 1.52 & 1.71 & 1.38 \\
\hline $2011 / 2012$ & 1.48 & 1.78 & 1.56 & 1.70 & 1.60 \\
\hline Mean 2008/2012 & 1.48 & 1.72 & 1.56 & 1.69 & 1.53 \\
\hline $2012 / 2013$ & 1.42 & 1.82 & 1.71 & 1.82 & 1.73 \\
\hline $2013 / 2014$ & 1.69 & 1.99 & 2.02 & 1.89 & 1.85 \\
\hline $2014 / 2015$ & 1.62 & 1.69 & 1.59 & 2.11 & 1.45 \\
\hline $2015 / 2016$ & 1.56 & 1.67 & 1.78 & 1.82 & 1.68 \\
\hline $2016 / 2017$ & 1.82 & 2.09 & 2.13 & 2.13 & 1.59 \\
\hline $2017 / 2018$ & 1.84 & 1.92 & 2.14 & 1.94 & 1.49 \\
\hline Mean 2012/2018 & 1.66 & 1.86 & 1.90 & 1.95 & 1.63 \\
\hline
\end{tabular}


Table 2. Cont.

\begin{tabular}{cccccc}
\hline \multicolumn{5}{c}{ B/Spearman Rank Correlation between Season t and Season t - 1 Rankings } \\
\hline Season t & French L1 & English EPL & Italian LC & Spanish LF & German BL \\
\hline $1996 / 1997$ & 0.50 & 0.63 & n.d. & 0.55 & $\mathbf{0 . 3 4}$ \\
$1997 / 1998$ & 0.46 & 0.43 & 0.65 & 0.61 & $\mathbf{0 . 3 9}$ \\
$1998 / 1999$ & 0.49 & 0.71 & 0.53 & 0.71 & $\mathbf{0 . 3 7}$ \\
$1999 / 2000$ & $\mathbf{0 . 2 4}$ & 0.83 & 0.81 & 0.59 & 0.70 \\
$2000 / 2001$ & $\mathbf{0 . 0 0}$ & 0.88 & 0.85 & 0.65 & 0.25 \\
$2001 / 2002$ & $\mathbf{0 . 0 8}$ & 0.61 & 0.75 & 0.61 & 0.69 \\
$2002 / 2003$ & $\mathbf{0 . 2 8}$ & 0.63 & 0.62 & 0.55 & 0.53 \\
$2003 / 2004$ & 0.60 & $\mathbf{0 . 4 3}$ & 0.81 & 0.45 & 0.44 \\
$2004 / 2005$ & 0.68 & $\mathbf{0 . 4 5}$ & 0.64 & 0.59 & 0.61 \\
$2005 / 2006$ & 0.67 & 0.66 & $\mathbf{0 . 4 3}$ & 0.48 & 0.75 \\
$2006 / 2007$ & $\mathbf{0 . 4 8}$ & 0.66 & 0.52 & 0.58 & 0.72 \\
$2007 / 2008$ & $\mathbf{0 . 2 0}$ & 0.66 & 0.65 & 0.59 & 0.49 \\
$2008 / 2009$ & $\mathbf{0 . 2 3}$ & 0.70 & 0.80 & 0.87 & 0.65 \\
$2009 / 2010$ & 0.71 & 0.75 & 0.59 & 0.63 & $\mathbf{0 . 3 4}$ \\
$2010 / 2011$ & 0.33 & 0.87 & 0.46 & 0.60 & $\mathbf{0 . 0 9}$ \\
$2011 / 2012$ & 0.48 & 0.86 & 0.75 & 0.40 & $\mathbf{0 . 0 9}$ \\
$2012 / 2013$ & $\mathbf{0 . 4 0}$ & 0.77 & 0.75 & 0.52 & 0.58 \\
$2013 / 2014$ & 0.59 & 0.56 & 0.49 & 0.49 & $\mathbf{0 . 3 4}$ \\
$2014 / 2015$ & 0.57 & 0.83 & $\mathbf{0 . 4 7}$ & 0.86 & 0.80 \\
$2015 / 2016$ & 0.66 & 0.57 & 0.59 & 0.71 & $\mathbf{0 . 4 3}$ \\
$2016 / 2017$ & 0.43 & 0.53 & 0.61 & 0.78 & $\mathbf{0 . 2 1}$ \\
$2017 / 2018$ & 0.75 & 0.53 & 0.92 & 0.48 & $\mathbf{0 . 4 0}$ \\
\hline Mean 1996/2017 & $\mathbf{0 . 4 5}$ & $\mathbf{0 . 6 6}$ & $\mathbf{0 . 6 5}$ & $\mathbf{0 . 5 8}$ & $\mathbf{0 . 5 1}$ \\
\hline
\end{tabular}

In bold (except the mean value): the lowest value of the rank correlation coefficient in a year; Source: calculated from the leagues' rankings.

The long-term competitive balance can be measured by a Spearman rank correlation between one year's final ranking and the previous year's ranking in the championship, which is written as:

$$
r_{s}=1-\frac{6 \sum_{i} d_{i}{ }^{2}}{n\left(n^{2}-1\right)} .
$$

The closer is this index to zero, the less two consecutive championships in the same league exhibit a correlated ranking, and the more the competition is balanced. The other way round, $r_{s}=1$ would mean that the same ranking is observed in a season $t$ and the past season $t-1$, i.e., the competition is absolutely imbalanced. Therefore, one can exactly predict the $t$ ranking when one knows the $t-1$ ranking; the championship result is entirely predictable, and there is no outcome uncertainty.

As Table 2 shows, FL1 performs even better in terms of long-term competitive balance, in particular from 1999 to 2002 and from 2006 to 2008, but also on average over all the observed period. Until 2008, on average, FL1 definitely was the least imbalanced among the Big Five leagues. In the following seasons, in particular after 2013, the competitive imbalance was fuelled by Paris Saint-Germain's and Monaco's recruitment strategy, which was geared toward attracting superstars. Since then, the German Bundesliga has become the most balanced league every year in the long run, except for 2012 and 2014. This confirms again that those clubs that belong to a more balanced league do not perform the best in European competitions, even if German clubs are ahead of French ones in this regard (Table 1).

The most imbalanced among the Big Five are, on average, the English Premier League and the Italian Serie A, followed by the Spanish La Liga (which is the only league among the five that has never been the most balanced in a year), i.e., the best three performing leagues in terms of winning European competitions. Since 2009, and despite the enforcement of the UEFA FFP after 2012, two trends have emerged: (a) the competitive balance in the Big Five leagues has deteriorated on average except for the Bundesliga; and (b) the English and Spanish leagues are becoming increasingly imbalanced, with a 2009-2017 Spearman correlation mean ( 0.70 and 0.61 , respectively) that is higher than their overall long-term average over 1996-2017. 
One can conclude that the more a league is balanced, the less strong are its top clubs compared to lower-ranked clubs, and the weaker they are in European competitions. As put by Sloane (2006, p. 221) "The most successful national teams gain entry into European club competitions and it may be necessary to be 'too strong' in terms of domestic competitions to compete successfully in Europe". It was found (Andreff and Bourg 2006) that FL1's most balanced championship eventually was a handicap for the top French clubs, whereas a worse domestic competitive balance seemed to be a good precondition or even a required launch pad in the English, Italian, and Spanish leagues for achieving the best sport performances in European competitions. The FL1 is still a typical case in point, all the more so because it is the poorest of the Big Five leagues in terms of average stadium attendance-that eventually translates also into the lowest TV rights revenues-and annual league revenue (Table 3). Even in 2017, the FL1 was still lagging behind the Italian Serie A in terms of attendance and revenue, and far behind the three other Big Five European soccer leagues. Conclusion: a more balanced domestic competition in a lower revenue league is not a springboard for its clubs toward high performance in European football contests.

Table 3. The average attendance per match and annual revenue, Big Five 1997-2017.

\begin{tabular}{|c|c|c|c|c|c|c|c|c|c|c|}
\hline \multirow{3}{*}{$\begin{array}{c}\text { Big Five } \\
\text { Leagues } \\
\text { Season }\end{array}$} & \multicolumn{5}{|c|}{ Average Attendance } & \multicolumn{5}{|c|}{ Annual Revenue } \\
\hline & \multicolumn{5}{|c|}{ (in Thousands) } & \multicolumn{5}{|c|}{ (in Million Euros) } \\
\hline & GBL & EPL & SLL & ISA & FL1 & GBL & EPL & SLL & ISA & FL1 \\
\hline 1996-1997 & 30.9 & 28.4 & 24.2 & 29.5 & 14.2 & 444 & 689 & 524 & 551 & 293 \\
\hline 1998-1999 & 30.9 & 30.6 & 22.4 & 30.7 & 19.8 & 577 & 995 & 612 & 714 & 393 \\
\hline 1999-2000 & 28.9 & 30.7 & 23.1 & 29.7 & 21.6 & 681 & 1147 & 722 & 1059 & 607 \\
\hline 2000-2001 & 28.4 & 32.8 & 21.4 & 29.1 & 22.6 & 880 & 1392 & 676 & 1151 & 644 \\
\hline 2001-2002 & 31.1 & 34.3 & 23.2 & 25.9 & 21.4 & 1043 & 1682 & 776 & 1127 & 643 \\
\hline 2002-2003 & 31.9 & 35.4 & 25.0 & 25.5 & 19.6 & 1108 & 1851 & 847 & 1162 & 689 \\
\hline 2003-2004 & 35.0 & 35.0 & 25.2 & 25.7 & 20.1 & 1058 & 1970 & 953 & 1153 & 655 \\
\hline 2004-2005 & 35.2 & 33.9 & 24.6 & 25.0 & 21.3 & 1236 & 1975 & 1029 & 1219 & 696 \\
\hline 2005-2006 & 38.2 & 33.9 & 25.7 & 21.4 & 21.5 & 1195 & 1995 & 1158 & 1277 & 910 \\
\hline 2006-2007 & 37.6 & 34.4 & 25.7 & 18.9 & 21.8 & 1379 & 2273 & 1326 & 1064 & 972 \\
\hline 2007-2008 & 39.0 & 36.1 & 25.3 & 23.1 & 21.8 & 1438 & 2441 & 1438 & 1421 & 989 \\
\hline 2008-2009 & 41.9 & 35.7 & 24.6 & 24.7 & 21.1 & 1575 & 2326 & 1501 & 1494 & 1048 \\
\hline 2009-2010 & 41.8 & 34.2 & 25.3 & 24.1 & 20.1 & 1664 & 2479 & 1644 & 1532 & 1072 \\
\hline 2010-2011 & 42.1 & 35.4 & 25.9 & 23.5 & 19.7 & 1746 & 2517 & 1719 & 1553 & 1040 \\
\hline 2011-2012 & 44.3 & 34.6 & 26.1 & 22.0 & 18.9 & 1872 & 2917 & 1782 & 1585 & 1136 \\
\hline 2012-2013 & 41.9 & 35.9 & 25.5 & 22.6 & 19.2 & 2018 & 2946 & 1868 & 1677 & 1297 \\
\hline 2013-2014 & 42.6 & 36.7 & 25.3 & 23.0 & 21.1 & 2275 & 3897 & 1933 & 1699 & 1498 \\
\hline 2014-2015 & 42.7 & 36.2 & 25.7 & 21.6 & 22.3 & 2392 & 4400 & 2053 & 1792 & 1418 \\
\hline 2015-2016 & 42.4 & 36.5 & 27.6 & 21.7 & 20.9 & 2712 & 4865 & 2437 & 1917 & 1485 \\
\hline 2016-2017 & 40.7 & 35.8 & 27.6 & 21.3 & 21.1 & 2793 & 5297 & 2854 & 2075 & 1643 \\
\hline
\end{tabular}

EPL, English Premier League; FL1, French Ligue 1; GBL, German Bundesliga; ISA, Italian Serie A; SLL, Spanish La Liga. Source: Deloitte (1998-2018).

Finally, compared to the other Big Five leagues, although the FL1 was the most-balanced league, it did not perform exceptionally well in European competitions, and did not attract large crowds to the stadia and large revenues to the clubs' budgets. Two questions emerge in the background: in current European football, are uncertainty of outcome (Rottenberg 1956) and competitive balance (Groot 2008) still strong factors of fan attractiveness, as has been assumed for decades about team sports leagues in standard sports economics? Is the described FL1 situation an acceptable price that is worthwhile paying to impose stringent club management and potential sanctions when a club does not stick to the DNCG rules and recommendations?

\section{Financial Deficits and Debts}

Lower sporting performance and lower revenue unfortunately did not translate into significantly lower wages and payrolls in top French football. Defining the gross payroll or gross wage cost of a football club as the sum of salaries and associated social contributions, the ratio between these 
expenditures and total revenue signals the pressure of labour (players' talent) costs on a club's management. In 1997, 1998, 2007, and 2008, this ratio was the highest in the FL1 among the Big Five leagues; in the other years, the FL1 often showed the second highest payroll to revenue ratio-usually over $60 \%$-behind the Italian Serie A, which is anything but an exemplary benchmark of good financial league management (Table 4).

Table 4. The ratio between gross payroll * (wage cost) and total revenue, Big Five 1997-2007.

\begin{tabular}{cccccc}
\hline Season & GBL & EPL & SLL & ISA & FL1 \\
\hline $1996-1997$ & 50 & 48 & 44 & 58 & 61 \\
$1997-1998$ & 54 & 52 & 53 & 64 & 69 \\
$1998-1999$ & 55 & 58 & 56 & 72 & 69 \\
$1999-2000$ & 56 & 62 & 54 & 62 & 53 \\
$2000-2001$ & 54 & 60 & 73 & 75 & 64 \\
$2001-2002$ & 53 & 62 & 72 & 90 & 69 \\
$2002-2003$ & 50 & 61 & 72 & 76 & 68 \\
$2003-2004$ & 55 & 61 & 64 & 73 & 69 \\
$2004-2005$ & 47 & 59 & 64 & 62 & 63 \\
$2005-2006$ & 51 & 62 & 64 & 58 & 59 \\
$2006-2007$ & 45 & 63 & 62 & 62 & 64 \\
$2007-2008$ & 50 & 62 & 63 & 68 & 71 \\
$2008-2009$ & 51 & 67 & 63 & 73 & 69 \\
$2009-2010$ & 54 & 69 & 59 & 77 & 73 \\
$2010-2011$ & 53 & 70 & 60 & 75 & 75 \\
$2011-2012$ & 51 & 70 & 59 & 74 & 74 \\
$2012-2013$ & 51 & 71 & 57 & 71 & 66 \\
$2013-2014$ & 49 & 58 & 63 & 71 & 64 \\
$2014-2015$ & 52 & 61 & 62 & 72 & 67 \\
$2015-2016$ & 49 & 63 & 61 & 70 & 69 \\
$2016-2017$ & 53 & 55 & 59 & 67 & 66 \\
\hline \multicolumn{5}{c}{ Source: Deloitte (1998-2018). } &
\end{tabular}

The common explanation for such a high weight of wages in the clubs' and league's budgets is, in an open league system, an arms race between clubs to acquire the best talents (Andreff 2012), which ends up in an excess of investment into players (Dietl et al. 2008). Clubs overbid each other for the best players and pay both high wages and skyrocketing transfer fees so that the arms race continuously fuels wage and fee inflation. More specifically, in the FL1 case, it was found that, in order to cover the cost of the arms race and the subsequent overinvestment in the payroll, the French league was able to ex post negotiate increasing TV rights revenues with TV channels in a kind of vicious circle between payroll inflation and TV rights inflation (Andreff 2007a). What is the consequence of such a strategy on the FL1's operating profit or loss?

First, it must be considered that, in the long run, the FL1 is a net exporting league as regards trade in players' talent. A priori, a trade surplus in player transfers could compensate, or more, for a league operating deficit. In some periods since 1997 (2000-2002, 2009, 2012-2013, 2016), the French league was a net importer of players for an overall amount of $€ 502.7$ million; all other years, it was a net exporter with a cumulative $€ 692.4$ million trade surplus (Table 5). At the end of the day, player transfer activity helped the FL1 come closer to balancing its current accounts thanks to a $€ 189.7$ million surplus over 20 seasons. However, this was not enough to guarantee that, every year, the league would break even or make an operating profit. 
Table 5. The French league's operating profit/loss and transfer fee balance, 1997-2007.

\begin{tabular}{ccc}
\hline & (Million $\boldsymbol{\emptyset})$ & \\
\hline Season & Operating & Transfer \\
\hline & Profit/Loss & Fee Balance \\
\hline $1996-1997$ & -7.0 & 25.1 \\
$1997-1998$ & -46.0 & 51.1 \\
$1999-1999$ & -70.0 & 65.9 \\
$2000-2000$ & 36.0 & 8.1 \\
$2001-2002$ & -41.0 & -19.3 \\
$2002-2003$ & -98.0 & -68.1 \\
$2003-2004$ & -61.0 & -100.2 \\
$2004-2005$ & -102.0 & 17.9 \\
$2005-2006$ & -15.0 & 3.0 \\
$2006-2007$ & 37.0 & 14.7 \\
$2007-2008$ & 23.0 & 31.7 \\
$2008-2009$ & -84.0 & 58.8 \\
$2009-2010$ & -64.0 & 41.9 \\
$2010-2011$ & -102.0 & -91.7 \\
$2011-2012$ & -97.0 & 73.4 \\
$2012-2013$ & -67.0 & 38.9 \\
$2013-2014$ & -3.0 & -26.8 \\
2014-2015 & -208.1 & -184.5 \\
$2015-2016$ & -57.3 & 114.7 \\
$2016-2017$ & 42.6 & 147.2 \\
Source: Direction Nationale du Contrôle de Gestion (DNCG 1998-2018). & -12.1 \\
\end{tabular}

For 17 years out of 20, the entire league was in the red, which means that the losses of those clubs in deficit were higher than the profits of those in the black despite the recurrent DNCG control and watchword for balancing expenditures with actual revenues. Recurrent deficits are quite common in open European football leagues. For instance, in 2012, right before the enforcement of the UEFA FFP, $63 \%$ of the 733 top division clubs in European football were in the red with an aggregate loss of $€ 1675$ million. French clubs, whatever their good or bad management and the role of the DNCG, were not able to escape this consequence of the arms race for talent on their current accounts.

Moreover, even though it has been assessed that the UEFA FFP regulation started to have an effect after 2012-2013, namely as presented in the UEFA benchmarking reports, this conclusion is not crystal clear in the case of the FL1. Indeed, its 2012-2013 deficits ( $€ 3$ million) were the lowest since the two profitable years 2006 and 2007. As early as 2013-2014, the FL1 exhibited its highest deficit ever reached. Over the next three years, the 2015-2016 operating profit did not compensate for the operating losses that were cumulated in 2014-2015 and 2016-2017. Thus, the UEFA FFP has not yet mopped up the recurrent deficits in the top French football league.

One problem with player transfers in European football is that often they are not entirely paid right at the moment when the player moves from club A to club B. Therefore, such a delayed payment creates in club A's balance sheet a specific debt that is coined the 'player transfer overdue' or a payment arrear. The payment arrear does not appear per se in Table 6, but the player transfer overdue represented $14 \%$ of all payment arrears in $2005-2006,10 \%$ in 2006-2007, $18 \%$ in 2007-2008, and, though they have been subject to more control since the enforcement of the UEFA FFP, these specific arrears were still up to $13 \%$ of the overall payment arrears in 2013-2014, 9\% in 2014-2015, and $11 \%$ in $2015-2016$ and 2016-2017. 
Table 6. The Ligue 1 balance sheet: liabilities, 2000-2017 (million $€$ ).

\begin{tabular}{cccccccc}
\hline Season & Net & Shareholders & Provisions & Financial & Payment & Total & Arrears/Total \\
\hline & Equity & Accounts & Risks & Debts & Arrears * & Liabilities & Debts (\%) \\
\hline $1999-2000$ & 89.3 & 163.5 & 123.0 & 64.5 & 362.9 & 803.2 & 84.9 \\
$2000-2001$ & 84.0 & 223.1 & 101.0 & 96.3 & 424.9 & 929.3 & 81.5 \\
$2001-2002$ & 142.8 & 141.7 & 59.6 & 86.1 & 416.9 & 847.2 & 82.9 \\
$2002-2003$ & 93.2 & 119.9 & 49.9 & 112.7 & 344.8 & 720.5 & 75.4 \\
$2003-2004$ & 139.4 & 60.1 & 37.3 & 66.1 & 298.1 & 601.0 & 81.9 \\
$2004-2005$ & 111.7 & 53.1 & 37.5 & 63.0 & 403.4 & 668.7 & 86.5 \\
$2005-2006$ & 159.6 & 75.2 & 52.5 & 70.4 & 461.6 & 819.3 & 86.8 \\
$2006-2007$ & 208.6 & 51.2 & 54.0 & 71.3 & 507.7 & 892.8 & 87.7 \\
$2007-2008$ & 213.4 & 61.8 & 34.6 & 62.4 & 627.6 & 999.7 & 91.0 \\
$2008-2009$ & 265.6 & 56.6 & 32.7 & 60.2 & 532.6 & 947.7 & 89.8 \\
$2009-2010$ & 189.0 & 104.9 & 25.4 & 94.2 & 515.7 & 929.3 & 84.6 \\
$2010-2011$ & 183.7 & 100.9 & 29.0 & 87.2 & 524.3 & 925.1 & 85.7 \\
$2011-2012$ & 143.2 & 214.6 & 24.6 & 105.2 & 392.8 & 1007.8 & 78.9 \\
$2012-2013$ & 167.5 & 83.5 & 32.1 & 105.0 & 597.6 & 1112.6 & 85.1 \\
$2013-2014$ & 225.3 & 243.8 & 39.9 & 194.3 & 806.4 & 1509.8 & 80.6 \\
$2014-2015$ & 286.4 & 412.3 & 42.5 & 297.4 & 814.5 & 1853.2 & 73.3 \\
$2015-2016$ & 291.2 & 449.8 & 51.9 & 460.2 & 718.0 & 1971.1 & 60.9 \\
$2016-2017$ & 346.0 & 573.0 & 62.1 & 386.5 & 735.8 & 2103.4 & 65.6 \\
\hline
\end{tabular}

* Payment arrears, tax arrears, and social contribution arrears. Source: DNCG (1998-2018).

Notice that other payment arrears aggregate in the league's balance sheet different commercial payment arrears, tax arrears, and social contribution arrears. Until 2011, they were about half of the total liabilities of FL1 clubs and the most important share, compared to financial debts (owed to banks and other credit institutions), of the clubs' debt: usually over $80 \%$ of total debts (Table 6). Whatever the assessment about the stringency or the latitudinarianism of DNCG auditing over French professional football clubs, recurrent, and rather large, payment arrears are not a signal that clubs are as well-managed as is often advertised by some French football supporters and decision-makers. Such evidence calls for a more theoretical approach (Section 5 below) of the so-called soft budget constraint in French and European football leagues and clubs.

\section{Payment Arrears and Payment Failure: A French Football Club Would Never Die!}

As early as 1974, the supervision of French professional football clubs' management had been entrusted to a body that became the DNCG in 1990. Since then, the DNCG has acted as a real auditing body, capable of implementing disciplinary sanctions against poorly managed clubs. Every season, the DNCG inspects the financial accounts of all clubs, and, since 2002, clubs' financial data are openly published. The DNCG's main official tasks are to audit clubs' financial accounts, supervise their bookkeeping, detect instances of misreporting, and assess the clubs' financial situation.

When a club is continually in the red, the DNCG can use carrot-and-stick tactics to encourage changes in management practice, so that the club's accounts return to the black. The process begins with warnings, advice, and recommendations with regard to urgent policy measures to be taken by the club's management. If the financial deficit does not disappear, sanctions can be applied: the DNCG is allowed to audit the payroll in detail, to prohibit the recruitment of new players for a certain period, to impose fines, and, as a last resort, to relegate the club to a lower division. Several clubs have been relegated since 1990 under this provision. The objective is to ensure the financial viability of the French championship in the sense that any club that starts the competition must be able to complete its fixture list over the entire season. The DNCG guarantees that each club will have sufficient financial resources throughout the season. However, the FL1 has experimented with more years in the red than in the black, although the deficits and debts were smaller than in the English, Italian, and Spanish leagues. The auditing body has prevented French clubs from sinking as deeply into indebtedness as some Italian, Spanish, and English clubs. 
It may seem strange that, on the one hand, French football has a strong auditing body, while on the other hand the FL1 repeatedly reports financial deficits. This paradox can be explained by a so-called soft budget constraint (Section 5 below). Questions have also been raised as to whether the DNCG is an independent auditor. All of its members are appointed from football backgrounds, such as the French Football Federation (FFF), the Ligue du Football Professionnel (LFP), and football players', coaches', and managers' unions.

As regards club debts, since 1999 the enforcement of the European competition policy has restricted the possibility of providing direct municipal subsidies to professional football clubs, in particular for bailing them out. Nevertheless, in contrast to most other industries, in European football a company (club) that is in the red will always find a way to be rescued, for instance through exceptional public subsidisation as during the Italian Calcio crisis in the mid-2000s, or with Catalan banks granting credits to FC Barcelona and Castillan banks to Real Madrid (Ascari and Gagnepain 2007), or by some sugar daddy, such as Abramovich in Chelsea, sheikh Mansur in Manchester City, Qatar Sports Investment in Paris-Saint-Germain, and Rybolovlev in Monaco. Leaving payment arrears to accumulate is another option for indirectly rescuing professional football clubs, if not bailing them out, a solution that was for many years privileged in the FL1.

Consequently, heavily indebted clubs — that would have been going bankrupt in another industry-are used to survive in French as well as European football. Storm and Nielsen (2012) underlined that a number of European professional football clubs chronically operated on the brink of insolvency for over a decade or so without going out of the business. For example, most Spanish clubs were operating at loss without ending in bankruptcies (Barajas and Rodriguez 2010). Despite recurrent losses, deficits, and debts, the clubs' survival rate is very high in English football (Kuper and Szymanski 2009). Even from 1893 to 1935, 22 English football clubs were liquidated, including well-known teams, such as Manchester United, Arsenal, and Aston Villa; most of them reappeared with the same or a different name, and only three definitely disappeared for ever, i.e., were actually liquidated.

In French football, and under French law, any debtor unable to meet its obligations is liable to enter a collective insolvency proceeding (Bayle 2009). More precisely, payment failure situations that trigger a legal response, which are defined as situations where current liabilities are greater than disposable assets, ${ }^{1}$ have been studied for the top two professional divisions (Ligue 1 and Ligue 2) from the 1970-71 to the 2013-14 seasons, and for the third basically amateur division (National 1) from 1993-94 to 2013-14 (Scelles et al. 2018). Seventy-nine cases of payment failure were found, of which only seven were from clubs in Ligue 1 despite many FL1 clubs having been in the red over the observed period. This again calls for an analysis of lax management fuelled by the soft budget constraint of FL1 clubs that are capable of attracting bailing out funds from banks, sugar daddies, other financiers, or, more simply, football regulation authorities that allow payment arrears to grow instead of calling for payment failure, liquidation, or bankruptcy.

The biggest share of payment failures is concentrated in Ligue 2, where smaller clubs (with lower revenue) are less able to attract bail-outs or new benefactors (Table 7). In fact, among the 25 professional and amateur clubs (in the top seven divisions) that have actually been liquidated ${ }^{2}$ between 1978 and 2017, only one really vanished: Calais, which was liquidated in 2017, has not (yet?) re-created an amateur team of adult football (Arrondel and Duhautois 2018). Arrondel and Duhautois paradoxically contend that professional football clubs are 'too small to fail' companies; even more so as regards amateur clubs.

1 Thus, a payment failure situation is different from what is usually defined as insolvency, i.e., when total liabilities are greater than total assets.

2 Only three of them are professional clubs that were, respectively, liquidated in 1991 (Reims, Ligue 2), 1993 (Tours, Ligue 2), and 2011 (Strasbourg, Ligue 1). In 2018-2019, they, respectively, played in Ligue 1 (Reims and Strasbourg) and Ligue 2 (Tours). 
Table 7. The number of payment failures in French football, 1970-2014.

\begin{tabular}{ccccc}
\hline Period & Ligue 1 & Ligue 2 & National 1 & Total \\
\hline $1970-1981$ & 2 & 8 & 0 & 10 \\
$1981-1992$ & 2 & 27 & 0 & 29 \\
$1992-2003$ & 2 & 6 & 16 & 24 \\
$2003-2014$ & 1 & 3 & 12 & 16 \\
Entire period & 7 & 44 & 28 & 79 \\
\hline
\end{tabular}

Source: Scelles et al. (2018).

Scelles et al. (2018) were not able to find a clear-cut relationship between pre-failure average stadium attendances that were assumed to be declining — thus match day revenues were decreasing as well —and the occurrence of payment failures. Such a result is consistent with the view that failures are probably more linked to lax club management-a soft budget constraint in more theoretical terms-than to a demand shock, as was contended by Szymanski (2012) in the case of English soccer.

\section{The Soft Budget Constraint's Influence on the Players' Labour Market}

The standard equilibrium model of North American closed team sports leagues (Fort and Quirk 1995) has been adapted to open leagues by Késenne (1996) under the following assumptions: (a) teams are win-maximisers; (b) therefore, they recruit as much talent as possible within their budget constraints and break-even; (c) talent is measured in units such that an additional unit of talent increases the win percent by one unit; under this convention, $\frac{\partial w_{i}}{\partial t_{i}}=1$, which allows for the substitution of the win percent $w_{i}$ of team $i$ by the quantity of recruited talent $t_{i}$ in its revenue function $R_{i}$; and (d) in a now globalised labour market that is triggered by the Bosman jurisprudence that rules open leagues, the free entry of players makes irrelevant the assumption of a fixed supply of talent (Késenne 2017). Teams are wage-takers in this market so that team $i$ :

$$
\begin{gathered}
\operatorname{Max}_{i} \\
R_{i}\left(m_{i}, t_{i}\right)-s . t_{i}-c_{i}^{0}=0
\end{gathered}
$$

where $m_{i}$ stands for team $i^{\prime}$ s market size, $s$ for the market equilibrium wage, and $c_{i}{ }^{0}$ for team $i^{\prime}$ s fixed cost.

Obviously, constraint Equation (4) is not satisfied in the European and French football leagues, since, recurrently, a number of clubs are in the red. It must be replaced by:

$$
R_{i}\left(m_{i}, t_{i}\right)-s . t_{i}-c_{i}^{0} \leq 0 .
$$

However, such a constraint substitution has both theoretical and modelling implications. First, Equation (5) means that some teams recurrently or permanently are not able to break even; thus, they are in the red without going bankrupt or being liquidated. This was a regular characteristic of state-owned enterprises in former communist centrally planned economies. Firms or other entities that were recurrently losing money without their activity being phased out were enjoying a so-called soft budget constraint in communist shortage economies (Kornaï 1980); a similar situation may theoretically and empirically prevail in some sectors of a market economy as well (Kornaï et al. 2003). When firms are run with a soft budget constraint, they form an excess demand for inputs that is coined a "Kornaï effect"; the Kornaï effect has been tested successfully (Goldfeld and Quandt 1988, 1993). When all or most enterprises do not break even, the whole economy is all the time in a typical disequilibrium of global excess demand of inputs, which is coined a 'shortage economy'.

When applied to a football league (Andreff 2007b, 2014b), the same theoretical story says: clubs that are run with a soft budget constraint recurrently develop an excess demand for their major input, i.e., players' talent. In practical terms, they overbid for talent on the players' labour market and engage 
in an arms race for inputs that are in short supply, in particular superstar players. Consequently, the players' market is in a permanent state of excess demand.

If several or most football clubs are managed with a soft budget constraint, the modelling consequences are as follows. Clubs Max $t_{i}$ under constraint Equation (5). Without a hard or balanced budget constraint (break-even point), there is no brake on an ever-growing demand for talent, while the number of players that are talented enough to play in professional football leagues is limited, say to $T_{0}$. The labour market for talents is in disequilibrium due to a team's aggregated excess demand in the face of a limited supply of player talents to the league $T_{0}$ :

$$
\sum_{i=1}^{n} t_{i}=T ; T \geq T_{0}
$$

where the number of teams in the league is $n(i=1, \ldots, n)$.

With an excess demand for talents, the marginal revenue productivity of labour $R M_{i}=\frac{\partial R_{i}\left(m_{i}, t_{i}\right)}{\partial t_{i}}$ cannot equalise the marginal unit cost of labour when the last unit of the $T_{0}$ talents is recruited, and the disequilibrium in the labour market for talents implies:

$$
R M_{i}=\frac{\partial R_{i}\left(m_{i}, t_{i}\right)}{\partial t_{i}} \leq s .
$$

All of the labour units, up to the last one recruited, are overpaid when excess demand prevails in the players' market. Due to their aggregate overall excess demand, teams are rationed by a short supply of talents and are eager to pay a salary that is much higher than the marginal labour productivity of talent, that is, to overpay players in order to attract them in a context of relative player shortage and harsh competition across the teams on the demand side of the labour market. ${ }^{3}$ Then, recruited players provide a lower labour productivity than the equilibrium salary they are paid for, which sounds like the exact opposite of Scully's sense of player exploitation (Scully 1974).

In European football leagues with win-maximising teams that operate under a soft budget constraint, players are paid more than they would have been at an equilibrium wage. Since all teams have embarked on an arms race to recruit players, namely, the few available superstars, they accept paying a wage that is quite higher than the marginal revenue productivity of labour ${ }^{4}$ in order to outbid competing teams: a fact that is evidenced in all European leagues after the Bosman case. At the end of the day, teams are cursed into paying too many wages for the marginal labour productivity they obtain from players (Andreff 2014b). Paying more than the equilibrium wage and recruiting less than the quantity of talents they demand, rationed teams are involved in an endless skyrocketing race of payroll and transfer fee increases, which is observed in European football as regards superstars' recruitment.

Another implication of excess demand in the labour market for player talents is that football teams with soft budget constraints attempt to recruit too many players, although they cannot afford as many as they would have wished due to the short supply of superstars. Teams spend their money without counting and accept making losses—and sometimes they cook the books to hide this reality-due to soft budget constraints. Moreover, when operating on the demand side of an excess demand input market, teams are always scared of being short of inputs without being certain that they will find one more superstar in the market due to inequality Equation (6). Thus, in reaction,

3 When a market is in disequilibrium, one side (for instance, supply) of the market is shorter than the other one (demand); therefore, excess demand. In an excess demand market, aggregating all the microeconomic demands (of all teams) results in a bigger quantity of talents than the aggregated quantity that is supplied by suppliers (all players). Usually, those economic agents on the shorter side of a market have stronger bargaining power than those on the longer side; they successfully negotiate and bargain on their own terms - for prices and transaction conditions-and obtain a better payoff for what they deliver to the market. Those agents on the longer side of the market have to adjust, reduce their demand (when there is excess demand), and accept forced substitutions.

4 And skyrocketing transfer fees as well. 
teams hoard labour (in large rosters) to circumvent the consequences of operating on a short supply input market. In European football, the very existence of a reservation and transfer system, until the Bosman ruling in 1995, enabled teams to keep their players. After the Bosman case, teams recruited on their rosters more players than they really needed. ${ }^{5}$ Thus, there is some slack in each team; teams are overmanned. This slack is beneficial to players in terms of the relationship between wages and both working time (very few players play all $90 \mathrm{~min}$ of each game in a season)—that is, work intensity-and labour productivity.

If one gives up the unrealistic and simplifying assumption of a homogeneous unit of talent that is adopted in the above standard model of team sports leagues, one has to introduce a qualitative differentiation between the most talented superstars and less talented journeymen players. It was assumed above that the supply of player talents is limited. Is this as likely to be true for journeymen players as for superstars? Obviously not, since one can witness in all top European football leagues a number of journeymen players who are unemployed at the start of every season. ${ }^{6}$ Unemployment is a crucial index of excess supply. Such an observation apparently contradicts inequality Equation (6). Therefore, for the journeymen player segment of the labour market, excess supply is to be modelled instead of excess demand on a superstar segment.

The next point to consider is whether teams' excess demand for superstars in one market segment is compensated by an excess supply of journeymen players in the other market segment. It is assumed here that there is not full compensation: excess demand for superstars exceeds excess supply of journeymen players, and inequality Equation (6) still remains relevant for the players' market overall.

Let $T_{s}$ stand for the overall number of available superstars and $T_{a}$ the overall number of available journeymen players. It follows that:

$$
T_{s}+T_{a}=T_{0}
$$

Now, a team has to maximise an assortment of superstar and journeymen player talents in order to maximise its wins Equation (9), and its soft budget constraint is to be rewritten in such a way as to take this assortment into account Equation (10). Below, $t_{s i}$ is defined as the demand for superstars by team $i, t_{a i}$ the demand for journeymen players by team $i, s_{s}$ the market wage for superstars, and $s_{a}$ the market wage for journeymen players. Thus, for team $i$ :

$$
\operatorname{Max}\left(t_{s i}+t_{a i}\right)
$$

Under a soft budget constraint, such as:

$$
R_{i}\left(m_{i}, t_{s i}+t_{a i}\right)-s_{s} \cdot t_{s i}-s_{a} \cdot t_{a i} \leq 0
$$

And

$$
\sum_{i=1}^{n}\left(t_{s i}+t_{a i}\right) \geq T_{0}
$$

If, as is assumed, the excess demand for superstars more than compensates for the excess supply for journeymen players, the labour market disequilibrium in the superstar segment becomes:

$$
\sum_{i=1}^{n} t_{s i} \geq T_{s}
$$

5 Since a soft budget constraint leads to labour hoarding within the enterprise (team) - thus hedging against the expected future labour market shortage-all European football teams are eager to recruit as many players as possible, including disposing of a great number of potential substitutes to seat on the touch-bench. This is also a means to deprive competing teams of talents.

6 Some of them, often not accounted for as unemployed, simply revise downwards the terms of their supply of talent and spill over their labour supply to a lower division team or a weaker foreign league. Supply (and demand) revision by spilling over from one market to another is a basic effect that results from rationing schemes and quantitative adjustment processes in disequilibrium models. 
In the superstar segment of the market, excess demand coincides with a wage that is higher than the marginal revenue productivity of labour:

$$
R M_{s i}=\frac{\partial R_{i}\left(m_{i}, t_{s i}\right)}{\partial t_{i}} \leq s_{s} .
$$

Superstars are not directly competing against each other, with every superstar being in a monopoly position over his/her practically non-substitutable specific talent. In the journeymen player segment of the market, the excess supply of talents Equation (14) drives the market wage down until it is lower than the marginal revenue productivity of labour Equation (15) for these lower quality and higher-competing talents:

$$
\begin{gathered}
\sum_{i=1}^{n} t_{a i} \leq T_{a} \\
R M_{a i}=\frac{\partial R_{i}\left(m_{i}, t_{a i}\right)}{\partial t_{i}} \geq s_{a} .
\end{gathered}
$$

Inequality Equation (15) shows that journeymen players are subject to exploitation in Scully's sense; they are paid less than their marginal productivity. They suffer from being in excess supply as well as from the monopsonistic situation of the league, which encompasses team owners that are more or less coordinated in the labour market; thus, journeymen players bear a rent that is levied by owners on their salaries. An opposite asymmetry prevails in the superstar segment, where the league's monopsony is countervailed by a strong monopoly situation of each superstar due to the uniqueness of his/her talents, skills, reputation, performances, record of achievements, and so on, and his/her absolute exclusivity over them. Thus, team owners have to overbid in terms of wage and transfer fee for recruiting Lionel Messi, Cristiano Ronaldo, and other superstars.

A disequilibrium model of a league with win-maximising teams operating under soft budget constraints in a segmented labour market describes an arms race for superstar talents that is fuelled by excess demand, superstars' skyrocketing wages that trigger teams' payroll overruns-and superstars' skyrocketing transfer fees - that deteriorate teams' financial balance, the unemployment of journeymen players that are in excess supply and are used as a safety valve or an adjustment variable by team owners, and their lower wages, which are paid at a rate below their marginal labour productivity. Consequently, both superstar wages and transfer fee inflation jeopardise clubs' financial stability, increase the risk of repeated deficits, and, in a kind of vicious circle, trigger lax management, which is possible due to a soft budget constraint that is fuelled by payment arrears (including overdue transfer fees), bail-outs, or another kind of subsidisation; in such a context, payment failure, and even more so bankruptcy, are more the exception than the rule.

The above model remains to be empirically tested. The paucity of data regarding clubs' payrolls and individual wages in all Big Five leagues cannot afford a straightforward testing of inequalities Equations (13) and (15). However, Bryson et al. (2014) have found a wage premium for migrant professional football players that partly reflects the superstar status of such players. Thus, observing the biggest transfers in European football can provide a first insight into the very existence of a superstar segment on the player transfer market with skyrocketing fees, which are probably accompanied by high wages.

Table 8 shows the aggregated value of transfer fees over 2014-2018 in the seven highest-spending clubs of the Big Five leagues. Most of them operate on the superstar segment of the market, and some of them have been implicated in transfers with fees in excess of $€ 50$ million (Neymar, M'Bappé, Pogba, etc.). Notice the large disparities across the leagues whose clubs drag the superstars: the English Premier League's top seven spending clubs have spent $70 \%$ more on transfer fees than the top seven spending clubs in La Liga and Serie A, and even 2.4 times and 3.2 times, respectively, the amount spent by the top seven clubs in the Bundesliga and Ligue 1. Expenditure disparities in the superstar transfer market, which generate financial gaps, are even deeper across the clubs than the leagues, with only FC 
Barcelona, Atletico Madrid, Real Madrid, Juventus, Inter Milan, AS Roma, and Paris Saint-Germain operating at a nearly comparable level of transfer expenditures as the top seven spending English clubs.

Table 8. The transfer fees for each of the Big Five's top seven spending clubs, 2014 to 2018.

\begin{tabular}{cccccc}
\hline English PL & Fees & Spanish LL & Fees & German BL & Fees \\
\hline Manchester City & 951.4 & FC Barcelona & 778.0 & Bayern Munich & 390.9 \\
Manchester United & 777.9 & Atletico Madrid & 479.6 & Borussia Dortmund & 368.7 \\
Chelsea & 749.2 & Real Madrid & 457.5 & Wolfsburg & 308.1 \\
Liverpool & 582.9 & Valencia & 308.5 & Bayer Leverkusen & 230.5 \\
Tottenham Hotspur & 446.5 & Sevilla & 253.0 & Leipzig & 191.0 \\
Arsenal & 420.6 & Villareal & 183.9 & Schalke 04 & 155.8 \\
Everton & 410.2 & Real Sociedad & 83.1 & Borussia Monchenglad & 134.2 \\
\hline Total & 4338.6 & Total & 2543.6 & Total & 1779.1 \\
\hline Italian SA & Fees & French L1 & Fees & & \\
Juventus & 592.7 & Paris Saint-Germain & 678.0 & & \\
Inter Milan & 432.7 & Olympique Marseille & 191.1 & & \\
AS Roma & 428.7 & Olympique Lyon & 139.2 & & \\
AC Milan & 368.5 & Lille OSC & 108.4 & & \\
Napoli & 344.3 & Rennes & 92.00 & & \\
Fiorentina & 186.5 & Saint-Etienne & 67.2 & & \\
Sampdoria & 167.8 & Bordeaux & 63.8 & &
\end{tabular}

A further empirical test would be to check whether the positive difference between the wage and the marginal revenue productivity of labour for superstar players is bigger in the English Premier League than in the Spanish La Liga and the Italian Serie A, and whether the difference in the Italian Serie A is bigger than in the German Bundesliga and the French Ligue 1. Analysing whether such differences are correlated with more or less stringent financial management in each league would open a new avenue for further research.

\section{Conclusions}

The empirical evidence that was gathered in this paper shows, in the case of French football Ligue 1, that financial performance has usually been presented by the league as a trade-off between sporting performance in European competitions and the league's finance, often detrimental to the first option, even though the actual financial performance of some French clubs is far from outstanding. The poor performance of French clubs in European competitions is worsened by the league having the best competitive balance among the Big Five European soccer leagues in the long run. This trend may be changing, though slightly, since the acquisition of Paris-Saint-Germain by Qatar Sports Investment, whose strategy of providing an abundance of money enables the club to recruit intensively with the explicit aim of winning a European competition. However, the UEFA's Financial Fair Play rules, in addition to the DNCG's financial audits, contain such a strategy within some definite limits. Clubs' accounting, deficits, payment arrears, player transfer overdue, and debts are now audited twice more in the French Ligue 1, once by the DNCG and then by the UEFA financial rules; however, some clubs are not yet able to curb payroll inflation and skyrocketing transfer fees. Nevertheless, clubs' budget constraints will remain soft as long as the threat of bankruptcy or definitive liquidation continues to be more a potential rather than a real practical perspective.

The novelty of the paper is to establish a link between the soft budget constraint and the players' labour market for talent where it crucially triggers an excess demand for players, in particular superstar players. Disequilibrium modelling of the labour market for talent has shown that the link with a club's finance is more complex than is usually analysed in theoretical mainstream (equilibrium) 
models of a team sports league. Overbidding to attract superstars, such as Neymar, Ronaldo, Messi, and M'Bappé, clubs consequently save on the other side of their payroll; that is, lower-paid journeymen players that are in excess supply on the labour market. Data paucity about players' individual wages hinders econometric testing of the aforementioned link and model so far, but a look at transfer fees, concentrating on a few of the top European soccer clubs, has provided a first insight into the arms race for talent that fuels excess demand for superstars and drives a number of clubs' finances into the red. Excess demand on the players' labour market will continue to be the price to pay for a persistent soft budget constraint with its fellow travelers payroll inflation and skyrocketing transfer fees.

There are two sides of the coin as regards policy implications. The first one is strictly financial, while the second one is about the belief that recruiting superstars is the only avenue to sporting success, recouping recruitment costs, and the subsequent club demand policy on the labour market for talent. The financial prerequisites of the UEFA's Financial Fair Play rules must be satisfied; otherwise, a club will be exposed to the threat of financial and sporting sanctions, including disqualification from participating to European competitions. With the French soccer league, a club will always be well advised to preliminary comply with the DNCG rules before passing the test of the UEFA rules, in particular if the DNCG rules will be stringently enforced. Subsequently, the number of French soccer clubs that do not break even should reduce and tend toward zero. However, this will neither make the payroll management easier nor the overbidding strategy on the labour market for talent viable.

The second set of implications is that those clubs that are overbidding for superstars must be aware that only a few of them (those winning the national championships or qualifying for European competitions) will be able to recoup their recruitment expenditures-transfer fees-and their subsequent superstar-inflated payrolls. Most of them are regularly doomed to be driven into a deficit after a poorer sporting performance than expected that does not accrue enough revenue to recoup recruitment expenditures. A number of French clubs have been cases in point, even Paris-Saint-Germain, in the past few years. Advising a less ambitious-often meaning less expensive-strategy on the labour market for talent in any case is sensible whatever the means. For example, the French rugby league has experimented with a salary cap since 2012, whereas soccer superstars playing in the French league are committed to paying an extra tax over $€ 1$ million revenue per month threshold (but, in fact, their clubs pay this tax instead). Overbidding, overbidding again, and repeatedly overbidding for superstar players is the easiest way for a club to attract the winner's curse in the labour market with its payment arrears, deficit, and debt.

Funding: This research received no external funding.

Conflicts of Interest: The author declares no conflict of interest.

\section{References}

Andreff, Wladimir. 2007a. Governance issues in French professional football. In Governance and Competition in Professional Sports Leagues. Edited by Jaume Garcia, Stefan Késenne and Placido Rodriguez. Oviedo: Ediciones de la Univeridad de Oviedo, pp. 55-86. ISBN 978-84-8317-667-2.

Andreff, Wladimir. 2007b. French football: A financial crisis rooted in weak governance. Journal of Sports Economics 8: 652-61. [CrossRef]

Andreff, Wladimir. 2012. Mondialisation économique du Sport. Manuel de référence en Economie du Sport. Bruxelles: De Boeck.

Andreff, Wladimir. 2014a. French professional football: how much different? In Handbook on the Economics of Professional Football. Edited by John Goddard and Peter Sloane. Cheltenham: Edward Elgar, pp. 298-321. ISBN 9781781003169.

Andreff, Wladimir. 2014b. Building blocks for a disequilibrium model of a European team sports league. International Journal of Sport Finance 9: 20-38. 
Andreff, Wladimir, and Jean-François Bourg. 2006. Broadcasting rights and competition in European football. In The Economics of Sport and the Media. Edited by Claude Jeanrenaud and Stefan Késenne. Cheltenham: Edward Elgar, pp. 37-70. ISBN 9781845427436.

Andreff, Wladimir, and Nicolas Scelles. 2017. Economic model of a professional football club in France. In Routledge Handbook of Football Marketing. Edited by Nicolas Chanavat, Michel Desbordes and Nicolas Lorgnier. London: Routledge, pp. 60-72. ISBN 9781138289321.

Andreff, Wladimir, and Paul Staudohar. 2000. The evolving European model of professional sports finance. Journal of Sports Economics 1: 257-76. [CrossRef]

Arrondel, Luc, and Richard Duhautois. 2018. L'argent du Football. Paris: Editions du CEPREMAP.

Ascari, Guido, and Philippe Gagnepain. 2007. Evaluating rent dissipation in the Spanish football industry. Journal of Sports Economics 8: 468-90. [CrossRef]

Barajas, Angel, and Placido Rodriguez. 2010. Spanish football clubs' finances: Crisis and player salaries. International Journal of Sport Finance 5: 52-66.

Bayle, Marcel. 2009. Description of French collective insolvency proceedings. In World Insolvency Systems: A Comparative Study. Edited by Otto Eduardo Fonseca Lobo. Toronto: Carswell, pp. 224-79. ISBN 9780 779822287.

Bryson, Alex, Giambattista G. Rossi, and Robert Simmons. 2014. The migrant wage premium in professional football: A superstar effect. Kyklos 67: 12-28. [CrossRef]

Deloitte. 1998-2018. Annual Review of Football Finance. Manchester: Sports Business Group.

Dietl, Helmut, Egon Franck, and Markus Lang. 2008. Overinvestment in team sports leagues: A contest theory model. Scottish Journal of Political Economy 55: 353-68. [CrossRef]

DNCG. 1998-2018. Rapport Financier du Football Professionnel Français. Paris: Direction Nationale du Contrôle de Gestion, Ligue de Football Professionnel.

Fort, Rodney D., and James Quirk. 1995. Cross-subsidization, incentives, and outcomes in professional team leagues. Journal of Economic Literature 33: 1265-99.

Goldfeld, Stephen M., and Richard E. Quandt. 1988. Budget constraints, bailouts and the firm under central planning. Journal of Comparative Economics 12: 502-20. [CrossRef]

Goldfeld, Stephen M., and Richard E. Quandt. 1993. Uncertainty, bailouts, and the Kornaï effect. Economics Letters 41: 113-19. [CrossRef]

Groot, Loek. 2008. Economics, Uncertainty and European Football: Trends in Competitive Balance. Cheltenham: Edward Elgar, ISBN 9781847205919.

Késenne, Stefan. 1996. League management in professional team sports with win maximising clubs. European Journal of Sport Management 2: 14-22.

Késenne, Stefan. 2017. The Economic Theory of Professional Team Sports: An Analytical Treatment, 2nd ed.Cheltenham: Edward Elgar, ISBN 9781781955383.

Kornaï, Janos. 1980. Economics of Shortage. Amsterdam: North Holland, ISBN 9780444860590.

Kornaï, Janos, Eric Maskin, and Gérard Roland. 2003. Understanding the soft budget constraint. Journal of Economic Literature 41: 1095-136. [CrossRef]

Kuper, Simon, and Stefan Szymanski. 2009. Why England Loses, Why Spain, Germany, and Brazil Win, and Why the U.S., Japan, Australia and Even, Iraq Are Destined to Become the Kings of the World's Most Popular Sport. London: Harper Collins. ISBN 9780007301119.

Rottenberg, Simon. 1956. The baseball players' labor market. Journal of Political Economy 54: 242-58. [CrossRef]

Scelles, Nicolas, Stefan Szymanski, and Nadine Dermit-Richard. 2018. Insolvency in French soccer: The case of payment failure. Journal of Sports Economics 19: 603-24. [CrossRef]

Scully, Gerald. 1974. Pay and performance in Major League Baseball. American Economic Review 64: 915-30.

Sloane, Peter J. 2006. Rottenberg and the economics of sport after 50 years. In Sports Economics after Fifty Years: Essays in Honour of Simon Rottenberg. Edited by Placido Rodriguez, Stefan Késenne and Jaume Garcia. Oviedo: Ediciones de la Universidad de Oviedo, pp. 211-26. ISBN 9788483176054.

Storm, Rasmus K, and Klaus Nielsen. 2012. Soft budget constraints in professional football. European Sport Management Quarterly 12: 183-201. [CrossRef] 
Szymanski, Stefan. 2012. Insolvency in English Professional Football: Irrational Exuberance or Negative Shocks? IASE \& NAASE Working Paper Series. Paper No. 12-02. Available online: college.holycross.edu/RePEc/ spe/Szymanski_Insolvency.pdf (accessed on 1 November 2012).

Transfermarkt: Football Transfers, Rumours, Market Values, News and Statistics. Available online: https://www. transfermarkt.fr (accessed on 8 June 2018).

(C) 2018 by the author. Licensee MDPI, Basel, Switzerland. This article is an open access article distributed under the terms and conditions of the Creative Commons Attribution (CC BY) license (http:/ / creativecommons.org/licenses/by/4.0/). 


\title{
Article \\ Revenue Sharing in Major League Baseball: The Moments That Meant so Much
}

\author{
Duane Rockerbie $^{1, *}$ and Stephen Easton ${ }^{2}$ \\ 1 Department of Economics, University of Lethbridge, Lethbridge, AB T1K3M4, Canada \\ 2 Department of Economics, Simon Fraser University, Burnaby, BC V5A1S6, Canada; easton@sfu.ca \\ * Correspondence: rockerbie@uleth.ca; Tel.: +1-403-329-2517
}

Received: 31 May 2018; Accepted: 2 August 2018; Published: 6 August 2018

\begin{abstract}
Revenue sharing is a common league policy in professional sports leagues. Several motivations for revenue sharing have been explored in the literature, including supporting small market teams, affecting league parity, suppressing player salaries, and improving team profitability. We investigate a different motivation. Risk-averse team owners, through their commissioner, are able to increase their utility by using revenue sharing to affect higher order moments of the revenue distribution. In particular, it may reduce the variance and kurtosis, as well as affecting the skewness of the league distribution of team local revenues. We first determine the extent to which revenue sharing affects these moments in theory, then we quantify the effects on utility for Major League Baseball over the period 2002-2013. Our results suggest that revenue sharing produced significant utility gains at little cost, which enhanced the positive effects noted by other studies.
\end{abstract}

Keywords: revenue sharing; welfare; moments; risk aversion

JEL Classification: Z28

\section{Introduction}

Many papers in the sports economics literature have studied the effects of different types of revenue sharing systems on league outcomes. The majority have focused on its effects on league parity using both theoretical models (Kesenne (2000, 2015); Miller (2007); Rockerbie (2009); Szymanski (2004) and Vrooman (2009) are examples), and empirical evidence (Maxcy 2009; Rockerbie 2017). Others have focused on the effects on player salaries (Hill and Jolly 2015), while others have focused on team profitability (Easton and Rockerbie 2005; Kesenne 2007). These papers assume that the motivation for a league to adopt revenue sharing is to encourage financial stability and to minimize the credible threats of rival leagues. Financial stability is an often-used term that is addressed only indirectly by creating links between parity and profitability to financial stability. Our purpose in this paper is to investigate the effects of revenue sharing on financial stability more directly by considering its effects on the league distribution of local revenues, and the potential benefits (and costs) that they generate for team owners. Specifically, we show that a straight pool revenue sharing system affects the variance, skewness, and kurtosis of the league revenue distribution in a systematic but non-linear fashion. We then quantify the gains to a representative team owner by assuming a risk-averse league commissioner whose objective is to reduce financial uncertainty for team owners. Our results using data for Major League Baseball (MLB) suggest that the benefits to team owners can be significant, and that they provide a motivation for revenue sharing that we have not seen explored in the literature.

A growing literature has considered how trade-induced economic growth has resulted in greater income inequality (Dixit and Norman 1986; Goldberg and Pavcnik 2007), and how an income tax system can redistribute income to enhance the potential gains from free trade and integration. Revenue sharing is essentially a tax system to redistribute revenues from rich to poor teams in professional 
sports leagues. We focus on the sharing of local revenues in this paper. However, sharing of marketing, media, and television revenues has become a standard practice as well. The National League of MLB adopted gate revenue sharing in 1876 and the American League in 1903 (fixed dollar amounts per home ticket sold). ${ }^{1}$ The National Hockey League (NHL) adopted a limited gate revenue sharing plan in 1925 (3.5\% of home gate receipts) ${ }^{2}$ and the National Football League (NFL) a much more extensive gate sharing plan in 1960 ( $40 \%$ of home gate receipts). ${ }^{3}$ Early in their histories, leagues often adopted revenue sharing during periods of rapid expansion that created a large imbalance in league revenues. Maintaining the financial stability of the league was important to ensure that teams had opponents to play games against and to stave off the threat of rival leagues. ${ }^{4}$ Today's revenue sharing plans are complex and extensive and are agreed to with players in their collective bargaining agreements. Virtually all local revenues are shared to some extent, including the local television network and cable revenues.

The long-standing gate sharing plan was used in both the National League and the American League up to the 1995 season. The 1996-2001 seasons saw MLB experimenting with different hybrid plans in each season. It was not until the 2002 season that MLB adopted the simple straight-pool revenue sharing plan that required each team to contribute $34 \%$ of its local revenue to the pool, with the pool then split up evenly among all 30 teams. ${ }^{5}$ A supplemental revenue sharing plan was established to divide up monies from the Major League Central Fund (national television rights, apparel and other rights held by Major League Baseball Properties) that were formally distributed evenly to all clubs. Each club's equal share was adjusted based on their revenue circumstance for the previous three seasons. The amount of the Central Fund to perform the adjustment was calculated to be $41.066 \%$ of the net transfer value of the straight-pool revenue sharing plan. For instance, in the last year of the agreement (2006) the net transfer value (the amount transferred from payer teams to payee teams) was approximately $\$ 1.62$ billion, giving the size of the Central Fund to be shared at $\$ 665.3$ million. To qualify to receive monies from this shared portion of the Central Fund, a club had to be a net payee in the straight-pool plan for the same season and had to have a mean local revenue for the preceding three seasons that was less than the mean local revenue for the league. The equal share for a payee was then topped up by multiplying size of the fund ( $\$ 665.3$ million in 2006) by a ratio, comprised of the difference in the league mean local revenue for the previous three seasons, and the recipient's mean local revenue for the previous three seasons, divided by the sum of these differences of all recipient teams in the last three seasons. All MLB teams received monies from the Central Fund; however, high revenue teams received less than low revenue teams.

The 2007 Collective Bargaining Agreement (CBA) saw the contribution rate drop to $31 \%$ in the straight-pool revenue sharing plan of local revenues, and a new supplemental pool plan. ${ }^{6}$ The supplemental pool contained enough revenue, taken from the Major League Central Fund, to top up the total revenue sharing pool to $48 \%$ of local revenues (or roughly $17 \%$ of total local revenues amounting to $\$ 967.3$ million in the last year of the agreement (2011)) and this was distributed to teams based on performance factors that reflected the size of local television and media markets. Large market teams carried negative performance factors, while small market teams carried positive performance factors (the sum of the performance factors being zero). These monies were then added to

\footnotetext{
See Surdham (2007).

See Ross (2015)

See Surdham (2007)

The NHL welcomed the Boston Bruins, New York Americans, and the Pittsburgh Pirates in 1925, and approved new franchises in Chicago and Detroit in 1926. The addition of these large American cities to the much smaller four Canadian cities already in the NHL created a bidding war for professional players that put the smaller franchises at a considerable financial disadvantage. The NFL had just survived the threat of the now defunct All-American Football Conference (AAFC) by absorbing three AAFC teams in 1950. The new American Football League (AFL) began operations in 1960 as a direct competitor to the long-established NFL.

5 http://roadsidephotos.sabr.org/baseball/BasicAgreement.pdf.

6 http://www.steroidsinbaseball.net/cba/cba_07_11.pdf.
} 
the equal shares received from the Central Fund to calculate a net among the amount received. Again, all teams received monies from the Central Fund, but large market teams received less than small market teams.

The contribution rate was increased to $34 \%$ in the 2012 CBA, while the basic form of the supplemental pool from the Central Fund was maintained from the 2007 CBA.

We did not model the supplemental revenue sharing pool in the rest of the paper due to its asymmetric effects on team revenues, and the fact that the plan changed significantly from the 2002-2006 to the 2007-2011 CBA's. Incorporating the plan into an algebraic model to predict the effects on the league total revenue distribution proved difficult, despite our efforts. Instead we chose to focus only on the straight-pool revenue sharing plan and its effects on the moments of the league local revenue distribution. This was a shortcoming of our approach; however, we leave the problem of the distribution of the Central Fund revenues to further research.

Theoretical models have focused mainly on the effects on parity and team profitability in levels. However, it is uncertain as to how a movement towards or away from parity in winning percentages affects the stability of league revenues. We considered the effects of revenue sharing on the league distribution of team revenues in terms of its second (variance), third (skewness), and fourth moments (kurtosis). Figures 1 and 2 plot the histograms and reports the relevant moments of local revenue for the 2002 and 2011 MLB seasons. The variance of local team revenue (excluding national media, apparel, and other rights revenues shared by all teams) after revenue sharing $\left(\sigma_{A}^{2}\right)$ was less than half $(43.5 \%$ and $46.7 \%$ ) of the variance of local team revenue before revenue sharing $\left(\sigma^{2}\right)$ in each respective season, and the third (29\%) and fourth (19\%) moments were also reduced. The biggest contributor to the revenue sharing plan in both seasons was the New York Yankees, contributing a net sum of approximately $\$ 52$ million in 2002 and $\$ 100$ million in 2011. The Yankees owners (G. and H. Steinbrenner) could not have been happy with making a net contribution of $\$ 754$ million over the 2002 to 2011 seasons; however, the Yankees carry only one vote when it comes to changing league policy. Although it is a net zero gain to the league in terms of total and average local revenue, the reduction in risk alone that revenue sharing provided must have been greatly valued by a majority of other owners.

Reducing its variance has obvious benefits with risk-averse team owners, but reducing its third and fourth moments ${ }^{7}$ has a more complex effect on benefits. ${ }^{8}$ Reducing skewness implies a more equal distribution of team revenues - a desirable result for a league composed of socialist owners, but team owners are capitalists who prefer more rather than less, and their commissioner is chosen to represent their financial interests. As we shall show, a league with a higher positive skewness has a lower likelihood of downside risk, and is preferred by the representative team owner. While it is not the worst outcome, equality of team revenues is preferred to a higher downside risk $\left(\sigma^{3}<0\right)$.

7 We refer to the average cubed deviation around the mean as $\sigma^{3}$ as it is clearly related to the idea of skewness. It is not the coefficient of skewness. The Pearson definition of skewness is $n^{-1} \sum\left(\left(R_{i}^{A}-\bar{R}\right) / \sigma\right)^{3}$; however, we refer to $\sigma^{3}$ as a characterization of skewness in the rest of the paper.

8 The third moment is characterized as being associated with "prudence" (Kimball 1990), and the fourth moment as being associated with "temperance" (Eeckhoudt et al. 1995). See Chiu (2005), or Eeckhoudt and Schlesinger (2013) for additional interpretation of these and higher order moments. 


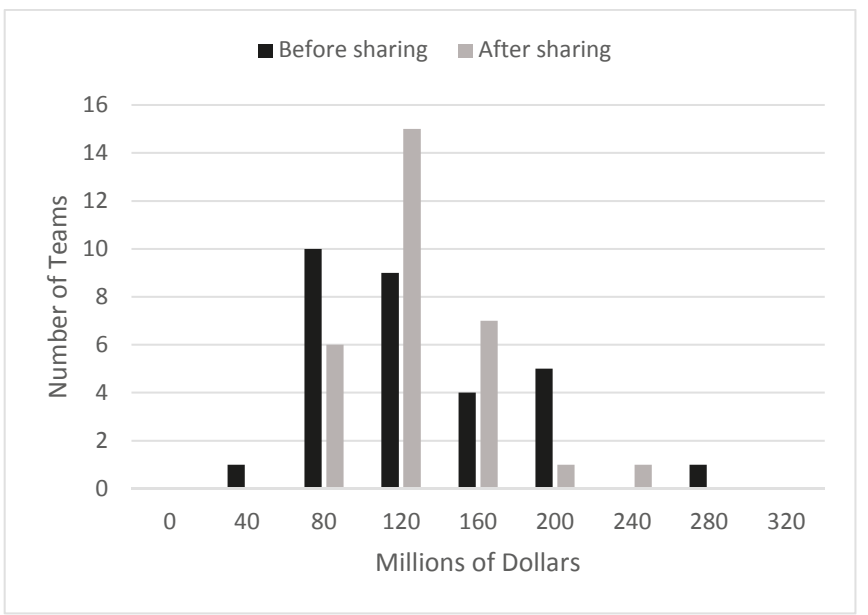

Figure 1. Local revenues pre- and post-revenue sharing in Major Baseball League (MLB), 2002 season. $\left(\bar{R}=\$ 109.4\right.$ million, $\sigma^{2}=2607.2, \sigma_{A}^{2}=1135.7, \sigma^{3}=3,720,200, \sigma_{A}^{3}=1,069,542, \sigma^{4}=24,251,058$, $\left.\sigma_{A}^{4}=4,601,574\right)$. Sources: Post-revenue sharing data taken from Rodney Fort's Sports Economics website, https://sites.google.com/site/rodswebpages/codes. Pre-revenue sharing data based on author's calculations.

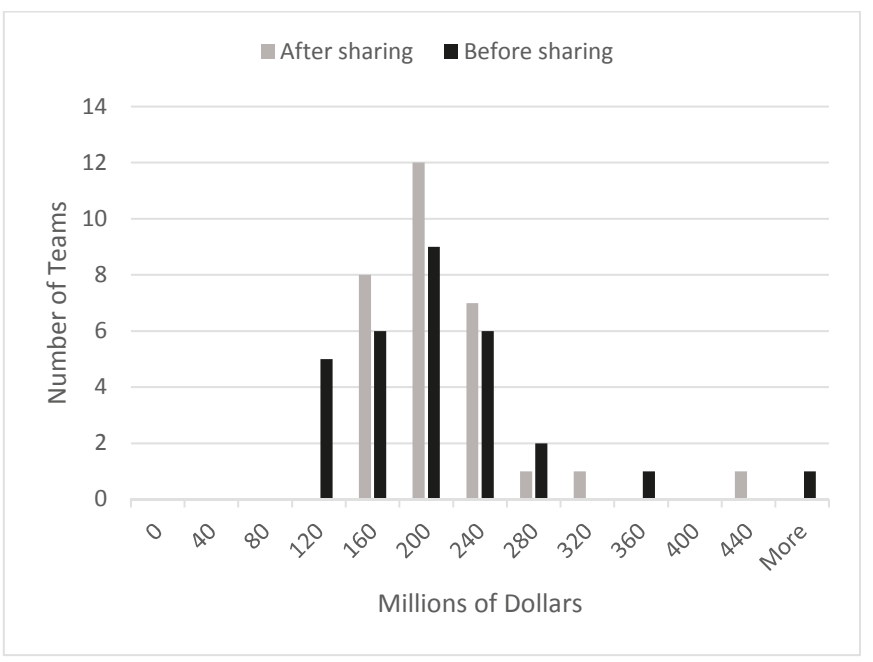

Figure 2. Local revenues pre and post-revenue sharing in MLB, 2011 season. $(\bar{R}=\$ 189.7$ million, $\left.\sigma^{2}=6234.2, \sigma_{A}^{2}=2968.1, \sigma^{3}=36,153,429, \sigma_{A}^{3}=5,053,763, \sigma^{4}=166,465,178, \sigma_{A}^{4}=93,707,469\right)$. Sources: Post-revenue sharing data taken from Rodney Fort's Sports Economics website, https:/ / sites. google.com/site/rodswebpages/codes. Pre-revenue sharing data based on author's calculations.

\section{Risk Aversion and Revenues}

To motivate the effects of revenue sharing, we will assume that team owners are risk-averse and maximize their utility from profit. This differs from the standard sports league model that assumes risk-neutral team owners who maximize profit (or winning or a combination of the two). 
Consumers are often thought of as being risk-averse when facing a gamble that will affect their income or wealth. In the simplest case of a sports league, a representative team owner faces an uncertain portion of team revenue (excluding fixed revenues that arise from the Major League Central Fund) from season to season, that takes on only two outcomes, high or low. These uncertain revenues arise from the inherent uncertainty of team performance due to injuries or changes in the performance of competing teams, or changing local market conditions. While team owners do not have the choice of accepting a certainty equivalent amount of revenue, as explained below, they may prefer league policies that reduce the variation (or higher moments) of team revenues and raise their utility.

When speaking of risk aversion in firms, the economics literature defines the owner of a firm as an "entrepreneur". The connotation is that being an entrepreneur means starting a new business that has risky/uncertain financial outcomes, instead of the faceless widget producer who faces a certain demand that is assumed in textbooks. ${ }^{9}$ Table 1 provides a summary of ownership structures in the four major North American professional sports leagues. The vast majority are partnerships (with the exception of MLB at 16 out of 30 teams) that identify as limited liability corporations (LLCs) for tax purposes $^{10}$ and identify one individual as the majority owner. In fact, the NFL prohibits standard corporate ownership of its teams, with the historical exception of the Green Bay Packers, which is community-owned. Consequently, thinking about professional sports teams as having one or two investor/owners who are responsible for most business decisions is completely appropriate, given their actual ownership structures.

Table 1. Ownership structures in North American professional sports leagues, 2018. ${ }^{11}$

\begin{tabular}{cccc}
\hline & Normal Corporation & Partnerships/LLC & Identify Majority Owner \\
\hline MLB & 14 & 16 & 28 \\
NBA & 10 & 20 & 30 \\
NHL & 6 & 25 & 30 \\
NFL & 1 & 31 & 31 \\
\hline
\end{tabular}

In the simplest case, if the firm delegates decisions to a manager whose pay is linked to firm performance, the firm may display risk-averse behavior. However, firms may display risk-aversion for several other reasons. Firms in a perfectly competitive industry may reduce output when facing demand uncertainty (Sandmo 1971); Leland (1972) demonstrates the same result for a risk-averse monopoly, while Asplund (2002) suggests that only greater cost uncertainty reduces output for a risk-averse oligopoly firm. Some empirical evidence is provided by Herranz et al. (2015) who show that risk-averse entrepreneurs run smaller, more highly leveraged firms with lower default risk. This behavior is consistent with U.S. business data for approximately 5 million small firms whose owners invest a large amount of their own wealth in the business, and typically work at the business.

\section{A League: When Monopoly Does Not Maximize Individual Profit}

Team owners are entrepreneurs who invest in costly talent that produces an uncertain outcome (wins). As Neale (1964) first noted, a professional sports firm requires other firms (teams) to produce an output (games) and earn revenue. At the local level, team owners are competitive on the field,

$9 \quad$ Frank Knight (1921) in Risk, Uncertainty and Profit, called attention to this reality as early as 1921.

10 The assets of owners of limited liability corporations (LLCs) are protected from creditors in the event of default of the LLC. Their corporate structure does not include a Board of Directors or Officers; instead, decisions rest with the owner(s). Any profit from the LLC is reported as taxable personal income for the owner(s) to avoid the double taxation of corporate profit and personal income received from dividends.

11 Source: https://www.baseball-reference.com/bullpen/List_of_Major_League_Baseball_principal_owners, https://en. wikipedia.org/wiki/List_of_NBA_team_owners, http://icehockey.wikia.com/wiki/List_of_NHL_Owners, https://en. wikipedia.org/wiki/List_of_NFL_franchise_owners. 
but engage in a joint venture at the league level. ${ }^{12}$ League policies that might appear to be collusive (a common set of rules, a playing schedule, a player draft, free agency, and so on) must be adopted to insure the survival of the league and, thus, each team. The fact that team owners often argue that revenue sharing is necessary for the stability of the league (Bontemps 2017) is some evidence that they are sensitive to profit risk. Revenue sharing requires the approval of a majority of team owners. For those owners who earn consistent profits, giving up some profit to insure that smaller market teams survive is a form of insurance premium for future revenue stability. Outside of a professional sports league, any movement towards a monopoly benefits the profit position for a firm, but not so for a professional sports team owner.

Risk aversion has a long tradition in the labor economics literature. Generally, risk-averse firms suffer much lower utility in the low demand state than in the high demand state; thus, they reduce their output and hire fewer workers to reduce costs and maintain profitability. Choudhary and Levine (2010) review this literature. Professional sports teams do not hire and fire homogeneous workers, but instead face fixed roster sizes. Hence, they must adjust payroll costs by increasing or reducing the stock of team talent. Krautmann (2017) found evidence to suggest that team owners demonstrate risk aversion by paying a premium to MLB players who demonstrate consistent performance. Maxcy (2004) suggested that team owners reward consistent players with longer term contracts. Consistent player performance translates into consistent team revenues, suggesting that team owners value consistent revenues that can be made even less variable with revenue sharing. ${ }^{13}$

Risk aversion has also been used to explain why workers prefer stable employment contracts that pay a lower wage in the face of uncertain productivity. Wages and employment will then appear to be somewhat inflexible during swings in productivity (business) cycles. Employers who are risk-neutral will be indifferent between such a contract and a bonus-based contract. A good reference is Thomas and Worrall (1988). This might explain why professional athletes may prefer long-term contracts with stable salaries to short-term performance-based contracts. Although this is an interesting research area, we consider the effects of revenue sharing only on team owners, admitting that risk aversion might play a role in contract negotiations and subsequent team owner utility.

Prudence, or in our case the reduction of downside risk, is a characteristic of the individual who buys insurance, and is described by the skewness of revenues. Risk aversion and prudence are not identical, but they are related (Kimball 1990; Chiu 2005). As we show below, a risk-averse team owner benefits from prudence and consequently reduces the likelihood of a bad revenue state.

To fix ideas, Eeckhoudt and Schlesinger (2013) imagine a lottery with two outcomes. In state 1, we receive $X-k$ in which $k$ is a fixed amount, and in state 2 , we receive $X+e$ where e is a mean zero random payout with finite variance. Now consider a second lottery in which the good state receives $X$ and the bad state receives $X-k+e$. Since the second lottery increases the downside risk but leaves the mean and the variance unchanged, a prudent individual is defined as one who prefers the first lottery to the second. The first lottery attaches the sure loss to the state with no risk, while in the second lottery, the sure loss is attached to the state with risk, e. This behavior means that for a given mean and variance, negative skewness in revenues is undesirable for the league.

Temperance describes a representative team owner who wishes to avoid a large probability density in both tails of the revenue distribution-avoiding extreme outcomes. This translates to a small value for the fourth moment (kurtosis) of the league revenue distribution.

12 See for example https://www.lexology.com/library/detail.aspx?g=31d92fbf-9e64-4aaa-a5e4-a1f56bc23c8a.

13 We are grateful to a referee for pointing out that there is a derived demand for minor league performance leading to major league outcomes. Although we do not explore this relationship, it has been considered with dramatically different conclusions in two sources. https://www.baseballamerica.com/stories/quantifying-the-effects-of-winning-in-the-minorleagues-on-player-development/, http://washusportsanalytics.weebly.com/our-research/the-value-of-minor-leagueseasoning. 


\section{The Model}

Our sports league is composed of $n$ teams. Each team owner contributes a share $(1-\alpha)$ of its local revenue into a straight pool, which is then divided evenly among the team owners at the end of each playing season. Local revenues are obtained primarily from ticket sales, but they may also contain other local revenues that increase with the performance of the team. We ignore other types of revenue that are not typically dependent upon team performance. To focus on the static consequences of revenue sharing, we do not explicitly model the determination of the profit-maximizing revenue for each team. We acknowledge that revenue sharing can affect the optimal choice of talent and thus team revenue. It is an undisputed result in the theoretical literature that revenue sharing reduces the demand for talented players and subsequently lowers salaries (Fort and Quirk 1995). This is a positive benefit for team profits that we cannot model without resorting to a simultaneous equation system composed of a marginal revenue function for each team. If one could model such a complex system, the increase in team profitability due to revenue sharing could only enhance the positive effects that we demonstrate here.

The bulk of the theoretical literature on revenue sharing has come into agreement that increased revenue sharing reduces league parity (Kesenne (2000, 2015), Miller (2007), Szymanski (2004), and Vrooman (2009) that could have negative consequences for consumer welfare if fans value close contests (the uncertainty of outcome hypothesis or UOH). Fort and Quirk (2010a, 2010b) use the sum of consumer and producer surpluses to compare welfare at different levels of league parity. Dietl, Lang and Werner (Dietl et al. 2009) show that revenue sharing increases welfare measured as the sum of consumer surplus and team profits. To capture this effect in our model would require an estimation of the effects of the 2002, 2007, and 2012 changes to the straight-pool revenue sharing plan on league parity, and an assumption of some sort of consumer welfare function that values the $\mathrm{UOH}$. Instead we have chosen to focus on the isolated effect of revenue sharing on the moments of the league distribution of revenues. We acknowledge this as a shortcoming of our approach and leave it to further research to investigate the salary and parity effects of revenue sharing on total league and consumer welfare.

Revenue for team $i$ after revenue sharing (where an " $A$ " distinguishes revenue after sharing) is given by:

$$
R_{i}^{A}=\alpha R_{i}+(1-\alpha) \sum R_{j} / n=\alpha R_{i}+(1-\alpha) \bar{R}
$$

In (1), $\bar{R}=\sum_{j=1}^{n} R_{j} / n$, the average team local revenue for the league before revenue sharing. ${ }^{14}$ We need not consider the theoretical result that revenue sharing reduces the incentive of team owners to acquire talent and earn revenue, since we are not solving a team owner maximization problem. Instead we accept that each $R_{j}$ has been determined ex-post by the profit maximizing decision of the owner of team $j$, accounting for the revenue sharing payments that each will contribute or receive.

Utility is representative of any one of the owners (a representative agent model) and is calculated as a constant relative risk aversion utility function of the form ${ }^{15}$ :

$$
U=R^{1-\theta} / 1-\theta
$$

The $\theta$ term is the coefficient of relative risk aversion and $R$ is the local revenue of a representative team owner. Revenue sharing affects the league distribution of revenues, and we focus our analysis on the utility effects for the resulting representative owner.

14 It is easy to show that the average local revenue is unchanged by revenue sharing. Using (1), $\bar{R}^{A}=\sum R_{j}^{A} / n=$ $\left(\sum \alpha R_{j}+\sum(1-\alpha) \bar{R}\right) / n=\alpha \bar{R}+(1-\alpha) \bar{R}=\bar{R}$.

15 The CRRA utility function is a popular choice in models of consumption and real business cycles for two reasons: risk aversion is invariant to the level of consumption, income and wealth; utility is stationary, that is, moving the same consumption path forward one or more periods does not change the preference ordering of goods to consume. See Lucas (1987). 
We utilize a Taylor series expansion of a representative owner's CRRA utility function as an approximation to the utility obtained from an expected utility maximization problem. This is the approach pioneered by Markowitz (1952) to develop his mean-variance portfolio model, although he only considered the first two moments of the return distribution. Kraus and Litzenberger (1976) extend the CAPM analysis to the third moment. This approach is not without controversy. Loistl (1976) demonstrated that a Taylor series expansion does not approximate the portfolio results of expected utility maximization very well, except for the case of a quadratic utility function. However, a number of papers have suggested that the degree of error is very slight, by the use of simulations of different choice models (Levy and Markowitz (1979), Pulley (1981), Kroll et al. (1984), Tew et al. (1991), and Tompkins (2000) are a few), typically on the order of $\$ 0.00025$ per dollar invested. In addition, their results suggest that the error decreases with the number of assets in the portfolio; in our case, teams sharing the revenue in the league. In our case, the Taylor series approximation adds the ease of measurement of utility, as well as bringing in the first four moments of the league revenue distribution into the discussion in a coherent way.

To approximate utility for the representative owner and to introduce the first four moments of the league revenue distribution, we take a Taylor series expansion of (2) around the average team local revenue, limited to the first four terms. ${ }^{16}$

$$
\begin{gathered}
U \approx \frac{\bar{R}^{1-\theta}}{1-\theta}+\bar{R}^{-\theta}(R-\bar{R})-\frac{\theta}{2} \bar{R}^{-\theta-1}(R-\bar{R})^{2}+\frac{\theta(\theta-1)}{3 !} \bar{R}^{-\theta-2}(R-\bar{R})^{3} \\
-\frac{\theta(\theta-1)(\theta-2)}{4 !} \bar{R}^{-\theta-3}(R-\bar{R})^{4}
\end{gathered}
$$

Before revenue sharing in any season, local revenue for the representative owner can deviate from its mean due to shocks that we specify as $R=\bar{R}+e$ without specifying the nature of these shocks, and assuming $E(e)=0$ and $\operatorname{Var}(e)=\sigma^{2}$. The average local revenue is unchanged after revenue sharing, hence the second term in (3) vanishes after taking its expected value, while the variance and skewness and kurtosis of local revenue after revenue sharing are denoted as:

$$
\begin{aligned}
& E\left(R_{i}^{A}-\bar{R}\right)^{2}=\sigma_{A}^{2}=\frac{1}{n} \sum\left(R_{i}^{A}-\bar{R}\right)^{2} \\
& E\left(R_{i}^{A}-\bar{R}\right)^{3}=\sigma_{A}^{3}=\frac{1}{n} \sum\left(R_{i}^{A}-\bar{R}\right)^{3} \\
& E\left(R_{i}^{A}-\bar{R}\right)^{4}=\sigma_{A}^{4}=\frac{1}{n} \sum\left(R_{i}^{A}-\bar{R}\right)^{4}
\end{aligned}
$$

Thus:

$$
\begin{gathered}
E(U)=\left[R^{1-\theta} / 1-\theta\right]-\frac{\theta}{2} \bar{R}^{-(1+\theta)} \sigma_{A}^{2}+\frac{\theta(\theta-1)}{6} \bar{R}^{-(2+\theta)} \sigma_{A}^{3} \\
-\frac{\theta(\theta-1)(\theta-2)}{4 !} \bar{R}^{-(3+\theta)} \sigma_{A}^{4}
\end{gathered}
$$

\subsection{Risk Aversion}

Risk aversion suggests that greater variability in team revenue $\left(\sigma_{A}^{2}\right)$ reduces utility. Risk-averse team owners seek to reduce the variability in revenues by diversifying their revenue "portfolios", and revenue sharing provides a mechanism to do this, although we do not pursue this team-specific

16 Lucas (1987) used the same expansion method to evaluate the welfare gain from consumption smoothing. He did not expand to the fourth term in (3), since he did not have the data necessary to compute the moments of the distribution of U.S. aggregate consumption. 
portfolio effect. ${ }^{17}$ Rather, we assume that the representative team owner is concerned with the variance and higher orders of the distribution of team local revenues around the team average.

\subsection{Skewness Reflects Prudence}

The effect of skewness on utility depends upon the degree of relative risk aversion. If the representative owner is risk-averse and we assume $\theta>1$, positive skewness in revenues $\left(\sigma_{A}^{3}>0\right)$ will increase expected utility. ${ }^{18}$ Positive skewness will reduce the likelihood that poor revenue for one or more teams will threaten the stability of the league. Revenue sharing is a policy that will also contribute to stability. Prudent owners will benefit from skewness. It is important not to confuse skewness in revenues with a lack of revenue equity that some might associate with lower welfare. In our model, the league wishes to see the majority of teams doing well on the revenue side. How revenue sharing affects skewness is specifically addressed in a later section; however, any improvement in revenue equity, as measured by a movement to a more symmetric league revenue distribution from positive skewness, will lower league utility.

To see each of the effects of the variance, skewness and kurtosis on utility, we consider each individually before amalgamating.

\subsection{Revenue Sharing and the Variance of Team Revenues}

To calculate the variance of team revenues after revenue sharing, one might be tempted to use the simple rule of variances that $\operatorname{Var} a X=a^{2} \operatorname{Var} X$, since part of the local revenue after sharing is just $\alpha R_{i}$, but this would ignore the payment received from the revenue-sharing pool. The variance of team revenues around the league average after revenue sharing is not as obvious as the simple rule, but it is not hard to derive:

$$
\sigma_{A}^{2}=E\left(R_{j}^{A}-\bar{R}\right)^{2}=\frac{1}{n} \sum_{j=1}^{n}\left(R_{j}^{A}-\bar{R}\right)^{2}
$$

Consider the bracketed term only for team $i$ and insert (1):

$$
\left(R_{i}^{A}-\bar{R}\right)^{2}=\left(\alpha R_{i}+(1-\alpha) \bar{R}-\bar{R}\right)^{2}=\left(\alpha\left(R_{i}-\bar{R}\right)\right)^{2}=\alpha^{2}\left(R_{i}-\bar{R}\right)^{2}
$$

Each of the $n$ teams will have the same expression as (6), with the terms inside the brackets using values for the individual team. Summing over the $\mathrm{n}$ teams gives:

$$
\sigma_{A}^{2}=\frac{1}{n} \sum_{j=1}^{n}\left(R_{j}^{A}-\bar{R}\right)^{2}=\alpha^{2} \frac{1}{n} \sum_{j=1}^{n}\left(R_{j}-\bar{R}\right)^{2}=\alpha^{2} \sigma^{2}
$$

The reduction in the variance of league revenues after revenue sharing is proportional to $\alpha^{2}$. If we think of the variance of local revenues as a measure of risk, revenue sharing reduces this risk by a factor of $0.69^{2}=0.4761$ in MLB ( $\alpha=0.69$ as per the 2016 CBA), which is a 31 percent reduction from no revenue sharing.

17 Revenue sharing in the form assumed in this paper allows team owners to diversify their revenue portfolios by essentially investing in the economic health of other teams. Two requirements are necessary for team owners to benefit from a portfolio effect. First, team revenues should display some sort of cyclical behavior; second, and related to the first requirement, a majority of teams should display a negative covariance with the revenues of other teams or the league average revenue. Most professional sports teams have periods of strong revenue growth, followed by periods of revenue stagnation or decline. The cyclical nature of winning percentages and a possible cause of this has been explored by Easton and Rockerbie (2010), and Rockerbie and Easton (2014). Revenues are at least partially determined by success on the field, however the cyclical nature of team revenues has not been deeply explored in the literature. The majority of team owners that vote in favor of revenue sharing might do so if they perceive a benefit from the portfolio effect, implying that their local revenue displays a negative covariance with the local revenues of other teams.

18 Below, we will argue for $\theta>3$. In the special case of $\theta=1$, we have a log utility function, and skewness does not affect the utility, from inspection of (4). 
Risk-averse team owners will value the reduction in risk that revenue sharing delivers. But by how much? The relevant part of (4) is $-\frac{\theta}{2} \bar{R}^{-(1+\theta)} \sigma_{A}^{2}$. Consider the one-shot adoption of revenue sharing that reduces $\alpha=1$ to $\alpha=0.69$. Expressing the increase in utility relative to marginal utility $\left(\bar{R}^{-\theta}\right.$ when evaluated at the mean) gives the increase in dollars per unit of utility. Next, dividing by the average local revenue for the league $(\bar{R})$ expresses the welfare change as a percentage of average league revenue ${ }^{19}$ :

$$
\frac{\Delta U / U^{\prime}}{\bar{R}}=-\frac{(\theta / 2) \bar{R}^{-(1+\theta)}\left(\sigma_{A}^{2}-\sigma^{2}\right)}{\bar{R}^{-\theta} \bar{R}}=-\frac{\theta\left(\alpha^{2}-1\right) \sigma^{2}}{2 \bar{R}^{2}}=\left(\frac{\theta}{2 \bar{R}^{2}}\right) 0.5239 \sigma^{2}>0
$$

The larger the variance in league local revenues before revenue sharing, the larger the welfare gains are from revenue sharing, and the larger is the average local revenue of the league, the smaller are the utility gains from revenue sharing. Leagues composed of very wealthy teams playing in large markets may stand little to gain in utility by instituting revenue sharing.

\subsection{Revenue Sharing and the Skewness of League Revenues}

Skewness is also important to the utility of the representative. Positive skewness provides higher utility because it indicates a low probability of a poor revenue outcome for one or more of the teams. Skewness after revenue sharing is defined as:

$$
\sigma_{A}^{3}=E\left(R_{j}^{A}-\bar{R}\right)^{3}=\frac{1}{n} \sum_{j=1}^{n}\left(R_{j}^{A}-\bar{R}\right)^{3}
$$

Using the same method used to derive the variance, the skewness in local revenues is given by:

$$
\sigma_{A}^{3}=\alpha^{3} \sigma^{3}
$$

The reduction in skewness of the league revenue distribution that revenue sharing delivers is proportional to $\alpha^{3}$. For MLB, this is $0.69^{3}=0.3285$, again a significant reduction, but in this case, a reduction in utility for the league if the league revenue distribution is positively skewed. How much will the league (representative owner) value the reduction in skewness with greater revenue sharing? The relevant part of (4) is $\frac{\theta(\theta-1)}{6} \bar{R}^{-(2+\theta)} \sigma_{A}^{3}$. Again, expressing the increase in utility relative to marginal utility, and then expressing it as a percentage of average league revenue gives the results of a decrease in welfare for the league by increasing revenue sharing:

$$
\frac{\Delta U / U^{\prime}}{\bar{R}}=\frac{\theta(\theta-1)}{6 \bar{R}^{3}} \sigma^{3}\left(0.69^{3}-1\right)=-\frac{\theta(\theta-1)}{6 \bar{R}^{3}} 0.6715 \sigma^{3}<0
$$

\subsection{Revenue Sharing and the Kurtosis of League Revenues}

Positive kurtosis indicates that the league revenue distribution has "heavy tails", or that there is a significant probability of extreme revenue results. This reduces the utility for the representative owner from the last term in (4). Kurtosis after revenue sharing is defined as:

$$
\sigma_{A}^{4}=E\left(R_{j}^{A}-\bar{R}\right)^{4}=\frac{1}{n} \sum_{j=1}^{n}\left(R_{j}^{A}-\bar{R}\right)^{4}
$$

\footnotetext{
19 The average revenue for the representative owner is the same as the average league revenue across all teams.
} 
Using the same method used to derive the variance, the kurtosis in local revenues is given by:

$$
\sigma_{A}^{4}=\alpha^{4} \sigma^{4}
$$

The reduction in kurtosis of the league revenue distribution that revenue sharing delivers is proportional to $\alpha^{4}$. A representative owner that displays temperance, values the reduction in kurtosis as provided by revenue sharing, by the amount $-\frac{\theta(\theta-1)(\theta-2)}{4 !} \bar{R}^{-(3+\theta)} \sigma_{A}^{4}$ from (4). Here, we are also assuming that $\theta>2$. Expressing the utility gain as a percentage of the average team revenue gives:

$$
\frac{\Delta U / U^{\prime}}{\bar{R}}=\frac{\theta(\theta-1)(\theta-2)}{24 \bar{R}^{4}} \sigma^{4}\left(0.69^{4}-1\right)=\frac{\theta(\theta-1)(\theta-2)}{24 \sigma^{4}} 0.7733 \sigma^{4}>0
$$

\section{Overall Utility Gains from Revenue Sharing}

Revenue sharing increases the utility for the representative owner by reducing the variance of local revenues around the league average and reducing kurtosis, but lowers the utility by reducing positive skewness. However, if skewness were to be negative, then revenue sharing would raise utility. The net change in utility is the sum of (8), (11), and (14).

$$
\text { Net } \frac{\Delta U / U^{\prime}}{\bar{R}}=-\frac{\theta\left(\alpha^{2}-1\right) \sigma^{2}}{2 \bar{R}^{2}}+\frac{\theta(\theta-1)\left(\alpha^{3}-1\right) \sigma^{3}}{6 \bar{R}^{3}}-\frac{\theta(\theta-1)(\theta-2)\left(\alpha^{4}-1\right) \sigma^{4}}{24 \bar{R}^{4}}
$$

The measurement of the utility gain in (15) requires the accurate data concerning the distribution of team revenues to be meaningful. Professional sports leagues do not make these data publicly available. We require local revenues before revenue sharing for every team in a professional sports league. MLB released accurate data for the 1995 through 2001 seasons in a supplement to its Blue Ribbon report (Major League Baseball 2001). Team local revenues before revenue sharing are reported in Table 2 of the report. ${ }^{20}$ Unfortunately MLB did not use the straight-pool revenue sharing plan that we assumed, in deriving Equations (7), (10), and (13) in any of these seasons. The Blue Ribbon report provided a unique glimpse into the financial numbers for MLB. ${ }^{21}$ As much as we would like to use data from the report, we cannot for two reasons. First, as already noted, the derivations of Equations (7), (10), and (13) that determine the properties of straight-pool revenue sharing on the variance and skewness of the league revenue distribution do not hold for the forms of revenue sharing used in the 1995-2001 seasons. Second, team owners form expectations of the amount of revenue to be contributed to the revenue sharing pool when making their talent acquisitions, setting ticket prices, and other financial decisions. These decisions incorporate the pre-revenue sharing local revenue figures. Using local revenue data for different revenue sharing plans is not consistent with team owner expectations.

Forbes magazine publishes estimates of gate revenue before revenue sharing for MLB, beginning in 1990. We have chosen the 2002-2013 MLB seasons, since the straight-pool revenue sharing plan was used in each season. Forbes reports the estimates of gate revenue, other revenue, and total revenue. ${ }^{22}$ Other revenue includes all other sources of local revenue (parking, concessions, marketing, local media,

20 Local revenue consists of gate receipts, local television, radio and cable rights fees, ballpark concessions, local advertising, sponsorship and publications, parking, suite rentals, and postseason and spring training revenues. Local revenues are the largest single component of most clubs' total annual revenues. The only other significant source of revenue is the Major League Central Fund revenue that is not distributed from the supplemental revenue sharing plan. See footnote 21.

21 Financial statements for MLB clubs are sometimes leaked by the press or presented voluntarily by MLB clubs, but only sporadically. See Rod Fort's website for limited data for the Seattle Mariners, Milwaukee Brewers, and Cleveland Indians (https://sites.google.com/site/rodswebpages/codes). More recent data for the Los Angeles Angels, Florida Marlins, and Pittsburgh Pirates can be found at http:/ / deadspin.com/5615096/mlb-confidential-the-financial-documents-baseballdoesnt-want-you-to-see-part-1.

22 The data are conveniently located at Rod Fort's website, https://sites.google.com/site/rodswebpages/codes. 
and so on), as well as the net revenue sharing payment received and the share of the national broadcast revenue. To evaluate Equation (15), we require total local revenue before revenue sharing. We first subtract the share of the national television broadcast revenue from the reported total local revenue $\mathrm{e}^{23}$ that is not shared through the supplemental revenue sharing plan. All the remaining local revenue is shared and is reported net of any revenue sharing payment. We calculate local revenue before sharing using the formula $R_{1}=\left(R_{1}^{A}-(1-a) \bar{R}\right) / \alpha$ using the values $\alpha=0.66, \alpha=0.69$, and $\alpha=0.66, \alpha=0.69$, and $\alpha=0.66$ for the 2002-2006, 2007-2011, and 2012-2013 periods respectively. Finally, we divided by the national consumer price index $(2002=100)$ to convert to real local revenues. ${ }^{24}$

In our Table 2, we estimated the utility gains to MLB in the 2002-2013. We use the parameter values $\alpha=0.66$ (2002-2006), $\alpha=0.69$ (2007-2011), $\alpha=0.66$ (2012-2013) and $\theta=3$. Our choice of value for $\theta$ is based on survey evidence found in Mehra and Prescott (1985); however, using $\theta=2$ eliminates any utility gains from temperance, and using $\theta=1$ eliminates any gains from skewness, so we chose $\theta=3$ to include all of the utility gains. The utility gain due to the decrease in the variance of team revenues ranged from $9.5 \%$ to $18.4 \%$, averaging $14.1 \%$ of the average team revenue, over and above what the change would have been without revenue sharing. The losses due to reducing positive skewness were modest, ranging from $-3.8 \%$ to $-22.5 \%$, averaging $-9.4 \%$. This utility-reducing effect of revenue sharing was evident in all of the 2002-2013 seasons.

Table 2. Average utility gains per team in MLB, 2002-2013 seasons. $(\alpha=0.66(2002-2006), \alpha=0.69$ (2007-2011), $\alpha=0.66$ (2012-2013), $\theta=3$ ).

\begin{tabular}{|c|c|c|c|c|c|c|c|c|c|}
\hline Season & $\bar{R}$ (\$millions) & $\sigma^{2}$ & $\sigma^{3}$ & $\sigma^{4}$ & $\begin{array}{l}\text { Utility } \\
\text { Gain from } \\
\text { Variance }^{1}\end{array}$ & $\begin{array}{l}\text { Utility Gain } \\
\text { from } \\
\text { Skewness }^{1}\end{array}$ & $\begin{array}{l}\text { Utility } \\
\text { Gain from } \\
\text { Kurtosis }^{1}\end{array}$ & $\begin{array}{l}\text { Total } \\
\text { Utility } \\
\text { Gain } 1\end{array}$ & $\begin{array}{c}\text { Total Utility } \\
\text { Gain in \$ } \\
\text { Millions }\end{array}$ \\
\hline 2002 & 109.4 & 2607.2 & 124,007 & $24,251,058$ & 0.184 & -0.067 & 0.034 & 0.151 & 16.55 \\
\hline 2003 & 114.33 & 2031.3 & 149,561 & $25,301,566$ & 0.132 & -0.071 & 0.030 & 0.090 & 10.32 \\
\hline 2004 & 123.77 & 2445.9 & 162,612 & $35,292,374$ & 0.135 & -0.061 & 0.030 & 0.105 & 12.94 \\
\hline 2005 & 133.86 & 2023.4 & 129,960 & $27,444,089$ & 0.095 & -0.038 & 0.017 & 0.074 & 9.91 \\
\hline 2006 & 142.06 & 2409 & 173,012 & $36,258,488$ & 0.101 & -0.043 & 0.018 & 0.076 & 10.81 \\
\hline 2007 & 131.32 & 2524.1 & 187,469 & $40,161,132$ & 0.114 & -0.055 & 0.026 & 0.085 & 11.19 \\
\hline 2008 & 134.92 & 3214 & 366,268 & $85,376,237$ & 0.135 & -0.096 & 0.047 & 0.086 & 11.78 \\
\hline 2009 & 137.62 & 4696.4 & 849,723 & $255,211,618$ & 0.191 & -0.212 & 0.131 & 0.110 & 15.36 \\
\hline 2010 & 150.78 & 3858.9 & 603,760 & $169,196,801$ & 0.132 & -0.117 & 0.062 & 0.078 & 11.78 \\
\hline 2011 & 152.19 & 3995.4 & 603,327 & $166,465,178$ & 0.134 & -0.113 & 0.059 & 0.080 & 12.21 \\
\hline 2012 & 159.3 & 4370.5 & 722,975 & $203,827,486$ & 0.143 & -0.124 & 0.062 & 0.081 & 13.03 \\
\hline 2013 & 161.1 & 4717.7 & 559,595 & $147,568,889$ & 0.145 & -0.087 & 0.039 & 0.097 & 16.12 \\
\hline
\end{tabular}

Our model suggests that revenue sharing should reduce any leptokurtic characteristic (kurtosis) of the league revenue distribution. From Table 2, the utility gain ranged from $1.7 \%$ to $6.2 \%$ of the average annual team revenue, with an average of $4.64 \%$. The last row of Table 2 presents the utility gain or loss from revenue sharing in dollars. For an individual team owner, revenue sharing delivered an average annual utility gain of $\$ 12.7$ million. The present value of these gains or losses for the average team is $\$ 138.5$ million, discounted back to the 2002 season using a 3\% discount rate, or $\$ 146.5$ million using a $2 \%$ discount rate. ${ }^{25}$ Much of this net utility gain arises from the decrease in variance of team revenues that revenue sharing delivers, while decreasing the leptokurtic league revenue distribution (kurtosis) provided smaller net benefits. The net utility gain could have been even larger if the league local revenue distribution (before revenue sharing) did not become increasingly positively skewed over the seven seasons: from a Pearson skewness coefficient value of 0.935 in 2002 to 2.64 in 2009, falling back to 1.73 in the 2013 season.

23 Each team received approximately $\$ 18.6$ million in each of the 2002 through 2006 seasons, and $\$ 23.7$ million in each of the 2007 through 2013 seasons. https://sites.google.com/site/rodswebpages/codes. These amount to an average share of local revenue of $18.5 \%$ in 2002 , gradually declining to $11.8 \%$ in 2013 .

24 http://www.usinflationcalculator.com/.

25 The average real interest rate (reported by the World Bank) was 3\% for the U.S. over the 2002-2011 period. 
Figure 3 reports the effect of changes in $\theta$ on the present value of the utility increase over the period. The curve reflects the increasing importance of skewness to the final utility gain. From (15) it is apparent that the impact on utility is a positive function of $\theta$. Higher values of $\theta$ reflect higher values of risk aversion, but as is clear it does not mean that utility changes must be uniform. Our choice of $\theta=3$ is quite conservative in light of the shape of Figure 3, and suggests that the utility gains from revenue sharing could be much larger than we compute.

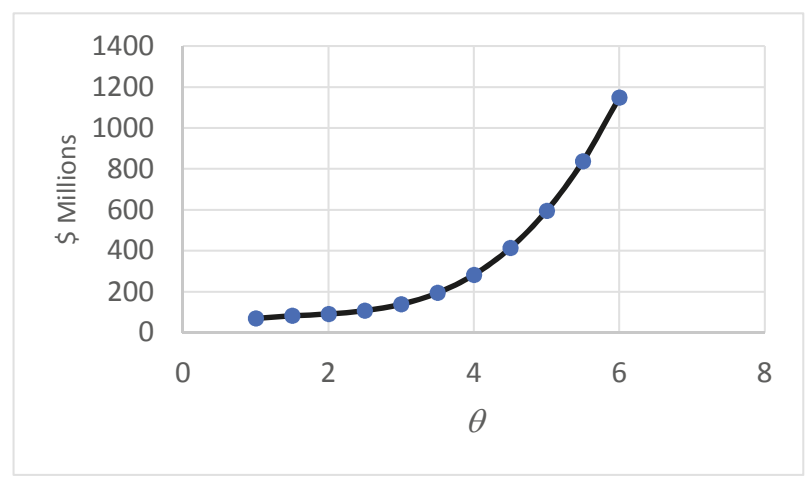

Figure 3. The prevent value in Dollars of the net utility gain with changes in $\theta$. (Discount rate $r=0.03$ and $\alpha=0.69$ and $\alpha=0.66$ as per text).

\section{Conclusions}

We have demonstrated significant utility gains to MLB from the straight pool revenue sharing system first adopted in the 2002 CBA. However, our measures of utility gain could be understated for several reasons. It may be that team owners are more risk-averse than we have assumed, implying that our values for $\theta$ are too small, but this seems unlikely. At the league level, stability of revenues could enhance the ability of a league commissioner to negotiate lucrative rights packages for television, internet, merchandising and so on. In the past, revenue sharing has also been a useful policy to prevent the formation of rival leagues by making the existing league attractive to cities that wish to join. At the team level, revenue sharing reduces the variance of local revenues after revenue sharing and hence reduces risk. This could have two beneficial effects for team owners. Lower risk can reduce the capital costs of new facilities for teams that wish to finance a portion or all of their new facilities. Local governments might be more willing to pick up a portion of the construction costs when they know that the team is on a stable financial footing and unlikely to leave for greener pastures once construction is finished. More importantly for team owners, low financial risk enhances the market value of the team when potential buyers are risk-averse. For many team owners, the financial rewards are the greatest when the team is sold.

Since revenue sharing costs little to implement, it would seem to be advantageous for a professional sports league to adopt it. In fact, further utility gains could be had by utilizing a progressive revenue tax. However, the wealthiest teams could oppose revenue sharing since the system penalizes on-field success and financial smarts. MLB has used a progressive competitive balance tax since the 1996 CBA. If their payrolls exceed the payroll threshold set in the most current CBA (\$195 million for the 2017 season) and if they are first-time offenders, teams pay a tax rate of $22.5 \%$ of the payroll overage. The tax rate increases to $30 \%$ for second-time offenders, $40 \%$ for third-time offenders and $50 \%$ for four or more offenses. It is estimated that the New York Yankees paid 
\$304 million in tax over the 2002-2016 seasons. ${ }^{26}$ Even though the tax system is progressive in some sense, the tax revenue is not redistributed to any of the MLB teams; hence the tax system lacks the redistributive effects of revenue sharing. Neither revenue sharing nor the competitive balance tax is an ideal system in a league utility sense.

Mirlees (1971) demonstrated that an optimal income tax system still features a progressive income tax rate, even after accounting for the negative work-incentive effects of the tax, although his criteria of welfare differed from ours in that he focused on utility from consumption for individual workers. It would be useful to explore whether the same result holds for the use of revenue sharing in a professional sports league using our measure of league welfare. However, it would necessitate specifying how the progressive revenue sharing tax affects the talent decisions of team owners; that is, stating what the function $R_{i}=R_{i}\left(\alpha, w_{i}\right)$ looks like. ${ }^{27}$ We leave that problem for future research.

Our paper is not without its shortcomings. Straight-pool revenue sharing has fairly predictable effects on team behavior that we chose to ignore in our static analysis. These include a decrease in player salaries, a redistribution of talent to large market teams, and a worsening of league parity. The ultimate effect on team profit is uncertain. Our concern is with the moments of the league local revenue distribution. Endogenizing these dynamic effects into a league model of local revenue with revenue sharing is a challenging task. We also abstract from the welfare effects of revenue sharing, and choose to only focus on the utility gains for the representative team owner. A more encompassing model of welfare would include the effects on team profits, and the effects on utility for consumers of MLB games arising from changes in consumer surplus and parity effects. This would require a general equilibrium model of league outcomes and consumer utility that we chose not to attempt. Finally, we consider only the effects of the straight-pool revenue sharing plan on the league local revenue distribution, ignoring the potential utility gains from the sharing of Central Fund revenues. Central Fund revenues do not arise from a tax on local revenues that arise from the profit-maximizing decisions of team owners. Instead they are typically treated in the literature as a fixed revenue that does not affect profit-maximizing decisions, although they obviously increase team profit. Nevertheless, we believe that the overlooking the distribution of Central Fund revenues is misplaced and worthy of future study.

Author Contributions: Authors equally contributed to the research and writing of the paper.

Conflicts of Interest: The authors declare no conflict of interest.

\section{References}

Asplund, Marcus. 2002. Risk-averse firms in oligopoly. International Journal of Industrial Organization 20: 995-1012. [CrossRef]

Bontemps, Tim. 2017. Why revenue sharing, one of the NBA's thorniest issues, demands a solution. The Washington Post, September 28, (Extracted on 6 February 2018).

Chiu, W. Henry. 2005. Skewness preference, risk aversion and the precedence changes on stochastic relations. Management Science 51: 1816-28. [CrossRef]

Choudhary, M. Ali, and Paul Levine. 2010. Risk-averse firms and employment dynamics. Oxford Economic Papers 3: 578-602. [CrossRef]

Dietl, Helmut, Markus Lang, and Stephan Werner. 2009. Social welfare in sports leagues with profit-maximizing and/or win-maximizing clubs. Southern Economic Journal 76: 375-96. [CrossRef]

Dixit, Avinash, and Victor Norman. 1986. Gains from trade without lump-sum compensation. Journal of International Economics 21: 111-22. [CrossRef]

26 Orinick (2017).

27 Marburger (1997) considers the effect of a progressive competitive balance tax on owner incentives and equilibrium outcomes, but does not consider a progressive revenue sharing tax. 
Easton, Stephen, and Duane Rockerbie. 2005. Revenue sharing, conjectures and scarce talent in a sports league model. Journal of Sports Economics 6: 359-78. [CrossRef]

Easton, Stephen, and Duane Rockerbie. 2010. The ebbs and flows of the game: Multiple equilibria in a sports league model. Journal of Sports Economics 11: 172-85.

Eeckhoudt, Louis, and Harris Schlesinger. 2013. Higher order risk attitudes. In Handbook of Insurance. Edited by Georges Dionne. New York: Springer, pp. 41-57.

Eeckhoudt, Louis, Christian Gollier, and Thierry Schneider. 1995. Risk-aversion, prudence and temperance: A unified approach. Economic Letters 48: 331-36. [CrossRef]

Fort, Rodney, and James Quirk. 1995. Cross-subsidization, incentives and team outcomes in professional team sports leagues. Journal of Economic Literature 33: 1265-99.

Fort, Rodney, and James Quirk. 2010a. Optimal competitive balance in single-game ticket sports leagues. Journal of Sports Economics 11: 587-601. [CrossRef]

Fort, Rodney, and James Quirk. 2010b. Optimal competitive balance in a season ticket league. Economic Inquiry 49: 464-73. [CrossRef]

Goldberg, Pinelopi Koujianou, and Nina Pavcnik. 2007. Distributional effects of globalization in developing countries. Journal of Economic Literature 45: 39-82. [CrossRef]

Herranz, Neus, Stefan Krasa, and Anne P. Villamil. 2015. Entrepreneurs, risk aversion and dynamic firms. Journal of Political Economy 123: 1133-76. [CrossRef]

Hill, James Richard, and Nicholas A. Jolly. 2015. Revenue sharing and player salaries in Major League Baseball. Journal of Sports Economics 18: 831-49. [CrossRef]

Kesenne, Stefan. 2000. Revenue sharing and competitive balance in professional team sports. Journal of Sports Economics 1: 56-65. [CrossRef]

Kesenne, Stefan. 2007. Revenue sharing and owner profits in professional sports models. Journal of Sports Economics 8: 519-29. [CrossRef]

Kesenne, Stefan. 2015. Revenue sharing and absolute league quality, talent investment and talent allocation. Scottish Journal of Political Economy 62: 51-58. [CrossRef]

Kimball, Miles. 1990. Precautionary saving in the small and in the large. Econometrica 58: 53-73. [CrossRef]

Knight, Frank. 1921. Risk Uncertainty and Profit. Boston: Houghton Mifflin Company, Reprinted in New York: Augustus M. Kelley, 1964.

Kraus, Alan, and Robert Litzenberger. 1976. Skewness preference and the valuation of risky assets. Journal of Finance 31: 1085-100.

Krautmann, Anthony. 2017. Risk-averse team owners and player's salaries in Major League Baseball. Journal of Sports Economics 18: 19-33. [CrossRef]

Kroll, Yoram, Haim Levy, and Harry Markowitz. 1984. Mean-variance versus direct utility maximization. Journal of Finance 39: 47-61. [CrossRef]

Leland, Hayne. 1972. Theory of the firm facing random demand. American Economic Review 62: 278-91.

Levy, Haim, and Harry Markowitz. 1979. Approximating expected utility by a function of mean and variance. American Economic Review 69: 308-17.

Loistl, Otto. 1976. The erroneous approximation of expected utility by means of a Taylor series expansion. American Economic Review 66: 904-10.

Lucas, Robert. 1987. Models of Business Cycles. Oxford: Blackwell Publishers.

Major League Baseball. 2001. Updated Supplement to the Report of the Independent Members of the Commissioner's Blue Ribbon Panel on Baseball Economics. December. Available online: http:// roadsidephotos.sabr.org/baseball/BRpanelupd.doc (accessed on 2 August 2017).

Marburger, Daniel. 1997. Gate revenue sharing and luxury taxes in professional sports. Contemporary Economic Policy 15: 114-23. [CrossRef]

Markowitz, Harry. 1952. Portfolio selection. Journal of Finance 7: 77-91.

Maxcy, Joel. 2004. Motivating long-term employment contracts: Risk management in Major League Baseball. Managerial and Decision Economics 25: 109-20. [CrossRef]

Maxcy, Joel. 2009. Progressive revenue sharing in Major League Baseball: The effect on player transfers and talent distribution. Review of Industrial Organization 35: 275-97. [CrossRef]

Mehra, Rajnish, and Edward Prescott. 1985. The equity premium: A puzzle. Journal of Monetary Economics 15: 145-61. [CrossRef] 
Miller, Phillip. 2007. Revenue sharing in sports leagues: The effects on talent distribution and competitive balance. Journal of Sports Economics 8: 62-82. [CrossRef]

Mirlees, James. 1971. An exploration in the theory of optimal income taxation. Review of Economic Studies 38: 175-208. [CrossRef]

Neale, Walter. 1964. The peculiar economics of professional sports. Quarterly Journal of Economics 78: 1-14. [CrossRef]

Orinick, Steve. 2017. Competitive Balance Tax. Available online: http://www.stevetheump.com/luxury_tax.htm (accessed on 2 August 2017).

Pulley, Lawrence. 1981. A general mean-variance approximation to expected utility for short holding periods. Journal of Financial and Quantitative Analysis 16: 361-73. [CrossRef]

Rockerbie, Duane. 2009. Free agent auctions and revenue sharing: A simple exposition. Journal of Sport Management 23: 87-98. [CrossRef]

Rockerbie, Duane. 2017. The invariance principle in baseball: New evidence. Applied Economics 50: 2613-21. [CrossRef]

Rockerbie, Duane, and Stephen Easton. 2014. The Run to the Pennant: A Multiple Equilibria Approach to Professional Sports Leagues. New York: Springer.

Ross, J. Andrew. 2015. Joining the Clubs: The Business of the National Hockey League to 1945. Syracuse: Syracuse University Press.

Sandmo, Agnar. 1971. On the theory of the competitive firm under price uncertainty. American Economic Review 61: 65-73.

Surdham, David. 2007. A tale of two gate-sharing plans: The National Football League and the National League, 1952-56. Southern Economic Journal 73: 931-46.

Szymanski, Stefan. 2004. Professional team sports are only a game: The Walrasian fixed-supply conjecture model, contest-Nash equilibrium, and the invariance principle. Journal of Sports Economics 5: 111-26. [CrossRef]

Tew, Bernard, Donald Reid, and Craig Witt. 1991. Opportunity cost of a mean-variance efficient choice. Financial Review 26: 31-44. [CrossRef]

Thomas, Jonathan, and Tim Worrall. 1988. Self-enforcing wage contracts. Review of Economic Studies 55: 541-53. [CrossRef]

Tompkins, D. 2000. The opportunity cost of E-V efficient portfolios. Academy of Accounting and Financial Studies Journal 4: 61-71.

Vrooman, John. 2009. Theory of the perfect game: Competitive balance in monopoly sports leagues. Review of Industrial Organization 34: 5-44. [CrossRef]

(C) 2018 by the authors. Licensee MDPI, Basel, Switzerland. This article is an open access article distributed under the terms and conditions of the Creative Commons Attribution (CC BY) license (http:/ / creativecommons.org/licenses/by/4.0/). 
Article

\title{
Attendance in the Canadian Hockey League: The Impact of Winning, Fighting, Uncertainty of Outcome, and Weather on Junior Hockey Attendance
}

\author{
Rodney Paul ${ }^{1, *}$, Andrew Weinbach ${ }^{2}$ and Nick Riccardi ${ }^{1}$ \\ 1 Department of Sport Management, Syracuse University, Syracuse, NY 13244, USA; nrricar@syr.edu \\ 2 Department of Finance and Economics, E. Craig Wall Sr. College of Business Administration, Coastal \\ Carolina University, Conway, SC 29528, USA; aweinbac@coastal.edu \\ * Correspondence: rpaul01@syr.edu
}

Received: 21 December 2018; Accepted: 13 February 2019; Published: 19 February 2019

\begin{abstract}
An attendance model is specified for the Canadian Hockey League (CHL), the top level of junior hockey in Canada with some teams located in the United States. The natural log of attendance is used as the dependent variable, with explanatory variables consisting of the timing of the game, team performance characteristics, uncertainty of outcome measures, and weather-related variables. Weekends and Mondays were the most popular days for games. Winning and fighting were shown to be popular team characteristics that drive attendance. Uncertainty of outcome plays little role, if any, in fan interest at this level, while precipitation significantly reduces attendance.
\end{abstract}

Keywords: attendance; hockey; fighting; uncertainty of outcome

JEL Classification: Z20; D12

\section{Introduction}

In sports, an important component of financial performance of a franchise is attendance. Attendance as a key factor of financial performance has been shown in sports such as soccer in France (Andreff 2018; Scelles et al. 2018) and in England (Szymanski 2017). Even in leagues with major television deals, attendance has a significant positive impact on the financial value of sports firms (i.e., Scelles et al. 2013c, 2016a, 2017).

This article focuses on the determinants of attendance in the Canadian Hockey League (CHL), which is the top-tier of junior hockey in Canada (with some franchises located in the United States as well). In recent years, two variables have been explored and debated as it relates to their role in hockey attendance. These two variables are fighting and uncertainty of outcome. Fighting has seemingly always been a hot topic as it relates to its implications on the sport. Recent examples of the study of the role of fighting in hockey include Burdekin and Morton (2015) and Rockerbie (2016). One argument on the business-side of hockey, as it relates to fighting, is that fisticuffs ${ }^{1}$ between the players is an aspect of the game that is enjoyed by fans. Various studies have linked the frequency of fighting to attendance, but these studies have mostly focused on older players as professionals. About uncertainty of outcome in relation to game competitive balance ${ }^{2}$, measured directly from game odds in the betting market, the

1 Fisticuffs refers to fighting with the fists, which occurs in hockey fights when players discard their gloves and fight with each other.

2 This study focuses on uncertainty of outcome related to the individual game. Other elements of uncertainty of outcome relate to seasonal factors such as a team being in contention for the playoffs or for a qualification in continental competitions. Studies related to this aspect of outcome uncertainty include Fort and Maxcy (2003), Garcia and Rodriguez (2002), Andreff and Scelles (2015), Scelles (2017), and Scelles et al. (2013a, 2013b, 2016b). 
traditional theory that fans enjoy games between evenly matched-teams (resulting in a high level of uncertainty of outcome) has been challenged by an alternative theory based upon reference-dependent preferences, loss aversion, and a desire to witness upsets (Coates et al. 2014). While these issues have been studied at the professional level for adults playing the sport, it is informative to ascertain how these factors, and others, affect fan decisions at the junior hockey level, where players are much younger than those participating in the professional ranks.

The CHL consists of three leagues, the Ontario Hockey League (OHL), the Quebec Major Junior Hockey League (QMJHL), and the Western Hockey League (WHL). Each league has their own regional restrictions in Canada and the United States from which they draw players and there are limited allowances for players from Europe and other places in the world through the CHL Import Draft. The CHL Import Draft allows CHL teams to draft players whose parents are not residents of Canada or the United States. These imports can only be obtained through the draft and each team may only have a maximum of two imports on their roster. The three leagues play their own individual seasons, followed by playoffs. In the two seasons (2016-17 and 2017-18) studied, the Ontario Hockey League had twenty teams, the Quebec Major Junior Hockey League had eighteen teams, and the Western Hockey League had twenty-two teams. In each league, sixteen teams qualified for the playoffs each season. The winner of each league's playoff, combined with the team from the host city (chosen in advance), played for the championship of the CHL in the MasterCard Memorial Cup at the conclusion of the hockey season.

To compete in the CHL, players must be at least sixteen years of age, with exemptions granted for players of "exceptional status", who may begin playing at the age of fifteen. Some players who were granted "exceptional status" include current National Hockey League (NHL) (the top hockey league in North America and the world) stars John Tavares, Aaron Ekblad, and Connor McDavid. Players in the CHL may play until they reach the age of twenty. Teams can have three "overage" (20-year old) players and up to four sixteen-year-old players (or fifteen with "exceptional status") on their rosters. The rules of the game mimic those of the NHL, including the allowance of fighting in the sport, which earns each player a five-minute penalty for this infraction. As a side note, from the perspective of the National Collegiate Athletic Association (NCAA) (a non-profit organization that regulates collegiate athletics), players who play in the CHL are considered professionals and lose their eligibility to play college hockey in the United States.

As mentioned at the start of the introduction, this study investigates the determinants of attendance for teams in the CHL. Using an ordinary least squares regression model, factors related to game timing, weather conditions, team performance, and outcome uncertainty are tested to determine their significance and influence on individual game attendance for each of the teams in the three leagues that comprise the Canadian Hockey League. Specifically, the main null hypotheses tested include the implications of the uncertainty of outcome hypothesis, the role of winning (measured as a points-per-game running average), and the role of fighting as it relates to fan interest. The uncertainty of outcome hypothesis has been shown to have mixed results across sports and it is informative to ascertain if this factor plays any role (and if so, what role) in fan decisions for junior hockey. Logically, winning would be expected to influence fan decisions and fighting has been shown in the past to be a significant factor in fan decisions. However, this league is for young players (twenty years of age and under) and is a key developmental level in the training of many young players. These factors may lead to fans having different preferences for junior hockey compared to professional hockey. Therefore, this research explicitly models and tests these null hypotheses for a sample of two complete regular seasons (playoff games were not included) in the CHL (2016-17 and 2017-18 seasons).

The paper is structured as follows. Section 2 provides a brief literature review on attendance studies as it relates to the sport of hockey. Section 3 describes the empirical model and presents the regression model results. The final section discusses the findings and concludes the paper. 


\section{Literature Review}

Recent literature on hockey attendance has focused on the role of structural breaks in time-series data over many seasons. Using data on teams in existence for over forty seasons (29 in Major League Baseball, 13 in the National Basketball Association, and 11 in the National Hockey League), Mills and Fort (2018) extended the study of structural break points to the team level. They found mixed evidence of the role of outcome uncertainty on attendance through empirical testing of game uncertainty, playoff uncertainty, and consecutive season uncertainty. They also found considerable differences in their team-level analysis compared to league-level analysis as it relates to break points in the data.

Treber et al. (2018) examined the NHL lockouts in 1994-95, 2004-05, and 2012-13. They found evidence of a decrease in attendance following the lockout of 1994-95 and a decrease in revenue for the league following the lockouts of 2004-05 and 2012-13. Although the lockouts had a negative influence on fan demand for NHL games, the authors suggest that the cost savings generated by the lockouts could be enough to offset the reduction in attendance and revenue, leading to the lockouts still being an optimal strategy for the league.

One of the key components of the economic research surrounding game-to-game hockey attendance is an investigation into fighting. The role of fighting in the NHL has been studied previously in Jones (1984), Jones et al. (1993), Jones et al. (1996) and Paul (2003). Fighting was shown to have a positive and significant effect on attendance in each study. Although there were differences in magnitude as it relates to the country where NHL games were played, the impact of fighting on attendance was seen in both Canadian and American cities. Rockerbie (2012) found that NHL fans respond positively to greater violence, with hitting having a greater effect on attendance than fighting.

In most European leagues, fighting is met with immediate rejection from the match, not a 5-min penalty as it is in the NHL and other leagues in North America. Although fighting is not allowed in the DEL league in Germany, evidence was found that penalty minutes, a proxy for physical play, increased attendance in this league (Coates et al. 2012). Physical play (using penalty minutes as a proxy) was not found to significantly impact attendance in the SM-Liiga in Finland (Coates et al. 2012). Fighting was not shown to have a statistically significant impact on attendance in junior hockey in the Quebec Major Junior Hockey League (Paul and Weinbach 2011).

Fighting and physicality may play a role in attendance in some leagues, but studies have also investigated if fighting tends to contribute to game outcome success. Leard and Doyle (2011) studied fighting, determining winners and losers of individual fights in the NHL, and did not find a statistically significant relationship between winning fights and winning games. Coates et al. (2012) found a negative relationship between fighting and team success in the NHL.

In terms of the North American minor hockey leagues, fighting has been shown to increase attendance in both the American Hockey League (Paul et al. 2013) and in the ECHL (Paul et al. 2015). At both levels, fighting had a positive and statistically significant effect on attendance. Further details, developed in research by Rockerbie (2017), describe fighting as a profit-maximizing strategy for American Hockey League teams. Fighting was also shown to have a positive and statistically significant impact on attendance in a lower-level minor league, the Southern Professional Hockey League (SPHL) (Paul 2018). Other factors that were found to influence attendance in these studies of minor league hockey were days and months of the season, city-specific demographics, and promotions.

Attendance at minor league games has also been studied in various capacities by Rascher et al. (2009) and Hong (2009). Rascher et al. (2009) discovered increases in attendance for minor league hockey during the NHL lockout of 2004-05. Hong (2009) performed research on the

3 ECHL used to stand for the East Coast Hockey League. As the league expanded, the abbreviation was no longer geographically accurate and the league name was shortened to just "ECHL" in 2003. ECHL still exists as the name, but each letter no longer stands for anything. 
marketing of minor league hockey games and found that teams that successfully drew fans to the arena had higher win percentages, star players, good fan relations, affordable prices, and substantial community involvement.

Another method of research surrounding interest in hockey is with surveys of fans at games. Zhang et al. (1996) found that familiarity with the sport, i.e., hockey knowledge, was important in forecasting game attendance and the level of ticket purchases for International Hockey League games. Zhang et al. (2001) studied social factors influencing minor league hockey attendance and found that health-promoting, achievement seeking, and stress and entertainment factors should be part of the marketing strategies of minor league teams. In a survey of Southern Professional Hockey League (SPHL) fans, violence was found to be important in explaining why fans attended games, although results differed by both gender and the level of ticket purchase (Andrew et al. 2009).

A separate key angle of this study relates to outcome uncertainty. A game expected to be uncertain could be an important consideration in the minds of fans when considering attending a game. The uncertainty of outcome hypothesis $(\mathrm{UOH})$ was first stipulated by Rottenberg (1956) and stated that fans would prefer to attend games where teams were evenly matched. Coates and Humphreys (2012) rejected the uncertainty of outcome hypothesis for the NHL. An alternative hypothesis has been suggested in the literature by Coates et al. (2014) that incorporates reference-dependent preferences and loss aversion. Although this research focuses on individual game level uncertainty of outcome, other uncertainty of outcome measures have been developed as it relates to season-long outcome uncertainty. Studies such as Fort and Maxcy (2003), Garcia and Rodriguez (2002), Andreff and Scelles (2015), Scelles (2017), and Scelles et al. (2013a, 2013b, 2016b) refer and/or examine the role of playoff or qualification for continental competition contention for seasonal outcome uncertainty.

Although outcome uncertainty and similar related theories are important for game-to-game attendance studies, such as the research in this paper, it is closely related to season-to-season studies of attendance that include estimates for competitive balance. Competitive balance is the concept of how evenly balanced a particular sports league is within a season and across seasons. Different measures include the use of the idealized standard deviation of win percentage (i.e., Scully 1989; Quirk and Fort 1997), the CB Ratio statistic (Humphreys 2002), and the use of Herfindahl Indices related to championships (i.e., Kringstad and Gerrard 2004). Another recent innovation as it relates to studies of competitive balance is the Hope Statistic (Kaplan et al. 2011; O'Reilly et al. 2008), which uses statistics related to how far out of a playoff spot a team finished (and has finished over a span of different seasons) to estimate "hope" for a franchise to turn into competitors for a playoff spot and championships in the coming season.

Although this research focuses on the determinants of game-to-game attendance for CHL teams, attendance is only part of the equation as it relates to team profitability. Nadeau and O'Reilly (2006) gathered data from NHL franchises for three NHL seasons and estimated a model to establish the determinants of NHL franchise profitability. They found that team success is important, but influences profits indirectly through the overall level of market support in the city. Other key components to franchise profitability they identified include historical performance, team playing style, team composition, arena location, local market characteristics and competition, and television, among others.

\section{Attendance Model and Results}

The dependent variable in the regression model is the log of attendance. Attendance figures were taken from the box scores of CHL games on the league websites. As box score figures, they suffer from the well-known fact that teams may not report the actual turnstile attendance for each game, perhaps including sold tickets for season ticket holders who were "no-shows" or other similar activities. Given that we did not have access to the true attendance figures from the team/leagues, we used the publicly available figures on team attendance. That said, there is considerable variation from game-to-game on attendance figures for each team that logically makes sense (i.e., higher attendance on weekends, with considerable variation across those weekend games throughout the season) which is revealed in the 
study. Until teams are forced to report actual attendance figures, this will always be a limitation of studies by researchers using publicly available figures.

The independent variables consist of controls for the timing of the game, on-ice performance variables, home win probability measures, and weather variables. The controls for the timing of the game include a dummy for the home opener in the sample where all games are included (specifications I and II). Home openers are typically popular with fans due to the festivities surrounding the start of the hockey season. We would expect the home opener dummy to have a positive and statistically significant effect on the log of attendance. The days between games variable (days between) is the number of days between the current home game and the last home game played. This measure is capped at 14 days (any period of longer than 14 days is listed as 14 days) across the sample. Home games played in rapid succession may suffer from a decline in fan interest due to the availability of attending another game in a short timeframe. If this variable impacts the decisions of fans, it should have a positive and significant effect on the log of attendance.

Dummy variables for the days of the week (with the excluded reference category of Wednesday), the months of the season (with the excluded reference category of January), and season (with the reference category of 2016-17) are included in the model to control for the differences in likely fan interest due to the chronological timing of the game. In terms of the days of the week, weekends are likely to be much more popular for fans due to the opportunity cost of their time on weekends compared to weekdays. Therefore, Fridays, Saturdays, and Sundays are likely to have positive and significant effects on attendance in the model. In terms of the months of the season, early season games (other than opening night) typically are tougher draws for fans, while late season games represent a push toward the playoffs. Therefore, we would expect the early months to have a negative effect on attendance and the late season months to have a positive impact. The season dummy is included to account for any structural difference between the two seasons in the sample.

The on-ice team performance variables include team success and fighting as it relates to game attendance. Team success is measured by points earned (on a per-game basis) during the season, which is a function of how often teams won games. In the CHL, teams receive two points for a win, one point for an overtime or shootout loss, and zero points for a regulation loss. These points are computed as a running average of points earned per game throughout the season. Fans have been shown to prefer successful teams to poorly performing teams across many sports and we would expect this variable to have a positive and significant effect on attendance.

Fighting is a controversial topic in hockey, but previous research has shown that fighting tends to attract fans in different North American hockey leagues. If fans of junior hockey in Canada prefer to see teams that fight more often, this variable should have a positive and significant effect on attendance. If, on the other hand, these players are deemed to be too young to be involved in fighting or fans do not want to see this as part of the game, the coefficient could be negative. Both points per game (PPG) and fights per game (FPG) are quite noisy at the start of the season as they are computed as running averages. Therefore, an alternative specification was run that did not include early-season games (September and early October) with the sample starting after October 15 (around a month into the season). These are shown as specifications III and IV in the table of results.

Home team win probabilities are computed to test the uncertainty of outcome hypothesis at the game level. Rottenberg (1956) first suggested that fans prefer to see games between evenly matched teams, which would result in an uncertain outcome. Various studies have shown conflicting results as it relates to outcome uncertainty across a wide range of sports. For the NHL, Coates and Humphreys (2012) rejected outcome uncertainty as games expected to be close showed lower in-person attendance figures. Recently, Coates et al. (2014) theoretically modelled outcome uncertainty and showed the possibility of a convex relationship (as opposed to a traditional concave relationship under the traditional uncertainty of outcome hypothesis) due to factors such as reference-dependent preferences and loss aversion on the part of fans. To measure home team win probability, we used betting market data for the CHL available from www.oddsportal.com and 
computed the implied home team win probability from the odds adjusting for the over round. To test for outcome uncertainty, we include two specifications. The first is a linear model that only includes the home team win probability. The other model is quadratic in nature and includes the home team win probability and home team win probability squared. If fans prefer outcome uncertainty, the home team win probability term should be positive and its square should be negative. If fans have loss aversion, preferences to see upsets, or other types of reference-dependent preferences, the signs on the coefficients could be reversed. If fans do not care about any of these factors when attending games, the results will be statistically insignificant.

The odds from www.oddsportal.com used in constructing the home team win probability include wagering market data for a home win, draw, or road win. There are not draws in hockey, but the draw bet represents a wager on the game being tied at the end of regulation. An alternative measure of home win probability which sums the home win probability and one-half of the draw probability of the game was also tried using the betting data. The results did not deviate much from the main results shown in the body of the paper, nor did it impact the statistical significance of the hypothesis tests. Results of this measure are available upon request from the authors.

The last category of independent variables included in the model relates to game day weather. Weather data for each city in the CHL was gathered from www.weatherunderground.com. Temperature, measured as degrees Fahrenheit, and precipitation level (in inches) were included in the model. These weather-related variables do not relate to conditions while fans are sitting at a game, as games are held indoors in arenas in the CHL, but to the transaction costs to fans of actually getting to and from the game from home or work. Cold weather, rain, and especially ice and snow could discourage fans from leaving the house to brave the elements to attend a game in person. If cold temperatures and rain or snow keep fans from attending junior hockey games, these variables should have negative and significant effects on the log of attendance.

Summary statistics of the non-binary variables in the model are shown in Table 1 below for the full sample of games.

Table 1. Summary statistics.

\begin{tabular}{cccc}
\hline Variable & Mean & Median & Standard Deviation \\
\hline Attendance & 3950.02 & 3454.00 & 2049.89 \\
PPG & 1.13 & 1.14 & 0.313 \\
FPG & 0.38 & 0.36 & 0.22 \\
Temperature & 29.82 & 32 & 18.06 \\
Precipitation & 0.05 & 0 & 0.15 \\
Home Win Probability & 0.45 & 0.44 & 0.13 \\
Days Between & 5.11 & 4 & 4.15 \\
\hline
\end{tabular}

The regression model results are shown in Table 2. Models I and II use the full season, while models III and IV omit the first month of the season (data starts on October 15) to allow for the points-per-game and fights-per-game running averages to stabilize. The coefficients and their respective $t$-values are shown for each specification. Due to heteroskedasticity and autocorrelation issues with the original results, HAC (heteroskedasticity- and autocorrelation-consistent)-consistent standard errors and covariances were used and reported in Table 2 with the Newey-West estimator. 
Table 2. Regression results for Canadian Hockey League (CHL) attendance model 2016-17 to 2017-18 seasons.

\begin{tabular}{|c|c|c|c|c|}
\hline \multirow{2}{*}{$\begin{array}{c}\text { Dependent Variable: } \\
\text { Log(Attendance) }\end{array}$} & \multicolumn{2}{|c|}{ Full Season Results } & \multicolumn{2}{|c|}{ Results without Early Season Games } \\
\hline & \multicolumn{2}{|c|}{$(n=4163)$} & \multicolumn{2}{|c|}{$(n=3707)$} \\
\hline Independent Variable & $\begin{array}{c}\text { (I) } \\
\text { Linear }\end{array}$ & $\begin{array}{c}\text { (II) } \\
\text { Quadratic }\end{array}$ & $\begin{array}{l}\text { (III) } \\
\text { Linear }\end{array}$ & $\begin{array}{c}\text { (IV) } \\
\text { Quadratic }\end{array}$ \\
\hline Intercept & $\begin{array}{l}7.3140 * * * \\
(155.0427)\end{array}$ & $\begin{array}{l}7.2733^{* * *} \\
(131.7108)\end{array}$ & $\begin{array}{l}7.2563 * * * \\
(180.4596)\end{array}$ & $\begin{array}{l}7.2123 \text { *** } \\
(149.8318)\end{array}$ \\
\hline Home Open & $\begin{array}{l}0.2721^{* * *} \\
(11.1604)\end{array}$ & $\begin{array}{l}0.2724^{* * *} \\
(11.1742)\end{array}$ & & \\
\hline Days Between & $\begin{array}{c}0.0049 * * * \\
(6.6067)\end{array}$ & $\begin{array}{c}0.0049^{* * *} \\
(6.6002)\end{array}$ & $\begin{array}{c}0.0058^{* * *} \\
(5.9985)\end{array}$ & $\begin{array}{c}0.0058^{* * *} \\
(5.9897)\end{array}$ \\
\hline Sunday & $\begin{array}{c}0.1262 * * * \\
(8.8796)\end{array}$ & $\begin{array}{c}0.1265^{* * *} \\
(8.8884)\end{array}$ & $\begin{array}{c}0.1351^{* * *} \\
(8.1790)\end{array}$ & $\begin{array}{c}0.1352 * * * \\
(8.1683)\end{array}$ \\
\hline Monday & $\begin{array}{c}0.2024^{* * *} \\
(6.1314)\end{array}$ & $\begin{array}{c}0.2023 * * * \\
(6.1281)\end{array}$ & $\begin{array}{c}0.2185^{* * *} \\
(5.1458)\end{array}$ & $\begin{array}{c}0.2185^{* * *} \\
(5.1433)\end{array}$ \\
\hline Tuesday & $\begin{array}{l}-0.0289 * \\
(-1.8330)\end{array}$ & $\begin{array}{l}-0.0289^{*} \\
(-1.8281)\end{array}$ & $\begin{array}{c}-0.0242 \\
(-1.2239)\end{array}$ & $\begin{array}{c}-0.0242 \\
(-1.2214)\end{array}$ \\
\hline Thursday & $\begin{array}{c}0.0584 \text { *** } \\
(3.4758)\end{array}$ & $\begin{array}{c}0.0583^{* * *} \\
(3.4770)\end{array}$ & $\begin{array}{c}0.0622 * * * \\
(2.7770)\end{array}$ & $\begin{array}{c}0.0622 * * * \\
(2.7726)\end{array}$ \\
\hline Friday & $\begin{array}{l}0.1402 * * * \\
(11.9616)\end{array}$ & $\begin{array}{l}0.1400 * * * \\
(11.9489)\end{array}$ & $\begin{array}{l}0.1450 * * * \\
(10.1132)\end{array}$ & $\begin{array}{l}0.1446^{* * *} \\
(10.0548)\end{array}$ \\
\hline Saturday & $\begin{array}{l}0.2117^{* * *} \\
(14.5227)\end{array}$ & $\begin{array}{l}0.2117^{* * *} \\
(14.5172)\end{array}$ & $\begin{array}{l}0.2254^{* * *} \\
(14.9650)\end{array}$ & $\begin{array}{l}0.2253^{* * *} \\
(14.9418)\end{array}$ \\
\hline September & $\begin{array}{c}-0.1350 * * * \\
(-6.5388)\end{array}$ & $\begin{array}{c}-0.1375 * * * \\
(-6.6472)\end{array}$ & & \\
\hline October & $\begin{array}{c}-0.1211 * * * \\
(-9.0090)\end{array}$ & $\begin{array}{c}-0.1235^{* * *} \\
(-9.1110)\end{array}$ & $\begin{array}{c}-0.1097^{* * *} \\
(-7.5897)\end{array}$ & $\begin{array}{c}-0.1120 * * * \\
(-7.7294)\end{array}$ \\
\hline November & $\begin{array}{c}-0.0378^{* * *} \\
(-3.4465)\end{array}$ & $\begin{array}{c}-0.0394 * * * \\
(-3.5651)\end{array}$ & $\begin{array}{c}-0.0390 * * * \\
(-3.0714)\end{array}$ & $\begin{array}{c}-0.0406 * * * \\
(-3.1905)\end{array}$ \\
\hline December & $\begin{array}{c}-0.0049 \\
(-0.5069)\end{array}$ & $\begin{array}{c}-0.0064 \\
(-0.6494)\end{array}$ & $\begin{array}{c}-0.0056 \\
(-0.3789)\end{array}$ & $\begin{array}{c}-0.0071 \\
(-0.4823)\end{array}$ \\
\hline February & $\begin{array}{c}0.0531^{* * *} \\
(5.2573)\end{array}$ & $\begin{array}{c}0.0538^{* * *} \\
(5.3455)\end{array}$ & $\begin{array}{c}0.0528^{* * *} \\
(4.6666)\end{array}$ & $\begin{array}{c}0.0537^{* * *} \\
(4.7437)\end{array}$ \\
\hline March & $\begin{array}{l}0.1483^{* * *} \\
(12.6849)\end{array}$ & $\begin{array}{l}0.1499^{* * *} \\
(12.7717)\end{array}$ & $\begin{array}{l}0.1477^{* * *} \\
(10.8667)\end{array}$ & $\begin{array}{l}0.1495^{* * *} \\
(10.8252)\end{array}$ \\
\hline 17-18 Season & $\begin{array}{c}0.0021 \\
(0.2726)\end{array}$ & $\begin{array}{c}0.0007 \\
(0.0954)\end{array}$ & $\begin{array}{c}0.0016 \\
(0.1887)\end{array}$ & $\begin{array}{c}-0.0001 \\
(-0.0144)\end{array}$ \\
\hline Points Per Game Average & $\begin{array}{c}0.0326^{* * *} \\
(3.1352)\end{array}$ & $\begin{array}{c}0.0406^{* * *} \\
(3.1009)\end{array}$ & $\begin{array}{c}0.0665^{* * *} \\
(3.9883)\end{array}$ & $\begin{array}{c}0.0656^{* * *} \\
(3.9435)\end{array}$ \\
\hline Fights Per Game Average & $\begin{array}{c}0.0327 \\
(1.4727)\end{array}$ & $\begin{array}{c}0.0321 \\
(1.4517)\end{array}$ & $\begin{array}{c}0.0690^{* * *} \\
(2.5987)\end{array}$ & $\begin{array}{c}0.0677^{* *} \\
(2.5630)\end{array}$ \\
\hline Home Win Probability & $\begin{array}{c}-0.0087 \\
(-0.0088)\end{array}$ & $\begin{array}{c}0.1834 \\
(1.2858)\end{array}$ & $\begin{array}{c}-0.0248 \\
(-0.8837)\end{array}$ & $\begin{array}{c}0.1872 \\
(1.4447)\end{array}$ \\
\hline Home Win Probability ${ }^{2}$ & & $\begin{array}{c}-0.2019 \\
(-1.3976)\end{array}$ & & $\begin{array}{l}-0.2225^{*} \\
(-1.6840)\end{array}$ \\
\hline Precipitation (in) & $\begin{array}{c}-0.0445^{* * *} \\
(-2.2474)\end{array}$ & $\begin{array}{l}-0.0451^{* *} \\
(-2.2734)\end{array}$ & $\begin{array}{l}-0.0580^{* *} \\
(-2.3236)\end{array}$ & $\begin{array}{l}-0.0589 * * \\
(-2.3496)\end{array}$ \\
\hline Temperature $\left(\mathrm{F}^{\circ}\right)$ & $\begin{array}{c}-0.0003 \\
(-1.0381)\end{array}$ & $\begin{array}{c}-0.0003 \\
(-0.9913)\end{array}$ & $\begin{array}{c}-4.30 \mathrm{e}-05 \\
(-0.1420)\end{array}$ & $\begin{array}{c}-2.60 \mathrm{e}-05 \\
(-0.0857)\end{array}$ \\
\hline Home Team Dummies & Yes & Yes & Yes & Yes \\
\hline$R$-squared & 0.8436 & 0.8437 & 0.8341 & 0.8342 \\
\hline Adj. $R$-squared & 0.8404 & 0.8405 & 0.8304 & 0.8305 \\
\hline
\end{tabular}

Statistical significance is noted by ${ }^{*}$-notation. Rejection of the null hypothesis that the coefficient is equal to zero is noted at the $10 \%(*), 5 \%(* *)$, and $1 \%(* *)$ levels. 
In summarizing the results, we will discuss the findings, in order, by category of independent variables. In terms of the control variables for the day, calendar date, and related variables, positive and statistically significant results at the $1 \%$ level were shown for teams' home openers in both specifications for the full sample of data (not included in the restricted sample due to the early season being eliminated from the data set). The number of days between home games (days between) was shown to have a positive and statistically significant effect on attendance across the four model specifications shown. Saturation of home games across a short period of time appear to be a detriment to attendance when it comes to the decision of fans to attend major Canadian junior hockey games.

The dummy variables for the days of the week revealed anticipated results as it related to weekend games. Friday, Saturday, and Sunday variables each had positive and statistically significant results at the $1 \%$ level, compared to the reference category day of Wednesday. Saturday had the highest attended weekend games in the CHL, followed by Friday and Sunday. A surprising result showed that the dummy variable for Monday had one of the largest effects on attendance. It was positive and statistically significant at the $1 \%$ level. Monday games are relatively infrequent in the CHL, but these games attracted larger crowds than other days. This could be due to scarcity of hockey on Mondays, due to a typically lighter NHL schedule on this day of the week as well. A word of caution on the Monday results is warranted, however, as the Monday result could be a direct effect of its relative infrequency on the schedule. The other days of the week were not shown to have statistically significant results across each of the model specifications shown.

Month of the season dummy variables (compared to January as the reference category) revealed distinct results about the importance of the timing of the season to CHL attendance. Dummy variables for September and October were shown to be negative and statistically significant at the $1 \%$ level across the relevant model specifications. November was also shown to have negative and significant effects on the log of attendance, but at the $5 \%$ or $10 \%$ level. On the other hand, games played late in the season in February and March were shown to have a positive and significant effect at the $1 \%$ level on attendance. During the late season push for the playoffs, more fans were shown to attend CHL games. A dummy for the 2017-18 Season, to distinguish the two seasons of attendance in our sample, was not shown to be statistically significant. Structurally, very little appeared to differ between the two seasons when it came to fan preferences for attending games across the three leagues of the CHL.

In terms of the on-ice performance variables of interest, the results revealed that fans preferred teams that both win and fight more often. The points-per-game variable was shown to have a positive and significant effect on the log of attendance at the $5 \%$ level and at the $1 \%$ level for all four models. Fans are sensitive to the win percentage of their local team. In addition, the other on-ice performance variable, fights-per-game, was also shown to have a positive and significant effect on attendance. As with the points-per-game variable, fights-per-game was not significant in the whole sample, but significant at the $5 \%$ and at the $1 \%$ levels in the restricted sample. Despite negative publicity about fighting in hockey, hockey fans attended games of teams that have players who fight more often. Even with the majority of the players in the CHL being under twenty years of age, with some as young as fifteen, the prospect of seeing fighting on the ice was shown to have a positive effect on attendance.

The regression results as it relates to outcome uncertainty revealed fans did not appear to care much about uncertainty of outcome. In both samples, the linear model showed that the home team win probability was statistically insignificant. In the quadratic specification, the probability of a home team win (and its square) were not found to be statistically significant in the overall sample and only the squared term was statistically significant (negative coefficient) in the sample, not including the beginning of the season. An f-test of the joint significance of both the home team win probability and its square could not reject the null that both coefficients simultaneously are equal to zero (f-stat of 1.8563 with a probability value of 0.1564 ). Fans of the CHL did not appear to be concerned with outcome uncertainty, nor did they appear to exhibit any of the preferences described by the model of Coates et al. (2014) as it relates to reference-dependent preferences or loss aversion. 
Precipitation, measured on game day in inches, was shown to have a negative impact on the $\log$ of attendance and was statistically significant at the $5 \%$ level. Temperature was not found to be statistically significant. CHL fans preferred to attend games on days with less (or no) precipitation. Even though the games occur indoors, precipitation appears to play a role in terms of the transaction costs in attending games in the rain or snow.

\section{Discussion and Conclusions}

This study investigated attendance in the CHL through an ordinary least squares regression model with the natural log of the attendance as the dependent variable. The CHL is the top tier of junior hockey in Canada, with some teams located in the United States. The three leagues in the $\mathrm{CHL}$, the Ontario Hockey League (OHL), the Quebec Major Junior Hockey League (QMJHL), and the Western Hockey League (WHL) are proving grounds for many players who aspire to play in the NHL and are relatively popular leagues in Canada and the United States. The independent variables in the model consisted of variables representing the timing of the game, on-ice performance measures, uncertainty of outcome, and weather-related variables.

Overall, fans of the CHL appear to mimic other fans of hockey in North America. They prefer successful home teams that tend to fight more often. This is despite the negative press associated with fighting in the game and the fact that most of these players are under twenty years of age. Fans prefer to go to games on weekends, rather than weekdays, are more interested in attending games late in the season during the playoff push, and the more recent the last home game, the lower the attendance. Uncertainty of outcome is not a major concern for the fans, while rain and snow tends to decrease attendance figures. The only real surprising finding for the league, outside of perhaps the influence of fighting, was the popularity of the few Monday games on the schedule. Due to a general scarcity of hockey in North America on Mondays, perhaps a more regular schedule of Monday contests could benefit the league if these games could replace less popular mid-week contests. In general, fans of junior hockey appear to value the same characteristics as professional hockey fans, just with younger players and smaller arenas.

Author Contributions: R.P. contributed background research, empirical modeling and analysis, and writing of the paper. A.W. contributed background research and writing of the paper. N.R. contributed data gathering and background research for the paper.

Funding: This research received no external funding.

Conflicts of Interest: The authors declare no conflict of interest.

\section{References}

Andrew, Damon P. S., Gi-Yong Koo, Rob Hardin, and T. Christopher Greenwell. 2009. Analyzing Motives of Minor League Hockey Fans: The Introduction of Violence as a Spectator Motive. International Journal of Sport Management and Marketing 5: 73-89. [CrossRef]

Andreff, Wladamir. 2018. Financial and sporting performance in French football Ligue 1: Influence on the players' market. International Journal of Financial Studies 6: 91. [CrossRef]

Andreff, Wladimir, and Nicholas Scelles. 2015. Walter C. Neale fifty years after: Beyond competitive balance, the league standing effect tested with French football data. Journal of Sports Economics 16: 819-34. [CrossRef]

Burdekin, Richard C. K., and Matthew G. Morton. 2015. Blood money: Violence for hire in the National Hockey League. International Journal of Sport Finance 10: 328-56.

Coates, Dennis, and Brad Humphreys. 2012. Game Attendance and Competitive Balance in the National Hockey League. Journal of Sports Economics 13: 364-77. [CrossRef]

Coates, Dennis, Marcel Battre, and Christian Deutscher. 2012. Does Violence in Professional Ice Hockey Pay? Cross Country Evidence from Three Leagues. Sports Economics: Management and Policy 4: 47-63.

Coates, Dennis, Brad Humphreys, and Li Zhou. 2014. Reference-Dependent Preferences, Loss Aversion, and Live Game Attendance. Economic Inquiry 52: 959-73. [CrossRef] 
Fort, Rodney, and Joel Maxcy. 2003. Comment: Competitive balance in sports leagues: An introduction. Journal of Sports Economics 4: 154-60. [CrossRef]

Garcia, Jaume, and Placido Rodriguez. 2002. The determinants of football match attendance revisited: Empirical evidence from the Spanish football league. Journal of Sports Economics 3: 18-38. [CrossRef]

Hong, Jinbae. 2009. A comparison of Motivational Factors Affecting Attendance between Avid and Casual Fans at Minor League Hockey Games. International Journal of Sport Management and Marketing 5: 115-31. [CrossRef]

Humphreys, Brad R. 2002. Alternative Measures of Competitive Balance in Sports Leagues. Journal of Sports Economics 3: 133-48. [CrossRef]

Jones, J. Colin H. 1984. Winners, Losers, and Hosers: Demand and Survival in the National Hockey League. Atlantic Economic Journal 12: 54-63. [CrossRef]

Jones, J. Colin H., Donald G. Ferguson, and Kenneth G. Stewart. 1993. Blood Sports and Cherry Pie: Some Economics of Violence in the National Hockey League. American Journal of Economics and Sociology 52: 87-101. [CrossRef]

Jones, J. Colin H., Kenneth G. Stewart, and R. Sunderman. 1996. From the Arena into the Streets: Hockey Violence, Economic Incentives, and Public Policy. American Journal of Economics and Sociology 55: 231-49. [CrossRef]

Kaplan, Alan, John Nadeau, and Norm O'Reilly. 2011. The Hope Statistic as an Alternative Measure of Competitive Balance. International Journal of Sport Finance 6: 170-84.

Kringstad, Morten, and Bill Gerrard. 2004. The Concepts of Competitive Balance and Uncertainty of Outcome. IASE Conference Papers, 0412. International Association of Sports Economists.

Leard, Benjamin, and Joanne Doyle. 2011. The Effect of Home Advantage, Momentum, and Fighting on Winning in the National Hockey League. Journal of Sports Economics 12: 538-60. [CrossRef]

Mills, Brian M., and Rodney Fort. 2018. Team-level time series analysis in MLB, the NBA, and the NHL: Attendance and outcome uncertainty. Journal of Sports Economics 19: 911-33. [CrossRef]

Nadeau, John, and Norm O'Reilly. 2006. Developing a Profitability Model for Professional Sport Leagues: The Case of the National Hockey League. International Journal of Sport Finance 1: 46-62.

O'Reilly, Norm, Alan Kaplan, Ryan Rahinel, and John Nadeau. 2008. If You Can't Win, Why Should I Buy a Ticket? Hope, Fan Welfare, and Competitive Balance. International Journal of Sport Finance 3: 106-18.

Paul, Rodney J. 2003. Variations in NHL Attendance: The Impact of Violence, Scoring, and Regional Rivalries. American Journal of Economics and Sociology 62: 345-64. [CrossRef]

Paul, Rodney J. 2018. The Role of Team Success, Fighting, and Other Factors in Southern Professional Hockey League Attendance. Southern Business and Economic Journal.

Paul, Rodney J., and Andrew P. Weinbach. 2011. Determinants of Attendance in the Quebec Major Junior Hockey League. Atlantic Economic Journal 39: 303-11. [CrossRef]

Paul, Rodney J., Andrew P. Weinbach, and Daniel Robbins. 2013. American Hockey League Attendance: A Study of Fan Preferences for Fighting, Team Performance, and Promotions. International Journal of Sport Finance 7: 21-38.

Paul, Rodney J., Andrew P. Weinbach, and Daniel Robbins. 2015. Fighting, Winning, Promotions, and Attendance in the ECHL. Sport, Business, and Management: An International Journal 5: 139-56. [CrossRef]

Quirk, James, and Rodney D. Fort. 1997. Pay Dirt: The Business of Professional Team Sports. Princeton: Princeton University Press.

Rascher, Daniel, Matthew Brown, Mark Nagel, and Chad McEvoy. 2009. Where did National Hockey League fans go during the 2004-05 Lockout? An Analysis of Economic Competition between Leagues. International Journal of Sport Management and Marketing 5: 183-95. [CrossRef]

Rockerbie, Duane W. 2012. The Demand for Violence in Hockey. In The Oxford Handbook of Sports Economics. Edited by L. Kahane and S. Shmanske. New York: Oxford University Press, vol. 1, pp. 159-76.

Rockerbie, Duane W. 2016. Fighting as a profit maximizing strategy in the National Hockey League: More evidence. Applied Economics 48: 292-99. [CrossRef]

Rockerbie, Duane W. 2017. Fighting as a Profit-Maximizing Strategy: The American Hockey League. In Breaking the Ice. Edited by B. Frick. New York: Springer, pp. 17-40.

Rottenberg, Simon. 1956. The Baseball Players' Labor Market. Journal of Political Economy 64: 242-58. [CrossRef]

Scelles, Nicholas. 2017. Star quality and competitive balance? Television audience demand for English Premier League football reconsidered. Applied Economics Letters 24: 1399-402. [CrossRef] 
Scelles, Nicholas, Christophe Durand, Lillane Bonnal, Daniel Goyeau, and Wladimir Andreff. 2013a. Competitive balance versus competitive intensity before a match: Is one of these two concepts more relevant in explaining attendance? The case of the French football Ligue 1 over the period 2008-2011. Applied Economics 45: 4184-92. [CrossRef]

Scelles, Nicholas, Christophe Durand, Lillane Bonnal, Daniel Goyeau, and Wladimr Andreff. 2013b. My team is in contention? Nice, I go to the stadium! Competitive intensity in the French football Ligue 1. Economics Bulletin 33: 2365-78.

Scelles, Nicholas, Boris Helleu, Christophe Durand, and Lillanne Bonnal. 2013c. Determinants of professional sports firm values in the United States and Europe: A comparison between sports over the period 2004-2011. International Journal of Sport Finance 8: 280-93.

Scelles, Nicholas, Boris Helleu, Christophe Durand, and Lillane Bonnal. 2016a. Professional sports firm values: Bringing new determinants to the foreground? A study of European soccer, 2005-2013. Journal of Sports Economics 17: 688-715. [CrossRef]

Scelles, Nicholas, Christophe Durand, Lillane Bonnal, Daniel Goyeau, and Wladimir Andreff. 2016b. Do All Sporting Prizes Have a Significant Positive Impact on Attendance in a European National Football League? Competitive Intensity in the French Ligue 1. Ekonomicheskaya Politika/Economic Policy 11: 82-107, English Version. Available online: https://mpra.ub.uni-muenchen.de/73844/ (accessed on 1 February 2019). (In Russian)

Scelles, Nicholas, Boris Helleu, Christophe Durand, Lillane Bonnal, and Stephen Morrow. 2017. Explaining the number of social media fans for North American and European professional clubs with determinants of their financial value. International Journal of Financial Studies 5: 25. [CrossRef]

Scelles, Nicholas, Stefan Szymanski, and Nadine Dermit-Richard. 2018. Insolvency in French soccer: The case of payment failure. Journal of Sports Economics 19: 603-24. [CrossRef]

Scully, Gerald W. 1989. The Business of Major League Baseball. Chicago: University of Chicago Press.

Szymanski, Stefan. 2017. Entry into exit: Insolvency in English professional football. Scottish Journal of Political Economy 64: 419-44. [CrossRef]

Treber, Jaret, Lawrence Mulcahy, and Manjul B. Sharma. 2018. Empty seats or empty threats? Examining the effects of the 1994-1995 and 2004-2005 lockouts on attendance and revenue in the National Hockey League. Journal of Sports Economics 19: 677-95. [CrossRef]

Zhang, James J., Dennis W. Smith, Dale G. Pease, and Matthew. T. Mahar. 1996. Spectator Knowledge of Hockey as a Significant Predictor of Game Attendance. Sport Marketing Quarterly 5: 41-48.

Zhang, James J., Dale G. Pease, Eddie T. Lam, U. L. Pham, L. M. Bellerive, J. T. Lee, D. P. Williamson, and K. A. Wall. 2001. Sociomotivational Factors Affecting Spectator Attendance at Minor League Hockey Games. Sport Marketing Quarterly 10: 43-56.

(C) 2019 by the authors. Licensee MDPI, Basel, Switzerland. This article is an open access article distributed under the terms and conditions of the Creative Commons Attribution (CC BY) license (http:/ / creativecommons.org/licenses/by/4.0/). 


\title{
Article \\ The Impact of College Athletic Success on Donations and Applicant Quality
}

\author{
Benjamin Baumer ${ }^{1}$ and Andrew Zimbalist ${ }^{2, *}$ \\ 1 Program in Statistical and Data Sciences, Smith College, Northampton, MA 01063, USA; bbaumer@smith.edu \\ 2 Department of Economics, Smith College, Northampton, MA 01063, USA \\ * Correspondence: azimbali@smith.edu
}

Received: 20 February 2019; Accepted: 20 March 2019; Published: 1 April 2019

\begin{abstract}
For the 65 colleges and universities that participate in the Power Five athletic conferences (Pac 12, Big 10, SEC, ACC, and Big 12), the football and men's basketball teams are highly visible. While these programs generate tens of millions of dollars in revenue annually, very few of them turn an operating "profit." Their existence is thus justified by the claim that athletic success leads to ancillary benefits for the academic institution, in terms of both quantity (e.g., more applications, donations, and state funding) and quality (e.g., stronger applicants, lower acceptance rates, higher yields). Previous studies provide only weak support for some of these claims. Using data from 2006-2016 and a multiple regression model with corrections for multiple testing, we find that while a successful football program is associated with more applicants, there is no effect on the composition of the student body or (with a few caveats) funding for the school through donations or state appropriations.
\end{abstract}

Keywords: college sports; finances; economics

JEL Classification: C4; I2; H7; Z2

\section{Introduction}

Intercollegiate athletics is in a turbulent period. Recruiting and academic scandals along with antitrust litigations are erupting with unprecedented frequency. The Rice Commission on reforming college basketball called for a panoply of structural reforms.

Meanwhile, the financial outcomes of college athletic departments remain bleak for the vast majority of institutions. NCAA reports consistently show that in recent years only about 20 out of roughly 130 athletic departments in FBS (the Football Bowl Subdivision of Division I, the most commercial subdivision in the NCAA) run an operating surplus. FBS itself is subdivided into the Power Five or Autonomous Conferences (Pac 12, Big 10, SEC, ACC and Big 12) with 65 schools and the five Non-Autonomous Conferences with 64 schools. The Power Five command the large television contracts, control the football championship playoff and enjoy much larger attendance at their games.

During the 2015-2016 school year, the median reported operating deficit at all FBS athletic programs was $\$ 14.4$ million. At the Power Five schools, the median reported operating deficit was \$3.6 million. There were 24 Power Five schools during 2015-2016 that experienced an operating surplus-the median surplus for these schools was $\$ 10$ million (NCAA 2017).

Because of accounting irregularities, however, it appears that most FBS athletic departments do not include significant shares of their capital costs in their reports to the NCAA. According to one NCAA study, capital costs, properly reckoned, exceed \$20 million annually at the average FBS school (Orszag and Orszag 2005). If these and other indirect costs were included, most estimates suggest that no more than a half dozen programs would have a true surplus.

To be sure, there is an active debate about the underlying economic reality of intercollegiate athletic programs. For instance, many economists assert that it is improper to include the cost of 
athletic scholarships in the financial reports because they do not represent the actual marginal costs to the school. That is, even though the school may charge $\$ 50,000$ tuition, the incremental cost of educating an additional student is close to zero. Put differently, an economics professor will get paid, say, $\$ 150,000$, whether she has 120 or 121 students in her introductory macroeconomics class and there are no additional facility costs incurred by the extra student.

While this is a fair point, it is also reasonable to note that fielding an FBS football team requires 85 scholarships. If the relevant alternative is having no football team, then it is no longer true that the incremental cost of educating 85 students is zero. Indeed, it is misleading to think that the marginal cost of educating a single football player is zero. The school expends considerable resources on tutoring centers and academic support to keep players eligible.

It might also be relevant to consider the opportunity cost of a football scholarship. If low income and highly qualified students do not get scholarships, and thus do not attend the school, then the school may suffer from lower graduation rates, fewer serious students in the classroom and a lower profile for its student body in terms of standardized test scores and school rank.

Further, even if all athletic aid were eliminated from the financials, it would only amount to a median savings of $\$ 4.6$ million-well below the median operating deficit of $\$ 14.4$ million in FBS. Moreover, standard athletic accounting does not include a host of indirect expenses, such as a share of the school president's time, travel, office, and administrative assistants' salaries.

The reality is that intercollegiate athletic departments are not profit maximizers. They do not have shareholders who demand quarterly profits to boost stock prices or corporate dividends. Instead, they have stakeholders who want victories. Subject to some constraints, athletic directors are win maximizers. The conventional method for maximizing wins is to hire well-known coaches at multi-million dollar salaries, invest lavishly in athletic and tutoring facilities and spend freely on recruitment. Thus, when revenues rise, the athletic director finds more than enough ways to spend the bounty. And even if the football or men's basketball team yields a surplus, much of it is drained by the deficits experienced by the 15 or more "non-revenue" men's and women's sports. The consequence is that the vast majority of programs run in deficit.

How, then, can these hyper-commercialized, massive athletic programs be justified? One line of defense holds that while the programs might run financial deficits, they provide invaluable exposure and advertising for the university. This branding value, in turn, produces an increase in applications. These applications fill empty beds in the dormitories and enable the college to be more selective in its admissions policies, yielding an improvement in the quality of the student body (usually measured in standardized test scores). Additionally, alumni and athletic boosters become excited by team success or media prominence and open up their wallets, leading to increased donations and endowment growth. And, in some cases, this line of reasoning goes, state legislators also become enthused and allocate more budgetary assistance to the university.

Of course, even if it could be verified that athletic success leads to these salutary outcomes, it would not justify the tens of millions of dollars of investment that most FBS universities make annually. This is because only roughly half of all teams have a winning record and only a handful of teams achieve top ranking. If regression analysis shows that winning is positively correlated with applications, this implies both that applications tend to go up when wins increase and that applications tend to go down when wins decrease. Further, many, if not most, FBS universities bend the rules or cheat in order to promote athletic success. Some of these schools get caught and scandals ensue. The resulting ignominy may have negative enduring effects on applications, donations and legislative appropriations. The lowering of admissions' standards for athletes and the creation of sham courses also serve to dilute the educational experience and intellectual spirit on the campus.

In this paper we endeavor to expand upon, clarify, and update the existing scholarly literature on whether athletic success in football and men's basketball leads to increased applications, enhanced quality of the student body, more donations and greater state support. This updating is important because the organization and rules affecting college sports have been in flux in the 21st century. 
We consider evidence from 2005-2006 through 2015-2016 for the 65 Power Five schools in the FBS. These schools are athletically the most successful and best known by a considerable margin and, therefore, the most likely to garner the positive publicity effects from athletic success.

In what follows we review the existing scholarship, describe our data sources and our data profile, discuss our models and results and draw conclusions. The evolution of the literature is not linear and the current state of knowledge remains ambiguous.

\section{Review of the Literature}

\subsection{Athletic Success and the Quantity and Quality of Applications}

One of the first and most frequently cited studies on the impact of athletic success on admissions is McCormick and Tinsley (1987). They gather data on 150 schools for 1971. On the basis of a multiple regression test with several control variables, they estimate that a school with a "big-time" athletics program had 3\% higher SAT scores than schools without such a program. They identified 63 of the schools in their sample to have a big-time program. A difficulty with this cross-sectional analysis is that characteristics not identified by the control variables of a school lead to an incomplete model specification. In an attempt to rectify this deficiency, McCormick and Tinsley test a second model with data from 1981 to 1984, focusing exclusively on schools with big-time programs. They explore the link between changes in SAT scores and changes in athletic performance over this period. None of the estimated coefficients are statistically different than zero at standard confidence levels.

Bremmer and Kesselring (1993) essayed a retest of the McCormick and Tinsley hypotheses, using data from 1989 for 132 schools and from 1981-1989 for 53 schools. They find no evidence that basketball or football success led to increased SAT scores of matriculated students.

Tucker and Amato (1993) adapt the McCormick and Tinsley model by using a new metric of athletic success-whether the school was in the Associated Press top twenty ranking in football or basketball. They find no relationship between basketball success and SAT scores, but that a football program ranked in the top twenty for ten consecutive years (1980-1989) would attract a freshman class with 3\% higher average SAT scores than a program which never ranked in the top twenty.

Murphy and Trandel (1994) construct a ten-year panel, 1978-1987, and use team win percentage as the measure of athletic success. They use school fixed effects and, thereby, control more effectively for unobserved differences among institutions. Murphy and Trandel find that a 50\% increase in a team's win percentage results in a rather small increase of only $1.3 \%$ in the number of its applicants.

Mixon (1995) employs a different measure of basketball success-the number of rounds through which the school's team advanced in March Madness in the spring before the applications were filed the next fall ${ }^{1}$. Mixon's estimate was positive and statistically significant, suggesting that the average SAT score in the entering class increased by 1.7 points for each additional round the school's team was in the tournament.

Toma and Cross (1998) examine the records for the thirteen different universities that won the FBS football championship between 1979 and 1992 and the eleven different universities that won the NCAA men's basketball tournament over the same period. They track the quantity and quality of undergraduate applications for five years preceding and succeeding their championship for each of these schools. They find a clear correlation between winning a championship and the number of applicants, but are unable to identify any measurable impact of a championship on the quality of admitted or entering students.

Zimbalist (2001) uses data from 86 FBS colleges from 1980 through 1995 and performs a variety of fixed effect multiple regressions, using different measures of athletic success. The tests reveal

1 Mixon also co-authored two cross-sectional studies based on data from 1990 and 1993 that found a relationship between athletic success or prominence and the attraction of a school to out-of-state residents (Mixon and Hsing 1994; Mixon and Ressler 1995). 
that, while there is some tendency for athletic success to increase applications, there is no significant relationship between athletic success and average SAT scores.

In a study under commission from the NCAA, Litan, Orszag, and Orszag (Litan et al. 2003) use a fixed-effects model for 1993-2001 and are unable to find a statistically significant relationship between football winning percentage and SAT scores of the incoming class. ${ }^{2}$

Tucker (2005) considers evidence from 1990, 1996, 2000, 2001 and 2002 from 78 Division I schools. He finds that after 1996 football success has a positive impact on the average SAT scores of the incoming class. He argues that the perfection of the Bowl Championship Series played a central role in bringing increased attention and, hence, advertising exposure to the top football programs.

Smith (2008), in contrast, considers data from Division I schools during 1994-2005 and finds little evidence to support a link between different measures of men's basketball success and four measurements of student quality. The one exception was that schools that had a "breakout" year (lagged two years) experienced an 8.86 point average increase in the SAT scores of the 75th percentile of the entering class. Breakout was defined in various ways, but basically denoted that a school went from a perennial losing record to a strong winning record.

Pope and Pope (2009), using a data set from 330 Division I schools during 1983-2002, find that certain types of athletic success appear to increase interest in a school from applicants with high, medium and low SAT scores, but that the increase in enrollments from the students with SAT scores above 600 in English and in Math is weaker and less reliable. Indeed, for some of the athletic performance variables the relationship between athletic success and the log of enrollment is significantly negative. Further, any impact tends to be in the next year with no significant effect after two or three years. In the end, Pope and Pope conclude that "the summary data ... would suggest that athletically successful schools actually saw slightly lower long-run growth in applications and enrollments." One important caveat in interpreting these results is that Pope and Pope test fixed effect multiple regressions with control variables and thirty-two athletic performance variables. At a 0.10 level of significance, one would anticipate that 3.2 variables would achieve statistical significance randomly. The authors should have, but did not, control for the multiplicity problem. ${ }^{3}$ Multicollinearity among the performance variables presents another challenge in interpreting the coefficients. ${ }^{4}$

Pope and Pope (2014) use a Division I data set of 332 schools during 1994-2001 to test the impact of men's basketball and football on the propensity of high school applicants to send their SAT scores to a school. They find that a school with stellar results in either sport receives on average up to $10 \%$ more SAT scores. They also find that the relationship is stronger for some demographic subgroups, such as males, people of color, out-of-state students and high school athletes. They do not test for actual applications to the school or for eventual enrollments. Pope and Pope model one to three year lags and find that the statistical significance of sports success "decays very quickly across time."

In sum, the various studies lend some support to the notion that robust athletic success can lead to an increase in applications to a school. The correlate of this proposition is that poor athletic performance can lead to falling applications. There is only weak support, if any, for the claim that sport success leads to an increase in the quality of students. The increase in applications in some cases, however, may assist a school in filling empty beds in its dormitories. These conclusions are supported anecdotally by a self study done at the University of Massachusetts following its ascent to basketball fame in the mid-1990s under John Calipari.

\footnotetext{
For a summary of the literature through 2004, see Frank (2004).

See, for instance, Benjamini and Hochberg (1995).

Castle and Kostelnik (2011) examine 14 Division II schools in Pennsylvania during 1995-2004 and find weak evidence that some measures of athletic success were correlated with an increase in applications and the SAT scores of the entering class. Three studies found that football success was associated with lower student grades; see Clotfelter (2011); Lindo, Swensen, and Waddell (Lindo et al. 2012); and Hernández-Julián and Rotthoff (2014).
} 
The period from fall 1988 to fall 1990 did not include outstanding basketball years. In 1991, UMass was a semi-finalist in the NIT and in the four years since has been featured consistently on national television, has been ranked consistently in the top twenty and has gone to the NCAA tournament ... It is clear that after double digit declines in out-of-state applications from fall 1988 to fall 1991, we experienced two years of double digit increases in fall 1993 and 1994. It has been suggested that this bump in applications might be related to, among other things, the greater awareness of the university beyond Massachusetts, at least partially as a result of the success in basketball.

It has been reported that the University of Connecticut experienced a similar application increase after their very successful Elite Eight season in 1991, with a 26\% increase in out-of-state and $6 \%$ increase of in-state applications. Despite the growth of applications correlated with UConn basketball success, the conclusion was that there was no impact on yield (enrollment divided by admittances). With the numbers of applications up, it would also be expected that the quality of students enrolled might increase because of a larger pool on which to draw. The Connecticut experience indicates no changes in the quality of students. In the UMass figures there was a decrease in the SAT scores of applicants and enrolled students for both in- and out-of-state students. In fact, this [1995-1996] was the first year that the SAT scores of out-of-state students fell below in-state. None of this suggests that team success carries beyond the application stage. In fact, in the year following the "Dream Season," UConn applications dropped back to earlier numbers. Their conclusion was that there was no lasting impact on the admission numbers. (Massachusetts Football Task Force 1996)

\subsection{Athletic Success and Alumni Giving}

Studies on alumni or other giving are less numerous and less complete. The primary reason for this is that the availability of data on alumni giving is spotty. Sigelman and Carter (1979) assemble data from the Council for Financial Aid to Education (CFAE) from 1966-1967 to 1975-1976 and test the relationship between the yearly change in total giving to the annual fund and athletic success, measured by win percentages in football and men's basketball and a dummy variable indicating whether the team participated in the post-season. Sigelman and Carter do not find any statistically significant relationships between giving and athletic success, and even note that some of the coefficients were negative.

Brooker and Klastorin (1981) critique the Sigelman and Carter study on the grounds that it does not control for institutional heterogeneity. They adjust for this by using institutional fixed effects and find some positive and some negative relationships between athletic success and giving. Together, they run tests on 1740 coefficients and find only $1.7 \%$ of them to be significant at the 0.10 level, which is fewer than the number that would be expected by chance. The authors do not report the magnitude of the effects.

Sigelman and Bookheimer (1983) introduce a fixed effects model and break down alumni contributions into two components, restricted gifts to the athletics department and unrestricted gifts to the annual fund. They find that the two types of giving are uncorrelated with each other and that only gifts to the athletics department are correlated with sport success (football, not basketball). More precisely, they estimate that a $10 \%$ increase in football win percentage over the previous four years leads to a $\$ 125,000$ increase in donations to the athletics department (measured in 1983 dollars).

Grimes and Chressanthis (1994) focus on one school, Mississippi State, over a 30-year period between 1962 and 1991. They considered success of the football, basketball and baseball teams. Winning success in football had a negative coefficient that was not statistically significant. Basketball's coefficient was significant at the 0.05 level and positive, but extremely small.

Baade and Sundberg (1996) construct a data set from Division I schools during 1973-1979. They employ both winning percentage and bowl or March Madness appearances as measures of sport 
success. They find no impact on giving from increased winning percentages, but a modest effect for postseason appearances. They do not distinguish between athletic and academic giving.

Rhoads and Gerking (2000) follow the modelling of Baade and Sundberg with data for 1986-1987 to $1995-1996 .^{5}$ They run their tests first without institutional fixed effects and find impact very similar to those of Baade and Sundberg. They run the tests again with fixed effects and none of the athletic success variables are statistically significant predictors of giving. Rhoads and Gerking also estimate that being placed on NCAA probation for a basketball violation reduces total giving by $\$ 1.6$ million (measured in 1987 dollars).

Turner, Meserve, and Bowen (Turner et al. 2001) consider a data set of 15 private schools during 1988-1989 to 1997-1998. Using a fixed effects model, they find that football win percentage has no significant effect on the rate of giving among alumni in FBS programs, but that it has a highly significant (at 0.01) and negative effect on the giving amount among alumni. Specifically, an increase of 12 wins is associated with a decrease in giving by $\$ 270$ for an average person.

Humphreys and Mondello (2007), based on 320 Division I schools from 1976 to 1996 find that postseason play was positively correlated with giving to athletics, but not to giving to academics. Stinson and Howard (2008) investigated 208 institutions from Divisions I-AA and I-AAA and found no correlation between giving to athletics and giving to academics. ${ }^{6}$

\subsection{Athletic Success and State Budgetary Support}

Three scholarly articles have explored the impact of university athletic success on legislative appropriations. Humphreys (2006) estimates a reduced form model with data from 1975 to 1996 that controls for state and institution specific characteristics. ${ }^{7}$ He finds that state appropriations are $8 \%$ higher for institutions in FBS (formerly Division IA), other things equal. The presence of an increase in state support for having an FBS football team of \$2.6 million on average (in 1982 dollars) may do little more than offset the additional net costs of fielding the team. Humphreys, however, does not find that either appearance in a bowl game or achieving a national ranking in the top 25 had a statistically significant impact on state appropriations.

Alexander and Kern (2010) consider 117 schools from FBS, FCS and Division II for the period 1983-1984 to 2006-2007. They do not explain why their sample is more heavily weighted to FBS or why certain schools were omitted. They find that increases in basketball and football win percentage for schools in FBS do produce a statistically significant increase in state appropriations, but appearances in major bowl games or in the NCAA Final Four does not. The three models that they test yield R-squares of $0.05,0.05$ and 0.08 , suggesting that they are underspecified and calling into question the reliability of their coefficient estimates.

Jones (2015) uses a difference-in-difference model that focused on six universities that transitioned from FCS to FBS between 2000 and 2010. Jones finds that when the six schools were compared to all

5 Goff (2000) also considers the impact of sport success on the endowment. Goff, however, only looks at endowment data only for two schools, Georgia Tech and Northwestern. While he finds no statistically significant relationship between sport success and donations at Georgia Tech, Goff does find one at Northwestern. However, Goff notes that the finding for Northwestern may have been affected by an accounting change at the school (moving a substantial amount of cash into long-term equity during the period studied.) In any event, the data base is much too thin to assign much importance to these results.

6 Koo and Dittmore (2014), based on an unexplained sample of 155 schools from Divisions I, II and III during 2002-2003 to 2011-2012, purport to find a positive correlation between athletic giving lagged one year and current academic giving. They conclude that athletic giving does not crowd out academic giving. They do not offer an explanation of why they lag athletic giving; any crowding out would presumably happen in the same year. It is also not clear what their full model is and whether, for instance, they detrended their data or used time fixed effects. Walker (2015) uses a sample of between 954 and 1052 schools during 2002-2011 and finds that appearances in the Final Four are significantly associated with increases in private donations, but, again, he does not break out athletic and academic donations and does not provide a full description of his model.

7 There was a prior study to Humphreys, but is was based on only one year (1980-1981) and 52 DIA schools (Coughlin and Erekson 1986). 
other FCS schools, there is no significant correlation between FBS affiliation and state appropriations. When the six schools are compared only to other FCS schools in the same region, there is still no significant correlation. Only when the comparison is made between FCS schools in the same region and within the same propensity score range ${ }^{8}$ did the move to FBS yield a significant relationship with state appropriations. Jones concludes that this result provides some support for the hypothesis of a positive effect between NCAA subdivision and state support.

\subsection{Anderson on Athletic Benefits}

Anderson (2017) deploys the most sophisticated econometric treatment of the relationships between athletic success and various school outcome variables in the extant literature, uses the most recent data, and has been cited numerous times as representing the state of current knowledge on these matters; hence, this paper warrants a separate and more detailed discussion. He considers a data set for FBS schools from 1986 to 2009 and employs a propensity score model to estimate these relationships. Anderson's motivation for adopting this framework is the difficulty of unraveling causality from observational data, especially given that selection bias (e.g., recruiting skill of coaches and administrators), reverse causality (e.g., athletic success begets donations, which are in turn spent to achieve greater athletic success), and confounding variables are likely present. $^{9}$

Anderson's basic approach is to use bookmaker spreads for individual football games to establish (via a fifth order polynomial logistic model) a probability of winning (the propensity score). Actual wins are then conditioned on the propensity score and used as the independent variable (or treatment). This method depends on the assumption that gambling is efficient (the bookmaker spread represents full and rationally-processed information to determine the likelihood of contest outcome; put differently, all the relevant variables that impact a game's result are subsumed into the point spread. ${ }^{10}$ ) Anderson then essentially runs school applications, SAT scores and donations on the difference between the actual and the expected wins during a season. Thus, Anderson is estimating the effect of unexpected wins (losses) on his school outcome variables.

While it is interesting to know what the effect of unexpected wins is, it is likely a different effect than wins or general athletic success. Few would question, for instance, that a football or men's basketball team that rises from sport oblivion to prominence in one year will experience an uptick in applications, donations or state appropriations (see previous discussion of UMass/UConn.) ${ }^{11}$ This is a different matter than a team perennially appearing in March's Elite Eight or Final Four or in the Football Championship Playoff.

Anderson does indeed find that unexpected wins are associated with increased applications, higher SAT scores and increased donations to the athletics department (but not to the general fund). Notably, Anderson's strongest result is for donations to the athletics department, but this finding

8 Jones' propensity score includes a number of school characteristics, including size, percentage of full-time students, percent of graduate students, degree of institutional urbanization, freshmen retention rate, and total education expenditures.

9 Reverse causality would not appear to a significant issue when considering applications or SAT scores and athletic success. That is, while it may be logical to expect athletic success to increase applications or SAT scores, it does not seem plausible that more applications or higher SAT scores would engender greater athletic success. Top football and basketball players in FBS are recruited and, by all accounts, base their decisions on factors related to the athletics program. The effects of confounding variables, such as the managerial talent of a school president or provost, along with other unquantifiable attributes, could be accounted for by team fixed effects. Reverse causality may be an issue with athletic success and donations. In such a case, however, one would expect that the presence of reverse causality would strengthen the estimated correlation between the variables. Since Anderson's use of a propensity score is intended to mitigate the impact of reverse causality, other things equal, one would expect his model to imply a weaker correlation between athletic success and donations, contrary to his findings.

10 For this crucial assumption to be statistically valid, the $R_{2}$ from this equation must be very high, approaching 1 . Anderson, however, does not mention what the $R_{2}$ is in this test. It is nonetheless true that the literature on sports betting markets indicates that they operate efficiently. See, for example, the discussion in Lopez, Matthews, and Baumer (Lopez et al. 2018).

11 Such a finding would be consistent with the empirical work of Smith (2008), op. cit., and his "breakout" variable. 
relies on a very incomplete data set on donations ( 495 observations for BCS ${ }^{12}$ athletic donations versus 1560 observations possible for 65 schools over 24 years). He also runs tests separately for the Power Five conferences within FBS and for the remaining FBS (or "Group of Five") conferences and finds that his relationships only hold for the Power Five schools.

Three other points from Anderson are worth noting. First, he finds little evidence that the positive effect of unexpected wins lasts more than one year. Second, his positive results appear to be considerably weaker than he claims. Thus, after correcting for multiple testing, none of his treatment variables are significant at the 0.05 level. His Alumni Athletic Operating Donations variable comes closest with significance at the 0.053 level, but this variable is missing more than two-thirds of its possible observations, creating a possible selection bias. ${ }^{13}$ Third, in his conclusion, Anderson misrepresents his own results when he states: "Consider a school that improves its season wins by three games ... . This school may expect alumni athletic donations to increase by $\$ 409,000$ (17\%), applications to increase by $406(3 \%)$...." But Anderson is not looking at the net benefit of three wins; he is looking the net benefit of three wins over expectation. That is, if a team wins three more games but the betting markets expected the team would win three more games, there would be no net benefit.

\subsection{Summary of the Existing Literature}

Overall, the literature on the impact of college sport success on the quantity and quality of applications and enrollments, donations to the athletics department and general fund, and state appropriations is mixed and somewhat inconclusive. When significant results have been found, they have tended to be small in practical magnitude. Much of the existing scholarship is limited by methodological issues and data availability and most studies have not considered evidence from the 2000s. Each new study appears to use a new set of schools, conferences or divisions, a different set of athletic success variables, distinct issues with missing data, and different modelling of the relationship between the treatment and outcome variable. Given the restructuring of the NCAA subdivisions and conferences, the emergence of conference-owned RSNs and attendant spurt in television revenues, the increased autonomy of the Power Five conferences and the enhanced role of athletics in university finances and governance since 2000, it makes sense to examine the stability of the relationships between success in sports and possible indirect benefits for the school with more recent data. In what follows, we attempt to overcome some of the methodological issues of previous work and to construct a more up-to-date data set.

\section{Our Data}

Anderson (2017) found that for 1986-2009, the Power Five conferences are the most athletically prominent and the most likely to experience benefits from athletic success. As an update, our data covers the eleven academic years from 2005-2006 through 2015-2016 (plus the three preceding years for lagged variables) for the 65 schools that were members of Power Five conferences in 2015-2016 ${ }^{14}$. Our data sources are the Council for Advancement and Support of Education annual Voluntary Support of Education (VSE) surveys, Integrated Postsecondary Education Data System (IPEDs) surveys, the National Center for Education Statistics for high school graduates, the US Census Bureau for demographic information, and Sports-Reference.com. The data are available through the colleges package for R, available on GitHub (Baumer 2018).

12 BCS stands for Bowl Championship Series and refers to universities prior to 2014 in today's Power Five conferences plus the former Big East conference. The BCS conferences were sometimes referred to as the AQ or Automatic Qualifying conferences.

13 Anderson, Table 3, p. 127. In his conclusion (p. 132), Anderson suggests that school investments in athletics may have net revenue payoffs, but to conclude this he misleads because the NCAA definition of revenue includes athletic donations, and, indeed, is a major share of athletic department revenues for FBS schools.

14 Conference alignment was retroactively fixed to the 2015-2016 alignment. A school like the University of Utah, which moved from the Mountain West Conference to the Pac-12 in 2012, is considered to have always belonged to the Pac-12 for the purposes of this study. 
Our school benefit response variables—summarized in Table 1—include the number of applications (Applied, measured in thousands), the average 75th percentile SAT score across three portions of the exam (SAT75p), the admissions rate (Admit) and yield (Yield), donations to athletics by alumni (Athletics, in millions of dollars), total donations by alumni (Alumni, in millions of dollars), total non-athletic donations by alumni (NonAthletics) and total state appropriations to the school (State, in millions of dollars), also computed per student (StatePC, in thousands).

Table 1. Data profile, response variables.

\begin{tabular}{cccccc}
\hline Statistic & N & Mean & St. Dev. & Pctl (25) & Pctl (75) \\
\hline Applied & 711 & 21.786 & 11.470 & 13.058 & 28.030 \\
SAT75p & 675 & 661.211 & 50.828 & 630.000 & 696.667 \\
Donations & 605 & 178.522 & 152.569 & 85.672 & 230.596 \\
Athletics & 356 & 20.128 & 14.453 & 11.939 & 26.523 \\
NonAthletics & 356 & 154.485 & 159.349 & 66.488 & 197.043 \\
State & 558 & 279.541 & 137.115 & 174.574 & 371.532 \\
StatePC & 557 & 58.073 & 26.899 & 39.911 & 71.806 \\
Yield & 711 & 0.408 & 0.111 & 0.338 & 0.459 \\
Admit & 711 & 0.591 & 0.214 & 0.453 & 0.762 \\
\hline
\end{tabular}

We note that for variables derived from IPEDS (acceptance rate, number of applicants, yield, and 75th percentile SAT score), we have nearly complete coverage with only one school (Maryland) failing to report in multiple years. Notably, as is the case with Anderson's data set, the extent of the missing data for donations is much larger. We have athletic donations data for only 356 school-years and total donations data for 605 school years out of a total possible 715 observations. The pattern of missing data in donations suggests a possible bias, as certain schools (mostly private, notably Notre Dame, Boston College, Miami (FL), Syracuse, Wake Forest) simply did not report donation data (the data is certainly not missing at random). Hence, our findings for the athletic donations response variable should be interpreted with caution. Of course, private schools do not receive state funding, but this does not fully account for the missing data for that variable-state-related schools like Penn State and Pittsburgh also did not report state funding. Many of these variables are strongly right-skewed, and in these cases we have fit the model to their logarithm.

Our athletic success treatment variables-summarized in Table 1 -include measures of being good, great, and the best at both basketball and football. Specifically, for both sports we record the cumulative winning percentage over the previous three seasons (BBWpct, $F B W p c t)$, as well as any Final Four appearances ${ }^{15}$ and national championships in any of the three preceding seasons. Thus, we consider one, two, and three year lags on the Final Four (BBFF1, BBFF2, BBFF3, and $F B F F 1, F B F F 2, F B F F 3$, respectively) and championship variables (BBChamps1, BBChamps2, BBChamps3, and FBChamps1, FBChamps2, FBChamps3, respectively). The choice to include cumulative winning percentage over three years-as opposed to say, winning percentage in each of the previous three years-was designed to smooth out year-to-year noise in winning percentage, while still reflecting relevant recent history.

Our control variables include median income per capita in the state (Income, in thousands of dollars), number of high school diplomas issued in the state in the previous year (HSDiplomas, in thousands), and state funding, both overall and per student (State and StatePC, respectively). These variables help account for variation in the income and population of each state, in addition to the support from state government (only relevant for public schools). While it may be the case that state household income is less relevant for private schools, such schools often draw regional interest

15 Final Four appearances in basketball are measured by performance in the NCAA Tournament. Final Four appearances in football are measured by end-of-season national ranking by the Associated Press. 
and represent only about one-fifth of the schools considered. Further, to control for the unobserved heterogeneity of the 65 institutions we tested both school (School) and year (Year) fixed effects, with both variables treated as categorical. ${ }^{16}$ The fixed effect for School should capture the effect of the long-term branding value of the school's athletic program (i.e., Duke basketball), as well as many other attributes. The fixed effect for Year should capture changes due to inflation and other economic conditions.

The data in Table 2 come exclusively from Sports-Reference and the US Census Bureau, and there is no missing data. As the number of high school diplomas awarded is right-skewed, we use the logarithm of this variable in our models.

Table 2. Data profile, explanatory variables.

\begin{tabular}{cccccc}
\hline Statistic & N & Mean & St. Dev. & Pctl (25) & Pctl (75) \\
\hline HSDiplomas & 715 & 106.500 & 100.914 & 39.227 & 127.515 \\
Income & 715 & 26.349 & 3.709 & 23.797 & 28.351 \\
BBFF1 & 715 & 0.046 & 0.210 & 0 & 0 \\
BBFF2 & 715 & 0.045 & 0.207 & 0 & 0 \\
BBFF3 & 715 & 0.045 & 0.207 & 0 & 0 \\
BBWpct & 715 & 0.599 & 0.124 & 0.514 & 0.694 \\
BBChamps1 & 715 & 0.013 & 0.112 & 0 & 0 \\
BBChamps2 & 715 & 0.011 & 0.105 & 0 & 0 \\
BBChamps3 & 715 & 0.013 & 0.112 & 0 & 0 \\
FBFF1 & 715 & 0.060 & 0.238 & 0 & 0 \\
FBFF2 & 715 & 0.060 & 0.238 & 0 & 0 \\
FBFF3 & 715 & 0.060 & 0.238 & 0 & 0 \\
FBWpct & 715 & 0.570 & 0.175 & 0.444 & 0.700 \\
FBChamps1 & 715 & 0.015 & 0.123 & 0 & 0 \\
FBChamps2 & 715 & 0.015 & 0.123 & 0 & 0 \\
FBChamps3 & 715 & 0.015 & 0.123 & 0 & 0 \\
\hline
\end{tabular}

\section{Our Models}

We tested a wide variety of models, including semi-logs, different lag patterns and interactive effects, and focus here on the most important results (please see our data Appendix A for additional information). ${ }^{17}$ Unless otherwise indicated, our standard errors are robust (using the $\mathrm{HC} 1$ sandwich variance-covariance matrix (Zeileis and Hothorn 2002)) and our $p$-values are corrected for multiplicity via the Benjamini-Hochberg method (Benjamini and Hochberg 1995) ${ }^{18}$, which controls the false discovery rate. All computations were performed in R version 3.4 (R Core Team 2018).

Our general regression model for each response variable $y_{j}$ is:

$$
\begin{aligned}
& \begin{array}{ll}
y_{i}= & \beta \cdot X+\varepsilon_{j}
\end{array} \\
& =\beta_{j 0}+\alpha_{j} \cdot \text { Year }+\gamma_{j} \cdot \text { School }+\beta_{j 1} \cdot \log (\text { HSDiplomas })+\beta_{j 2} \cdot \text { Income } \\
& +\theta_{j 1} \cdot \text { BBWpct }+\theta_{j 2} \cdot \text { BBChamps } 1+\theta_{j 3} \cdot \text { BBChamps } 2+\theta_{j 4} \cdot \text { BBChamps3 } \\
& +\quad \theta_{j 5} \cdot B B F F 1+\theta_{j 6} \cdot B B F F 2+\theta_{j 7} \cdot B B F F 3 \\
& +\lambda_{j 1} \cdot F B W p c t+\lambda_{j 2} \cdot F B C h a m p s 1+\lambda_{j 3} \cdot F B C h a m p s 2+\lambda_{j 4} \cdot F B \text { Champs } 3 \\
& +\quad \lambda_{j 5} \cdot F B F F 1+\lambda_{j 6} \cdot F B F F 2+\lambda_{j 7} \cdot F B F F 3 \\
& +\quad \varepsilon_{j}
\end{aligned}
$$

16 We also collected many variables that were not included in our regression models. For example, cost of attendance, state population, etc. These variables are included in the colleges package (Baumer 2018), but are often incomplete and/or strongly correlated with our other explanatory variables.

17 None of the models we explored but are not reporting offered substantially different or contradictory results to the ones offered here.

18 All reported $p$-values were adjusted using the p.adjust() function in the stats package. 
where each $\alpha_{j}$ is a vector of length 10 containing the fixed effects associated with each academic year (relative to 2005-2006), each $\gamma_{j}$ is a vector of length 64 containing the fixed effects associated with each school (relative to the University of Alabama, which comes first alphabetically ${ }^{19}$ ), $\beta_{j 1}$ and $\beta_{j 2}$ are control variables associated with the number of high school diplomas granted in the previous year and the per capita income in the corresponding state, the $\theta^{\prime}$ 's are associated with the school's recent success in basketball, the $\lambda$ 's are associated with the school's recent success in football, and the error terms $\epsilon_{j} \sim N\left(0, \sigma_{\epsilon_{j}}\right)$, for some fixed value of $\sigma_{\epsilon_{j}}{ }^{20}$ For readability we omit the jsubscripts in what follows.

\section{Our Results}

In each of the models we fit, School and Year (which is treated as a categorical variable) were statistically significant. For clarity of presentation we relegate these results to our data Appendix A, but these effects capture much of the variability in the data. There are obvious broad trends, such as a general increase in the number of applications over time, and obvious school-specific effects for which these variables control. Multicollinearity among the explanatory variables of interest-as measured by generalized variance inflation factors (Fox and Monette 1992)—does not appear to be problematic in these models. ${ }^{21}$

\subsection{Athletic Success and the Quantity and Quality of Applications}

Our first model, shown below, tests the effect of athletic success on school applications,

$$
y_{1}=\log (\text { Applied })=\beta_{1} \cdot X+\epsilon_{1} .
$$

Results from this model are shown in Table 3.

19 The success of the University of Alabama's football team impacts our interpretation of the football-related variables. However, using Alabama as the reference group has no impact on any term's statistically significance, since we consider only the significance of the School variable as a whole.

20 Note that our models do not directly account for the possibility that a school is not simultaneously investing in competitive athletics and other areas of school achievement or marketing. That is, if a school hired a new football coach for $\$ 10$ million, leading to an appearance in the national football playoffs, at the same time that it hired two nobel prize winning professors and began a multimillion dollar marketing campaign, then attributing an increase in applications, in entering students SAT scores or in alumni donations to football success would be spurious. There are two caveats to such an endogeneity concern. First, we do employ institutional fixed effects that may attenuate or eliminate such a problem. Second, we do not know of any evidence that such behavior occurred. In any event, we are not attributing causality to the treatment variables in our models; rather, we are noting the presence or absence of statistically significant relationships and the magnitude of such relationships.

21 We computed generalized variance inflation factors raised to the $1 /(2 \cdot d f)$ power, as recommend by Fox and Monette $(1992)$ for all explanatory variables in all models. Those factors were only above 2 for the control variables number of high school diplomas (ranging from 20.8 to 23.9) and per capita income (8.9 to 10.0). 
Table 3. Models for Applicants.

\begin{tabular}{|c|c|c|}
\hline & \multicolumn{2}{|c|}{ Dependent Variable } \\
\hline & $\begin{array}{c}\log (\text { Applied) } \\
\text { (1) }\end{array}$ & $\begin{array}{l}\text { Admit } \\
\text { (2) }\end{array}$ \\
\hline $\log$ (HSDiplomas) & $\begin{array}{c}0.127(0.124) \\
p=0.440\end{array}$ & $\begin{array}{c}-0.086(0.075) \\
p=0.399\end{array}$ \\
\hline Income & $\begin{array}{c}0.012(0.011) \\
p=0.424\end{array}$ & $\begin{array}{c}0.003(0.006) \\
p=0.763\end{array}$ \\
\hline BBFF1 & $\begin{array}{c}-0.014(0.022) \\
p=0.676\end{array}$ & $\begin{array}{c}-0.002(0.013) \\
p=0.954\end{array}$ \\
\hline BBFF2 & $\begin{array}{c}-0.030(0.019) \\
p=0.209\end{array}$ & $\begin{array}{c}-0.001(0.020) \\
p=0.990\end{array}$ \\
\hline BBFF3 & $\begin{array}{c}0.018(0.024) \\
p=0.593\end{array}$ & $\begin{array}{c}-0.008(0.017) \\
p=0.826\end{array}$ \\
\hline BBWpct & $\begin{array}{c}0.067(0.059) \\
p=0.412\end{array}$ & $\begin{array}{c}-0.009(0.036) \\
p=0.919\end{array}$ \\
\hline BBChamps1 & $\begin{array}{c}0.059(0.033) \\
p=0.145\end{array}$ & $\begin{array}{c}-0.008(0.020) \\
p=0.857\end{array}$ \\
\hline BBChamps2 & $\begin{array}{l}0.095(0.035) \\
p=0.016^{* *}\end{array}$ & $\begin{array}{c}-0.003(0.023) \\
p=0.094\end{array}$ \\
\hline BBChamps3 & $\begin{array}{c}-0.010(0.046) \\
p=0.855\end{array}$ & $\begin{array}{c}0.018(0.022) \\
p=0.605\end{array}$ \\
\hline FBFF1 & $\begin{array}{c}0.031(0.022) \\
p=0.270\end{array}$ & $\begin{array}{c}-0.008(0.009) \\
p=0.596\end{array}$ \\
\hline FBFF2 & $\begin{array}{c}0.010(0.021) \\
p=0.778\end{array}$ & $\begin{array}{c}0.004(0.008) \\
p=0.810\end{array}$ \\
\hline FBFF3 & $\begin{array}{c}0.023(0.020) \\
p=0.412\end{array}$ & $\begin{array}{c}-0.005(0.008) \\
p=0.713\end{array}$ \\
\hline FBWpct & $\begin{array}{l}0.144(0.044) \\
p=0.004^{* * *}\end{array}$ & $\begin{array}{c}-0.053(0.024) \\
p=0.077^{*}\end{array}$ \\
\hline FBChamps1 & $\begin{array}{c}0.013(0.042) \\
p=0.832\end{array}$ & $\begin{array}{c}-0.021(0.015) \\
p=0.322\end{array}$ \\
\hline FBChamps2 & $\begin{array}{c}0.045(0.042) \\
p=0.424\end{array}$ & $\begin{array}{c}-0.009(0.017) \\
p=0.763\end{array}$ \\
\hline FBChamps3 & $\begin{array}{c}0.042(0.043) \\
p=0.459\end{array}$ & $\begin{array}{c}0.004(0.018) \\
p=0.919\end{array}$ \\
\hline Constant & $\begin{array}{l}1.810(0.571) \\
p=0.005^{* * *}\end{array}$ & $\begin{array}{l}0.930(0.336) \\
p=0.020^{* *}\end{array}$ \\
\hline Observations & 711 & 711 \\
\hline $\mathrm{R}^{2}$ & 0.955 & 0.920 \\
\hline Adjusted $\mathrm{R}^{2}$ & 0.949 & 0.909 \\
\hline Residual Std. Error $(\mathrm{df}=620)$ & 0.115 & 0.065 \\
\hline F Statistic $(\mathrm{df}=90 ; 620)$ & $147.817 * * *$ & $79.434 * * *$ \\
\hline
\end{tabular}

Out of the 14 athletic performance variables, only two are statistically significant at the 0.10 level: BBChamps2 and FBWpct. BBChamps 2 is significant at the 0.05 level and its coefficient $\left(\theta_{3}\right)$ indicates a 
national championship two years earlier is associated with a $10 \%$ increase in applications. ${ }^{22}$ FBWpct is significant at the 0.001 level and its coefficient $\left(\lambda_{1}\right)$ indicates an additional win per year on average over the previous three seasons is associated with a $1.1 \%$ increase in applications. ${ }^{23}$

These results are consistent with the bulk of previous literature that big-time football and men's basketball success does provide an advertising (and/or anticipated quality of life) effect which boosts applications to a university. Two additional observations are in order. First, the effect for increasing win percentage in the regular season does not apply to basketball (after controlling for football) and for football the magnitude of the effect is rather modest. Thus, direct advertising of a school's academic programs and campus life might be more effective in generating applications than investing in its basketball or football success. Second, the other observed impact occurs only for the rarest of accomplishments ( 1 out of 65 in each year): a national championship. Investing in creating a national championship basketball or football team entails very high risk for rather ordinary returns. Further, the returns in the form of increased applications appear to delay for one year and then dissipate by year three.

Table 3 also shows the results for a model for the rate of admissions. These results are highly consistent with the previous ones, due to the obvious functional dependence between the rate of admission and the number of applicants (the number of students is largely fixed at most schools). The negative coefficient for football winning percentage-the only variable to achieve statistical significance at the 0.10 level-implies that greater success in football is associated with higher selectivity.

Albeit tenuous, the existence of a statistically significant link between athletic success and applications leads to the next question: whether athletic success improves a school's admission yield (the percent of admitted students who enroll.) We ran the following equation to test this relationship.

$$
y_{3}=\text { Yield }=\beta_{3} \cdot X+\epsilon_{3}
$$

Results for this model as shown in Table 4. Of the 14 athletic performance variables, only one is statistically significant at the 0.10 level. FBWpct is significant at the 0.05 level with an association between an extra regular season win on average over the previous three years and an increased yield of 0.476 percentage points; that is, a yield of $30 \%$ would increase to $30.476 \%$. While football's impact appears to be statistically significant but small, performance of the men's basketball team does not have a statistically significant impact on yield.

If athletic success may lead to an uptick in applications, even with a steady yield, the school may become more selective. Greater selectivity, in turn, may lead to an improvement on the quality of the student body, often represented by a school's SAT scores.

In the following equation we test what impact athletic success has on the 75th percentile of SAT scores across the three sections of the exam (Math, English, Writing) for the 65 Power Five schools in our sample.

$$
y_{4}=S A T 75 p=\beta_{4} \cdot X+\epsilon_{4}
$$

The results from this model are also shown in Table 4. Only one of the 14 athletic performance variables achieve statistical significance at the 0.10 level: $B B W p c t$. The coefficient of $B B W p c t\left(\theta_{1}\right)$ implies that every regular season win on average over three years is associated with a 0.6 point increase in the average across the English, Writing and Math portions of the SAT for the 75th percentile of the school's student body —a statistically significant effect with no practical impact.

22 The coefficient was 0.095 and $\exp (0.095)=1.1$.

23 The coefficient was 0.144 and $\exp (0.144 / 13)=1.011$ (divided by an average of 13 regular season games). 
Table 4. Models for Admissions.

\begin{tabular}{|c|c|c|}
\hline & \multicolumn{2}{|c|}{ Dependent Variable } \\
\hline & $\begin{array}{l}\text { SAT75p } \\
\text { (1) }\end{array}$ & $\begin{array}{l}\text { Yield } \\
(2)\end{array}$ \\
\hline $\log$ (HSDiplomas) & $\begin{array}{c}17.070(14.516) \\
p=0.397\end{array}$ & $\begin{array}{c}0.082(0.059) \\
p=0.255\end{array}$ \\
\hline Income & $\begin{array}{c}-1.457(1.033) \\
p=0.286\end{array}$ & $\begin{array}{c}0.001(0.005) \\
p=0.880\end{array}$ \\
\hline BBFF1 & $\begin{array}{c}0.108(3.459) \\
p=0.980\end{array}$ & $\begin{array}{c}0.003(0.012) \\
p=0.902\end{array}$ \\
\hline BBFF2 & $\begin{array}{c}-0.100(3.914) \\
p=0.980\end{array}$ & $\begin{array}{c}0.015(0.022) \\
p=0.627\end{array}$ \\
\hline BBFF3 & $\begin{array}{c}1.963(3.631) \\
p=0.741\end{array}$ & $\begin{array}{c}0.0002(0.013) \\
p=0.887\end{array}$ \\
\hline BBWpct & $\begin{array}{c}17.937(7.451) \\
p=0.041^{* *}\end{array}$ & $\begin{array}{c}-0.002(0.013) \\
p=0.987\end{array}$ \\
\hline BBChamps1 & $\begin{array}{c}-7.067(6.423) \\
p=0.418\end{array}$ & $\begin{array}{c}0.0003(0.017) \\
p=0.987\end{array}$ \\
\hline BBChamps2 & $\begin{array}{c}-0.140(5.528) \\
p=0.980\end{array}$ & $\begin{array}{c}-0.019(0.022) \\
p=0.512\end{array}$ \\
\hline BBChamps3 & $\begin{array}{c}-2.869(6.094) \\
p=0.787\end{array}$ & $\begin{array}{c}-0.001(0.015) \\
p=0.980\end{array}$ \\
\hline FBFF1 & $\begin{array}{c}-9.598(7.237) \\
p=0.327\end{array}$ & $\begin{array}{c}-0.001(0.009) \\
p=0.944\end{array}$ \\
\hline FBFF2 & $\begin{array}{c}1.231(3.781) \\
p=0.874\end{array}$ & $\begin{array}{c}-0.005(0.007) \\
p=0.573\end{array}$ \\
\hline FBFF3 & $\begin{array}{c}-7.317(6.818) \\
p=0.426\end{array}$ & $\begin{array}{c}-0.011(0.008) \\
p=0.241\end{array}$ \\
\hline FBWpct & $\begin{array}{c}-4.963(6.418) \\
p=0.600\end{array}$ & $\begin{array}{c}0.062(0.023) \\
p=0.019^{* *}\end{array}$ \\
\hline FBChamps1 & $\begin{array}{c}7.934(9.794) \\
p=0.589\end{array}$ & $\begin{array}{c}-0.002(0.014) \\
p=0.944\end{array}$ \\
\hline FBChamps2 & $\begin{array}{c}-1.843(4.135) \\
p=0.798\end{array}$ & $\begin{array}{c}-0.012(0.016) \\
p=0.586\end{array}$ \\
\hline FBChamps3 & $\begin{array}{c}-0.445(9.155) \\
p=0.980\end{array}$ & $\begin{array}{c}-0.020(0.011) \\
p=0.139\end{array}$ \\
\hline Constant & $\begin{array}{c}580.580(55.642) \\
p=0.000^{* * *}\end{array}$ & $\begin{array}{c}0.152(0.265) \\
p=0.698\end{array}$ \\
\hline Observations & 675 & 711 \\
\hline $\mathrm{R}^{2}$ & 0.925 & 0.803 \\
\hline Adjusted $\mathrm{R}^{2}$ & 0.914 & 0.775 \\
\hline Residual Std. Error $(\mathrm{df}=620)$ & $14.941(\mathrm{df}=585)$ & $0.053(\mathrm{df}=620)$ \\
\hline F Statistic $(\mathrm{df}=90 ; 620)$ & $81.070 * * *(\mathrm{df}=89 ; 585)$ & $\begin{array}{c}28.153 * * *(\mathrm{df}=90 \\
620)\end{array}$ \\
\hline
\end{tabular}

Note: ${ }^{*} p<0.1 ;{ }^{* *} p<0.05 ;{ }^{* * *} p<0.01$. 


\subsection{Athletic Success and Alumni Giving}

Our next test explores the relationship between alumni donations and athletic success. As was the case with Anderson (2017), who also relied on data from the annual survey of the Council for Aid to Education, there is a substantial problem with missing data. Many of the respondent schools simply do not answer the survey questions on alumni donations or do not do so completely or on a regular annual basis. In Anderson's data set, approximately two-thirds of donation data is missing, in ours approximately $15 \%$ of overall donations and about half of athletics donations are missing (359 out of 715). Accordingly, although there is no obvious pattern to which schools did not report, our results must be interpreted with caution. The following equation examines the relationship between alumni donations to athletics and athletic performance, with the standard control variables. Its results are shown in Table 5.

$$
y_{5}=\log (\text { Athletics })=\beta_{5} \cdot X+\epsilon_{5}
$$

Table 5. Models for Donations.

\begin{tabular}{|c|c|c|}
\hline & \multicolumn{2}{|c|}{ Dependent Variable } \\
\hline & $\begin{array}{c}\log \text { (Athletics) } \\
\text { (1) }\end{array}$ & $\begin{array}{c}\log \text { (NonAthletics) } \\
\text { (2) }\end{array}$ \\
\hline $\log$ (HSDiplomas) & $\begin{array}{c}-0.453(1.144) \\
p=0.932\end{array}$ & $\begin{array}{c}0.508(0.331) \\
p=0.269\end{array}$ \\
\hline Income & $\begin{array}{c}0.040(0.090) \\
p=0.919\end{array}$ & $\begin{array}{c}0.068(0.029) \\
p=0.058 *\end{array}$ \\
\hline BBFF1 & $\begin{array}{c}-0.118(0.307) \\
p=0.932\end{array}$ & $\begin{array}{c}0.123(0.085) \\
p=0.292\end{array}$ \\
\hline BBFF2 & $\begin{array}{c}0.014(0.151) \\
p=0.978\end{array}$ & $\begin{array}{c}-0.027(0.068) \\
p=0.887\end{array}$ \\
\hline BBFF3 & $\begin{array}{c}0.113(0.137) \\
p=0.919\end{array}$ & $\begin{array}{c}0.010(0.058) \\
p=0.929\end{array}$ \\
\hline BBWpct & $\begin{array}{c}0.331(0.510) \\
p=0.919\end{array}$ & $\begin{array}{c}-0.020(0.183) \\
p=0.952\end{array}$ \\
\hline BBChamps1 & $\begin{array}{c}-0.092(0.290) \\
p=0.932\end{array}$ & $\begin{array}{c}-0.052(0.171) \\
p=0.893\end{array}$ \\
\hline BBChamps2 & $\begin{array}{c}-0.153(0.254) \\
p=0.919\end{array}$ & $\begin{array}{c}0.036(0.080) \\
p=0.876\end{array}$ \\
\hline BBChamps3 & $\begin{array}{c}-0.349(0.194) \\
p=0.629\end{array}$ & $\begin{array}{c}0.020(0.075) \\
p=0.893\end{array}$ \\
\hline FBFF1 & $\begin{array}{c}0.027(0.328) \\
p=0.978\end{array}$ & $\begin{array}{c}-0.087(0.086) \\
p=0.584\end{array}$ \\
\hline FBFF2 & $\begin{array}{c}0.349(0.333) \\
p=0.919\end{array}$ & $\begin{array}{c}-0.046(0.067) \\
p=0.759\end{array}$ \\
\hline FBFF3 & $\begin{array}{c}0.203(0.269) \\
p=0.919\end{array}$ & $\begin{array}{c}-0.120(0.071) \\
p=0.201\end{array}$ \\
\hline FBWpct & $\begin{array}{c}0.321(0.273) \\
p=0.919\end{array}$ & $\begin{array}{c}0.250(0.111) \\
p=0.071^{*}\end{array}$ \\
\hline
\end{tabular}


Table 5. Cont.

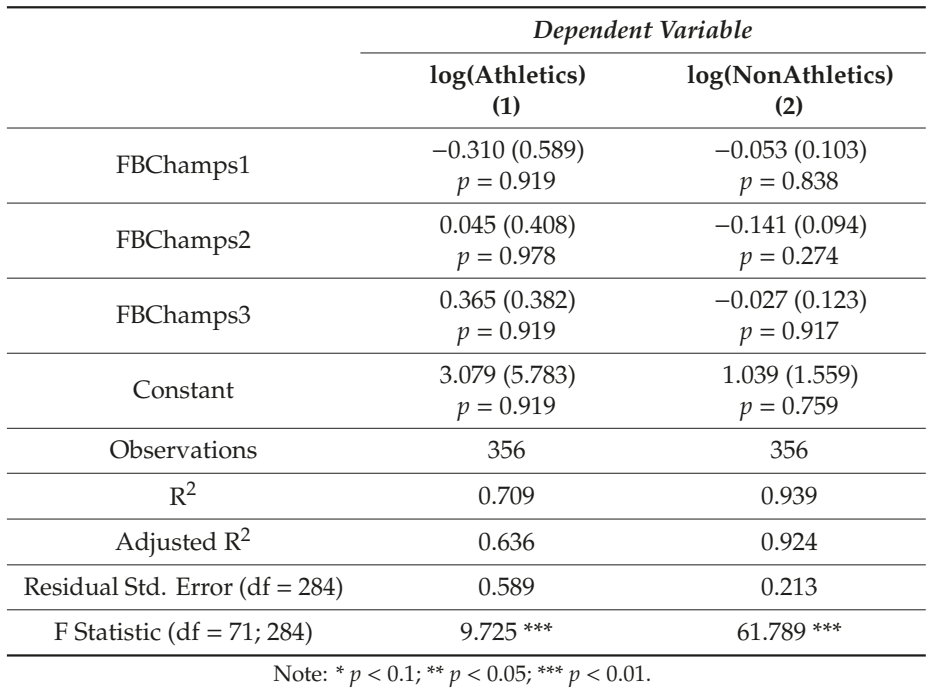

None of the 14 athletic performance variables is statistically significant at the 0.10 level. ${ }^{24}$

$$
y_{6}=\log (\text { NonAthletics })=\beta_{6} \cdot X+\epsilon_{6}
$$

This equation examines the relationship between donations to the school's general fund minus athletic donations (Non-Athletic Donations) and athletic performance.

Only one of the 14 athletic performance variables is statistically significant at the 0.10 level: $F B W p c t$. However, the effect size-an expected increase of $1.94 \%$ for each additional victory per year-is small. Nine of the 14 coefficients had negative signs.

\subsection{Athletic Success and State Budgetary Support}

Our final model was on the relationship between academic performance and state funding for public universities. The results are shown in Table 6.

$$
y_{7}=\text { State }=\beta_{7} \cdot X+\epsilon_{7}
$$

Three of the 14 athletic performance variables were significant at the 0.10 level: BBFF1, FBFF1, and FBFF2.

The nominal interpretation of the first coefficient $\left(\theta_{5}\right)$ is that a Final Four appearance in the previous basketball season is associated with a $5.3 \%$ increase in state funding. However, this is nearly offset by a -3.9 decrease associated with actually winning the championship, although this effect is not statistically significant. It is hard to square the idea that teams that reach the Final Four tend to receive greater increases in state funding than teams that win the championship.

24 The high adjusted $p$-values for the coefficients in the Athletics regression are a result of the unadjusted $p$-values being relatively uniformly distributed with a large mean (0.48). 
Table 6. Models for Funding.

\begin{tabular}{|c|c|c|}
\hline & \multicolumn{2}{|c|}{ Dependent Variable } \\
\hline & $\begin{array}{c}\log (\text { State }) \\
\text { (1) }\end{array}$ & $\begin{array}{c}\log (\text { StatePC }) \\
(2)\end{array}$ \\
\hline $\log$ (HSDiplomas) & $\begin{array}{c}-0.103(0.198) \\
p=0.705\end{array}$ & $\begin{array}{c}-0.024(0.177) \\
p=0.905\end{array}$ \\
\hline Income & $\begin{array}{c}-0.028(0.031) \\
p=0.471\end{array}$ & $\begin{array}{c}-0.032(0.023) \\
p=0.214\end{array}$ \\
\hline BBFF1 & $\begin{array}{c}0.052(0.023) \\
p=0.044 * *\end{array}$ & $\begin{array}{c}0.049(0.030) \\
p=0.154\end{array}$ \\
\hline BBFF2 & $\begin{array}{c}0.032(0.029) \\
p=0.377\end{array}$ & $\begin{array}{c}0.037(0.034) \\
p=0.338\end{array}$ \\
\hline BBFF3 & $\begin{array}{c}-0.005(0.041) \\
p=0.937\end{array}$ & $\begin{array}{c}-0.011(0.050) \\
p=0.870\end{array}$ \\
\hline BBWpct & $\begin{array}{c}0.042(0.117) \\
p=0.800\end{array}$ & $\begin{array}{c}0.059(0.095) \\
p=0.623\end{array}$ \\
\hline BBChamps1 & $\begin{array}{c}-0.040(0.043) \\
p=0.471\end{array}$ & $\begin{array}{c}-0.071(0.058) \\
p=0.296\end{array}$ \\
\hline BBChamps2 & $\begin{array}{c}-2.869(6.094) \\
p=0.787\end{array}$ & $\begin{array}{c}-0.058(0.052) \\
p=0.334\end{array}$ \\
\hline BBChamps3 & $\begin{array}{c}-0.016(0.052) \\
p=0.823\end{array}$ & $\begin{array}{c}-0.017(0.069) \\
p=0.867\end{array}$ \\
\hline FBFF1 & $\begin{array}{c}-0.064(0.031) \\
p=0.073 *\end{array}$ & $\begin{array}{c}-0.079(0.031) \\
p=0.019^{* *}\end{array}$ \\
\hline FBFF2 & $\begin{array}{c}-0.059(0.029) \\
p=0.079 *\end{array}$ & $\begin{array}{c}-0.039(0.031) \\
p=0.276\end{array}$ \\
\hline FBFF3 & $\begin{array}{c}-0.035(0.027) \\
p=0.286\end{array}$ & $\begin{array}{c}-0.028(0.025) \\
p=0.338\end{array}$ \\
\hline FBWpct & $\begin{array}{c}-0.159(0.155) \\
p=0.411\end{array}$ & $\begin{array}{c}-0.023(0.109) \\
p=0.870\end{array}$ \\
\hline FBChamps1 & $\begin{array}{c}0.073(0.041) \\
p=0.129\end{array}$ & $\begin{array}{c}0.094(0.056) \\
p=0.151\end{array}$ \\
\hline FBChamps2 & $\begin{array}{c}0.057(0.052) \\
p=0.387\end{array}$ & $\begin{array}{c}0.041(0.067) \\
p=0.623\end{array}$ \\
\hline FBChamps3 & $\begin{array}{c}0.011(0.034) \\
p=0.823\end{array}$ & $\begin{array}{c}0.006(0.045) \\
p=0.905\end{array}$ \\
\hline Constant & $\begin{array}{c}5.863(1.225) \\
p=0.00001^{* * *}\end{array}$ & $\begin{array}{c}4.190(0.966) \\
p=0.00005^{\text {**** }}\end{array}$ \\
\hline Observations & 558 & 557 \\
\hline $\mathrm{R}^{2}$ & 0.949 & 0.942 \\
\hline Adjusted $\mathrm{R}^{2}$ & 0.941 & 0.933 \\
\hline Residual Std. Error $(\mathrm{df}=481)$ & 0.216 & 0.177 \\
\hline F Statistic $(\mathrm{df}=76 ; 481)$ & $117.728^{* * *}$ & $103.449^{* * *}$ \\
\hline
\end{tabular}

Further muddying the waters is the fact that the effects on the football side show the same offsetting pattern, but in the opposite direction (negative for reaching the Final Four, positive for winning the championship). 
When we consider the state funding per capita (as in Table 6), the statistical significance of all variables save for $F B F F 1$ disappears, and the direction of the effect remains negative.

\section{Conclusions}

Previous literature on the effect of athletic success on applications, quality of the student body, donations and state funding has been inconclusive. Researchers have employed different methodologies and models and most have been limited by incomplete data. We develop a recent data set for the Power Five conferences during the eleven years from 2006 through 2016 and use fixed effects linear regression models to retest these relationships. We report robust standard errors and control for multiple testing. We find that certain measures of football success have a modest positive and short-lived impact on student applications, but no clear impact on admission yield or on the quality of the student body. Although hampered by incomplete data, we also found that athletic success did not have a statistically significant effect on donations. Final Four appearances in both basketball and football showed some statistical significance associated with state funding, but the direction and robustness of these findings is unclear.

Author Contributions: The authors contributed equally to this article.

Acknowledgments: The authors would like to thank Junzhou Liu, our data collection assistant, as well as Michael Lopez, Roger Noll, Brad Humphreys, Ann Kaplan, Nick Horton, Dennis Coates, the reviewers and the associate editor for helpful comments and suggestions.

Conflicts of Interest: The authors declare no conflict of interest

\section{Appendix A}

ANOVA tables

Below we present the ANOVA tables for all models discussed in the paper. Note the persistent statistical significance of the Year and School terms.

Table A1. ANOVA table for $\log ($ Applied).

\begin{tabular}{cccccc}
\hline & Df & Sum Sq & Mean Sq & F Value & $\operatorname{Pr}(>$ F $)$ \\
\hline Year & 10 & 26.197 & 2.620 & 198.729 & 0.000 \\
school_name & 64 & 148.990 & 2.328 & 176.601 & 0.000 \\
log(hs_diplomas_lag1) & 1 & 0.008 & 0.008 & 0.578 & 0.447 \\
per_capita_income & 1 & 0.008 & 0.008 & 0.602 & 0.438 \\
bball_avg_wpct_lag3 & 1 & 0.020 & 0.020 & 1.5474 & 0.214 \\
bb_champs_lag1 & 1 & 0.011 & 0.011 & 0.867 & 0.352 \\
bb_champs_lag2 & 1 & 0.056 & 0.056 & 4.278 & 0.039 \\
bb_champs_lag3 & 1 & 0.008 & 0.008 & 0.613 & 0.434 \\
fball_avg_wpct_lag3 & 1 & 0.288 & 0.288 & 21.859 & 0.000 \\
fb_champs_lag1 & 1 & 0.016 & 0.016 & 1.241 & 0.266 \\
fb_champs_lag2 & 1 & 0.023 & 0.023 & 1.777 & 0.183 \\
fb_champs_lag3 & 1 & 0.036 & 0.036 & 2.749 & 0.098 \\
Residuals & 626 & 8.252 & 0.013 & & \\
\hline
\end{tabular}


Table A2. ANOVA table for SAT75p.

\begin{tabular}{cccccc}
\hline & Df & Sum Sq & Mean Sq & F Value & Pr(>F) \\
\hline Year & 10 & $12,802.322$ & $12,802.322$ & 5.654 & 0.000 \\
school_name & 63 & $1,591,052.696$ & $25,254.805$ & 111.543 & 0.000 \\
log(hs_diplomas_lag1) & 1 & 417.541 & 417.541 & 1.844 & 0.175 \\
per_capita_income & 1 & 400.511 & 400.511 & 1.769 & 0.184 \\
bball_avg_wpct_lag3 & 1 & 1199.903 & 1199.903 & 5.300 & 0.022 \\
bb_champs_lag1 & 1 & 278.781 & 278.781 & 1.231 & 0.268 \\
bb_champs_lag2 & 1 & 8.558 & 8.558 & 0.038 & 0.846 \\
bb_champs_lag3 & 1 & 20.627 & 20.627 & 0.091 & 0.763 \\
fball_avg_wpct_lag3 & 1 & 865.252 & 865.252 & 3.822 & 0.051 \\
fb_champs_lag1 & 1 & 0.010 & 0.010 & 0.000 & 0.995 \\
fb_champs_lag2 & 1 & 7.444 & 7.444 & 0.033 & 0.856 \\
fb_champs_lag3 & 1 & 394.777 & 394.777 & 1.744 & 0.187 \\
Residuals & 591 & $133,810.192$ & 226.413 & & \\
\hline
\end{tabular}

Table A3. ANOVA table for $\log$ (Donations).

\begin{tabular}{cccccc}
\hline & Df & Sum Sq & Mean Sq & F Value & $\operatorname{Pr}(>$ F $)$ \\
\hline Year & 10 & 9.510 & 9.510 & 33.107 & 0.000 \\
school_name & 59 & 241.490 & 4.093 & 142.499 & 0.000 \\
log(hs_diplomas_lag1) & 1 & 0.176 & 0.176 & 6.141 & 0.014 \\
per_capita_income & 1 & 0.302 & 0.302 & 10.500 & 0.001 \\
bball_avg_wpct_lag3 & 1 & 0.000 & 0.000 & 0.011 & 0.918 \\
bb_champs_lag1 & 1 & 0.005 & 0.005 & 0.180 & 0.671 \\
bb_champs_lag2 & 1 & 0.015 & 0.015 & 0.510 & 0.476 \\
bb_champs_lag3 & 1 & 0.028 & 0.028 & 0.988 & 0.321 \\
fball_avg_wpct_lag3 & 1 & 0.204 & 0.204 & 7.100 & 0.008 \\
fb_champs_lag1 & 1 & 0.016 & 0.016 & 0.573 & 0.450 \\
fb_champs_lag2 & 1 & 0.001 & 0.001 & 0.027 & 0.870 \\
fb_champs_lag3 & 1 & 0.030 & 0.030 & 1.033 & 0.310 \\
Residuals & 525 & 15.080 & 0.029 & & \\
\hline
\end{tabular}

Table A4. ANOVA table for $\log$ (Athletics).

\begin{tabular}{cccccc}
\hline & Df & Sum Sq & Mean Sq & F Value & Pr( $>$ F $)$ \\
\hline Year & 10 & 10.467 & 1.047 & 3.028 & 0.001 \\
school_name & 45 & 225.721 & 5.016 & 14.513 & 0.000 \\
log(hs_diplomas_lag1) & 1 & 0.051 & 0.051 & 0.147 & 0.702 \\
per_capita_income & 1 & 0.071 & 0.071 & 0.204 & 0.652 \\
bball_avg_wpct_lag3 & 1 & 0.125 & 0.125 & 0.362 & 0.548 \\
bb_champs_lag1 & 1 & 0.045 & 0.045 & 0.129 & 0.720 \\
bb_champs_lag2 & 1 & 0.002 & 0.002 & 0.005 & 0.941 \\
bb_champs_lag3 & 1 & 0.078 & 0.078 & 0.226 & 0.635 \\
fball_avg_wpct_lag3 & 1 & 0.647 & 0.647 & 1.8722 & 0.172 \\
fb_champs_lag1 & 1 & 0.446 & 0.446 & 1.289 & 0.257 \\
fb_champs_lag2 & 1 & 0.150 & 0.150 & 0.433 & 0.511 \\
fb_champs_lag3 & 1 & 0.4360. & 0.436 & 1.263 & 0.262 \\
Residuals & 290 & 100.232 & 0.346 & & \\
\hline
\end{tabular}


Table A5. ANOVA table for $\log$ (NonAthletics).

\begin{tabular}{cccccc}
\hline & Df & Sum Sq & Mean Sq & F Value & Pr( $>$ F $)$ \\
\hline Year & 10 & 8.851 & 0.885 & 19.548 & 0.000 \\
school_name & 45 & 188.907 & 4.198 & 92.717 & 0.000 \\
log(hs_diplomas_lag1) & 1 & 0.066 & 0.066 & 1.457 & 0.228 \\
per_capita_income & 1 & 0.316 & 0.316 & 6.979 & 0.009 \\
bball_avg_wpct_lag3 & 1 & 0.000 & 0.000 & 0.001 & 0.977 \\
bb_champs_lag1 & 1 & 0.006 & 0.006 & 0.140 & 0.708 \\
bb_champs_lag2 & 1 & 0.001 & 0.001 & 0.016 & 0.898 \\
bb_champs_lag3 & 1 & 0.010 & 0.010 & 0.226 & 0.635 \\
fball_avg_wpct_lag3 & 1 & 0.157 & 0.157 & 3.462 & 0.064 \\
fb_champs_lag1 & 1 & 0.024 & 0.024 & 0.523 & 0.470 \\
fb_champs_lag2 & 1 & 0.066 & 0.066 & 1.459 & 0.228 \\
fb_champs_lag3 & 1 & 0.023 & 0.023 & 0.517 & 0.473 \\
Residuals & 290 & 13.130 & 0.045 & & \\
\hline
\end{tabular}

Table A6. ANOVA table for $\log$ (State).

\begin{tabular}{cccccc}
\hline & Df & Sum Sq & Mean Sq & F Value & $\operatorname{Pr}(>$ F $)$ \\
\hline Year & 10 & 1.997 & 0.200 & 4.294 & 0.000 \\
school_name & 50 & 414.854 & 8.297 & 178.446 & 0.000 \\
log(hs_diplomas_lag1) & 1 & 0.003 & 0.003 & 0.066 & 0.798 \\
per_capita_income & 1 & 0.094 & 0.094 & 2.013 & 0.157 \\
bball_avg_wpct_lag3 & 1 & 0.006 & 0.006 & 0.125 & 0.724 \\
bb_champs_lag1 & 1 & 0.004 & 0.004 & 0.096 & 0.756 \\
bb_champs_lag2 & 1 & 0.003 & 0.003 & 0.067 & 0.796 \\
bb_champs_lag3 & 1 & 0.000 & 0.000 & 0.004 & 0.950 \\
fball_avg_wpct_lag3 & 1 & 0.075 & 0.075 & 1.607 & 0.205 \\
fb_champs_lag1 & 1 & 0.003 & 0.003 & 0.063 & 0.801 \\
fb_champs_lag2 & 1 & 0.001 & 0.001 & 0.019 & 0.891 \\
fb_champs_lag3 & 1 & 0.004 & 0.004 & 0.086 & 0.770 \\
Residuals & 487 & 22.644 & 0.046 & & \\
\hline
\end{tabular}

Table A7. ANOVA table for $\log ($ StatePC).

\begin{tabular}{cccccc}
\hline & Df & Sum Sq & Mean Sq & F Value & Pr( $>$ F $)$ \\
\hline Year & 10 & 5.056 & 5.056 & 16.124 & 0.000 \\
school_name & 50 & 240.754 & 4.815 & 153.543 & 0.000 \\
log(hs_diplomas_lag1) & 1 & 0.002 & 0.002 & 0.061 & 0.804 \\
per_capita_income & 1 & 0.106 & 0.106 & 3.387 & 0.066 \\
bball_avg_wpct_lag3 & 1 & 0.022 & 0.022 & 0.690 & 0.407 \\
bb_champs_lag1 & 1 & 0.000 & 0.000 & 0.004 & 0.953 \\
bb_champs_lag2 & 1 & 0.006 & 0.006 & 0.202 & 0.653 \\
bb_champs_lag3 & 1 & 0.004 & 0.004 & 0.139 & 0.710 \\
fball_avg_wpct_lag3 & 1 & 0.027 & 0.027 & 0.861 & 0.354 \\
fb_champs_lag1 & 1 & 0.005 & 0.005 & 0.167 & 0.683 \\
fb_champs_lag2 & 1 & 0.001 & 0.001 & 0.042 & 0.838 \\
fb_champs_lag3 & 1 & 0.003 & 0.003 & 0.083 & 0.774 \\
Residuals & 486 & 15.241 & 0.031 & & \\
\hline
\end{tabular}


Table A8. ANOVA table for Yield.

\begin{tabular}{cccccc}
\hline & Df & Sum Sq & Mean Sq & F Value & Pr( $>$ F $)$ \\
\hline Year & 10 & 0.823 & 0.082 & 29.646 & 0.000 \\
school_name & 64 & 6.200 & 6.200 & 34.880 & 0.000 \\
log(hs_diplomas_lag1) & 1 & 0.007 & 0.007 & 2.608 & 0.107 \\
per_capita_income & 1 & 0.000 & 0.000 & 0.151 & 0.698 \\
bball_avg_wpct_lag3 & 1 & 0.000 & 0.000 & 0.117 & 0.732 \\
bb_champs_lag1 & 1 & 0.001 & 0.001 & 0.395 & 0.530 \\
bb_champs_lag2 & 1 & 0.000 & 0.000 & 0.021 & 0.884 \\
bb_champs_lag3 & 1 & 0.000 & 0.000 & 0.001 & 0.976 \\
fball_avg_wpct_lag3 & 1 & 0.022 & 0.022 & 7.883 & 0.005 \\
fb_champs_lag1 & 1 & 0.000 & 0.000 & 0.057 & 0.812 \\
fb_champs_lag2 & 1 & 0.002 & 0.002 & 0.825 & 0.364 \\
fb_champs_lag3 & 1 & 0.008 & 0.008 & 2.791 & 0.095 \\
Residuals & 626 & 1.739 & 0.003 & & \\
\hline
\end{tabular}

Table A9. ANOVA table for Admit.

\begin{tabular}{cccccc}
\hline & Df & Sum Sq & Mean Sq & F Value & $\operatorname{Pr}(>$ F $)$ \\
\hline Year & 10 & 0.364 & 0.036 & 8.796 & 0.000 \\
school_name & 64 & 29.422 & 0.460 & 111.044 & 0.000 \\
log(hs_diplomas_lag1) & 1 & 0.009 & 0.009 & 2.088 & 0.149 \\
per_capita_income & 1 & 0.002 & 0.002 & 0.494 & 0.482 \\
bball_avg_wpct_lag3 & 1 & 0.001 & 0.001 & 0.257 & 0.612 \\
bb_champs_lag1 & 1 & 0.002 & 0.002 & 0.367 & 0.545 \\
bb_champs_lag2 & 1 & 0.001 & 0.001 & 0.256 & 0.613 \\
bb_champs_lag3 & 1 & 0.000 & 0.000 & 0.017 & 0.896 \\
fball_avg_wpct_lag3 & 1 & 0.034 & 0.034 & 8.164 & 0.004 \\
fb_champs_lag1 & 1 & 0.007 & 0.007 & 1.604 & 0.206 \\
fb_champs_lag2 & 1 & 0.001 & 0.001 & 0.321 & 0.571 \\
fb_champs_lag3 & 1 & 0.000 & 0.000 & 0.000 & 0.990 \\
Residuals & 626 & 2.592 & 0.004 & & \\
\hline
\end{tabular}

\section{References}

Alexander, Donald L., and William Kern. 2010. Does Athletic Success Generate Legislative Largess from Sports-Crazed Representatives? The Impact of Athletic Success on State Appropriations to Colleges and Universities. International Journal of Sport Finance 5: 253-67.

Anderson, Michael L. 2017. The Benefits of College Athletic Success: An Application of the Propensity Score Design. Review of Economics and Statistics 99: 119-34. [CrossRef]

Baade, Robert A., and Jeffrey O. Sundberg. 1996. What Determines Alumni Generosity? Economics of Education Review 15: 75-82. [CrossRef]

Baumer, Benjamin S. 2018. Colleges: Data About College Enrollments, Donations, and Athletics. Available online: http://github.com/beanumber/colleges (accessed on 1 November 2018).

Benjamini, Yoav, and Yosef Hochberg. 1995. Controlling the False Discovery Rate: A Practical and Powerful Approach to Multiple Testing. Journal of the Royal Statistical Society. Series B (Methodological) 57: 289-300. [CrossRef]

Bremmer, Dale S., and Randall G. Kesselring. 1993. The Advertising Effect of University Athletic Success: A Reappraisal of the Evidence. The Quarterly Review of Economics and Finance 33: 409-21. [CrossRef]

Brooker, George W., and Theodore D. Klastorin. 1981. To the Victors Belong the Spoils? College Athletics and Alumni Giving. Social Science Quarterly 62: 744-50.

Castle, Joshua, and Robert Kostelnik. 2011. The Effects of an Institution's Athletic Success on the Future Freshmen Application Pool at Ncaa Division Ii Universities. Journal of Issues in Intercollegiate Athletics 4: 411-27.

Clotfelter, Charles T. 2011. Big-Time Sports in American Universities. New York: Cambridge University Press. 
Coughlin, Cletus C., and O. Homer Erekson. 1986. Determinants of State Aid and Voluntary Support of Higher Education. Economics of Education Review 5: 179-90. [CrossRef]

Fox, John, and Georges Monette. 1992. Generalized collinearity diagnostics. Journal of the American Statistical Association 87: 178-83. [CrossRef]

Frank, Robert H. 2004. Challenging the Myth: A Review of the Links among College Athletic Success, Student Quality, and Donations. Miami: Knight Foundation Commission on Intercollegiate Athletics.

Goff, Brian. 2000. Effects of University Athletics on the University: A Review and Extension of Empirical Assessment. Journal of Sport Management 14: 85-104. [CrossRef]

Grimes, Paul W., and George A. Chressanthis. 1994. Alumni Contributions to Academics: The Role of Intercollegiate Sports and Ncaa Sanctions. American Journal of Economics and Sociology 53: 27-40. [CrossRef]

Hernández-Julián, Rey, and Kurt W. Rotthoff. 2014. The Impact of College Football on Academic Achievement. Economics of Education Review 43: 141-47. [CrossRef]

Humphreys, Brad R. 2006. The Relationship Between Big-Time College Football and State Appropriations for Higher Education. International Journal of Sport Finance 1: 119-28.

Humphreys, Brad R., and Michael Mondello. 2007. Intercollegiate Athletic Success and Donations at Ncaa Division I Institutions. Journal of Sport Management 21: 265-80. [CrossRef]

Jones, Willis A. 2015. High-Level Football and Appropriations to Universities: Are Sports-Crazed Representatives Responsive to Ncaa Divisional Affiliation? Journal of Education Finance 40: 438-55.

Koo, Gi-Yong, and Stephen W. Dittmore. 2014. Effects of Intercollegiate Athletics on Private Giving in Higher Education. Journal of Issues in Intercollegiate Athletics 7: 1-16.

Lindo, Jason M., Isaac D. Swensen, and Glen R. Waddell. 2012. Are Big-Time Sports a Threat to Student Achievement? American Economic Journal: Applied Economics 4: 254-74. [CrossRef]

Litan, Robert E., Jonathan M. Orszag, and Peter R. Orszag. 2003. The Empirical Effects of Collegiate Athletics: An Interim Report. Washington, DC, USA: Sebago Associates.

Lopez, Michael, Gregory J. Matthews, and Benjamin S. Baumer. 2018. How Often Does the Best Team Win? A Unified Approach to Understanding Randomness in North American Sport. Annals of Applied Statistics 12: 2483-516. [CrossRef]

Massachusetts Football Task Force. 1996. Final Report of the I-a Football Task Force. Boston: University of Massachusetts.

McCormick, Robert E., and Maurice Tinsley. 1987. Athletics Versus Academics? Evidence from Sat Scores. Journal of Political Economy 95: 1103-16. [CrossRef]

Mixon, Franklin G., Jr. 1995. Athletics Versus Academics? Rejoining the Evidence from Sat Scores. Education Economics 3: 277-83. [CrossRef]

Mixon, Franklin G., Jr., and Yu Hsing. 1994. The Determinants of Out-of-State Enrollments in Higher Education: A Tobit Analysis. Economics of Education Review 13: 329-35. [CrossRef]

Mixon, Franklin G., Jr., and Rand W. Ressler. 1995. An Empirical Note on the Impact of College Athletics on Tuition Revenues. Applied Economics Letters 2: 383-87. [CrossRef]

Murphy, Robert G., and Gregory A. Trandel. 1994. The Relation between a University's Football Record and the Size of Its Applicant Pool. Economics of Education Review 13: 265-70. [CrossRef]

NCAA. 2017. Revenues and Expenses of Division I Intercollegiate Athletics Program, 2004-2016. Indianapolis: NCAA.

Orszag, Jonathan M., and Peter R. Orszag. 2005. The Physical Capital Stock Used in Collegiate Athletics. Indianapolis: NCAA.

Pope, Devin G., and Jaren C. Pope. 2009. The Impact of College Sports Success on the Quantity and Quality of Student Applications. Southern Economic Journal 75: 750-80.

Pope, Devin G., and Jaren C. Pope. 2014. Understanding College Application Decisions: Why College Sports Success Matters. Journal of Sports Economics 15: 107-31. [CrossRef]

R Core Team. 2018. R: A Language and Environment for Statistical Computing. Vienna: R Foundation for Statistical Computing.

Rhoads, Thomas A., and Shelby Gerking. 2000. Educational Contributions, Academic Quality, and Athletic Success. Contemporary Economic Policy 18: 248-58. [CrossRef]

Sigelman, Lee, and Samuel Bookheimer. 1983. Is It Whether You Win or Lose? Monetary Contributions to Big-Time College Athletic Programs. Social Science Quarterly 64: 347-59.

Sigelman, Lee, and Robert Carter. 1979. Win One for the Giver? Alumni Giving and Big-Time College Sports. Social Science Quarterly 60: 284-94. 
Smith, D. Randall. 2008. Big-Time College Basketball and the Advertising Effect: Does Success Really Matter? Journal of Sports Economics 9: 387-406. [CrossRef]

Stinson, Jeffrey L., and Dennis R. Howard. 2008. Winning Does Matter: Patterns in Private Giving to Athletic and Academic Programs at NCAA Division I-AA and I-AAA Institutions. Sport Management Review 11: 1-20. [CrossRef]

Toma, J. Douglas, and Michael E. Cross. 1998. Intercollegiate Athletics and Student College Choice: Exploring the Impact of Championship Seasons on Undergraduate Applications. Research in Higher Education 39: 633-61. [CrossRef]

Tucker, Irvin B. 2005. Big-Time Pigskin Success: Is There an Advertising Effect? Journal of Sports Economics 6: 222-29. [CrossRef]

Tucker, Irvin B., and Louis Amato. 1993. Does Big-Time Success in Football or Basketball Affect Sat Scores? Economics of Education Review 12: 177-81. [CrossRef]

Turner, Sarah E., Lauren A. Meserve, and William G. Bowen. 2001. Winning and Giving a Study of the Responsiveness of Giving to Performance on the Field. Social Science Quarterly 82: 812-26. [CrossRef]

Walker, Adam G. 2015. Division I Intercollegiate Athletics Success and the Financial Impact on Universities. SAGE Open 5: 1-13. [CrossRef]

Zeileis, Achim, and Torsten Hothorn. 2002. Diagnostic Checking in Regression Relationships. R News 2: 7-10.

Zimbalist, Andrew. 2001. Unpaid Professionals: Commercialism and Conflict in Big-Time College Sports. Princeton: Princeton University Press.

(C) 2019 by the authors. Licensee MDPI, Basel, Switzerland. This article is an open access article distributed under the terms and conditions of the Creative Commons Attribution (CC BY) license (http://creativecommons.org/licenses/by/4.0/). 


\title{
Article \\ Country of Origin Effects on the Average Annual Values of NHL Player Contracts
}

\author{
Aju J. Fenn *, Lucas Gerdes and Samuel Rothstein \\ Economics \& Business department, Colorado College, Colorado Springs, CO 80919, USA; \\ L_gerdes@coloradocollege.edu (L.G.); Samuel.Rothstein@coloradocollege.edu (S.R.) \\ * Correspondence: Aju.Fenn@coloradocollege.edu
}

Received: 25 March 2019; Accepted: 10 May 2019; Published: 17 May 2019

\begin{abstract}
Using data from 2005 to 2016, this paper examines if players in the National Hockey League (NHL) are being paid a positive differential for their services due to the competition from the Kontinental Hockey League (KHL) and the Swedish Hockey League (SHL). In order to control for performance, we use two different large datasets, $(\mathrm{N}=4046)$ and $(\mathrm{N}=1717)$. In keeping with the existing literature, we use lagged performance statistics and dummy variables to control for the type of NHL contract. The first dataset contains lagged career performance statistics, while the performance statistics are based on the statistics generated during the years under the player's previous contract. Fixed effects least squares (FELS) and quantile regression results suggest that player production statistics, contract status, and country of origin are significant determinants of NHL player salaries.
\end{abstract}

Keywords: NHL; KHL; country of origin; salary

JEL Classification: J44; J71; L83; Z21; Z22

\section{Introduction}

The Kontinental Hockey League (KHL) was founded in 2008. It comprises of 27 teams based in Belarus, China, Finland, Kazakhstan, Latvia, Russia, and Slovakia. The Swedish Hockey League (SHL) was founded in 1975. It comprises of 14 teams that play their games in Sweden. The existence of these two leagues may provide an alternative to the National Hockey League (NHL) for players who want to play professional hockey. We examine if players that may play in these leagues because of their country of origin now command a higher salary in the NHL.

Figure 1 plots the annual average value (AAV) for players by their country of origin. AAV is the total salary over the term of a contract divided by the length of the contract in years plus annualized performance bonuses. The data are taken from https://www.capfriendly.com. In the 2015-2016 season, the NHL consisted of players from all over the globe, with players of Canadian descent dominating the league at $49 \%$. Second on the list were players from the United States at $24.6 \%$. Players of Swedish descent came third, making up $8.6 \%$ of the league, followed by Russians at $4.1 \%$. Players from Czech Republic and Finland each represented 3.9\% of the league. Looking at Figure 1, it is clear that median Russian, Swedish, Finnish, and Czech salaries exceed those of American and Canadians for every given year. Is this because Russian and European players are more talented than their American and Canadian counterparts? Or is it because Russian and European players have more leverage in NHL salary negotiations because of the demand from the KHL and the SHL for their services? We use salary and NHL statistics from the 2005-2016 seasons to explore these questions. 


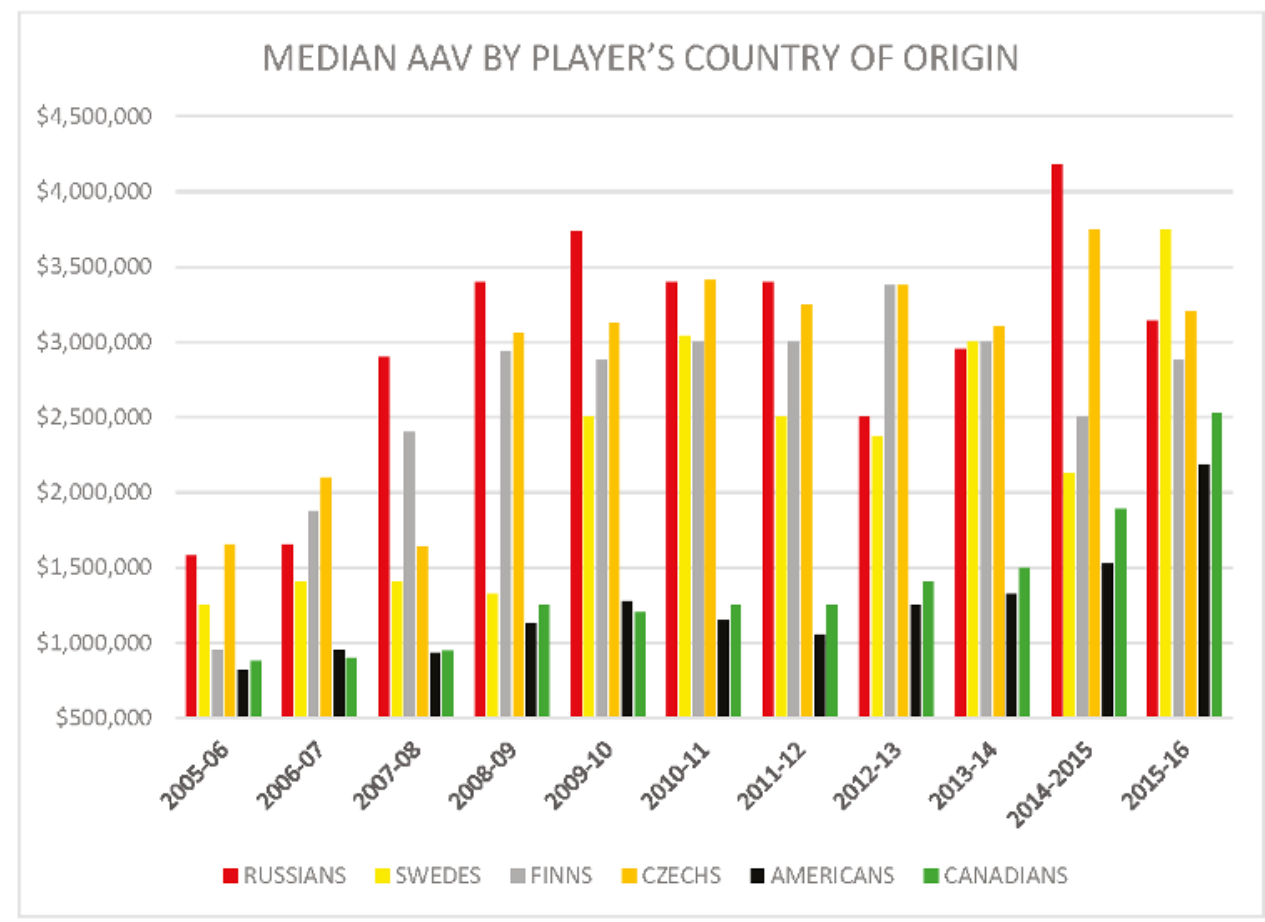

Figure 1. Review.

\section{Literature Review}

Salary discrimination and entry discrimination have both been studied extensively in North American professional sports (Kahn 1992; Holmes 2011; Yang and Lin 2012). Earlier studies focus on the discrimination against Francophones on Anglophone Canadian NHL teams (Lavoie et al. 1987; Jones and Walsh 1988). Previous studies on the NHL found salary discrimination against European players in the NHL (Bruggink and Williams 2009). Recently, Christie and Lavoie found discrimination against young Russian players in the NHL draft (Christie and Lavoie 2015).

There is also an established literature on salary and player performance in the NHL. There are many statistics that can determine what a player may be worth. The most common statistics used are points (for offensive production), penalty minutes (for defensive intensity), and a plus/minus statistic for a combination of both offensive and defensive skills (Idson and Kahane 2001). The impact of a player's statistics on their salary can be challenging due to the fact that players are paid based on statistics of their play in previous years (Kahane 2001). Kahane uses lagged career statistics to account for this fact. Brander and Egan use on-ice statistics from the year immediately prior to the contract that determines the player's salary in their dataset (Brander and Egan 2018). They also control for the type of player contract using dummy variables. We too use lagged on-ice statistics for the same reasons and dummy variables to control for the type of player contracts. Holmes studies the impact of performance on salary in Major League Baseball (Holmes 2011). He points out that ordinary least squares (OLS) models that employ a single dummy for ethnicity may fail to detect discrimination at various levels of the salary distribution. His approach is to use a quantile regression model, which detects the subtleties of discrimination at different quantiles. Vincent and Eastman also employ quantile regression to examine the impact of performance on salary at different quantiles of the NHL wage distribution (Vincent and Eastman 2009). They claim that the standard conditional expectations model employed by OLS misses some important subtleties of the earnings determination in the NHL, as opposing effects 
at different quantiles may cancel each other out in a single mean conditional expectations OLS model. We also present results from quantile regressions in addition to fixed effects ordinary least squares results (FELS).

\section{Data}

Two panel datasets, $(\mathrm{N}=4046)$ and $(\mathrm{N}=1717)$, are used in this study. The first dataset, called career lagged statistics data, uses player-years as the unit of observation. The second dataset, called previous contract statistics data, uses player contracts as the unit of observation. Both datasets include players that played in the NHL during the 2005-2006 to 2015-2016 seasons. Players must have played over 25 games in at least one season over the course of their career or their previous contract to be considered a full time player for the purposes of this study. Goalies are excluded because their statistics are quite different from other players. We also exclude any players that were traded during a season to another team. The original NHL statistical player data come from http://www.hockeyabstract.com and Rob Vollman, while the annual average value (AAV) data come from https://www.capfriendly.com.

The first panel dataset has player-years as the unit of observation. The nominal version of the dependent variable in this dataset is called the AAV. The AAV is the total salary over the term of a contract divided by the length of the contract in years plus annualized performance bonuses. We use AAV in part because it also factors in performance bonuses. This figure is used instead of total salary due to the variance in pay per season and the unavailability of total salary for some players. We obtain real AAV in year $t$ by deflating nominal AAV in year $t$ by the NHL salary cap in year $t$. AAV is expressed as a percentage of the NHL salary cap in a given year. Salary cap is used as the deflator instead of the consumer price index (CPI) because the salary cap rises faster than the CPI. We thank an anonymous referee for this helpful suggestion. As with Kahane, our first dataset uses lagged career statistics. In other words, player $i$ 's AAV in year $t$ is a function of his career statistics accumulated until year $t-1$. The first dataset includes players on all types of contracts, including players on entry level contracts. We include a table of sample statistics by country of origin for this dataset in Table 1 . We thank an anonymous referee for suggesting this table.

Table 1. Sample statistics by country (career lagged dataset)

\begin{tabular}{|c|c|c|c|c|c|c|c|c|c|c|c|}
\hline \multicolumn{12}{|c|}{ Averages with Standard Deviations Below } \\
\hline & AAV & $\begin{array}{l}\text { Games } \\
\text { Played }\end{array}$ & $\begin{array}{c}\text { Goals } \\
\text { per } \\
\text { Game }\end{array}$ & $\begin{array}{c}\text { Assists } \\
\text { per } \\
\text { Game }\end{array}$ & $\begin{array}{l}\text { Plus- } \\
\text { Minus }\end{array}$ & $\begin{array}{c}\text { Penalty } \\
\text { Minutes } \\
\text { per Game }\end{array}$ & $\begin{array}{l}\text { Shots } \\
\text { per } \\
\text { Game }\end{array}$ & $\begin{array}{c}\text { Time on } \\
\text { Ice per } \\
\text { Game }\end{array}$ & $\begin{array}{c}\text { Total } \\
\text { Defensemen }\end{array}$ & $\begin{array}{l}\text { Total Left } \\
\text { Handed } \\
\text { Players }\end{array}$ & $\mathbf{N}$ \\
\hline \multirow[t]{2}{*}{ Canadians } & $\$ 2,358,205$ & 315.11 & 0.14 & 0.22 & 2.23 & 0.46 & 1.54 & 14.97 & 675 & 1388 & 2231 \\
\hline & $1,975,705$ & 269.03 & 0.11 & 0.14 & 35.69 & 0.40 & 0.72 & 4.27 & & & \\
\hline \multirow[t]{2}{*}{ USA } & $\$ 2,100,078$ & 265.89 & 0.13 & 0.21 & 0.16 & 0.38 & 1.56 & 15.43 & 350 & 468 & 913 \\
\hline & $1,713,163$ & 235.43 & 0.10 & 0.12 & 24.65 & 0.29 & 0.68 & 3.87 & & & \\
\hline \multirow[t]{2}{*}{ Russians } & $\$ 3,977,614$ & 375.47 & 0.22 & 0.33 & 21.24 & 0.32 & 2.05 & 17 & 54 & 117 & 148 \\
\hline & $2,619,935$ & 298.29 & 0.18 & 0.18 & 54.33 & 0.16 & 1.11 & 3.77 & & & \\
\hline \multirow[t]{2}{*}{ Swedes } & $\$ 2,662,338$ & 282.59 & 0.13 & 0.24 & 23.55 & 0.26 & 1.64 & 17 & 103 & 185 & 226 \\
\hline & $1,797,811$ & 250.14 & 0.11 & 0.14 & 45.00 & 0.15 & 0.78 & 3.62 & & & \\
\hline \multirow[t]{2}{*}{ Finns } & $\$ 3,119,577$ & 414.64 & 0.17 & 0.29 & 9.05 & 0.32 & 1.76 & 16 & 25 & 87 & 101 \\
\hline & $1,912,461$ & 339.72 & 0.11 & 0.13 & 32.19 & 0.15 & 0.63 & 3.92 & & & \\
\hline \multirow[t]{2}{*}{ Czechs } & $\$ 3,212,325$ & 428.48 & 0.15 & 0.29 & 16.73 & 0.37 & 1.67 & 17.06 & 103 & 196 & 252 \\
\hline & $1,820,973$ & 280.99 & 0.10 & 0.13 & 50.47 & 0.27 & 0.58 & 3.85 & & & \\
\hline \multirow[t]{2}{*}{ OTHERS } & $\$ 2,773,339$ & 317.11 & 0.16 & 0.26 & 3.17 & 0.31 & 1.73 & 16 & 55 & 140 & 175 \\
\hline & $2,101,381$ & 259.39 & 0.13 & 0.13 & 27.53 & 0.23 & 0.63 & 3.59 & & & \\
\hline
\end{tabular}

AAV: annual average value.

The second panel dataset has contract-years as the unit of observation. The dependent variable in the second dataset (previous contract statistics) is the real AAV of a player in the first year of a new contract. Once again, we obtain real AAV in year $t$ by deflating nominal AAV in year $t$ by the NHL salary cap in year $t$. AAV is expressed as a percentage of the NHL salary cap in a given year for the reasons stated above. The player statistics in the second (contract lagged statistics) are the player's statistics averaged over the years of their last contract. After excluding observations for missing data, 
this reduces the number of data points from 4046 to 1717. Both datasets contain dummy variables to control for the type of player contract. We thank an anonymous referee for this excellent suggestion. The previous contract dataset does not have players on entry level contracts; therefore, in keeping with Brander and Egan, restricted free agents (RFA) are the default comparison group. Both datasets also contain dummy variables for the player's country of origin, team, and annual fixed effects. The second dataset does not have players on entry level contracts, as they have no previous NHL contract on-ice statistics. For the most part, academic researchers in the literature use lagged career statistics, while NHL executives tend to look at more recent measures of player performance, such as their statistics from their last few years. A notable exception is Brander and Egan, who use statistics from the year prior to the current contract. It is interesting to compare and contrast the results from the career lagged statistics dataset and the previous contract statistics dataset.

\section{Empirical Model}

The first empirical model, given by Equation (1), is applied to all players in both datasets. The second model, given by Equation (2), is estimated separately for defensemen and forwards in both datasets. We thank an anonymous referee for this suggestion. We employ dummy variables to capture the effects of nationality on salary. In addition, we also employ team specific and annual dummy variables to control for team and annual effects.

Real AAV $=\beta_{1}+\beta_{2}$ Games played $+\beta_{3}$ Goals per game $+\beta_{4}$ Assists per game $+\beta_{5}$ Plus-minus

$+\beta_{6}$ Penalty minutes per game $+\beta_{7}$ Shots per game $+\beta_{8}$ Time on ice per game

$+\beta_{9}$ Defenseman Dummy $+\beta_{10}$ Defenseman Dummy $X$ Time on ice per game

$+\beta_{11}$ Left Handed Player Dummy $+\beta_{12}$ RFA Dummy $+\beta_{12}$ UFA Dummy

$+\beta_{13}$ TFP35 Dummy $+\beta_{14}$ UFA Years Lost Dummy

Real AAV $=\beta_{1}+\beta_{2}$ Games played $+\beta_{3}$ Goals per game $+\beta_{4}$ Assists per game $+\beta_{5}$ Plus-minus

$+\beta_{6}$ Penalty minutes per game $+\beta_{7}$ Shots per game $+\beta_{8}$ Time on ice per game

$+\beta_{9}$ Left Handed Player Dummy $+\beta_{10}$ RFA Dummy $+\beta_{11}$ UFA Dummy

$+\beta_{12}$ TFP35 Dummy $+\beta_{13}$ UFA Years Lost Dummy

Real AAV is nominal AAV expressed as a percentage of the NHL salary cap in a given year. UFA stands for unrestricted free agents.

The on-ice variables are taken from (Kahane 2001). Games played is the total amount of games a player has played in during his career in $t-1$ years or during his last contract, depending on the dataset. Each of the on-ice performance statistics is averaged over the entire course of the player's previous years in the NHL for the lagged career statistics dataset and over the course of the years of his last contract for the previous contract statistics dataset. Goals per game is the amount of goals a player scored per game. Assists per game represents the amount of assists per game a player made divided by the number of games that he has played. Points are left out of the study because they are made up of goals and assists, both of which are already counted for. Plus-minus represents a player's career plus/minus figure, a measurement describing the amount of times a player is on the ice for a goal or a goal against. If a player is out for a goal, then he gets a +1 rating, and if he is out for a goal against, he gets a -1 rating. Penalty minutes per game is the amount of penalty minutes taken per game during the time period in question. According to a referee, this is a good indicator of toughness for a player, and teams are willing to pay more for that player characteristic.

The literature finds that salary is influenced positively with goals and assists per game, plus-minus, and penalty minutes (Bruggink and Williams 2009). Shots per game is given by the total number of shots taken divided by the total number of games played. It is used as an indicator of offensive play other than goals and assists. Time on ice per game represents average time on ice per game for a player during his career. This indicates how much a player was on the ice for his team and usually shows if the player was used in special team situations. 
In keeping with Coates (2017), we control for left handed players using the left handed player dummy that takes on a value of one if the player is left handed and zero otherwise. Coates finds that left handed players are paid a premium.

Defensemen play more minutes than forwards, thus we estimate the model separately for each group using Equation (2). The defenseman dummy takes on a value of one if the player is a defenseman and takes on a value of zero otherwise. At the suggestion of a referee, we account for the extra time played by defensemen by interacting the defensemen dummy with the time on ice variable when estimating (1) over both groups of players. This allows the slope of the time on ice variable to differ between defensemen and forwards. Our maintained hypothesis is that defensemen are usually paid less than other players but that they are paid more for their time on ice than forwards. We also include dummy variables to control for the player's country of origin. We classify players into seven groups: Canadian, American, Russian, Swedish, Finnish, Czech, and Other. We include dummy variables for all groups except Canadians. Thus, all country dummies are in reference to the AAVs earned by Canadian players in the NHL.

Following Brander and Egan, we also include contract type dummies in both equations to control for the types of contracts and their impact on AAV. We thank an anonymous referee for this excellent suggestion. The reader is referred to Brander and Egan (page 86) for an excellent discussion of the different types of contracts and their impact on a player's AAV. Most players start their careers on an entry level contract. This is the type of contract that we omit from the regression. Therefore, all contract dummy coefficients are to be interpreted relative to the impact of an entry level contract on player earnings. The RFA dummy takes on a value of one if the player is on a restricted free agent contract and zero otherwise. The UFA dummy takes on a value of one if the player is on an unrestricted free agent contract and zero otherwise. The TFP35 dummy takes on a value of one if the player is on a 35 plus TFP contract and zero otherwise. The UFA Years Lost variable is the number of years above the age of 27 that a player continues to play on as an RFA. According to Brander and Egan, UFAs have much more bargaining power than RFAs. TFP35s can also sell their services to the highest bidder but have some salary cap implications that reduce their bargaining power compared to UFAs. Brander and Egan find that players who play on beyond the age of 27 as RFAs receive a slight premium relative to other RFA players in order to do so. They capture this effect using the UFA years lost dummy variable.

\section{Empirical Results}

We employ fixed effects OLS estimators and quantile regression estimators for Equations (1) and (2) in both datasets. Table 2 contains the FELS results for Equations (1) and (2) for all players. At the suggestion of an anonymous referee, we also estimate Equations (1) and (2) separately for forwards and for defensemen. Columns (1) to (3) are estimates of Equations (1) and (2) from the career lagged statistics dataset. Column (1) is the estimate of Equation (1), while columns (2) and (3) are the estimates of Equation (2) applied to defensemen and forwards, respectively, for the career statistics lagged dataset. Similarly, columns (4) to (6) contain the FELS estimates of Equations (1) and (2) estimated from the contract lagged dataset. We also employ Newey-West robust standard errors for the FELS models, because White and Breusch-Godfrey tests indicate the presence of both Heteroskedasticity and Serial Correlation, respectively. In keeping with Brander and Egan, we use a linear functional form instead of the semi-logarithmic functional form proposed by Mincer (1958). 
Table 2. Fixed effects ordinary least squares (FELS) regression results.

\begin{tabular}{|c|c|c|c|c|c|c|}
\hline \multirow{2}{*}{$\begin{array}{c}\text { Dependent Variable } \\
\text { Real AAV }\end{array}$} & \multicolumn{3}{|c|}{ Lagged Career Statistics } & \multicolumn{3}{|c|}{ Previous Contract Statistics } \\
\hline & $\begin{array}{l}\text { All Players } \\
\text { Column (1) }\end{array}$ & $\begin{array}{l}\text { Defensemen } \\
\text { Column (2) }\end{array}$ & $\begin{array}{l}\text { Forwards } \\
\text { Column (3) }\end{array}$ & $\begin{array}{l}\text { All Players } \\
\text { Column (4) }\end{array}$ & $\begin{array}{l}\text { Defensemen } \\
\text { Column (5) }\end{array}$ & $\begin{array}{l}\text { Forwards } \\
\text { Column (6) }\end{array}$ \\
\hline Independent Variables & $\begin{array}{l}\text { Coefficient } \\
\text { ( } t \text {-Statistic) }\end{array}$ & $\begin{array}{l}\text { Coefficient } \\
(t \text {-Statistic) }\end{array}$ & $\begin{array}{l}\text { Coefficient } \\
(t \text {-Statistic) }\end{array}$ & $\begin{array}{l}\text { Coefficient } \\
\text { ( } t \text {-Statistic) }\end{array}$ & $\begin{array}{l}\text { Coefficient } \\
(t \text {-Statistic) }\end{array}$ & $\begin{array}{l}\text { Coefficient } \\
\text { ( } t \text {-Statistic) }\end{array}$ \\
\hline Games played & $\begin{array}{c}0.003 \\
(10.228) *\end{array}$ & $\begin{array}{c}0.005 \\
(8.560) *\end{array}$ & $\begin{array}{c}0.003 \\
(7.026) *\end{array}$ & $\begin{array}{c}0.009 \\
(3.588) *\end{array}$ & $\begin{array}{c}0.017 \\
(3.662) *\end{array}$ & $\begin{array}{c}0.005 \\
(2.189)^{* *}\end{array}$ \\
\hline Goals per game & $\begin{array}{c}3.982 \\
(3.906) *\end{array}$ & $\begin{array}{c}3.016 \\
(1.835)^{* * *}\end{array}$ & $\begin{array}{c}2.840 \\
(2.382) * *\end{array}$ & $\begin{array}{c}4.669 \\
(3.478) *\end{array}$ & $\begin{array}{c}4.815 \\
(2.382) * *\end{array}$ & $\begin{array}{c}3.802 \\
(2.346)^{* *}\end{array}$ \\
\hline Assists per game & $\begin{array}{c}5.230 \\
(7.734)^{*}\end{array}$ & $\begin{array}{c}3.853 \\
(3.839) *\end{array}$ & $\begin{array}{c}6.581 \\
(8.070)^{*}\end{array}$ & $\begin{array}{c}5.240 \\
(7.787)^{*}\end{array}$ & $\begin{array}{c}2.949 \\
(2.723) *\end{array}$ & $\begin{array}{c}6.489 \\
(7.384) *\end{array}$ \\
\hline Plus-minus & $\begin{array}{c}0.007 \\
(4.458) *\end{array}$ & $\begin{array}{c}0.007 \\
(2.981) *\end{array}$ & $\begin{array}{c}0.007 \\
(3.395) *\end{array}$ & $\begin{array}{c}0.040 \\
(5.314)\end{array}$ & $\begin{array}{c}0.043 \\
(3.829) *\end{array}$ & $\begin{array}{c}0.033 \\
(3.227) *\end{array}$ \\
\hline $\begin{array}{l}\text { Penalty minutes per } \\
\text { game }\end{array}$ & $\begin{array}{c}0.710 \\
(4.663) *\end{array}$ & $\begin{array}{c}0.876 \\
(2.877) *\end{array}$ & $\begin{array}{c}0.652 \\
(4.229) *\end{array}$ & $\begin{array}{c}0.665 \\
(6.540) *\end{array}$ & $\begin{array}{c}0.515 \\
(2.137)^{* *}\end{array}$ & $\begin{array}{c}0.723 \\
(6.108) *\end{array}$ \\
\hline Shots per game & $\begin{array}{c}0.680 \\
(5.047) *\end{array}$ & $\begin{array}{c}0.425 \\
(2.352) * *\end{array}$ & $\begin{array}{c}0.918 \\
(5.603) *\end{array}$ & $\begin{array}{c}0.747 \\
(4.770)^{*}\end{array}$ & $\begin{array}{c}0.431 \\
(1.579)\end{array}$ & $\begin{array}{c}0.976 \\
(5.675) *\end{array}$ \\
\hline Time on ice per game & $\begin{array}{c}0.146 \\
(5.597) * \\
-0.795 \\
(-1.92) * * *\end{array}$ & $\begin{array}{c}0.225 \\
(8.030) *\end{array}$ & $\begin{array}{c}0.110 \\
(3.532) *\end{array}$ & $\begin{array}{c}0.157 \\
(4.961) * \\
-1.198 \\
(-2.356) * *\end{array}$ & $\begin{array}{c}0.282 \\
(7.823) *\end{array}$ & $\begin{array}{c}0.125 \\
(3.146)\end{array}$ \\
\hline $\begin{array}{l}\text { Defenseman X Time } \\
\text { on ice }\end{array}$ & $\begin{array}{c}0.063 \\
(2.265)^{*}\end{array}$ & & & $\begin{array}{c}0.087 \\
(2.373) *\end{array}$ & & \\
\hline Left Handed player & $\begin{array}{c}0.089 \\
(0.976)\end{array}$ & $\begin{array}{c}0.105 \\
(0.693)\end{array}$ & $\begin{array}{c}0.018 \\
(0.174)\end{array}$ & $\begin{array}{c}0.039 \\
(0.419)\end{array}$ & $\begin{array}{c}0.070 \\
(0.411)\end{array}$ & $\begin{array}{c}0.009 \\
(0.0826)\end{array}$ \\
\hline USA & $\begin{array}{l}-0.139 \\
(-1.374)\end{array}$ & $\begin{array}{c}0.004 \\
(0.022)\end{array}$ & $\begin{array}{c}-0.203 \\
(-1.693)^{* * *}\end{array}$ & $\begin{array}{l}-0.083 \\
(-0.766)\end{array}$ & $\begin{array}{c}-0.146 \\
(-0.853)\end{array}$ & $\begin{array}{c}-0.030 \\
(-0.232)\end{array}$ \\
\hline Russia & $\begin{array}{c}0.723 \\
(3.27) *\end{array}$ & $\begin{array}{c}0.750 \\
(2.296)^{* *}\end{array}$ & $\begin{array}{c}0.654 \\
(2.350)\end{array}$ & $\begin{array}{c}0.809 \\
(3.057) *\end{array}$ & $\begin{array}{c}0.766 \\
(1.90)^{* * *}\end{array}$ & $\begin{array}{c}0.832 \\
(2.384) *\end{array}$ \\
\hline Sweden & $\begin{array}{c}0.129 \\
(0.787)\end{array}$ & $\begin{array}{c}0.457 \\
(1.775)^{* * *}\end{array}$ & $\begin{array}{c}-0.179 \\
(-0.890)\end{array}$ & $\begin{array}{c}0.192 \\
(0.859)\end{array}$ & $\begin{array}{c}0.627 \\
(2.009)\end{array}$ & $\begin{array}{c}-0.163 \\
(-0.606)\end{array}$ \\
\hline Finland & $\begin{array}{c}0.298 \\
(0.639)\end{array}$ & $\begin{array}{c}0.079 \\
(0.108)\end{array}$ & $\begin{array}{c}0.374 \\
(0.714)\end{array}$ & $\begin{array}{c}-0.348 \\
(-0.984)\end{array}$ & $\begin{array}{c}-0.188 \\
(-0.215)\end{array}$ & $\begin{array}{c}-0.374 \\
(-0.919)\end{array}$ \\
\hline Czechoslovakia & $\begin{array}{c}0.214 \\
(1.103)\end{array}$ & $\begin{array}{c}0.407 \\
(1.349)\end{array}$ & $\begin{array}{c}0.071 \\
(0.356)\end{array}$ & $\begin{array}{c}0.370 \\
(1.601)\end{array}$ & $\begin{array}{c}0.629 \\
(1.72)^{* * *}\end{array}$ & $\begin{array}{c}0.209 \\
(0.772)\end{array}$ \\
\hline Other Country & $\begin{array}{c}0.188 \\
(0.763)\end{array}$ & $\begin{array}{c}-0.005 \\
(-0.012)\end{array}$ & $\begin{array}{c}0.334 \\
(1.186)\end{array}$ & $\begin{array}{c}-0.121 \\
(-0.425)\end{array}$ & $\begin{array}{c}-0.357 \\
(-0.803)\end{array}$ & $\begin{array}{c}0.098 \\
(0.301)\end{array}$ \\
\hline RFA Dummy & $\begin{array}{c}0.526 \\
(4.198) *\end{array}$ & $\begin{array}{c}0.379 \\
(1.953)^{* * *}\end{array}$ & $\begin{array}{c}0.621 \\
(3.925)^{*}\end{array}$ & & & \\
\hline UFA Dummy & $\begin{array}{c}0.464 \\
(2.986) *\end{array}$ & $\begin{array}{c}0.417 \\
(1.636)\end{array}$ & $\begin{array}{c}0.513 \\
(2.672) *\end{array}$ & $\begin{array}{c}0.280 \\
(3.161)^{*}\end{array}$ & $\begin{array}{c}0.446 \\
(2.771) *\end{array}$ & $\begin{array}{c}0.146 \\
(1.397)\end{array}$ \\
\hline TFP35 Dummy & $\begin{array}{c}-2.126 \\
(-8.967)\end{array}$ & $\begin{array}{c}-1.868 \\
(-5.599)^{*}\end{array}$ & $\begin{array}{c}-2.333 \\
(-7.646)^{*}\end{array}$ & $\begin{array}{c}-0.780 \\
(-3.805)^{*}\end{array}$ & $\begin{array}{c}-0.618 \\
(-1.626)\end{array}$ & $\begin{array}{c}-0.830 \\
(-3.203)^{*}\end{array}$ \\
\hline UFA Years Lost Dummy & $\begin{array}{c}0.046 \\
(0.644)\end{array}$ & $\begin{array}{c}-0.173 \\
(-1.440)\end{array}$ & $\begin{array}{c}0.157 \\
(2.196) \text { ** }\end{array}$ & $\begin{array}{c}-0.109 \\
(-0.635)\end{array}$ & $\begin{array}{c}-0.241 \\
(-1.472)\end{array}$ & $\begin{array}{c}0.140 \\
(0.554)\end{array}$ \\
\hline Adjusted $R^{2}$ & 0.69 & 0.65 & 0.72 & 0.70 & 0.64 & 0.74 \\
\hline F-stat & 150.64 & 45.33 & 118.32 & 68.63 & 19.21 & 57.31 \\
\hline $\mathrm{N}$ & 4046 & 1365 & 2681 & 1717 & 579 & 1138 \\
\hline
\end{tabular}

* Significant at the $1 \%$ level, ${ }^{* *}$ Significant at the $5 \%$ level, ${ }^{* * *}$ Significant at the $10 \%$ level. Newey-West robust standard errors are employed.

The FELS results, columns (1) through (6), in Table 2 support all of the maintained hypotheses about player statistics and salary. All of the performance measure-games played, goals per game, assists per game, etc. - are statistically significant across both datasets, and the coefficients of the various performance statistics have the expected positive signs for all three groups of players (all players, defensemen, and forwards). A unit increase in a given continuous independent variable is interpreted as a percentage change of real AAV equal to the coefficient of the given variable. In column (1), an increase in one game played results in a 0.01 percent increase in a player's salary, where salary is expressed as a percentage of the NHL salary cap, and so on. Penalty minutes per game are positive and significant in both datasets. The dummy variable for defenseman is negative and statistically significant 
in both datasets, indicating that defensemen get paid less than forwards. However, defensemen do play more minutes, and the positive and significant sign on the defensemen and time on ice interaction variable has a positive and significant sign. The dummy variable for left handed players is insignificant in both datasets. Both Russian and Swedish players command a higher salary over their Canadian counterparts (the omitted player category). The adjusted R-squares from both datasets are pretty close in magnitude. The difference in the magnitude of corresponding on-ice coefficients between both datasets is also quite small. Therefore, as a practical matter, the FELS results suggest that using one year lagged career statistics or statistics from the player's last contract does not make much of a difference in the findings. The dummy variable for left handed players (Left Handed player) is insignificant across all three groups of players in both the career lagged and the contract lagged statistics datasets.

Country of origin effects are captured by the dummy variables named for the players' countries of origin (USA, Russia, Sweden, Finland, Czechoslovakia, and Other). The comparison group is Canadian players. Players of Russian origin have positive and significant coefficients across all models in both datasets. This indicates that Russians are paid more than their Canadian counterparts. The dummy variable coefficient for Swedish defensemen is positive and significant in both the lagged career and the previous contract datasets (columns (2) and (4)), indicating that some Swedish players also command a premium. Czech defensemen command a higher AAV but only based on the previous contract dataset. Finally, USA forwards get paid less than their Canadian counterparts based on the career lagged dataset alone. The reader may refer back to Table 1 to compare and contrast sample statistics by player's country of origin.

We include contract status dummy variables in all of our models, because a player's contract status impacts their bargaining power and consequently their AAV. We are thankful to an anonymous referee for suggesting this improvement. Compared to entry level players, players who are restricted and unrestricted free agents command a premium. The contract status dummy variables, RFA, UFA, and TFP35, have the expected signs and are significant in most of the models. The comparison group in the career lagged statistics dataset is players on entry level contracts, while the comparison group in the previous contract dataset is restricted free agents. Both the RFA and the UFA dummies are positive and significant in the majority of the regression estimates. TFP35 players command a slightly lower premium than other UFAs because of certain salary cap rules. This is consistent with the negative sign on the TFP35 dummy. Finally, the UFA years lost dummy is positive and significant only for forwards in the career lagged dataset. Brander and Egan suggest that this is because RFAs that give up some years of unrestricted free agency are expected to receive slightly larger RFA contracts to compensate them for the delay to becoming unrestricted free agents.

We turn next to the quantile regressions estimates of Equation (1) from both the career lagged statistics dataset and the previous contract statistics dataset. We use Huber-White robust standard errors. As Vincent and Eastman point out, different variables have varying impacts at different quantiles of the wage distribution. Quantile regression estimates allow us to estimate these impacts at different quantiles of the wage distribution. The quantile regression results for the career lagged dataset are displayed in Table 3, while Table 4 gives the quantile regression results based on the player's previous contract statistics. The career lagged dataset contains players on all types of contracts. The comparison group is players on entry level contracts. The previous contract dataset only contains players that are RFAs, UFAs, and TFP35s, thus the default comparison group in Table 4 is RFAs. We employ robust Huber-Sandwich standard errors and covariances for the quantile regressions. Once again, we do not report the annual and the team specific dummy variables for the sake of brevity.

The coefficient on games played is positive and significant across the 10th, the 25th, and the 50th quantiles in both datasets. Goals and assists per game are significant and positive across all quantiles in both datasets. The plus-minus variable is significant and positive up to the 75th quantile in the lagged career statistics dataset (Table 3) and across all quantiles in the previous contract dataset (Table 4). Penalty minutes per game is significant across all quantiles in the lagged career statistics dataset and is 
significant and positive up to the 75th quantile in the lagged contract statistics dataset (Table 4). Shots per game and time on ice per game are significant across all quantiles in both datasets.

Defensemen are paid less than forwards at the 50th, the 75th, and the 90th quantiles across both datasets. However, this effect is lessened when the defensemen time on ice interaction dummy has a positive and significant coefficient at the same quantiles in both datasets. The net effect of the defensemen dummy coefficient plus the defensemen time on ice interaction dummy coefficient is still negative at the 50th, the 75th, and the 90th quantiles. Once again, the dummy variable for left handed players is insignificant across all quantiles in both datasets.

Table 3. Quantile regression results based on lagged career statistics.

\begin{tabular}{|c|c|c|c|c|c|}
\hline Dependent Variable & Real AAV & & & & \\
\hline Regression Level & 10th Quantile & 25th Quantile & 50th Quantile & 75th Quantile & 90th Quantile \\
\hline Independent Variable & $\begin{array}{c}\text { Coefficient } \\
t \text {-Statistic }\end{array}$ & $\begin{array}{c}\text { Coefficient } \\
t \text {-Statistic }\end{array}$ & $\begin{array}{c}\text { Coefficient } \\
t \text {-Statistic }\end{array}$ & $\begin{array}{c}\text { Coefficient } \\
t \text {-Statistic }\end{array}$ & $\begin{array}{c}\text { Coefficient } \\
t \text {-Statistic }\end{array}$ \\
\hline Games played & $\begin{array}{c}0.003 \\
(15.416) *\end{array}$ & $\begin{array}{c}0.004 \\
(19.826) *\end{array}$ & $\begin{array}{c}0.004 \\
(13.218) *\end{array}$ & $\begin{array}{c}0.003 \\
(10.377) *\end{array}$ & $\begin{array}{c}0.003 \\
(6.679) *\end{array}$ \\
\hline Goals per game & $\begin{array}{c}1.257 \\
(3.287) *\end{array}$ & $\begin{array}{c}2.907 \\
(4.106) *\end{array}$ & $\begin{array}{c}4.559 \\
(5.94) *\end{array}$ & $\begin{array}{c}4.931 \\
(5.768) *\end{array}$ & $\begin{array}{c}7.443 \\
(7.185) *\end{array}$ \\
\hline Assists per game & $\begin{array}{c}1.191 \\
(3.06) *\end{array}$ & $\begin{array}{c}3.110 \\
(6.72) *\end{array}$ & $\begin{array}{c}4.933 \\
(9.246) *\end{array}$ & $\begin{array}{c}7.361 \\
(13.895) *\end{array}$ & $\begin{array}{c}8.609 \\
(8.753) *\end{array}$ \\
\hline Plus-minus & $\begin{array}{c}0.010 \\
(6.11) *\end{array}$ & $\begin{array}{c}0.012 \\
(9.03) *\end{array}$ & $\begin{array}{c}0.009 \\
(7.016) *\end{array}$ & $\begin{array}{c}0.006 \\
(4.92) *\end{array}$ & $\begin{array}{c}0.003 \\
(0.921)\end{array}$ \\
\hline Penalty minutes per game & $\begin{array}{c}0.225 \\
(4.249) *\end{array}$ & $\begin{array}{c}0.490 \\
(5.614) *\end{array}$ & $\begin{array}{c}0.692 \\
(6.731)\end{array}$ & $\begin{array}{c}0.719 \\
(6.26)^{*}\end{array}$ & $\begin{array}{c}0.550 \\
(3.872) *\end{array}$ \\
\hline Shots per game & $\begin{array}{c}0.295 \\
(4.209) *\end{array}$ & $\begin{array}{c}0.427 \\
(4.143) *\end{array}$ & $\begin{array}{c}0.648 \\
(5.956) *\end{array}$ & $\begin{array}{c}0.728 \\
(7.137) *\end{array}$ & $\begin{array}{c}0.463 \\
(3.67)^{*}\end{array}$ \\
\hline $\begin{array}{c}\text { Time on ice per game } \\
\text { (TOIPG) }\end{array}$ & $\begin{array}{c}0.036 \\
(2.323)^{* *}\end{array}$ & $\begin{array}{c}0.077 \\
(3.357)\end{array}$ & $\begin{array}{c}0.107 \\
(5.569) *\end{array}$ & $\begin{array}{c}0.102 \\
(5.415)^{*}\end{array}$ & $\begin{array}{c}0.104 \\
(4.05) *\end{array}$ \\
\hline Defenseman & $\begin{array}{l}-0.567 \\
(-1.119)\end{array}$ & $\begin{array}{l}-0.689 \\
(-1.311)\end{array}$ & $\begin{array}{c}-1.378 \\
(-3.593)\end{array}$ & $\begin{array}{c}-1.116 \\
(-3.884)\end{array}$ & $\begin{array}{c}-1.060 \\
(-3.253)\end{array}$ \\
\hline Defenseman X TOIPG & $\begin{array}{c}0.040 \\
(1.252)\end{array}$ & $\begin{array}{c}0.052 \\
(1.489)\end{array}$ & $\begin{array}{c}0.104 \\
(4.33) *\end{array}$ & $\begin{array}{c}0.108 \\
(5.852) *\end{array}$ & $\begin{array}{c}0.123 \\
(5.551)\end{array}$ \\
\hline Left Handed player & $\begin{array}{l}-0.023 \\
(-0.55)\end{array}$ & $\begin{array}{l}0.046 \\
(0.79)\end{array}$ & $\begin{array}{l}-0.002 \\
(-0.024)\end{array}$ & $\begin{array}{c}0.124 \\
(1.745)\end{array}$ & $\begin{array}{c}0.032 \\
(0.294)\end{array}$ \\
\hline USADUMMY & $\begin{array}{l}0.030 \\
(0.624)\end{array}$ & $\begin{array}{c}0.034 \\
(0.565)\end{array}$ & $\begin{array}{c}-0.180 \\
(-2.554)^{* *}\end{array}$ & $\begin{array}{c}-0.149 \\
(-1.878)^{* * *}\end{array}$ & $\begin{array}{l}-0.126 \\
(-0.967)\end{array}$ \\
\hline RUSDUMMY & $\begin{array}{c}0.441 \\
(2.088) * *\end{array}$ & $\begin{array}{c}0.827 \\
(5.571) *\end{array}$ & $\begin{array}{c}0.902 \\
(3.566) *\end{array}$ & $\begin{array}{c}0.753 \\
(4.427) *\end{array}$ & $\begin{array}{c}0.418 \\
(1.782)\end{array}$ \\
\hline SWEDUMMY & $\begin{array}{c}0.316 \\
(3.048) *\end{array}$ & $\begin{array}{c}0.300 \\
(2.493)^{* *}\end{array}$ & $\begin{array}{c}0.136 \\
(0.905)\end{array}$ & $\begin{array}{c}0.087 \\
(0.631)\end{array}$ & $\begin{array}{c}0.088 \\
(0.374)\end{array}$ \\
\hline FINDUMMY & $\begin{array}{c}0.144 \\
(0.942)\end{array}$ & $\begin{array}{c}0.155 \\
(0.679)\end{array}$ & $\begin{array}{c}0.202 \\
(0.877)\end{array}$ & $\begin{array}{c}0.344 \\
(1.573)\end{array}$ & $\begin{array}{c}0.360 \\
(0.747)\end{array}$ \\
\hline CZEDUMMY & $\begin{array}{c}0.409 \\
(3.348)\end{array}$ & $\begin{array}{c}0.436 \\
(3.446)\end{array}$ & $\begin{array}{l}0.121 \\
(0.904)\end{array}$ & $\begin{array}{c}0.046 \\
(0.288)\end{array}$ & $\begin{array}{c}-0.120 \\
(-0.528)\end{array}$ \\
\hline OTHERDUMMY & $\begin{array}{c}-0.008 \\
(-0.072)\end{array}$ & $\begin{array}{c}0.057 \\
(0.364)\end{array}$ & $\begin{array}{c}0.122 \\
(0.624)\end{array}$ & $\begin{array}{c}0.066 \\
(0.378)\end{array}$ & $\begin{array}{c}0.506 \\
(1.237)\end{array}$ \\
\hline RFA Dummy & $\begin{array}{c}0.272 \\
(2.74) *\end{array}$ & $\begin{array}{c}0.405 \\
(3.699) *\end{array}$ & $\begin{array}{c}0.273 \\
(2.394) *\end{array}$ & $\begin{array}{c}-0.034 \\
(-0.285)\end{array}$ & $\begin{array}{c}-0.529 \\
(-2.726) *\end{array}$ \\
\hline UFA Dummy & $\begin{array}{c}-0.111 \\
(-0.969)\end{array}$ & $\begin{array}{c}0.021 \\
(0.145)\end{array}$ & $\begin{array}{c}0.158 \\
(1.141)\end{array}$ & $\begin{array}{c}0.175 \\
(1.257)\end{array}$ & $\begin{array}{l}-0.142 \\
(-0.612)\end{array}$ \\
\hline TFP35 Dummy & $\begin{array}{c}-1.737 \\
(-4.729) *\end{array}$ & $\begin{array}{c}-2.085 \\
(-8.97) *\end{array}$ & $\begin{array}{c}-1.837 \\
(-9.042)\end{array}$ & $\begin{array}{c}-2.020 \\
(-11.206)\end{array}$ & $\begin{array}{c}-1.837 \\
(-6.818)\end{array}$ \\
\hline UFA Years lost & $\begin{array}{c}0.316 \\
(2.805) *\end{array}$ & $\begin{array}{c}0.139 \\
(1.878)^{* * *}\end{array}$ & $\begin{array}{c}0.093135 \\
(1.646)^{* * *}\end{array}$ & $\begin{array}{c}-0.045358 \\
(-0.754)\end{array}$ & $\begin{array}{c}-0.150418 \\
(-1.198)\end{array}$ \\
\hline
\end{tabular}

${ }^{*}$ Significant at the $1 \%$ level, ${ }^{* *}$ Significant at the $5 \%$ level, ${ }^{* * *}$ Significant at the $10 \%$ level. Robust standard errors are employed.

The country of origin dummies show that Russian players are paid more than Canadian players at all quantiles except the 90th quantile in both datasets. Swedes and Finns are paid more at the 10th and the 25th quantiles according to the estimates from the lagged career statistics dataset. However, 
according to the regressions based on the contract lagged statistics dataset, they are paid more only at the median quantile. American players are underpaid relative to the Canadian group of players at the 50th quantile based on the lagged career dataset in Table 3.

Table 4. Quantile regression results based on previous contract statistics.

\begin{tabular}{|c|c|c|c|c|c|}
\hline Dependent Variable & Real AAV & & & & \\
\hline Independent Variable & $\begin{array}{c}\text { Coefficient } \\
t \text {-Statistic }\end{array}$ & $\begin{array}{l}\text { Coefficient } \\
t \text {-Statistic }\end{array}$ & $\begin{array}{c}\text { Coefficient } \\
t \text {-Statistic }\end{array}$ & $\begin{array}{l}\text { Coefficient } \\
t \text {-Statistic }\end{array}$ & $\begin{array}{c}\text { Coefficient } \\
t \text {-Statistic }\end{array}$ \\
\hline Games played & $\begin{array}{c}0.011 \\
(8.733) *\end{array}$ & $\begin{array}{c}0.012 \\
(7.203) *\end{array}$ & $\begin{array}{c}0.004 \\
(1.783)^{* * *}\end{array}$ & $\begin{array}{l}-0.004 \\
(-1.071)\end{array}$ & $\begin{array}{c}-0.007 \\
(-1.394)\end{array}$ \\
\hline Assists per game & $\begin{array}{c}0.894 \\
(2.42) * *\end{array}$ & $\begin{array}{c}2.693 \\
(4.839) *\end{array}$ & $\begin{array}{c}5.127 \\
(7.122) *\end{array}$ & $\begin{array}{c}7.804 \\
(7.851) *\end{array}$ & $\begin{array}{c}8.740 \\
(8.147) *\end{array}$ \\
\hline Plus-minus & $\begin{array}{c}0.022 \\
(4.197) *\end{array}$ & $\begin{array}{c}0.027 \\
(4.115) *\end{array}$ & $\begin{array}{c}0.030 \\
(4.225) *\end{array}$ & $\begin{array}{c}0.030 \\
(3.318) *\end{array}$ & $\begin{array}{c}0.031 \\
(2.635) *\end{array}$ \\
\hline Penalty minutes per game & $\begin{array}{c}0.269 \\
(4.554) *\end{array}$ & $\begin{array}{c}0.491 \\
(6.902) *\end{array}$ & $\begin{array}{c}0.686 \\
(5.8) *\end{array}$ & $\begin{array}{c}0.606 \\
(3.846) *\end{array}$ & $\begin{array}{c}0.476 \\
(1.669)\end{array}$ \\
\hline Shots per game & $\begin{array}{c}0.202 \\
(2.553) * *\end{array}$ & $\begin{array}{c}0.482 \\
(4.773) *\end{array}$ & $\begin{array}{c}0.592 \\
(3.981) *\end{array}$ & $\begin{array}{c}0.733 \\
(5.315) *\end{array}$ & $\begin{array}{c}0.630 \\
(2.444)^{* *}\end{array}$ \\
\hline $\begin{array}{c}\text { Time on ice per game } \\
\text { (TOIPG) }\end{array}$ & $\begin{array}{c}0.069 \\
(3.984) *\end{array}$ & $\begin{array}{c}0.096 \\
(4.574) *\end{array}$ & $\begin{array}{c}0.118 \\
(4.589) *\end{array}$ & $\begin{array}{c}0.107 \\
(4.085) *\end{array}$ & $\begin{array}{c}0.073 \\
(2.26)^{* *}\end{array}$ \\
\hline Defenseman & $\begin{array}{l}-0.209 \\
(-0.397)\end{array}$ & $\begin{array}{l}-0.996 \\
(-1.16)\end{array}$ & $\begin{array}{c}-2.332 \\
(-4.522)\end{array}$ & $\begin{array}{c}-1.696 \\
(-4.363) *\end{array}$ & $\begin{array}{c}-2.043 \\
(-3.423)\end{array}$ \\
\hline Defenseman X TOIPG & $\begin{array}{c}0.009 \\
(0.259)\end{array}$ & $\begin{array}{c}0.064 \\
(1.136)\end{array}$ & $\begin{array}{c}0.166 \\
(4.861) *\end{array}$ & $\begin{array}{c}0.155 \\
(5.885)\end{array}$ & $\begin{array}{c}0.202 \\
(4.705) *\end{array}$ \\
\hline Left Handed player & $\begin{array}{c}-0.015 \\
(-0.278)\end{array}$ & $\begin{array}{c}0.068 \\
(0.957)\end{array}$ & $\begin{array}{c}0.040 \\
(0.428)\end{array}$ & $\begin{array}{c}-0.076 \\
(-0.733)\end{array}$ & $\begin{array}{c}0.043 \\
(0.314)\end{array}$ \\
\hline USADUMMY & $\begin{array}{c}-0.031 \\
(-0.514)\end{array}$ & $\begin{array}{c}0.021 \\
(0.266)\end{array}$ & $\begin{array}{c}-0.004 \\
(-0.035)\end{array}$ & $\begin{array}{c}-0.140 \\
(-1.235)\end{array}$ & $\begin{array}{c}-0.051 \\
(-0.269)\end{array}$ \\
\hline RUSDUMMY & $\begin{array}{c}0.454 \\
(1.982)\end{array}$ & $\begin{array}{c}0.592 \\
(1.753)^{* * *}\end{array}$ & $\begin{array}{c}0.671 \\
(2.816) *\end{array}$ & $\begin{array}{c}0.839 \\
(2.254) * *\end{array}$ & $\begin{array}{l}0.517 \\
(1.39)\end{array}$ \\
\hline SWEDUMMY & $\begin{array}{c}0.190 \\
(1.283)\end{array}$ & $\begin{array}{c}0.182 \\
(0.915)\end{array}$ & $\begin{array}{c}0.563 \\
(2.645) *\end{array}$ & $\begin{array}{c}0.373 \\
(1.564)\end{array}$ & $\begin{array}{c}0.212 \\
(0.748)\end{array}$ \\
\hline FINDUMMY & $\begin{array}{c}-0.019 \\
(-0.094)\end{array}$ & $\begin{array}{c}-0.258 \\
(-0.799)\end{array}$ & $\begin{array}{c}0.008 \\
(0.023)\end{array}$ & $\begin{array}{c}-0.082 \\
(-0.232)\end{array}$ & $\begin{array}{c}0.420 \\
(0.485)\end{array}$ \\
\hline CZEDUMMY & $\begin{array}{c}0.219 \\
(1.131)\end{array}$ & $\begin{array}{c}0.483 \\
(2.997) *\end{array}$ & $\begin{array}{c}0.470 \\
(2.544)^{* *}\end{array}$ & $\begin{array}{c}-0.076 \\
(-0.366)\end{array}$ & $\begin{array}{c}-0.336 \\
(-0.988)\end{array}$ \\
\hline OTHERDUMMY & $\begin{array}{c}-0.034 \\
(-0.258)\end{array}$ & $\begin{array}{l}-0.154 \\
(-0.79)\end{array}$ & $\begin{array}{c}-0.284 \\
(-1.238)\end{array}$ & $\begin{array}{c}0.090 \\
(0.326)\end{array}$ & $\begin{array}{c}-0.212 \\
(-0.505)\end{array}$ \\
\hline UFA Dummy & $\begin{array}{c}-0.052 \\
(-0.863)\end{array}$ & $\begin{array}{c}0.110 \\
(1.347)\end{array}$ & $\begin{array}{c}0.335 \\
(3.632) *\end{array}$ & $\begin{array}{c}0.460 \\
(4.423) *\end{array}$ & $\begin{array}{c}0.452 \\
(2.879) *\end{array}$ \\
\hline TFP35 Dummy & $\begin{array}{c}-0.053 \\
(-0.334)\end{array}$ & $\begin{array}{l}-0.360 \\
(-1.68)\end{array}$ & $\begin{array}{c}-0.605 \\
(-2.597)\end{array}$ & $\begin{array}{c}-0.799 \\
(-3.411)\end{array}$ & $\begin{array}{c}-0.752 \\
(-2.642)\end{array}$ \\
\hline UFA Years lost & $\begin{array}{c}-0.165 \\
(-1.132)\end{array}$ & $\begin{array}{c}0.003 \\
(0.043)\end{array}$ & $\begin{array}{c}-0.024 \\
(-0.1)\end{array}$ & $\begin{array}{l}-0.040 \\
(-0.141)\end{array}$ & $\begin{array}{c}-0.538 \\
(-5.854)\end{array}$ \\
\hline
\end{tabular}

* Significant at the $1 \%$ level, ${ }^{* *}$ Significant at the $5 \%$ level, ${ }^{* * *}$ Significant at the $10 \%$ level. Robust standard errors are employed.

The RFA contract status dummy is positive and significant in Table 3 up to the median quartile. Table 4 does not contain the RFA dummy because RFAs make up the comparison group in the contract lagged dataset. The UFA dummy is insignificant at all quantiles in the career lagged statistics dataset in Table 3. However, it is significant and positive at the 50th, the 75th, and the 90th quantiles in the contract lagged statistics dataset. This is in keeping with the logic that unrestricted free agents have more bargaining power and are likely to secure higher AAVs. The TFP35 dummy is negative and significant across all quantiles in the career lagged statistics dataset, while it is negatively significant at the 50th, the 75th, and the 90th quantiles in the contract lagged statistics dataset. This is in keeping with the reasoning that more restrictive salary cap rules make teams less likely to award high TFP35 contracts. The contract status dummies tend to perform better in the contract statistics lagged dataset 
than the career lagged statistics performance dataset. General managers are more likely to base their decisions on a player's recent productivity from their last few years rather than on their career statistics. For older players, such as those in the TFP35 category, there could be a significant difference in those statistics.

\section{Conclusions}

The purpose of this paper is to examine if the country of origin influences a player's average annual contract value in the NHL after controlling for on ice performance, contract status, and position. We use two different sets of on-ice statistics to control for on-ice performance. The first dataset contains players' average annual values of their current contract in each year and a lagged career average of their various on ice statistics. This is the type of data used in most academic studies. The second dataset looks at player's real average annual value in the first year of a new contract as a function of their average on-ice statistics during their last contract. This is the type of data that most NHL teams are likely to use when making contract offers.

The FELS results for on-ice production statistics are quite similar across both datasets. We find that players annual average values increase with their on-ice performance measured by games played, goals per game, assists per game, their plus-minus statistic, penalty minutes per game, shots per game, and their time on ice per game. However, the FELS results suggest that defensemen get paid less than forwards. The FELS results from both datasets do not support the idea that left handed players are paid more for being left handed. After controlling for on-ice productivity, contract status, and position, we find that Russian players are paid more than others in the NHL across the board in all FELS regressions based on both datasets. We also find that Swedish and Czech defensemen get paid more than their Canadian counterparts.

The quantile regression results are a little more nuanced and insightful. These results for both datasets show that on-ice productivity, for the most part, is related positively to NHL salaries. In general, goals per game, assists per game, plus-minus, penalty minutes, and shots per game are related positively and significantly to player salary. However, according to the estimates from the contract lagged statistics, games played is not significant in determining salary at the 75th and the 90th quantiles. This suggests that NHL general managers view the relationship between games played and higher end salaries differently than the results from academic studies, which find games played and salary to be related at all quantiles.

We find that defensemen are paid less than forwards at the 50th, the 75th, and the 90th quantiles in both datasets. However, when accounting for the time on ice played by defensemen, we find that defensemen are paid a little more than forwards for their time on ice. This allows us to understand why past FELS results in the literature found that defensemen get paid less than forwards. However, this slight increase is not enough to offset the negative differential in pay between forwards and defensemen, and defensemen still get paid less than forwards at the middle to upper quantiles of the distribution. These results are consistent with previous findings by Kahane (2001). However, unlike Coates (2017), we do not find any significant salary differential for left handed players.

The results from the contract lagged statistics dataset show that Russians get paid more at every quantile up to the 75th quantile. Players from other countries do not see additional compensation above the median quantile. There is also a country of origin effect on compensation for Swedish and Czech players from the lower to the middle quantiles, depending on the dataset used. Given that the KHL and the SHL cannot outbid NHL teams for the very top talent, it makes sense that country of origin dummies are insignificant beyond the median quantile (for the previous contract dataset). The only exception is Russia, which is significant at the 75th quantile. These country of origin effects are observed after controlling for on-ice performance, contract status, team effects, annual effects, and player position. Given that NHL teams are trying to win subject to a hard salary cap, the only plausible explanation is that some of these Russian, Swedish, and Czech players have leverage in negotiations due to the availability of options to play in other leagues such as the SHL and the KHL. 
According to the dataset based on lagged career statistics, Russians get paid more in the NHL at every quantile. However, NHL teams are more likely to award contracts based on recent performance as measured by the previous contract dataset.

In closing, this study suggests that, while the statistical significance of most on ice performance variables on AAV are very similar between career lagged statistics and previous contract lagged statistics datasets, there may be differences in the magnitude of the coefficients. Academics may be missing nuances of salary studies by just focusing on lagged career statistics instead of statistics generated during the player's most recent contract. In addition, the use of quantile regression produces interesting results at different points of the wage distribution that are masked by the use of a simple ordinary least squares estimator.

Author Contributions: All authors contributed equally to this work.

Funding: The authors are thankful for funding from the Chapman and Betty Soucek funds from Colorado College.

Acknowledgments: We are grateful for the comments from two anonymous referees from this journal, Neal Rappaport from Colorado College, Dennis Coates and other session participants and the Southern Economics Meetings. Any remaining errors are our own. We would also like to thank Andrew Farny, Jacob Miller, Rae Conlon and Alan Fox for their outstanding work as our research assistants.

Conflicts of Interest: None that we know of.

\section{References}

Brander, James A., and Edward J. Egan. 2018. Seniority Wages in the National Hockey League. Eastern Economic Journal 44: 84-96. [CrossRef]

Bruggink, Thomas H., and Daniel Williams. 2009. Discrimination against Europeans in the National Hockey League: Are Players Getting Their Fair Pay? American Economist 54: 82-90. [CrossRef]

Christie, Tom, and Marc Lavoie. 2015. Entry Discrimination in the NHL: Evolution and the KHL Effect. Eastern Economic Journal 41: 214-29. [CrossRef]

Coates, Dennis. 2017. Returns to Handedness in Hockey. In Breaking the Ice: The Economics of Hockey. Edited by Bernd Frick. Berlin and Heidelberg: Springer, pp. 41-56.

Holmes, Paul. 2011. New Evidence of Salary Discrimination in Major League Baseball. Labour Economics 18: 320-31. [CrossRef]

Idson, Todd, and Leo Kahane. 2001. Team Effects on Compensation: An Application to Salary Determination in the National Hockey League. The Economics of Sport 1: 583-95. [CrossRef]

Jones, J. C. H., and William Walsh. 1988. Salary Determination in the National Hockey League: The Effects of Skills, Franchise Characteristics, and Discrimination. Industrial and Labor Relations Review 41: 592-604. [CrossRef]

Kahane, Leo H. 2001. Team and Player Effects on NHL Player Salaries: A Hierarchical Linear Model Approach. Applied Economics Letters 8: 629-32. [CrossRef]

Kahn, Lawrence M. 1992. The Effects of Race on Professional Football Players' Compensation. Industrial and Labor Relations Review 45: 295-310. [CrossRef]

Lavoie, Marc, Gilles Grenier, and Serge Coulombe. 1987. Discrimination and Performance Differentials in the National Hockey League. Canadian Public Policy 13: 407-22. [CrossRef]

Mincer, Jacob. 1958. Investment in Human Capital and Personal Income Distribution. Journal of Political Economy 66: 281-302. [CrossRef]

Vincent, Claude, and Byron Eastman. 2009. Determinants of Pay in the NHL: A Quantile Regression Approach. Journal of Sports Economics 10: 256-77. [CrossRef]

Yang, Chih-Hain, and Hsuan-Yu Lin. 2012. Is There Salary Discrimination by Nationality in the NBA?: Foreign Talent or Foreign Market. Journal of Sports Economics 13: 53-75. [CrossRef]

(C) 2019 by the authors. Licensee MDPI, Basel, Switzerland. This article is an open access article distributed under the terms and conditions of the Creative Commons Attribution (CC BY) license (http://creativecommons.org/licenses/by/4.0/). 


\title{
Howzat? The Financial Health of English Cricket: Not Out, Yet
}

\author{
Daniel Plumley *, Rob Wilson, Robbie Millar and Simon Shibli \\ Sport Business Management, Sheffield Hallam University, Sheffield S1 1WB, UK; r.j.wilson@shu.ac.uk (R.W.); \\ r.millar@shu.ac.uk (R.M.); s.shibli@shu.ac.uk (S.S.) \\ * Correspondence: d.j.plumley@shu.ac.uk
}

Received: 21 December 2018; Accepted: 8 February 2019; Published: 19 February 2019

\begin{abstract}
In 1997 a review of the financial health of English county cricket highlighted strategic weaknesses within the professional game, principally an over-reliance by clubs on the annual grants provided to them by the England and Wales Cricket Board (ECB). Without such grants the teams, in general terms, would be insolvent. Using the financial statements of the First Class Cricket Counties, this paper explores how the financial position and performance of the county game has changed, 20 years on from the seminal study. A series of structural changes to the game had been made, yet financial problems are still evident. Counties are as reliant on central grant income as they were in 1997, although there are cases where clubs have made strategic enhancements and are becoming self-sustainable as going concerns. Rather than the ECB directly funding county revenue it should be working in collaboration with individual clubs to achieve developments in the game from the grassroots upwards, in order to help clubs grow their own revenue streams.
\end{abstract}

Keywords: finance; financial health; cricket; professional team sport; profit maximisation; subsidy; grants

JEL Classification: G; Z2; Z23

\section{Introduction}

In 1997, just over 20 years ago, a paper published by Shibli and Wilkinson-Riddle in the Journal of Applied Accounting Research examined the financial health of English county cricket, specifically the finances of the 18 first-class counties. The article highlighted strategic weaknesses within the professional game, principally an over-reliance by clubs on the annual grants provided to them (to support income generation) by the England and Wales Cricket Board (ECB), essentially rendering the teams, in general terms, insolvent should the grants ever be removed. The grant money from the ECB remains and constitutes a distribution of international match-related revenues driven by the England National Team and is, therefore, dependant on the national team's sporting success and attractiveness to spectators, sponsors and broadcasters. Additionally, Shibli and Wilkinson-Riddle (1997) confirmed that an extremely low proportion of clubs' total revenue came from the paying public watching county cricket, that levels of debt at some clubs were unsustainable and that without the ECB hand-outs many clubs would cease to exist as a going concern.

To that end, we set out to examine the current financial health of the domestic game, 20 years on, in 2018. Cricket, from a participation perspective, is second only to football in England, yet the professional game has not seen the revenue growth, at the elite end, in line with football, yet there have been major developments in the domestic game during the last 20 years in terms of its changing format and structure. Indeed, in 2002, the ECB realised it had to open the game up to new audiences to reverse the trend of dwindling attendances and financial uncertainty affecting the 18 counties. The advent of Twenty20 (T20) cricket came in 2003 and it was a revolutionary step forward, as matches could take place after work and last for no more than three hours. Most importantly, the domestic 
T20 season was scheduled to take place during the school summer holidays, making it particularly attractive to families. T20 was a ground-breaking success; matches were regularly played to sell-out crowds and have become an important revenue stream for counties. Stuart Robson former Head of Marketing at the ECB stated:

“ $£ 200,000$ of ticket revenue would have been double the amount derived from any other competition. It was a proper cash cow to those smaller grounds and a life saver. Without Twenty20 at a professional level the domestic game in this country would be in a very precarious state by now." (The Independent 2017)

This fundamental shift in the English cricket landscape can be seen around the world, with the introduction of various franchise-based competitions, most notably the Indian Premier League and Big Bash in Australia, which have become lucrative multi-million pound leagues (The Guardian 2017a). The ECB reacted and recently introduced a new franchise city-based T20 format due to launch in 2020 in an effort to maintain its market share (The ECB 2018).

The emergence in popularity of One Day Internationals (ODIs) has led to new broadcasting contracts being agreed with Sky and the BBC. These new arrangements provide broadcasting revenue totalling $£ 1.1$ billion over a five year period from 2020-2024 (The Guardian 2017b). Not only is this $£ 220 \mathrm{~m}$-a-year deal worth nearly three times what Sky is paying for current exclusive rights ( $£ 75 \mathrm{~m}$-a-year) but it will also see live coverage return to free-to-air television for the first time since 2006 - a statement that perhaps suggests that the move to a subscription only model might have removed the game from the eyes of the masses and impacted negatively on grassroots participation. This deal will also allow the ECB to meet its promise of providing central grant money to the 18 counties of $£ 1.3 \mathrm{~m}$ each. However, as we have seen historically, counties have perhaps been over-reliant on this grant in the past (Shibli and Wilkinson-Riddle 1997).

The dichotomy between on-field and off-field performance in professional team sports, exacerbated by the commercialisation of sport during the last two decades, according to Wilson and Plumley (2017), and the need for clubs to balance both financial and sporting performance has led to a multitude of academic papers in the area of sport finance. Sport teams tend to be fairly unique entities with the majority strategically positioning themselves to maximise performance both on and off the pitch, whilst simultaneously satisfying a number of different stakeholders.

As previous research suggests, reconciling the "on-field/off field" equation in professional team sport is not easy and it has proved a highly contentious issue in recent years (Chadwick 2009). Often, discussion transcends towards what has been labelled the 'twin' objectives of professional sports teams (e.g., Plumley et al. 2017). One is financial, in relation to business operations, and the other is sporting, in relation to on-pitch performance and trophy success.

There is also substantial academic literature, which considers the relationship between financial and sporting performance in professional team sports (e.g., Kesenne 2000; Garcia-del-Barrio and Szymanski 2009; Sloane 2015; Szymanski and Kuypers 1999). Historically, much of the wider literature has pointed to these 'twin objectives' being at odds with one another and creating 'financial crises' at the club level as sporting objectives supersede financial decision making, plunging clubs into operational losses. Most notably, this literature has focused on European football across a number of different countries (e.g., Andreff 2007; Barros 2006; Buraimo et al. 2006; Dietl and Franck 2007). Notwithstanding this historical narrative, the financial problems in football, at least generally, appear to be abating, in part through stricter regulations aimed at financial sustainability and encouraging clubs to spend within their means (e.g., UEFA Financial Fair Play) although there are still some problems at individual club level. However, financial problems are not only exclusive to football in relation to professional team sports in the UK. Previous research has also highlighted financial problems in rugby union (e.g., O'Brien and Slack 1999, 2003; Williams 2012; Wilson and Plumley 2017) and rugby league (Wilson et al. 2015). However, aside from the paper by Shibli and Wilkinson-Riddle (1997), there is a lack of literature available on the financial health of county cricket in the UK. 
Consequently, the primary aim of this paper is to analyse the current state of the UK County Championship and its member clubs in an attempt to understand the financial climate of the game in 2018. This will help determine whether each cricket county is an attractive product, within the UK professional sport system, and are capable of fulfilling the fundamental requirements of a league association. Our data focuses on the 18 first-class counties that take part in the County Championship. The financial information pertains to all business aspects of the clubs including their respective one-day and T20 teams and whether or not they host international matches or other events at their grounds. This approach allows for a holistic measurement of financial performance in respect of these clubs and helps to determine whether each club would meet a going concern requirement were central grants ever withdrawn. The remainder of this paper is structured as follows. First we consider the theoretical context of accounting theory and professional team sports before considering the literature available on the County Championship itself. Following this, the paper discusses the methods applied and the findings before concluding with the key challenges that the sport faces and highlighting the potential areas of growth for the sport in the future.

\section{Theoretical Framework and Literature Review}

\subsection{On Truth and Fairness in Accounting Policies}

We structure our theoretical framework on accounting policies and practice on the argument of the contested nature of a conceptual framework for accounting, a topic that is prevalent in much of the extant literature. We use this as a guide to state that whilst the analysis of financial information may still be debated in relation to the techniques used, and the figures contained within in annual reports, there is still a regulatory framework in place that companies have agreed to adhere to (especially in the UK). As such, we argue that despite the inconsistencies in the literature presented below, the measurement and analysis techniques used in this study are rigorous and appropriate based on the data we put forward.

Firstly, let us define the term 'conceptual framework'. International Generally Accepted Accounting Principles GAAP (International GAAP 2005) state that, in general terms, a conceptual framework is a statement of generally accepted theoretical principles which form the frame of reference for a particular field of enquiry. In terms of financial reporting, these theoretical principles provide the basis for both the development of new reporting practices and the evaluation of existing ones. Since the emphasis of financial reporting is on the provision of information that is useful in making business and economic decisions, a conceptual framework will form the theoretical basis for determining which events should be accounted for, how they should be measured and how they should be communicated to the user. Therefore, a conceptual framework for financial reporting must be substantially practical in its application (International GAAP 2005).

Much of the critique surrounding the conceptual framework of accounting centres on the struggle to distinguish the separation of accounting from societal happenings. Indeed, Hines (1991) suggested that the conceptual framework is elaborated around a highly problematic conception of the relationship between financial accounting and economic reality. The view of Hines that the meaning and significance of conceptual framework projects is not so much functional and technical, but rather social and cultural is shared by a number of other authors (see for example, Boland 1989; Burrell 1987; Hopwood 1990; Miller and O'Leary 1987; Richardson 1987; Tinker 1988; Willmott 1986). All of these authors argue that financial accounting practices are implicated in the construction and reproduction of the social world. Furthermore, the conceptual framework projects similarly play a part in the process of the social construction of reality (see for example, Booth and Cocks 1989; Hines 1991). One of the main arguments here is that accounts, and the numbers contained within them, can be manipulated subjectively.

This view is shared in a recent article by Sunder (2016) who states that conflicts among the claims of the shortcomings of financial reporting point to the political elements of the problem inherent in 
collective choice in society. Since 'better' in this context (the accounting policies) depends on the interest group whose perspective is chosen for analysis, politics lies at the heart of accounting policy. Thus, Sunder (2016) argues that any regulations should also consider social norms and market competition.

There has also been considerable focus in accounting literature on the transition from Historical Cost Accounting (HCA) to Fair Value Accounting (FVA) which occurred in 2005. For a more historical overview of both these policies, readers are referred to Georgiou and Jack (2011). The move to FVA appears to have been largely positive yet it is still difficult to detach the practice from societal influences. The move towards fair value measurement is frequently characterised as a shift in paradigms (e.g., Barlev and Haddad 2003, p. 383). Accordingly, with respect to financial reporting, a paradigm is defined as a set of shared beliefs on the objectives of financial reporting and on the accounting principles by which these can be achieved. It is grounded in elaborated assumptions, and characteristically requires a theoretical foundation or vindication. Once a financial reporting paradigm is adopted by regulatory bodies, it becomes the guiding principle for accounting regulation, that is, standard-setting (Hitz 2007).

Fair value accounting is, put simply, an income definition that anchors on changes in assets and liabilities rather than on the vague notion of 'nondistortion' (Bevis 1965, p. 104), which had increasingly been perceived as a pretext for discretionary definitions of balance sheet positions. Additionally, researchers and regulators felt uncomfortable with a balance sheet that had no informative purpose of its own (Hitz 2007). However, despite being the dominant practice in present day accounting, FVA is still not without its critics. It is argued that the concept of 'fair value' measurement emerged in financial accounting and was accepted in the abstract long before it was a subject of analysis and dispute (Bromwich 2007). Furthermore, 'fair value' is not, itself, a single measurement methodology, but encompasses a variety of approaches for the estimation of an exit value. Therefore, it is hardly surprising that many of the arguments which have been developed for and against the use of fair values in accounting are not well-supported by evidence (Laux and Leuz 2009); with disputants often talking past each other.

It is evident from the literature that throughout history the legitimacy of accounting practices and principles has been questioned. Furthermore, there are also implications and challenges based on the qualitative characteristics of accounting information, namely reliability, relevance, comparability and materiality. In the profession of accounting, the debate between FVA and HCA, it appears, is likely to be prolonged, as the unintended consequence of more firmly embedding an acceptance of the appropriateness of fair values for some balance sheet items has been to confer further pragmatic legitimation for mixed measurements in annual reports. It is possible that moral and cognitive arguments in favour of mixed measurement may emerge, or the debates on cost or value based accounting continue, as they have done for over a century. The emergence of new reporting forms should be carefully observed and recorded, as a basis for a longitudinal study of the diffusion of practice and processes of legitimacy (Georgiou and Jack 2011).

The authors acknowledge that accounting theory remains a contested issue, but accounts have to be prepared in line with accounting principles and the current standards in place. Furthermore, accounts are prepared with a 'true and fair' view and decision usefulness in mind and the supporting of financial figures with qualitative characteristics of accounting information provides a reliable and valid framework upon which analysis can be undertaken. In respect to English Cricket, clubs are subject to compliance with FRS 102 rather than international accounting rules, although there is overlap between the two.

\subsection{The Economic Theory of Professional Team Sport}

Professional team sports are intrinsically different from other businesses, in which a firm is likely to prosper if it can eliminate competition and establish a position as a monopoly supplier (Dobson and Goddard 2011), being profitable and responsible for earned revenue, in this context, naturally provides competitive advantage; you can afford to pay players higher wages for example. In sport, however, 
it does not pay for one team to establish such a position due to the joint nature of 'production' in sports. With this in mind, it is paramount for league organisers that their 'product' on the pitch is a contest between equally matched opponents. The practical economic problem with this notion, however, is that professional sport leagues form imperfectly competitive natural cartels where games are played between teams with asymmetric market power (Vrooman 2015). Sport teams might not be able to eliminate the competition, but they still try to be dominant over the rest. Ultimately, the 'biggest' clubs, often in respect of size, resources and fan base, tend to win more than they lose. As a result, professional sport teams operate in a uniquely eccentric environment and comparisons between the economic environment of professional team sports and that of more traditional commercial businesses have been well documented by sports economists (e.g., Dobson and Goddard 2011; Leach and Szymanski 2015).

Thus, a key priority for professional sport leagues is the economic concepts of uncertainty of outcome, competitive balance and profit and utility maximisation (e.g., Buraimo et al. 2015; Fort 2015; Kesenne 2015; Leach and Szymanski 2015; Sloane 2015; Vrooman 2015). Much of the historical literature surrounding professional team sports was developed by US sport economists and focused on North American team sports. Naturally, over time, the literature has evolved to compare the North American and European model of professional team sports (see Hoehn and Szymanski 1999; Andreff and Staudohar 2000; Sloane 2006; Szymanski 2003). There are distinct differences between the two models notably draft systems, revenue sharing, salary caps and closed league systems with no promotion or relegation between leagues (regulatory policies that are in place in North American team sports but not in the European model). Despite these differences, there has also been some convergence between the two models on certain features. In both Europe and the North America, sports leagues are joint ventures that can be viewed as a single entity. Clubs are separately owned with discretion to set prices, market the games, and adopt strategies to compete with other clubs. However, such strategies must be executed under the regulations of the league.

Precisely why such differences have arisen in the two continents has never been fully explained (Sloane 2015). However, Szymanski and Zimbalist (2005) contrast the development of baseball and soccer, with the latter spreading throughout the world, first under the influence of British expatriates and then by local elites, whereas baseball was much more inward looking and concerned with commercial development. Previous literature has argued that profit maximisation is the prime objective of North American leagues and team owners, so profitability is the main factor influencing decisions concerning the award of franchises and relocation (Dobson and Goddard 2011). Contrastingly, other authors have suggested that the European sports model is more closely related to utility or 'win' maximisation (see Sloane 1971; Kesenne 2000; Garcia-del-Barrio and Szymanski 2009).

\section{The County Championship}

The County Cricket Championship is unusual in many ways when compared against received economic theory. This is because it has historically taken elements of both models of professional team sport (European and North American) to structure its competition. It is also the only team sport in the UK where clubs receive central grant money from the governing body (England and Wales Cricket Board (ECB)). The origins of the competition can be traced back to 1890 but the present day format began taking shape around the mid-1960s when bonus points were introduced to the scoring system alongside the already established points system relating to wins and losses. Up until 2000, all member teams competed in one league with no promotion and relegation and entries to the league decided on an application basis. This mirrored the North American style model for professional team sport outlined in the previous section. However, post-2000 the league has been split into two divisions with promotion and relegation between them. Originally, there were three teams promoted and relegated between divisions although this has since been reduced to two teams since 2006.

In some respects, the County Championship bears some resemblance to rugby league's Super League in this regard. When the Super League was formed, it can be argued that the plan was to take elements from both models of professional team sports. Essentially, rugby league was attempting to 
replicate the English Premier League in football whilst maintaining American team sport principles of salary caps and no promotion or relegation (up until the 2014 season). Wilson et al. (2015) argued that Rugby League is, in global terms, a minority sport but has clearly been modernised in recent times through the advent of subscription television and other global processes. It could be argued that cricket is in a similar position in the UK as it battles with both rugby league and rugby union to be the second most popular sport behind football.

The challenges facing cricket's County Championship are not new. Indeed, Ammon (2017) began a media piece on the beginning of the County Championship season with the following quote:

"The beginning of every new cricket season brings with it reports of county cricket in demise, accompanied by pictures of a solitary, cold supporter in a stand, surrounded by rows of empty plastic seats. It is the stereotypical image of county cricket watched by a man and a dog, and of its impending death - killed by public apathy and crippling financial issues. For as long as I can remember, people have been prophesying the death of county cricket" (Ammon 2017)

The article goes on to state that the clubs themselves still appear reliant on the central grant money from the ECB, that county game attendances are modest and that participation in the sport itself has been declining in recent years (Ammon 2017). Again, similarities can be drawn here with rugby league and the findings of Wilson et al. (2015) who outlined a similar picture in rugby league. This combination of factors appears unsustainable at league level but for as long as the county clubs are operating as going concerns, producing players for the international England team and producing entertaining cricket, is cricket just doing its job? The evidence in other sports is that the league and its member clubs would be better off becoming more self-sustaining entities, particularly if the financial position of the ECB was to weaken in the future and central grant money had to be cut.

One piece of positive news in relation to this is the recent broadcasting deal that has just been agreed with Sky Sports and BBC which will see live domestic cricket return to terrestrial television for the first time since the 2005 Ashes series (BBC 2018). Not only that, but the deal is worth a record total of $£ 1.1$ billion running for five years and commencing in 2020. However, as part of the deal, the ECB has stipulated that it will increase the central grant money to clubs. This is fine in principle but, again, highlights the issues facing the County Championship and its reliance on ECB central funding.

To that end, and given the context outlined in the introduction, now is a worthy time to study the financial state of play in respect of the County Championship and its member clubs. There have been a small number of academic articles in relation to cricket but these have historically focused on institutional change (Wright and Zammuto 2013), the globalisation of the sport (Gupta 2004), brand extensions and facility utilisation (Pritchard 2016) and the market valuation of cricket players (Saikia et al. 2013). To the authors' knowledge, this is the first paper of its kind to focus on the financial performance of English cricket clubs since the seminal paper by Shibli and Wilkinson-Riddle in 1997.

\section{Methods}

Data for this research was obtained by analysing the annual accounts of the 18 first-class counties for the last three years available at the time of writing, covering financial data from 2014-2016. Financial data was not available for two clubs in certain years (Worcestershire (2014) and Middlesex (2016)) whilst the accounts for Northamptonshire do not reveal the total figure of ECB grant income that they receive.

Analysis was performed using recognised industry techniques (see Wilson et al. 2013). Financial results were analysed in relation to the five key areas of financial performance-all relevant to professional sports clubs and investment. These were: growth, profitability, ROCE (return on capital employed), liquidity and defensive positioning. The first three indicators relate to an organisation's ability to generate profit and return for its owners and also to maintain a sustainable future. The latter relate to an organisation's ability to meet its liabilities as they fall due and also how certain organisations 
are financed and how much capital is made up of debt finance. Ratio analysis is a widely used technique to measure financial performance across a number of industries and organisations including, but not limited to, the airline industry (Feng and Wang 2000), power/energy industry (Sueyoshi 2005) and the manufacturing industry (Ponikvar et al. 2009).

Alternative models for analysing performance in professional team sports have been excluded on the basis of accessibility to data, particularly in relation to the financial statements of county cricket clubs. Chadwick (2009) outlined that performance measurement in sport has to include both the financial and the non-financial and it is important that this paper considered non-financial factors as well when analysing the current state of the game. It is this holistic approach to data collection and analysis that is the key benefit from a methodological perspective and it also provides a further robustness to the subsequent results and discussion.

\section{Financial Health}

In respect of turnover, there appears to be a polarisation between the counties that host international test cricket and those that do not (see Figure 1). This point is further underlined by the four highest average turnover figures relating to four counties who have historically regularly hosted test cricket (Surrey, Warwickshire, Lancashire and Nottinghamshire). Indeed, Surrey's average revenue of around $£ 27 \mathrm{~m}$ for 2014-2016 is particularly impressive compared with the revenue profile of the 17 other counties. Although a regular spot on the Test match rota bolsters Surrey's finances, it has developed new revenue streams utilising its facilities to host conferences and events.

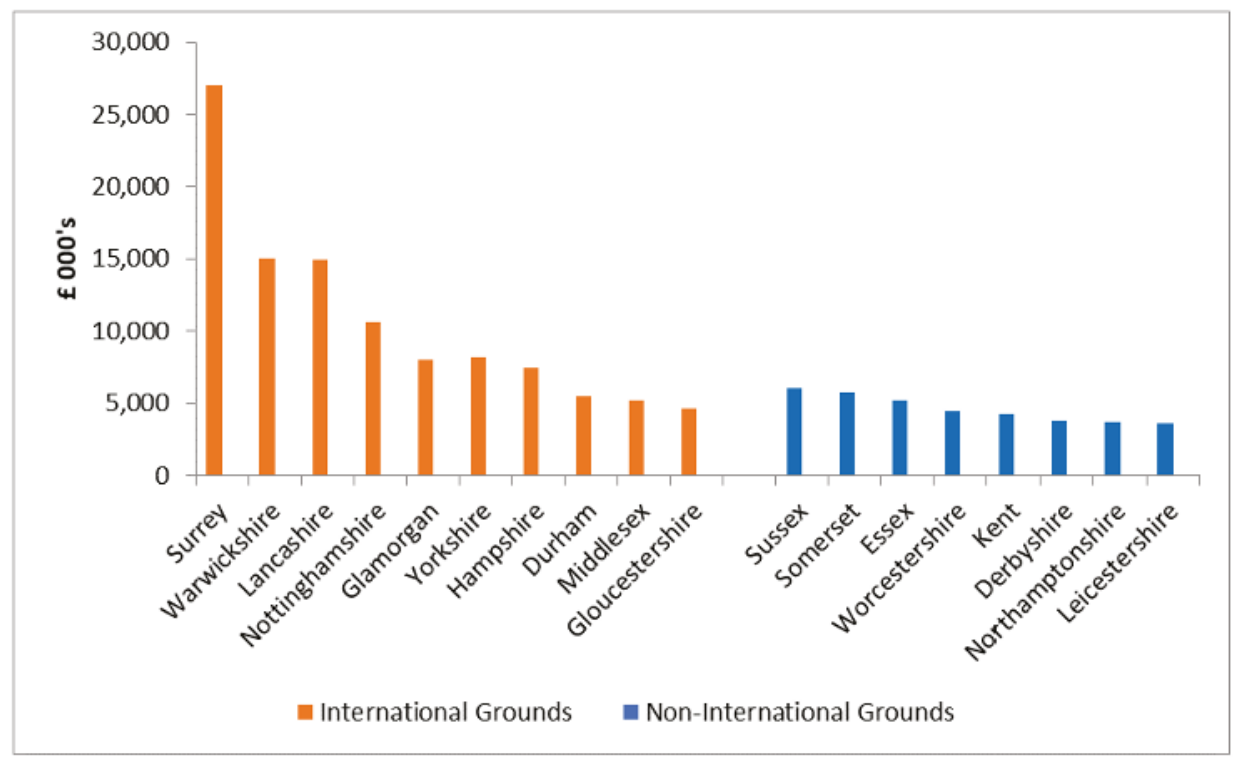

Figure 1. Average turnover in $£ 000$ s (2014-2016).

Furthermore, of the counties that have relatively low revenue, a high proportion of this is attributable to the ECB grant income. In some cases, this ECB grant income accounts for over half of a club's total revenue (Middlesex, Worcestershire, Kent, Derbyshire, and Leicestershire) (see Figure 2). 


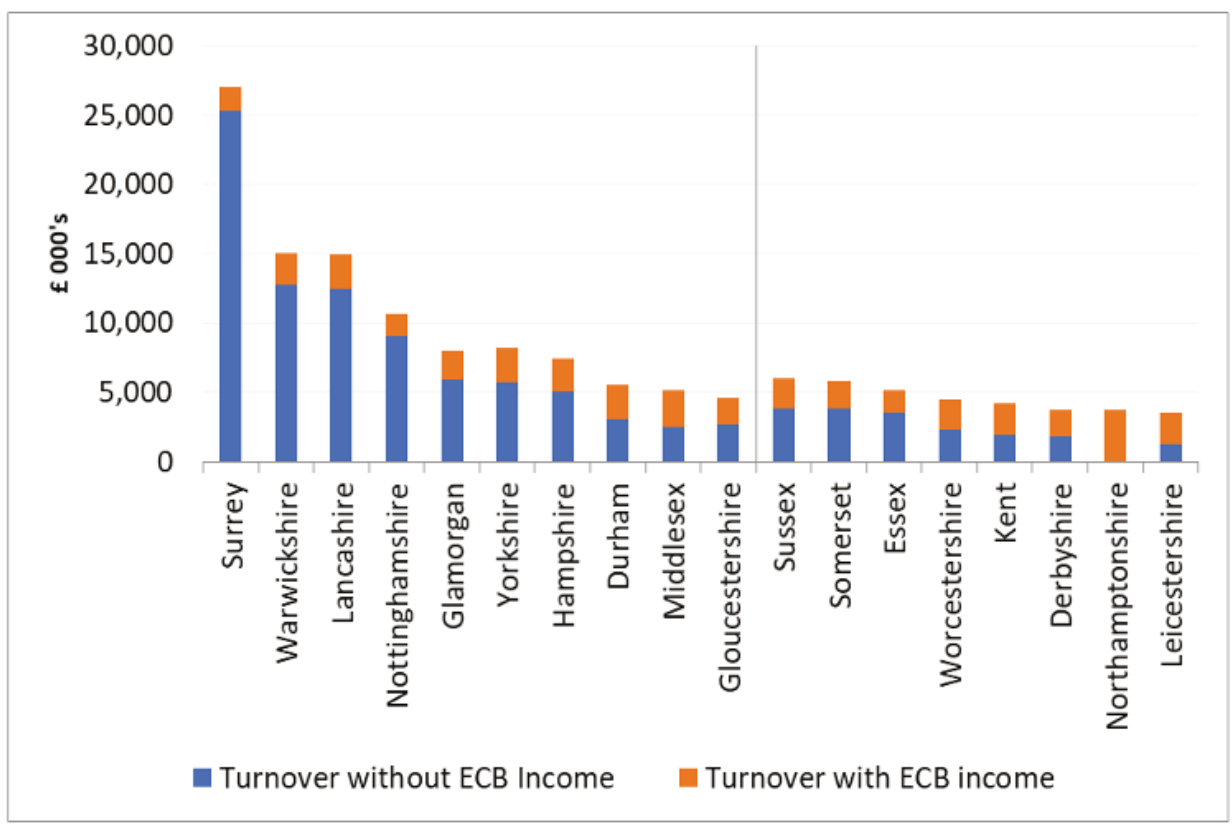

Figure 2. Average 'earned' vs. 'unearned' income in $£ 000$ s (2014-2016).

This finding leads to further financial problems, in respect of general financial health, when considering profitability (see Figure 3). A number of clubs are just about breaking-even taking into account the subsidy from the ECB and if we were to hypothetically remove this income then only Glamorgan would still have posted a net profit overall for the time period studied. This point suggests that, from a revenue perspective at least, there is an over-reliance on 'unearned' income from the ECB.

The ECB continues to support the domestic game (and other aspects of the sport down to grassroots level), which is obviously a positive for the clubs. However, this relationship is dependent on two things; (1) that the clubs do not become over-reliant on this central grant (which it appears some are) and (2) that the ECB can continue to afford the central grant payments to the county network. At the present time, the ECB appears to be capable of doing this and plans its business activities on a four-year cycle to include lucrative home Test series against Australia (The Ashes) and India. However, the ECB states that the central grants is one of its largest areas of expenditure and in the most recent set of accounts (year ending January 2017) the ECB's administrative expenditure increased by $£ 23.0 \mathrm{~m}$ during the year from $£ 114.2 \mathrm{~m}$ to $£ 137.2 \mathrm{~m}$-attributable to the increased level of distributions made to the counties.

Overall, 11 of the 18 counties have a debt ratio of over $75 \%$ (a percentage that is considered a cause for concern when considering financial health). For two clubs, Yorkshire $(110 \%)$ and Lancashire $(108 \%)$ the debt ratio is over $100 \%$. Indeed, the average balance sheet debt for the 18 first-class counties stood at $£ 14.46 \mathrm{~m}$ for 2014-2016 although within this there was large individual debt figures attributed to Yorkshire ( $£ 33.7 \mathrm{~m})$, Warwickshire $(£ 35.8 \mathrm{~m})$, Surrey $(£ 36 \mathrm{~m})$ and Lancashire ( $£ 53.5 \mathrm{~m})$. Some clubs posted a much better figure in respect of average balance sheet debt with Sussex, for example, having a debt ratio as low as $14 \%$ and average balance sheet debt of $£ 1.7 \mathrm{~m}$. 


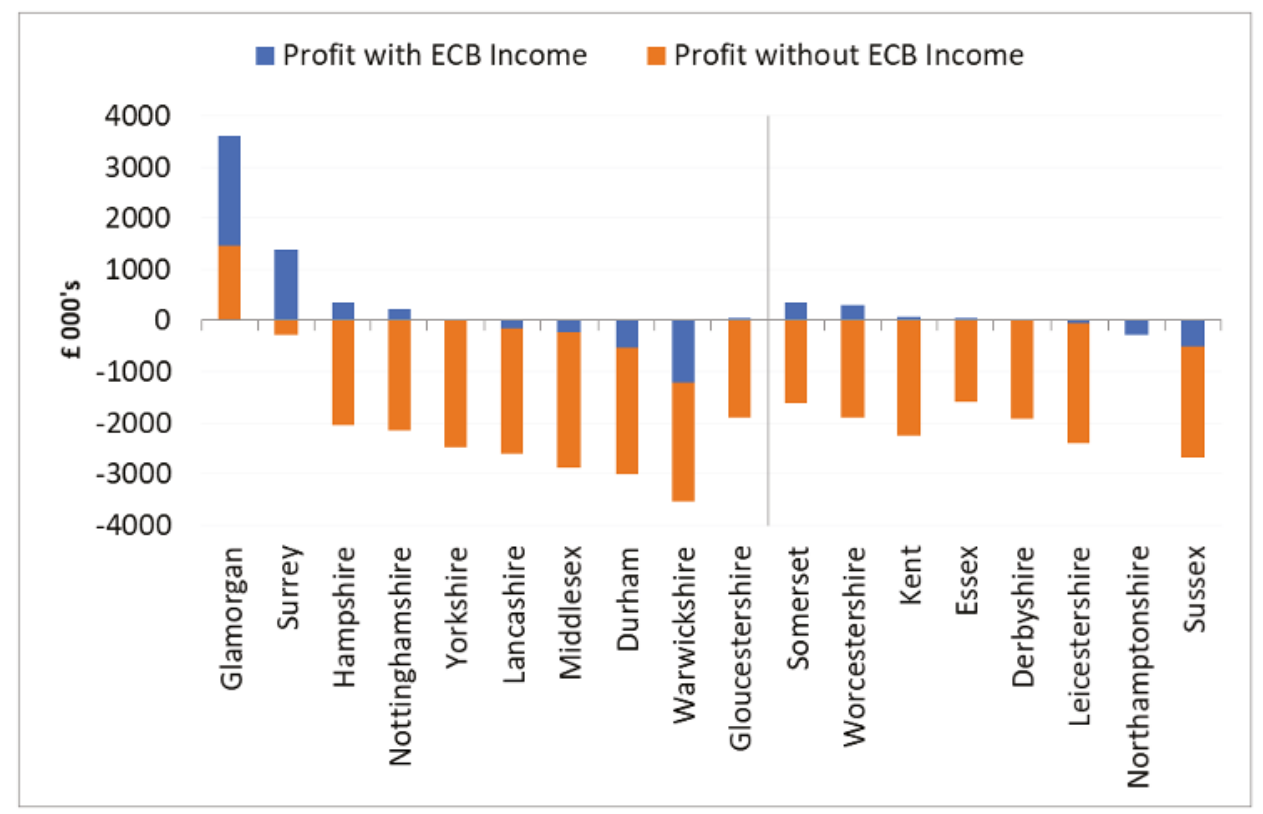

Figure 3. Average profit/(loss) in $£ 000$ s (2014-2016).

\subsection{Dominating the Game}

In financial terms Surrey is leading the way, as shown in Figure 2 its average turnover over the last 3 years is almost twice that of its nearest rivals (Warwickshire and Lancashire). Surrey's fiscal dominance is built on the foundations of guaranteed international Test cricket, as it always hosts the last Test match of the summer, which is usually against a high profile opponent. Geographically, being based in London Surrey can charge a premium for international tickets and The Oval is the second largest cricket ground after Lords. International fixtures are typically sold out, which puts an added importance on one of the main benefits of being a Surrey member, as members gain priority access to international tickets.

Since the re-vamped domestic T20 competition has moved to Friday nights, Surrey has seized this opportunity to increase revenue. The club have marketed these T20 fixtures to families with family only sections, cheap tickets and child-friendly activities; as well as to young professionals as events for post-work socialising whilst watching the cricket. This new approach to marketing has resulted in a high-demand for tickets and the majority of Surrey's home T20 matches are sold out.

The area which sets Surrey apart from the other counties, is the revenue it gains through the use of its facilities to host corporate events and conferences. Figure 4 shows a breakdown of Surrey's revenue from the 2016 financial year, $46 \%$ of revenue came from 'Oval Events', which are these non-cricketing events. This sum is more than the revenue from the ECB Grant, international matches and domestic matches put together. To put this finding in to further perspective, this single revenue stream if set against other counties total revenue, would sit third behind only Lancashire and Warwickshire. These non-cricketing events are vitally important to counties as they bring in revenue all-year round, as grounds are not used for cricket between October and March. 


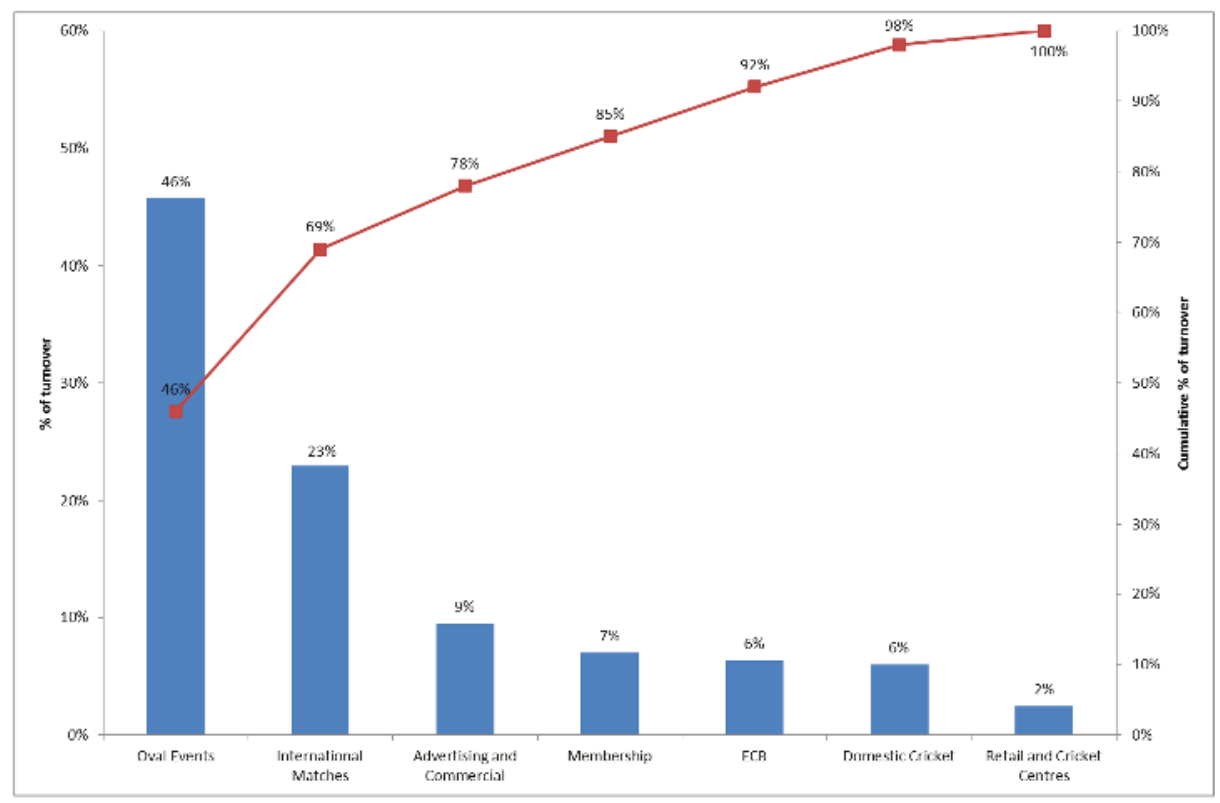

Figure 4. Breakdown of Surrey's 2016 turnover.

To develop this funding stream further and increase capacity of The Oval, planning permission has been granted to build new conference facilities and additional tiers on the adjoining stand, which will see capacity increase to just under 28,000 (Surrey CCC 2018). This capital investment will cost around $£ 55$ million, which when compared with other counties is a monumental sum. However, with a healthy balance sheet and revenue growth expected, this is a sensible venture for the club that will only increase the financial gap between itself and the other counties.

\subsection{Contrasting Fortunes}

In 1992, Durham County Cricket Club (DCCC) was accepted into first-class cricket to become the 18th first class county to compete in the County Championship. This was the first time a new county had been introduced into the County Championship since Glamorgan in 1921. Durham's vision was to bring cricket back to the North East of England, with a long-term ambition to regularly host international matches in the county. In 1996 the club moved to its new purpose built ground The Riverside. For the 1999 Cricket World Cup, Durham was awarded two group matches (Pakistan vs. Scotland and Australia vs. Bangladesh). The continued transformation of the ground was assured when the ECB awarded Durham its first England international, to host an ODI against the West Indies in 2000. The county received Test status in 2003 and hosted its first ever Test match when England faced Zimbabwe that summer. This was a landmark moment for the club as it was the first new Test ground since 1902 and signalled Durham's competency in hosting international matches, as it was placed on the list of grounds that would host at least one international match each summer.

With the guarantee of seemingly lucrative international cricket revenue, Durham began to invest more capital in facilities and upgraded The Riverside to increase capacity and improve the spectator experience. Figure 5 shows Durham's last 10 annual turnover figures, it is noticeable that the three years with the highest annual turnover are when it hosted a Test match (2007, 2009 and 2013). The year 2013 was ground-breaking as Durham was awarded an Ashes Test match; previously it had only hosted the 'lesser' Test matches. However, to secure the Ashes Test match, the club had to invest heavily in the bidding process to the ECB. As a result for the Ashes Test match the club had to charge 
a significant fee for tickets in order to see a return on its investment. Although the club saw record turnover in 2013 and achieved an operating surplus, this was a one-off year. Even though the staging of the Test match was successful, with the first three days being a sell-out, Durham was still down the pecking order below the established Test grounds and, therefore, not guaranteed a Test match every summer.

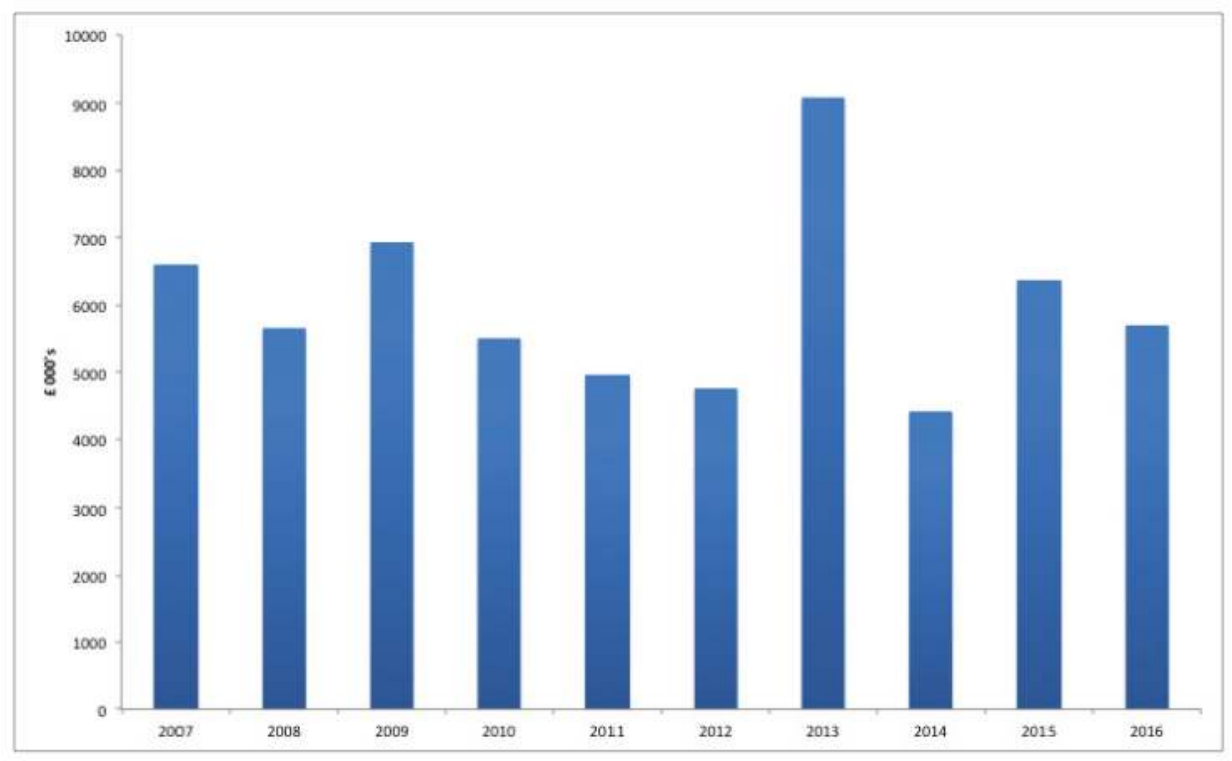

Figure 5. Durham's annual turnover 2007-2016.

In 2014, a year after the Ashes Test match, Durham hosted an ODI against Sri Lanka in May, which is not the premier slot in the English cricket summer. This step down in the prestige of its international cricket offer had a significant negative impact on the county's finances. Turnover halved compared with the 2013 Ashes year, which resulted in an overall $£ 1.1$ million deficit. The club knew it could not rely on the lucrative international fixtures as their main source of income, therefore focused on growing the revenue from T20 fixtures, which had moved to a more marketable Friday night slot during the 2015 season. Six permanent floodlights were installed to allow day/night matches to be played and the county's T20 team was re-branded to the 'Durham Jets'. In addition, the club sought to identify new revenue streams by planning to build a hotel and conference facilities on the site of The Riverside (DCCC Annual Report, Durham CCC 2015).

The last Test match Durham hosted was against Sri Lanka in 2016, which again was in the early part of the English cricketing summer. The result was the lowest turnover of the four Test match hosting years (2007, 2009, 2013 and 2016). Figure 6 displays Durham's debt ratio over the last 10 years. As previously stated anything over $75 \%$ is considered a cause for concern and Durham apart from 2009 and 2010 has consistently exceeded this figure. The club's growth has been reliant on external borrowing to fund capital investments, mainly from Durham County Council. However, the club's financial health demonstrates a lack of liquidity with their cash-flow focused on, and around, the cricketing summer (April to September). Unfortunately, with creditors calling in their debts, a financial restructure had to take place to stop the club being the first county cricket club to enter administration. In 2016 the ECB bailed out Durham, in order for the club to pay its creditors (The Telegraph 2018). However, the club faced stiff penalties (relegation and deduction of points). This is a prime example of the risk county cricket clubs face if creditors call in their debts. Ultimately the 
majority of clubs could not afford to pay their creditors if debts were called in and Durham was the first club to succumb to this pressure.

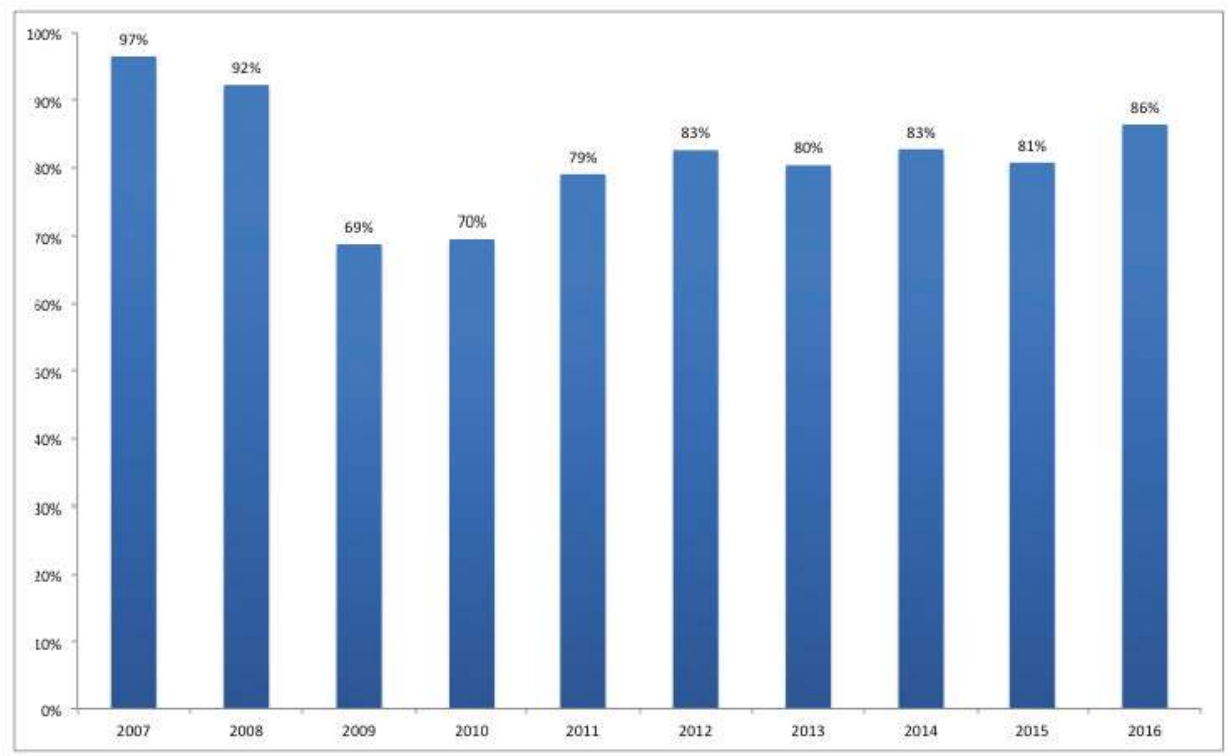

Figure 6. Durham's debt ratio 2007-2016.

\subsection{How Does This Compare with 1997?}

On the face of it, it appears as though the counties still have a problem with profitability and that debt (in relation to the absolute amounts on the balance sheets) has increased. The over-reliance on the ECB grant income is consistent if not more prominent now than it was in 1997, particularly for the 'non-international counties'. There have undoubtedly been positive developments in the game during the last 20 years such as the birth and growth of the T20 game and introducing the sport to younger people but there remains a problem with the financial health of some individual county clubs, particularly those that do not or cannot host Test cricket, which continues to be the pinnacle of the game from a sporting and commercial perspective.

\subsection{What Can Cricket Do to Improve Its Position?}

There are some positive developments taking place in cricket that can help the ECB and its county clubs to become financially sustainable including the new TV deal mentioned previously and the introduction of the new T20 franchise league due to begin in 2020. However, both of these come with caveats. If the TV deal allows the ECB to increase the central income to clubs, then is there a danger of clubs becoming more reliant on that than ever before. In relation to the T20 franchises, could such a system actually be of detriment to the 'smaller' non-international ground counties? The T20 city franchise will be positive for the counties who are going to host the teams, but could be negative for the ones that are not. For example, some of the small counties who rely on ECB income also rely on the income they generate through T20 matches. The new franchise league could take spectators away from the current T20 matches to the T20 franchise matches, starving the smaller counties of even more income and putting it in the pockets of the international ground counties.

It is not an easy problem to solve and the ECB will face challenges in the short and medium term in respect of county club finances. The county game still struggles with attendances and the best income stream for clubs at this point in time remains in hosting international Test match cricket. Indeed, 
the most recent figures released by Nottinghamshire for the year ending 2017 point to just this fact. The club made a pre-tax profit of $£ 279,000$ compared to a $£ 741,000$ loss in 2016 and chairman Richard Tennant stated that the change 'demonstrates the importance of hosting Test cricket at Trent Bridge' (BBC 2018). It is important that the ECB considers the financial situation of the non-international hosting counties alongside the international hosting ones to avoid a situation where the county cricket system begins to be dominated financially by a select number of clubs.

The problems of cricket and its clubs in respect of financial mismanagement are not exclusive. Past research has already outlined individual problems at club level in English professional football (Buraimo et al. 2006), English rugby union (Wilson and Plumley 2017) and English rugby league (Wilson et al. 2015). Whilst the positives for cricket are that it has tried to counter some of the issues by pursuing aggressive strategies that have developed modified versions of their own game (such as T20), there is also a real danger of overkill in relation to adding more and more variants of essentially the same sport. There is little doubt that innovation has become necessary in professional team sport given the commercial gains to be made in a global sporting environment. However, the number of different formats offered by cricket could also dilute the product overall, which subsequently makes it difficult for clubs to manage competing cost centres. A further issue in professional cricket is that the international game is the pinnacle and players focus solely on making the English national team, often to the detriment of the county championship clubs.

\section{Conclusions}

This paper has effectively outlined that the county championship clubs are arguably as reliant on the central grant income from the ECB as they were 20 years ago. Whilst the ECB is undoubtedly trying to do the right thing by providing the clubs with this funding, there is a clear financial argument that clubs must become 'self-sufficient' without this income, under the proviso that it may not always be available. As such, the ECB and the counties need to work more closely together and be more strategic in their approach to growing participation, which, in turn, can help support spectator growth and revenue generation. Counties can achieve this by incentivising clubs financially to improve their community schemes and outreach activity, thus engaging actively with the next generation of cricket players and observers. There is the requirement of the league and its governing body to maintain a sustained level of competition amongst its member clubs in line with the theoretical determinants of what makes an attractive sports league considering the 'joint' production nature of professional team sports (see Dobson and Goddard 2011; Hogan et al. 2013; Neale 1964).

Whilst the 'joint' production nature of professional team sports is of prime importance, there is a need for the member clubs individually to support the governing body to achieve its objectives and for them to operate in a more prudent financial manner. Of equal importance, is the need for clubs to be more autonomous with facility use, thus increasing the opportunity for secondary spend and additional revenue. Wilson et al. (2015) stated a similar point in relation to rugby league clubs and the same is true for cricket. Some clubs have made positive strides in respect of utilising their grounds better for other events such as conferences and concerts and this must become the business model of the majority in the future. Indeed the reliance on central grants or subsidy is not unique to English cricket and is replicated, in some way in other sports. English Football League Clubs receive a solidarity payment for example, stemming from the English Premier League TV deal which supports the solvency of its member clubs. These payments however, come from their 'mother' league rather than the governing body. Professional sport teams can only earn revenue through three main streams and one of those (in respect of broadcasting revenue) is effectively unearned. As such, the importance of maximising matchday and commercial income (through additional secondary spend activities) is of a paramount importance in county cricket where the broadcasting fees have historically been low in comparison with other sports. A further disconnect in cricket, as evidenced by this paper, is the status held by being Counties holding International Test Matches hosting ground. Clubs often overstretch themselves financially in an attempt to secure Test Match status and we have seen the 
issues that this can cause financially in the case of Durham. Consequently, there is an argument that clubs should not focus on securing Test Match status and instead attempt to generate secondary revenue through engaging more in the local area linked to community and outreach schemes. Despite this view, it should also be recognised that the four day game has a very restricted demographic appeal and exists mainly to provide a production line for the national team rather than a standalone sport in its own right. The national team then reinvests the proceeds of Test matches and one day internationals via the ECB. Clubs, quite rightly, may well see the grants from the ECB as a dividend for the work they put into player development.

This paper has provided a valuable contribution to the literature on the financial health of professional team sports and provides an update to the paper by Shibli and Wilkinson-Riddle in 1997. This paper also contributes to contemporary literature that has documented the issues in professional team sports in the UK in recent years such as football (e.g., Buraimo et al. 2006; Wilson et al. 2013), cricket (e.g., Shibli and Wilkinson-Riddle 1997), rugby union (e.g., Hogan et al. 2013; O’Brien and Slack 1999, 2003; Wilson and Plumley 2017) and rugby league (Wilson et al. 2015). The findings of this paper, in respect of poor financial health (by commercial standards) and the influence of governing body intervention are consistent with the findings of these authors.

The paper indicates that there remains a problem with the attractiveness of the county championship which is a product of questionable financial value at club level and reluctance by the ECB to force the clubs to become self-sustainable. The study focused on in-depth financial analysis of all county championship clubs and, unfortunately, the indicators outlined paint an austere picture. For example, in general terms, revenues are not high enough to generate sufficient growth within the game. Coupled with this is the fact that attendances, across all clubs, are stagnating in general terms. Furthermore, this reduced attendance does not encourage growth in revenue and therefore limits financial health, given that attendance figures are the main source of income generation for the majority of clubs.

In summary, with reference to cricket, the paper concludes that the county championship has not developed significantly, in business terms, since 1997. It would, however, be unfair to suggest that issues with financial performance are exclusive to county championship clubs and comparisons with other professional team sports will be evident. Indeed, other leagues do experience similar problems. Yet such comparisons to sports such as football are perhaps less relevant given that attendance figures and participation levels in that sport are the highest they have ever been. Additionally, the money associated with professional football in line with broadcasting deals and club income streams is a level far above county championship clubs at the present time. The results in this paper demonstrate that despite twenty years of history and a number of structural changes, in general terms, the clubs competing in the county championship are failing to generate profits, expand the supporter base or grow commercial revenues with a better national and international profile. The ECB and the clubs need to work closer together and the ECB should in actual fact be attempting to make the clubs self-sustainable rather than propping them up financially year-on-year.

Author Contributions: Conceptualization, R.W. and S.S.; methodology, D.P. and R.M.; software, R.M.; validation, D.P. and R.M.; formal analysis, D.P. and R.M.; investigation, D.P. and R.M.; resources, D.P. and R.M.; data curation, D.P. and R.M.; writing —original draft preparation, D.P. and R.M.; writing —review and editing, R.W. and S.S.; visualization, R.W. and S.S.; supervision, S.S.; project administration, D.P.; funding acquisition, N/A.

Funding: Please add: This research received no external funding.

Conflicts of Interest: The authors declare no conflict of interest.

\section{References}

Ammon, Elizabeth. 2017. Available online: http://www.espn.co.uk/cricket/story/_/id/19064584/elizabethammonstate-english-county-cricket (accessed on 21 December 2018).

Andreff, Wladimir, and Paul D. Staudohar. 2000. The Evolving Model of Professional Sports Finance. Journal of Sports Economics 1: 257-76. [CrossRef] 
Andreff, Wladimir. 2007. French Football: A Financial Crisis Rooted in Weak Governance. Journal of Sports Economics 8: 652-61. [CrossRef]

Barlev, Benzion, and Joshua Rene Haddad. 2003. Fair value accounting and the management of the firm. Critical Perspectives on Accounting 14: 383-415. [CrossRef]

Barros, Carlos Pestana. 2006. Portuguese Football. Journal of Sports Economics 7: 96-104. [CrossRef]

BBC. 2018. Available online: http://www.bbc.co.uk/sport/cricket/43211323 (accessed on 21 December 2018).

Bevis, Herman W. 1965. Corporate Financial Reporting in a Competitive Economy. New York: Macmillan.

Boland, Richard J. 1989. Beyond the objectivist and the subjectivist: Learning to read accounting as text. Accounting, Organizations and Society 14: 591-604. [CrossRef]

Booth, Peter, and Neil Cocks. 1989. Critical research issues in accounting standard setting. Journal of Business Finance and Accounting 17: 511-28. [CrossRef]

Bromwich, Michael. 2007. Fair values: Imaginary prices and mystical markets-A clarificatory review. In The Routledge Companion to Fair Value and Financial Reporting. Edited by Peter Walton. Oxon: Routledge, pp. 46-67.

Buraimo, Babatunde, Bernd Frick, Michael Hickfang, and Rob Simmons. 2015. The economics of long-term contracts in the footballers' labour market. Scottish Journal of Political Economy 62: 8-24. [CrossRef]

Buraimo, Babatunde, Rob Simmons, and Stefan Szymanski. 2006. English Football. Journal of Sports Economics 7: 29-46. [CrossRef]

Burrell, Gibson. 1987. No accounting for sexuality. Accounting, Organizations and Society 12: 89-102. [CrossRef]

Chadwick, Simon. 2009. From outside lane to inside track: sport management research in the twenty-first century. Management Decision 47: 191-203. [CrossRef]

Dietl, Helmut M., and Egon Franck. 2007. Governance Failure and Financial Crisis in German Football. Journal of Sports Economics 8: 662-69. [CrossRef]

Dobson, Stephen, and John A. Goddard. 2011. The Economics of Football, 2nd ed. Cambridge: University Press.

Durham CCC. 2015. Annual Report and Accounts. Durham: Durham CCC.

Feng, Cheng-Min, and Rong-Tsu Wang. 2000. Performance evaluation for airlines including the consideration of financial ratios. Journal of Air Transport Management 6: 133-42. [CrossRef]

Fort, Rodney. 2015. Managerial objectives: A retrospective on utility maximization in pro team sports. Scottish Journal of Political Economy 62: 75-89. [CrossRef]

Garcia-del-Barrio, Pedro, and Stefan Szymanski. 2009. Goal! Profit maximisation versus win maximisation in soccer. Review of Industrial Organisation 34: 45-68. [CrossRef]

Georgiou, Omiros, and Lisa Jack. 2011. In pursuit of legitimacy: A history behind fair value accounting. The British Accounting Review 43: 311-23. [CrossRef]

Gupta, Amit. 2004. The globalization of cricket: The rise of the non-West. The International Journal of the History of Sport 21: 257-76. [CrossRef]

Hines, Ruth D. 1991. The FASB's conceptual framework, financial accounting and the maintenance of the social world. Accounting, Organizations and Society 16: 313-31. [CrossRef]

Hitz, Joerg-Markus. 2007. The decision usefulness of fair value accounting-A theoretical perspective. European Accounting Review 16: 323-62. [CrossRef]

Hoehn, Thomas, and Stefan Szymanski. 1999. The Americanization of European Football. Economic Policy 28: 205-40. [CrossRef]

Hogan, Vincent, Patrick Massey, and Shane Massey. 2013. Competitive balance and match attendance in European rugby union leagues. The Economic and Social Review 44: 425-46.

Hopwood, Anthony G. 1990. Accounting and organization change. Accounting, Auditing and Accountability Journal 3: 7-17. [CrossRef]

International GAAP. 2005. Generally Accepted Accounting Practices under International Financial Reporting Standards. London: LexisNexis.

Kesenne, Stefan. 2000. Revenue Sharing and Competitive Balance in Professional Team Sports. Journal of Sports Economics 1: 56-65. [CrossRef]

Kesenne, Stefan. 2015. Revenue sharing and absolute league quality: Talent investment and talent allocation. Scottish Journal of Political Economy 62: 51-58. [CrossRef]

Laux, Christian, and Christian Leuz. 2009. The crisis of fair value accounting: Making sense of the recent debate. Accounting, Organizations and Society 34: 826-34. [CrossRef] 
Leach, Stephanie, and Stefan Szymanski. 2015. Making money out of football. Scottish Journal of Political Economy 62: 25-50. [CrossRef]

Miller, Peter, and Ted O'Leary. 1987. Accounting and the construction of the governable person. Accounting, Organizations and Society 12: 235-66. [CrossRef]

Neale, Walter C. 1964. The peculiar economics of professional sports. Quarterly Journal of Economics 78: 1-14. [CrossRef]

O'Brien, Danny, and Trevor Slack. 1999. Deinstitutionalising the amateur ethic: An empirical examination of change in a rugby union football club. Sport Management Review 2: 24-42. [CrossRef]

O'Brien, Danny, and Trevor Slack. 2003. An analysis of change in an organizational field: The professionalization of English rugby union. Journal of Sport Management 17: 417-48. [CrossRef]

Plumley, Daniel, Robert Wilson, and Simon Shibli. 2017. A holistic performance analysis of English professional football clubs 1992-2013. Journal of Applied Sport Management 9: 1-29. [CrossRef]

Ponikvar, Nina, Maks Tajnikar, and Ksenja Pušnik. 2009. Performance ratios for managerial decision-making in a growing firm. Journal of Business Economics and Management 10: 109-20. [CrossRef]

Pritchard, Adrian. 2016. It's not just cricket-The portfolios of the English/Welsh cricket teams. Sport, Business and Management: An International Journal 6: 19-35. [CrossRef]

Richardson, Alan J. 1987. Accounting as a legitimating institution. Accounting, Organizations and Society 12: 341-56. [CrossRef]

Saikia, Hemanta, Dibyojyoti Bhattacharjee, and Atanu Bhattacharjee. 2013. Performance based market valuation of cricketers in IPL. Sport, Business and Management: An International Journal 3: 127-46. [CrossRef]

Shibli, S., and G. J. Wilkinson-Riddle. 1997. The financial health of English Cricket-An analysis based upon the 1995 annual reports and financial statements of the 18 first class counties. Journal of Applied Accounting Research 4: 4-37.

Sloane, Peter J. 1971. The Economics of Professional Football: The Football Club as a Utility Maximiser. Scottish Journal of Political Economy 17: 121-46. [CrossRef]

Sloane, Peter J. 2006. Rottenberg and the economics of sports after 50 years. In Sports Economics after 50 Years. Edited by Placido Rodriguez, Stefan Kesenne and Jaume Garcia. Essays in Honour of Simon Rottenberg. Spain: University of Oviedo, pp. 211-26.

Sloane, Peter J. 2015. The economics of professional football revisited. Scottish Journal of Political Economy 62: 1-7. [CrossRef]

Sueyoshi, Toshiyuki. 2005. Financial Ratio Analysis of the electric power industry. Asia-Pacific Journal of Operational Research 22: 349-76. [CrossRef]

Sunder, Shyam. 2016. Better financial reporting: meanings and means. Journal of Accounting and Public Policy 35: 211-23. [CrossRef]

Surrey CCC. 2018. Annual Report and Accounts. Surrey: Surrey CCC.

Szymanski, Stefan, and Andrew S. Zimbalist. 2005. National Pastime: How Americans Play Baseball and the Rest of the World Plays Soccer. Washington: Brookings Institution Press.

Szymanski, Stefan, and Tim Kuypers. 1999. Winners and Losers: The Business Strategy of Football. London: Viking Books.

Szymanski, Stefan. 2003. The Economic Design of Sporting Contests. Journal of Economic Literature 41: 1137-87. [CrossRef]

The ECB. 2018. Available online: https:/ /www.ecb.co.uk/news/623583/where-will-major-matches-be-playedfrom-2020 (accessed on 21 December 2018).

The Guardian. 2017a. Available online: https://www.theguardian.com/sport/2017/feb/20/ipl-auction-benstokes-sets-record-tymal-mills-indian-premier-league (accessed on 21 December 2018).

The Guardian. 2017b. Available online: https://www.theguardian.com/sport/2017/jun/30/live-cricket-returnbbc-twenty20-tournament (accessed on 21 December 2018).

The Independent. 2017. Available online: https://www.independent.co.uk/sport/cricket/t20-twenty20-newtournament-natwest-blast-love-it-hate-domestic-game-back-from-brink-a8291796.html (accessed on 21 December 2018).

The Telegraph. 2018. Available online: https://www.telegraph.co.uk/cricket/2017/06/30/game-changing-tvdeal-sky-bbc-will-broaden-crickets-appeal-says / (accessed on 21 December 2018). 
Tinker, Tony. 1988. Panglossian accounting theories: The science of apologising in style. Accounting, Organizations and Society 13: 165-90. [CrossRef]

Vrooman, John. 2015. Sportsman leagues. Scottish Journal of Political Economy 62: 90-115. [CrossRef]

Williams, Peter. 2012. Any given Saturday: Competitive balance in elite English rugby union. Managing Leisure 17: 88-106. [CrossRef]

Willmott, Hugh. 1986. Organising the profession: A theoretical and historical examination of the development of the major accounting bodies in the UK. Accounting, Organizations and Society 11: 555-82. [CrossRef]

Wilson, Rob, and Daniel Plumley. 2017. Different shaped ball, same financial problems? A holistic performance assessment of English Rugby Union (2006-2015). Sport, Business and Management: An International Journal 7: 141-56. [CrossRef]

Wilson, Rob, Daniel Plumley, and David Barrett. 2015. Staring into the abyss? The state of UK rugby's Super League. Managing Sport and Leisure 20: 293-310. [CrossRef]

Wilson, Robert, Daniel Plumley, and Girish Ramchandani. 2013. The relationship between ownership structure and club performance in the English Premier League. Sport, Business and Management: An International Journal 3: 19-36. [CrossRef]

Wright, April L., and Raymond F. Zammuto. 2013. Creating opportunities for institutional entrepreneurship: The Colonel and the Cup in English County Cricket. Journal of Business Venturing 28: 51-68. [CrossRef]

(C) 2019 by the authors. Licensee MDPI, Basel, Switzerland. This article is an open access article distributed under the terms and conditions of the Creative Commons Attribution (CC BY) license (http:/ / creativecommons.org/licenses/by/4.0/). 


\title{
Article \\ Performance Bonuses and Effort: Evidence from Fight Night Awards in Mixed Martial Arts
}

\author{
Paul Gift \\ Pepperdine Graziadio Business School, Los Angeles, CA 90045, USA; paul.gift@pepperdine.edu \\ Received: 12 January 2019; Accepted: 10 February 2019; Published: 20 February 2019
}

\begin{abstract}
This paper investigates the role of fight night bonus awards on fighter behavior in the Ultimate Fighting Championship (UFC) and World Extreme Cage (WEC) fighting mixed martial arts (MMA) promotions. Behavior is analyzed using detailed fighter performance statistics, exploiting variation in bonus size across events and over time. Findings suggest that fighters are not meaningfully influenced by bonus levels within the range observed in the sample period and possible explanations are discussed. Fight night bonuses appear to serve as a lottery compensation mechanism to ex post reward performances consistent with an MMA promotion's desires rather than ex ante incentivize such performances. Findings have implications for strategic MMA promoter decisions and contribute more broadly to the personnel economics literature on incentives and compensation.
\end{abstract}

Keywords: bonuses; effort; fighter performance; mixed martial arts (MMA); Ultimate Fighting Championship (UFC); World Extreme Cagefighting (WEC); Zuffa LLC

JEL Classification: J33; M52; Z22

\section{Introduction}

A tournament occurs when economic agents compete for rewards on the basis of relative rank. The non-linear compensation structure of tournament rewards is designed to induce optimal effort levels and tournament theory predicts that more effort will be put into production when there is a large difference between winning and losing payouts (Lazear and Oyer 2012). Sports contests can be an ideal laboratory to test aspects of tournament theory, such as the incentive effects of bonuses or various compensation structures, as athlete performance is typically rigorously tracked, monetary incentives well documented, and the goal of production (winning, scoring, defending, etc.) is also generally well defined.

Much of the existing sports economics literature on monetary incentives and performance comes from less frequently examined sports. Ehrenberg and Bognanno (1990a, 1990b) analyze performance and prize money data from the PGA tour and find that larger total money prizes and marginal returns to effort in the final round each lead to lower golfer scores. Becker and Huselid (1992) examine two car-racing panels (NASCAR and IMSA) and find that larger tournament spreads have a positive impact on performance, and drivers undertake more risky behavior as the spread increases. In foot racing, Maloney and McCormick (2000) find that larger average prize sizes and prize spreads lead to lower race times. Lynch and Zax (2000) also study foot racing and appear to find evidence supporting the incentive effects of larger prize spreads. However, once controls for runner ability are included, most of their significant effects disappear. They argue that race times appeared faster with larger prizes because they attracted faster runners.

In mixed martial arts (MMA), much of the literature has examined the determinants of pay-per-view (PPV) demand or event attendance (Tainsky et al. 2012; Watanabe 2012; Tainsky et al. 2013; Watanabe 2015; Reams and Shapiro 2017), while Collier et al. (2012) and Gift (2018) analyzed MMA 
judges with Gift finding that judges tend to show favoritism towards larger betting favorites, those with insurmountable leads, and the fighter who won the previous round. Finally, in boxing, where fighter compensation is contracted in advance and performance and win bonuses are not utilized, Tenorio (2000) found suggestive evidence, through examination of successful title defenses, to argue for a moral hazard in effort exertion.

The present paper examines the incentive effects of fight night bonus awards in MMA. The sport of MMA is an intriguing non-experimental laboratory to examine bonus incentives because fighter performance statistics are meticulously and rigorously tracked by a statistical agency, FightMetric LLC, and fight night bonuses can be substantial, often 300 percent or more of a fighter's guaranteed show money compensation. During the sample period of the present study, bonuses were typically awarded following the conclusion of each event for Fight of the Night (FOTN), Knockout of the Night (KOTN), and Submission of the Night (SOTN). FOTN was awarded to "each of the fighters in the best fight of the night" (Ultimate Fighting Championship (UFC) 2014). Precise definitions of KOTN and SOTN were not made explicit but presumably were awarded to the fighters with the best knockout/technical knockout (KO/TKO) and submission finishes of the night, respectively. ${ }^{1}$

MMA bonuses essentially define a tournament-within-a-tournament compensation structure. Competition within an MMA promotion over time can be considered one long, continuous rank-order tournament. The current "winner" is the champion of each weight class and there is a constant stream of challengers. Consistent with tournament theory, there is a large disparity in the pay of highly-ranked fighters relative to their low-ranked counterparts. Champions and top-tier fighters can earn hundreds of thousands or even millions of dollars per fight while newly-signed fighters earned as little as \$2000 to show and $\$ 2000$ to win as recently as 2006 , increasing to $\$ 8000$ to show/win by the end of the sample period.

Within the continuous tournament for rankings and champion status in each weight class is a separate tournament that takes place within each event-a tournament for bonus awards. Thus, there can be conflicting incentives between exerting effort towards winning the fight and exerting effort towards obtaining a bonus, possibly to the detriment of winning.

In the remainder of the paper, I examine the effect of changes in monetary rewards on observable performance outcomes such as fight finishes, action, and positioning. I find no evidence that fighters are meaningfully influenced by bonus levels within the observed range and argue this is likely due to auxiliary incentives such as the non-linear compensation structure as fighters progress up the rankings, the potential effect of win bonuses, and the critical importance of winning for maintaining a roster spot in elite MMA.

\section{MMA/UFC Background}

Television critic Howard Rosenberg is credited with the first documented use of the term "mixed martial arts" (U.S. House of Representatives Committee on Energy and Commerce 2017) after UFC 1 matched a variety of martial arts styles against each other in a no-holds-barred competition. ${ }^{2}$ MMA has since become a legalized ${ }^{3}$ and regulated combat sport involving striking and grappling in standing positions or on the ground. MMA bouts may be held in either a ring or cage enclosure, but all bouts in the present study took place in an octagon-shaped cage.

In early 2001, Zuffa LLC purchased the UFC and soon grew into the largest MMA promotion and live PPV event provider in the world (UFC 2019). In December 2006, Zuffa purchased rival promoter World Extreme Cage (WEC) fighting and quickly transitioned the new acquisition to lighter weight divisions. Zuffa did not use the WEC as a feeder to the UFC, but rather an extension of the UFC into

1 FightMetric does not separately record whether a fight ended by knockout (KO) or technical knockout (TKO), so they will collectively be referred to as $\mathrm{KO} / \mathrm{TKO}$ for the remainder of the paper.

2 There were only two fouls at UFC 1: Eye gouging and biting. By 2017, there were 26 fouls under the Unified Rules of MMA. In the U.S., MMA is now legal in all 50 states following New York's legalization of the sport in 2016 (Bieler 2016). 
the lower weight classes. Eighty percent of Zuffa's bouts with the WEC took place in the lightweight, featherweight, and bantamweight divisions. The dataset for this paper encompasses UFC and WEC events during the times they were owned by Zuffa and operated using the Unified Rules of MMA.

Bonuses were not part of the fighter pay structure in the early days of the UFC and Zuffa's ownership. Fighters received their contracted show money (and win money should they be victorious) as well as possible side-letter payments, PPV points, and any discretionary "locker room" bonuses the promotion decided to pay the fighter.

The first fight night bonus award was given at UFC Fight Night 3 on 16 January 2006. Throughout that year, most, but not all, events included fight night bonuses. Since UFC 66 on 30 December 2006, every UFC event has included such performance bonuses. The amount of the awards varied over time until March 2013 when the UFC standardized its bonuses at \$50,000 for all future events (MMA Junkie Staff 2013). ${ }^{4}$ The WEC offered performance bonuses for every event in the sample from January 2007 through December 2010. Its bonuses were typically smaller than those of the UFC. In December 2010, the WEC was shuttered and its fighters were absorbed into the UFC and its higher bonus structure.

Two long-time UFC fighters confirmed in private interviews that bonus amounts were communicated to all fighters during the pre-fight meeting on the day of weigh-ins. ${ }^{5}$ Thus, it appears fighters are ex ante aware of the monetary prize they will receive should they win a fight night award.

Following UFC 169 in February 2014, the UFC substituted two Performance of the Night (POTN) bonuses for KOTN and SOTN, partially to provide more flexibility in rewarding top fight finishes. If an event had no submissions, SOTN could not be awarded (likewise for KOTN), but there may have been two deserving $\mathrm{KO} / \mathrm{TKO}$ finishes. POTN provides a more flexible mechanism to reward desired fight finishes no matter the type: $\mathrm{KO} / \mathrm{TKO}$ or submission. However, from a research perspective it may influence the incentive mechanism examined in this paper. Thus, the sample period of the present study ends at UFC 169 on 1 February 2014, the final UFC event with KOTN and SOTN awards.

\section{Data}

The dataset for the present study encompasses the Zuffa-owned and operated UFC and WEC promotions from 4 May 2001-when the Unified Rules of MMA were first implemented in the UFC-through 1 February 2014. Data on fight night bonuses were collected using publicly-available reports from major MMA media outlets such as MMA Fighting and MMA Junkie.

\subsection{FightMetric LLC}

Fighter performance statistics were obtained from FightMetric for all UFC and WEC events promoted under the Zuffa banner from UFC 31 on 4 May 2001 through UFC 169 on 1 February $2014 .^{6}$ For each bout, FightMetric tracks over 100 fighter performance statistics covering striking, knockdowns, takedowns, grappling, submissions, and time spent in different positions. The statistics are documented and verified using frame-by-frame analysis of the bout video, if need be (Genauer 2013).

For the purposes of the present study, FightMetric does not distinguish between punches, kicks, knees, and elbows. They are all classified as "strikes" with their type being "jab" or "power." A jab is a non-power strike and FightMetric uses physical cues to determine if a strike has power or not. Submissions include chokes, where blood is cut off to the brain or breathing impaired, and joint locks, where pressure is applied to large joints such as elbows, shoulders, wrists, ankles, or knees in a manner in which they are not intended to bend. FightMetric also tracks the amount of time each fighter spends

4 There were four exceptions to the UFC's standardized bonus policy through the end of the sample period in February 2014 resulting in bonuses of $\$ 60,000$ (twice), $\$ 65,000$, and $\$ 75,000$. In one case, a fighter reportedly convinced UFC President Dana White to increase the bonus to $\$ 65,000$ during the pre-fight meeting, which suggests fighters are cognizant of bonus sizes leading up to an event (Marrocco 2013).

5 Weigh-ins took place one day prior to each event.

6 FightMetric is the official statistics provider of the UFC. 
at distance, in the clinch, and on the ground. ${ }^{7}$ Table 1 contains complete descriptions of the variables employed in the present study.

Table 1. Variable descriptions.

\begin{tabular}{|c|c|}
\hline Variable Label & Description \\
\hline \multicolumn{2}{|l|}{ Dependent } \\
\hline FINISH & $\begin{array}{l}\text { Indicator variable equal to one if a fighter won by } \mathrm{KO} / \mathrm{TKO} \text { or submission, } \\
\text { and zero otherwise. }\end{array}$ \\
\hline KOTKO & $\begin{array}{l}\text { Indicator variable equal to one if a fighter won by } \mathrm{KO} / \mathrm{TKO} \text {, and zero } \\
\text { otherwise. }\end{array}$ \\
\hline SUBMISSION & $\begin{array}{l}\text { Indicator variable equal to one if a fighter won by submission, and zero } \\
\text { otherwise. }\end{array}$ \\
\hline STRIKERATE & Total strikes attempted per five minutes. \\
\hline PSTRIKERATE & $\begin{array}{l}\text { Total power strikes attempted per five minutes. FightMetric uses various } \\
\text { cues such as whether a strike is a kick, knee, elbow, or punch, how the strike } \\
\text { is thrown, the effect on the opponent, etc. to determine if a strike has power. }\end{array}$ \\
\hline DISTANCEPCT & $\begin{array}{l}\text { Percent of total fight time a fighter is standing and not touching the } \\
\text { opponent ( } 0-100 \text { scale). }\end{array}$ \\
\hline GROUNDPCT & Percent of total fight time a fighter is on the ground ( $0-100$ scale). \\
\hline \multicolumn{2}{|l|}{ Independent } \\
\hline BONUS & $\begin{array}{l}\text { Monetary amount of any FOTN, KOTN, or SOTN awards for each event } \\
\text { (in thousands). }\end{array}$ \\
\hline REALBONUS & Inflation-adjusted BONUS using the Consumer Price Index. \\
\hline AGE & Age (in years). \\
\hline HEIGHT & Height (in inches). \\
\hline $\mathrm{REACH}$ & Reach (in inches). \\
\hline LEFTVSRIGHT & $\begin{array}{l}\text { Indicator variable equal to one if a fighter is left-handed (i.e., a southpaw) } \\
\text { fighting against a right-handed opponent, and zero otherwise. }\end{array}$ \\
\hline EXPER & The number of Zuffa bouts a fighter has in the FightMetric database. \\
\hline SNPROB & Standard normalization win probability of Sauer (2005). \\
\hline MAINEVENT & $\begin{array}{l}\text { Indicator variable equal to one if the bout headlined the event, } \\
\text { and zero otherwise. }\end{array}$ \\
\hline 5ROUNDS & $\begin{array}{l}\text { Indicator variable equal to one if the bout was scheduled for five rounds, } \\
\text { and zero otherwise. }\end{array}$ \\
\hline TITLE & $\begin{array}{l}\text { Indicator variable equal to one if the bout was a title fight, } \\
\text { and zero otherwise. }\end{array}$ \\
\hline PPV & $\begin{array}{l}\text { Indicator variable equal to one if the bout took place on a PPV event, and } \\
\text { zero otherwise. }\end{array}$ \\
\hline КОТКОРСТ & A fighter's prior percentage of wins by KO/TKO. \\
\hline SUBPCT & A fighter's prior percentage of wins by submission. \\
\hline WEIGHT & Weight class. Used for fixed effects. \\
\hline
\end{tabular}

7 Fighters are "at distance" when they are standing but separated, "in the clinch" when they are standing and touching each other, and "on the ground" when at least one of them is not standing. 


\subsection{Descriptive Statistics}

Descriptive statistics for the events, bouts, and bonus awards included in the sample are presented in Table 2. The full dataset includes over 250 events and more than 2500 bouts. When events contained bonus awards, the vast majority of the time one award of each type was allocated at the end of the night (93 percent for FOTN, 92 percent for KOTN, and 87 percent for SOTN). In the rare situations where no KOTN or SOTN was awarded, the event usually did not experience any qualifying KO/TKOs or submissions.

Table 2. Event size and award statistics by promotion.

\begin{tabular}{|c|c|c|c|c|c|c|}
\hline & \multicolumn{2}{|c|}{ UFC } & \multicolumn{2}{|c|}{ WEC } & \multicolumn{2}{|c|}{ Total } \\
\hline \multicolumn{7}{|l|}{ All Events } \\
\hline Events & \multicolumn{2}{|c|}{227} & \multicolumn{2}{|c|}{29} & \multicolumn{2}{|c|}{256} \\
\hline Bouts & \multicolumn{2}{|c|}{2315} & \multicolumn{2}{|c|}{274} & \multicolumn{2}{|c|}{2589} \\
\hline Fighter-Bouts & \multicolumn{2}{|c|}{4630} & \multicolumn{2}{|c|}{548} & \multicolumn{2}{|c|}{5178} \\
\hline \multicolumn{7}{|c|}{ Events with Bonus Awards } \\
\hline Events & \multicolumn{2}{|c|}{192} & \multicolumn{2}{|c|}{29} & \multicolumn{2}{|c|}{221} \\
\hline Bouts & \multicolumn{2}{|c|}{2035} & \multicolumn{2}{|c|}{274} & \multicolumn{2}{|c|}{2309} \\
\hline Fighter-Bouts & \multicolumn{2}{|c|}{4070} & \multicolumn{2}{|c|}{548} & \multicolumn{2}{|c|}{4618} \\
\hline \multicolumn{7}{|c|}{ FOTN Awards per Event with Bonus } \\
\hline Zero & 3 & $2 \%$ & 1 & $3 \%$ & 4 & $2 \%$ \\
\hline One & 180 & $94 \%$ & 25 & $86 \%$ & 205 & $93 \%$ \\
\hline Two & 8 & $4 \%$ & 3 & $10 \%$ & 11 & $5 \%$ \\
\hline Three & $\underline{1}$ & $\underline{1 \%}$ & $\underline{0}$ & $\underline{0 \%}$ & $\underline{1}$ & $\underline{0 \%}$ \\
\hline Total & 192 & $100 \%$ & 29 & $100 \%$ & 221 & $100 \%$ \\
\hline \multicolumn{7}{|c|}{ KOTN Awards per Event with Bonus } \\
\hline Zero & 8 & $4 \%$ & 1 & $3 \%$ & 9 & $4 \%$ \\
\hline One & 176 & $92 \%$ & 28 & $97 \%$ & 204 & $92 \%$ \\
\hline Two & 7 & $4 \%$ & 0 & $0 \%$ & 7 & $3 \%$ \\
\hline Three & $\underline{1}$ & $\underline{1 \%}$ & $\underline{0}$ & $\underline{0 \%}$ & $\underline{1}$ & $\underline{0 \%}$ \\
\hline Total & 192 & $100 \%$ & 29 & $100 \%$ & 221 & $100 \%$ \\
\hline \multicolumn{7}{|c|}{ SOTN Awards per Event with Bonus } \\
\hline Zero & 19 & $10 \%$ & 2 & $7 \%$ & 21 & $10 \%$ \\
\hline One & 166 & $86 \%$ & 27 & $93 \%$ & 193 & $87 \%$ \\
\hline Two & $\underline{7}$ & $\underline{4 \%}$ & $\underline{0}$ & $\underline{0 \%}$ & $\underline{7}$ & $3 \%$ \\
\hline Total & 192 & $100 \%$ & 29 & $100 \%$ & 221 & $100 \%$ \\
\hline
\end{tabular}

Note: For all Zuffa-owned Ultimate Fighting Championship (UFC) and World Extreme Cage (WEC) bouts from 4 May 2001 through 1 February 2014

The first 35 UFC events in the dataset did not have bonus awards. In total, 192 UFC events had bonus awards ranging in value from $\$ 25,000$ to $\$ 129,000$. For the WEC, all 29 events had bonus awards ranging in value from $\$ 7500$ to $\$ 10,000$, with one exception. ${ }^{8}$ Figure 1 presents the time trend of bonus awards showing their variation event-by-event and over time, as well as the more recent period with bonuses standardized at $\$ 50,000$.

8 The promotion's sole PPV event, WEC 48, had bonus awards of $\$ 65,000$. 


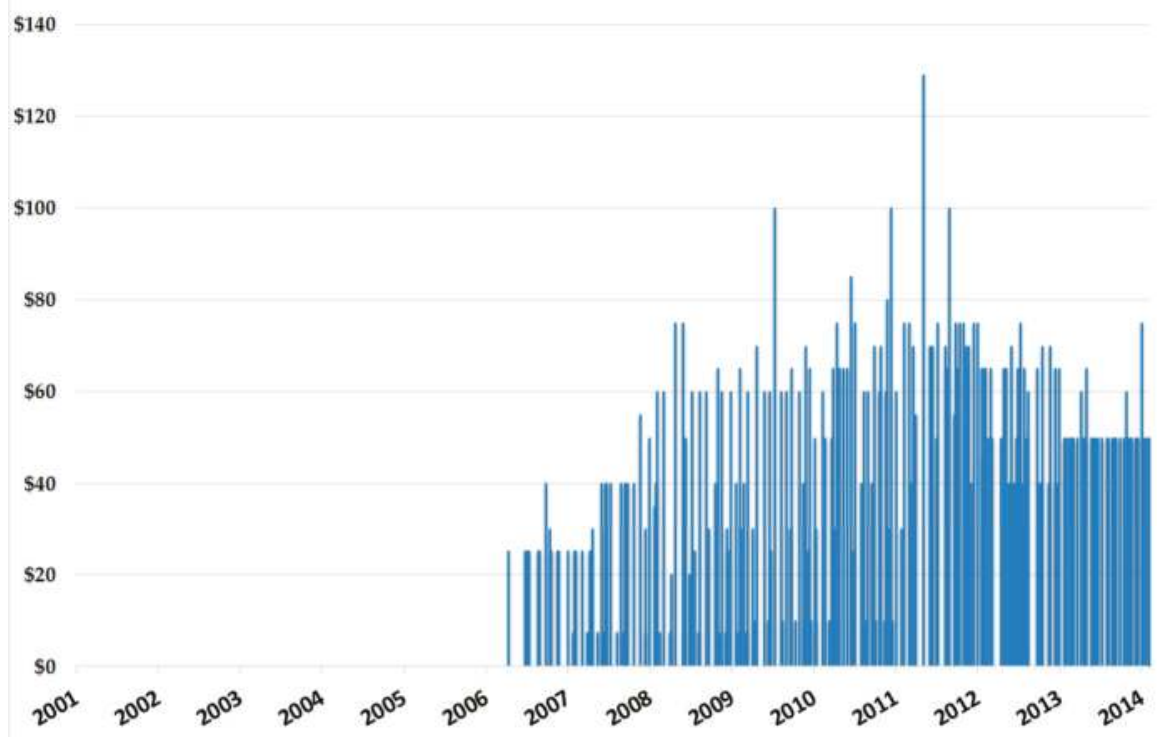

Figure 1. Fight night bonuses over time. Note: For all Zuffa-owned UFC and WEC bouts from 4 May 2001 through 1 February 2014. Data in thousands.

Table 3 presents summary statistics of the variables used in the analysis. The top panel contains potential performance variables of interest relating to fight finishes (FINISH, KOTKO, and SUBMISSION), action (STRIKERATE and PSTRIKERATE), and fight positioning (DISTANCEPCT and GROUNDPCT). The bottom panel contains bonuses and controls for fighter characteristics tracked by FightMetric (AGE, HEIGHT, REACH, and LEFTVSRIGHT), experience, and win probability; bout characteristics that may explain differences in performance variables such as whether the bout was a main event, title, or five-round fight; and an event characteristic for whether the event was on PPV. When regression analyses are performed, AGE, HEIGHT, REACH, LEFTVSRIGHT, and EXPER are the difference in values between the fighter in question and the opponent.

Table 3. Summary statistics.

\begin{tabular}{lccccc}
\hline Variables & Mean & S.D. & N & Min & Max \\
\hline Dependent & & & & & \\
FINISH & 0.29 & 0.45 & 5178 & 0 & 1 \\
KOTKO & 0.17 & 0.38 & 5178 & 0 & 1 \\
SUBMISSION & 0.11 & 0.32 & 5178 & 0 & 1 \\
STRIKERATE & 44.92 & 22.07 & 5178 & 0.0 & 416.7 \\
PSTRIKERATE & 22.01 & 13.52 & 5178 & 0.0 & 416.7 \\
DISTANCEPCT & 45.84 & 27.69 & 5178 & 1.0 & 100.0 \\
GROUNDPCT & 37.90 & 26.94 & 5178 & 0.0 & 97.2 \\
\hline
\end{tabular}


Table 3. Cont.

\begin{tabular}{lccccc}
\hline Variables & Mean & S.D. & N & Min & Max \\
\hline Independent & & & & & \\
BONUS & 42.35 & 25.20 & 5178 & 0 & 129 \\
REALBONUS & 45.09 & 26.58 & 5178 & 0 & 136 \\
AGE & 29.17 & 3.99 & 5120 & 18.5 & 47.9 \\
HEIGHT & 70.80 & 3.16 & 5174 & 61.0 & 83.0 \\
REACH & 72.71 & 3.65 & 4443 & 62.0 & 84.5 \\
LEFTVSRIGHT & 0.15 & 0.36 & 5062 & 0 & 1 \\
EXPER & 5.39 & 4.45 & 5178 & 1 & 24 \\
SNPROB & 50.00 & 18.88 & 4912 & 7.0 & 93.0 \\
MAINEVENT & 0.10 & 0.30 & 5178 & 0 & 1 \\
5ROUNDS & 0.08 & 0.27 & 5178 & 0 & 1 \\
TITLE & 0.07 & 0.25 & 5178 & 0 & 1 \\
PPV & 0.51 & 0.50 & 5178 & 0 & 1 \\
KOTKOPCT & 0.32 & 0.35 & 4161 & 0 & 1 \\
SUBPCT & 0.23 & 0.32 & 4161 & 0 & 1 \\
\hline
\end{tabular}

Note: For all Zuffa-owned UFC and WEC bouts from 4 May 2001 through 1 February 2014. Bout-level observations for each fighter. STRIKERATE, PSTRIKERATE, DISTANCEPCT, and GROUNDPCT means are weighted by total time. REALBONUS is the inflation-adjusted BONUS using the Consumer Price Index (CPI).

\section{Model}

The identification strategy in this paper exploits the variation of fight night bonus awards over time and across events. Two models were employed to explain fighter performance outcomes $(Y)$. The first directly examines the role of inflation-adjusted bonuses, REALBONUS, and is specified as:

$$
\begin{aligned}
Y_{f b w t}= & \beta_{0}+\gamma_{t}+\gamma_{w}+\beta_{1} \cdot R E A L B O N U S_{b w w}+\beta_{2} \cdot A G E_{f b w t}+\beta_{3} \cdot \text { HEIGHT }_{f b w t} \\
& +\beta_{4} \cdot \text { REACH } \\
& +\beta_{7 b w t} \cdot \beta_{5} \cdot \beta_{5} \cdot \text { LEFTVSRIGH }_{f b w t}+\beta_{8} \cdot \text { MAINEVENT }_{b w w t}+\beta_{9} \cdot 5 \text { ROUNDS } \\
& +\beta_{10} \cdot \text { TITLE }_{b w t}+\beta_{11} \cdot \text { PPV }_{b w t}+\varepsilon_{f b w t}
\end{aligned}
$$

where $f b w t$ denotes fighter $f$ in bout $b$ in weight class $w$ in time period $t . \lambda_{t}$ and $\gamma_{w}$ are fixed effects for 14 time periods from 2001 to 2014 and nine weight classes, respectively. The parameter of interest is $\beta_{1}$, the marginal effect of REALBONUS.

The second model includes an interaction term allowing the marginal effect of REALBONUS to vary by pre-fight characteristics KOTKOPCT or SUBPCT. It is specified as:

$$
\begin{gathered}
Y_{f b w t}=\beta_{0}+\gamma_{t}+\gamma_{w}+\beta_{1} \cdot R E A L B O N U S_{b w t}+\beta_{2} \cdot X_{f b w t} \\
+\beta_{3} \cdot R E A L B O N U S_{b w t} \cdot X_{f b w t}+\beta_{4} \cdot A G E_{f b w t}+\beta_{5} \cdot H E I G H T_{f b w t} \\
+\beta_{6} \cdot R E A C H_{f b w t}+\beta_{7} \cdot L E F T V S R I G H T_{f b w t}+\beta_{8} \cdot \text { EXPER }_{f b w t} \\
+\beta_{9} \cdot \text { SNPROB }_{f b w t}+\beta_{10} \cdot M A I N E V E N T_{b w t}+\beta_{11} \cdot 5 R O U N D S_{b w t} \\
+\beta_{12} \cdot \text { TITLE }_{b w t}+\beta_{13} \cdot P P V_{b w t}+\varepsilon_{f b w t}
\end{gathered}
$$

where $X$ is either KOTKOPCT or SUBPCT depending on the performance outcome examined. The equation of interest is the marginal effect of REALBONUS $\left(\beta_{1}+\beta_{3} \cdot X\right)$, which will be examined at the 10th, 25th, 50th, 75th, and 90th percentiles of $X$.

Equations (1) and (2) were estimated using logit and OLS regressions for binary and continuous performance outcomes, respectively. Standard errors were cluster-corrected at the event level as some performance outcome error terms were correlated across fighter-bout observations. For example, if one fighter's FINISH indicator is " 1 ," the opponent's will be " 0 ," leading to a negative correlation of error terms within bouts. 


\section{Empirical Results}

Table 4 presents results for five performance outcomes relating to finishing the fight and action. Results suggest that older fighters earn fewer finishes, due to reduced wins by $\mathrm{KO} / \mathrm{TKO}$, and tend to have lower overall and power striking rates. Fighters with a longer reach and southpaw's fighting orthodox fighters appear to earn more finishes, again through $\mathrm{KO} / \mathrm{TKO}$. More experienced fighters saw an increase in submission finishes while fighters with higher betting odds had significant increases in all performance outcomes. However, changes in REALBONUS did not have a significant impact on fight finishes or striking activity.

Table 4. Effect of fight night bonuses on performance variables of interest.

\begin{tabular}{|c|c|c|c|c|c|c|c|c|c|c|}
\hline \multirow[t]{2}{*}{ Variable } & \multicolumn{2}{|c|}{$\begin{array}{c}\text { (1) } \\
\text { FINISH }\end{array}$} & \multicolumn{2}{|c|}{$\begin{array}{c}(2) \\
\text { КOTKO }\end{array}$} & \multicolumn{2}{|c|}{$\begin{array}{c}\text { (3) } \\
\text { SUBMISSION }\end{array}$} & \multicolumn{2}{|c|}{$\begin{array}{c}\text { (4) } \\
\text { STRIKERATE }\end{array}$} & \multicolumn{2}{|c|}{$\begin{array}{c}(5) \\
\text { PSTRIKERATE }\end{array}$} \\
\hline & Beta & S.E. & Beta & S.E. & Beta & S.E. & Beta & S.E. & Beta & S.E. \\
\hline AGE & $-0.039 * * *$ & 0.010 & $-0.049^{* * *}$ & 0.011 & -0.009 & 0.013 & $-0.196^{* * *}$ & 0.072 & $-0.154^{* * *}$ & 0.039 \\
\hline HEIGHT & -0.011 & 0.023 & -0.038 & 0.025 & 0.030 & 0.031 & $0.481 * *$ & 0.189 & -0.107 & 0.095 \\
\hline $\mathrm{REACH}$ & $0.039 * *$ & 0.018 & $0.032 *$ & 0.018 & 0.035 & 0.024 & 0.202 & 0.138 & 0.008 & 0.073 \\
\hline EXPER & -0.002 & 0.010 & $-0.022 *$ & 0.012 & $0.033 * * *$ & 0.011 & 0.065 & 0.074 & -0.004 & 0.038 \\
\hline SNPROB & $0.028 * * *$ & 0.003 & $0.024 * * *$ & 0.003 & $0.024 * * *$ & 0.003 & $0.139 * * *$ & 0.021 & $0.082 * * *$ & 0.010 \\
\hline MAINEVENT & -0.167 & 0.135 & -0.015 & 0.157 & -0.377 * & 0.225 & 1.207 & 1.790 & 0.710 & 1.168 \\
\hline 5ROUNDS & $0.624 * * *$ & 0.217 & 0.642 ** & 0.275 & 0.166 & 0.514 & -1.164 & 2.952 & -3.160 & 2.106 \\
\hline TITLE & -0.283 & 0.208 & -0.343 & 0.274 & 0.072 & 0.521 & -3.934 & 2.748 & 0.527 & 1.915 \\
\hline PPV & $-0.217^{* * *}$ & 0.074 & -0.092 & 0.108 & $-0.336^{* * *}$ & 0.131 & 1.024 & 0.994 & -0.141 & 0.752 \\
\hline
\end{tabular}

Note: Regressions 1 to 3 utilize a logit model while regressions 4 to 5 utilize OLS and are weighted by total time. AGE, HEIGHT, REACH, LEFTVSRIGHT, and EXPER are the difference in values between the fighter in question and the opponent. All regressions contain year and weight class fixed effects. Standard errors were cluster-corrected at the event level. ${ }^{* * *}, * *$, and ${ }^{*}$ indicate significance at the 1,5 , and 10 percent levels, respectively.

It is possible that certain types of fighters may have different motivations when bonus levels change. Those with a history of knockout finishes may devote more effort towards obtaining a $\mathrm{KO} / \mathrm{TKO}$, throwing heavy strikes, or remaining in the best position to win a KOTN award. Those with a history of submission finishes may devote more effort towards obtaining a submission or being in the best position to win a SOTN award. To that end, the next two figures show the distribution of fight positions from which fighters won KOTN awards relative to all other KO/TKO finishes (Figure 2) and SOTN awards relative to all other submission finishes (Figure 3). Figure 2 supports the notion that $\mathrm{KO} / \mathrm{TKO}$ from the distance position (i.e., the big knockout blow) are more likely to be perceived as higher quality by promotion executives than "ground and pound" finishes on the canvas. If fighters are aware of this, those attempting to win KOTN may be incentivized to try to keep the fight at distance.

Figure 3 suggests that submissions are different. A particular fight position doesn't appear more likely to win SOTN, but the vast majority of submissions (87 percent) took place on the ground. A fighter incentivized to win SOTN will surely take a submission wherever he or she can get it but may apply extra effort to take and keep the fight on the ground knowing most submissions occur from that position.

Table 5 presents results when interactions were included to control for potential differences in fighter types. The first four columns show that fighters with a greater history (i.e., percentage) of $\mathrm{KO} / \mathrm{TKO}$ finishes tended to be more likely to earn a $\mathrm{KO} / \mathrm{TKO}$ finish in their current bout, had higher overall and power striking rates, and tended to spend more fight time at distance. The final two columns suggest that those with a greater history of submission finishes were more likely to achieve a submission in their current bout and tended to spend more fight time on the ground, where the majority of submissions occur. The interaction of REALBONUS with either KOTKOPCT or SUBPCT allows the marginal effect of bonus levels to vary by a fighter's prior history with KO/TKOs or submissions. These marginal effects are examined at the 10th, 25th, 50th, 75 th, and 90 th percentiles in 
Figure 4 and are presented with 95 percent confidence bands. All marginal effects of REALBONUS were insignificant, suggesting that while fighters of various types may strike and position themselves differently with different likelihoods of obtaining $\mathrm{KO} / \mathrm{TKO}$ or submission finishes, their performances do not appear to be meaningfully influenced by the level of fight night bonuses.

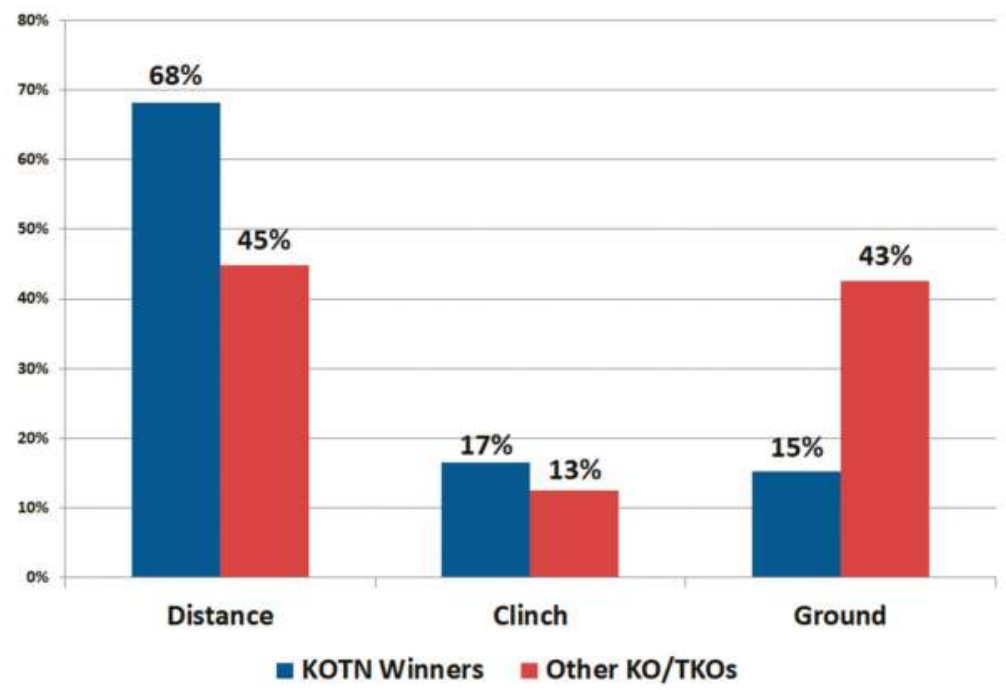

Figure 2. Fight ending positions for Knockout of the Night (KOTN) finishes and other KO/TKOs. Note: For all Zuffa-owned UFC and WEC bouts from 4 May 2001 through 1 February 2014.

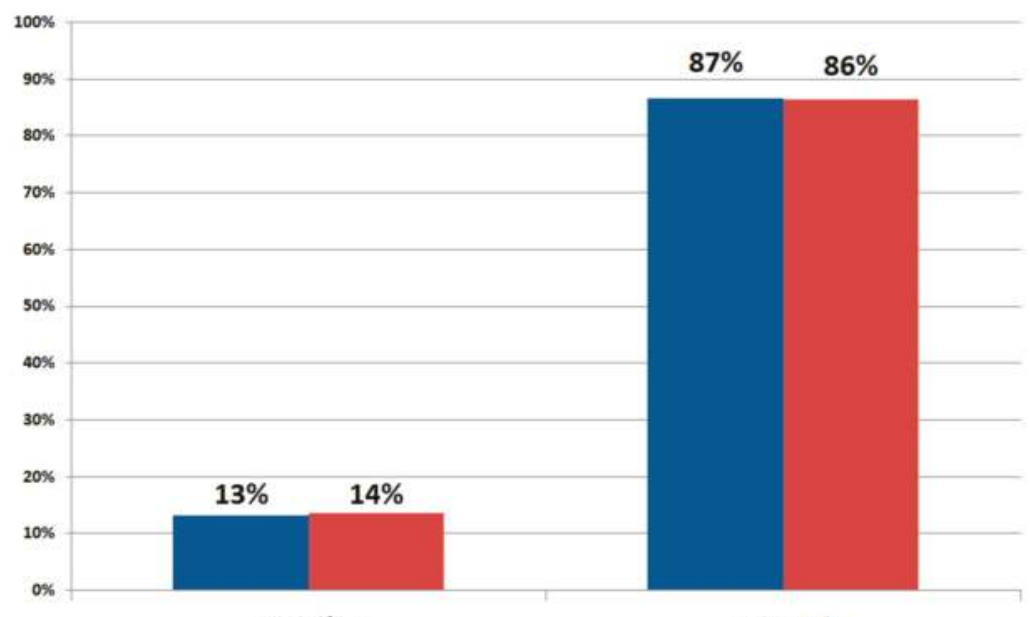

Standing
Ground

- SOTN Winners Other Submissions

Figure 3. Fight ending positions for Submission of the Night (SOTN) finishes and other submissions. Note: For all Zuffa-owned UFC and WEC bouts from 4 May 2001 through 1 February 2014. Standing position is when fighters are either at distance or in the clinch. 


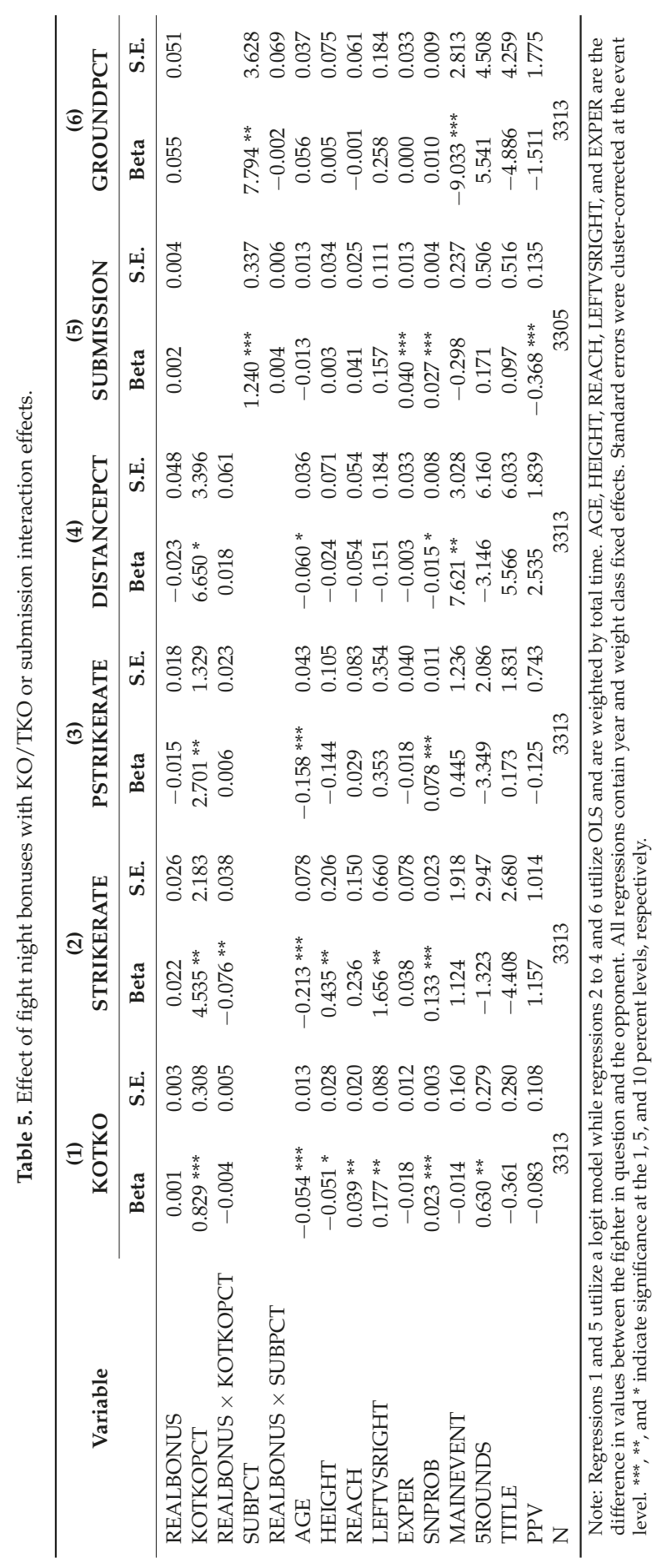


КОТKO

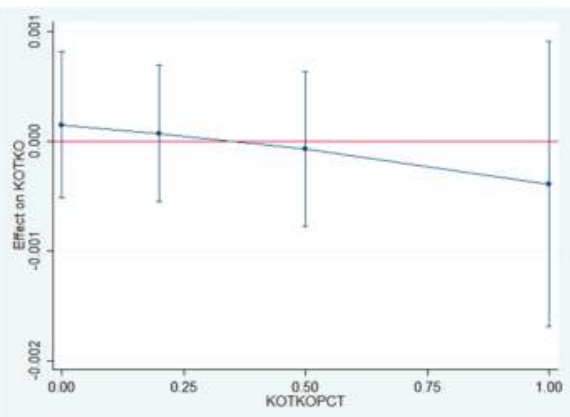

PSTRIKERATE

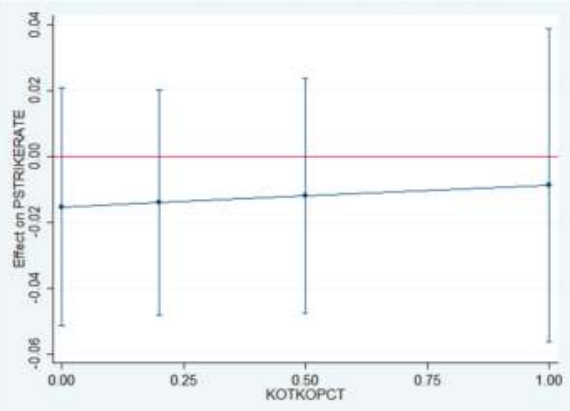

SUBMISSION

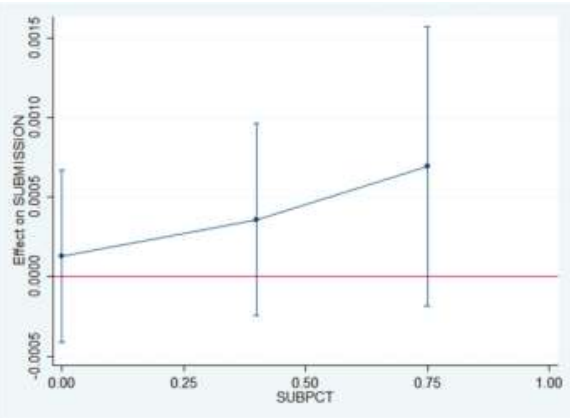

STRIKERATE
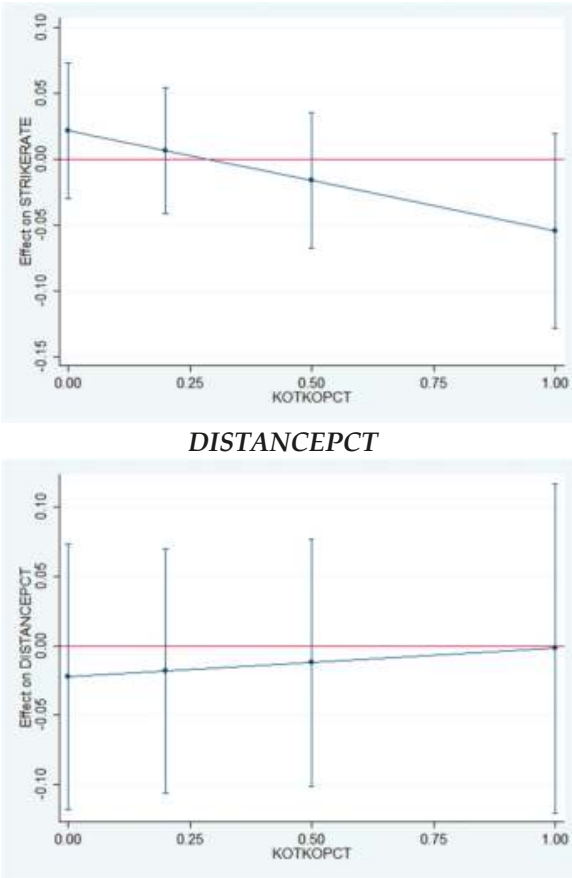

GROUNDPCT

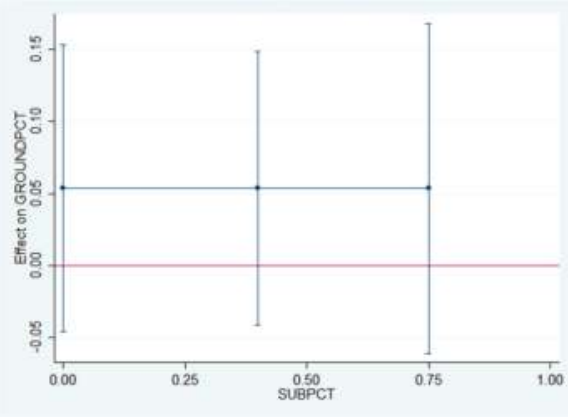

Figure 4. Marginal effects of REALBONUS with KOTKOPCT or SUBPCT interactions. Note: For all Zuffa-owned UFC and WEC bouts from 4 May 2001 through 1 February 2014. The 10th and 25th percentiles of KOTKOPCT and the 10th, 25th, and 50th percentiles of SUBPCT were identical at zero percent.

\section{Discussion}

Fight night bonuses in MMA are not unique to Zuffa (under the UFC and WEC promotions). Other promotions have utilized KOTN, SOTN, and FOTN bonuses or variants such as a special bonus for specific finishing moves, a bonus for every finish, or bonuses for making an "impression" on the CEO. To my knowledge, this is the first study to examine the incentive effects of particular MMA bonuses on fighter performance.

Tournament theory predicts that more effort will be put into production when there is a large difference between winning and losing payouts. Zuffa fighter payouts are known to take a variety of different potential forms, per court documents (Le et al. 2018). All fighters receive their contractual 
show money. Most fighters, but not all, earn a win money bonus for winning their bout, and it is often an amount equal to their show money. Some fighters receive contractual side-letter compensation, some earn PPV points, and "locker room" bonuses are sometimes paid to fighters at the discretion of UFC management. The latter three forms of compensation are private information between fighters and the UFC. However, show and win money payments are occasionally disclosed by the state or tribal athletic commissions regulating the event.

Since every fighter is, at minimum, guaranteed their show money, such data were collected from the Nevada State Athletic Commission for UFC events promoted in the state from 2001 to 2014 as well as 49 events in other states from public media reports. In all, show money data were collected for 2860 of the fighter-bouts in the sample period (55.2 percent). While an inherently incomplete picture of fighter compensation, Figure 5 shows the distribution of show money as one might expect in the tournament over time to become champion. Eighty-one percent of fighter appearances earned $\$ 25,000$ or less in guaranteed show money while 3.1 percent, generally champions or otherwise popular fighters, earned $\$ 150,000$ or more. The figure also allows for a visual distributional comparison of show money relative to fight night bonus amounts. For 76.1 percent of fighter appearances, a fight night bonus was worth more than their guaranteed show money and, on average, those bonuses were 269 percent larger than show money. Additionally, fighters can potentially win KOTN or SOTN in conjunction with FOTN to further increase their monetary compensation. ${ }^{9}$ Hence, relative to contracted show money compensation, Zuffa fight night bonuses should theoretically serve as a substantial monetary inducement to influence fighter behavior inside the cage.

While fighters are aware of bonus sizes before an event and have even lobbied UFC President Dana White to increase them (Marrocco 2013), the evidence in the present study does not suggest that MMA fighters' in-cage performances are affected by such monetary incentives. All findings suggest that fight finishes, striking activity, and fight positioning are unaffected by the size of fight night bonus awards.

While it is beyond the scope of this paper to perform an in-depth analysis on the mechanisms contributing to such a benign effect, fighter perceptions and the possibility of conflicting incentives may offer plausible explanations. First, marginal changes in effort levels from what they otherwise would have been without fight night bonuses may be perceived as only trivially affecting one's probability of finishing the opponent or generating excitement. When fighters are locked in the cage, not only are their livelihoods be on the line, but also their health and, potentially, their lives. Fighters may thus already be sufficiently incentivized to exert effort, not only to win the fight, but to keep from absorbing too much physical damage in the process.

Second, the marginal cost of additional effort may be substantial when opportunity costs are considered. As supported earlier by Figure 5, the compensation structure is heavily skewed in favor of champions, former champions, and those near the top of the rankings, not only in terms of salaries but also in-cage and out-of-cage endorsements. If marginal effort towards obtaining a bonus is detrimental to the probability of winning (e.g., hunting for a knockout), these non-linear future earnings would be further at risk.; and more immediately, a fighter's win bonus would be at risk. While win bonuses are often identical to a fighter's show money and therefore smaller than fight night bonuses, they are a guaranteed payment to all victorious fighters who have them in their promotional contract.

Third, the structure of fighter contracts may be another explanatory factor behind the findings of this paper. As a private company, the terms of Zuffa's fighter contracts were not public knowledge until a 2013 legal dispute led to disclosure of the promotion's standard contract. ${ }^{10}$ Examination of its terms reveals another potential incentive for devoting effort towards winning the bout instead of obtaining a bonus. Fighters typically sign multi-fight, exclusive contracts with the UFC, but they can

9 For example, Pat Barry won $\$ 120,000$ in bonuses (KOTN and FOTN) at UFC 104 while his contracted show and win money were $\$ 7000$ each.

10 In December 2012, Bellator's former lightweight champion, Eddie Alvarez, signed with the UFC. Bellator exercised its right of first refusal and sued Alvarez to enforce its contractual matching rights. 
be released any time they are "not declared the winner" of a bout (Snowden 2013). Thus, not only does a win progress a fighter up the rankings and towards higher future non-linear rewards, it also ensures the maintenance of their roster spot in the top MMA promotion in the world.
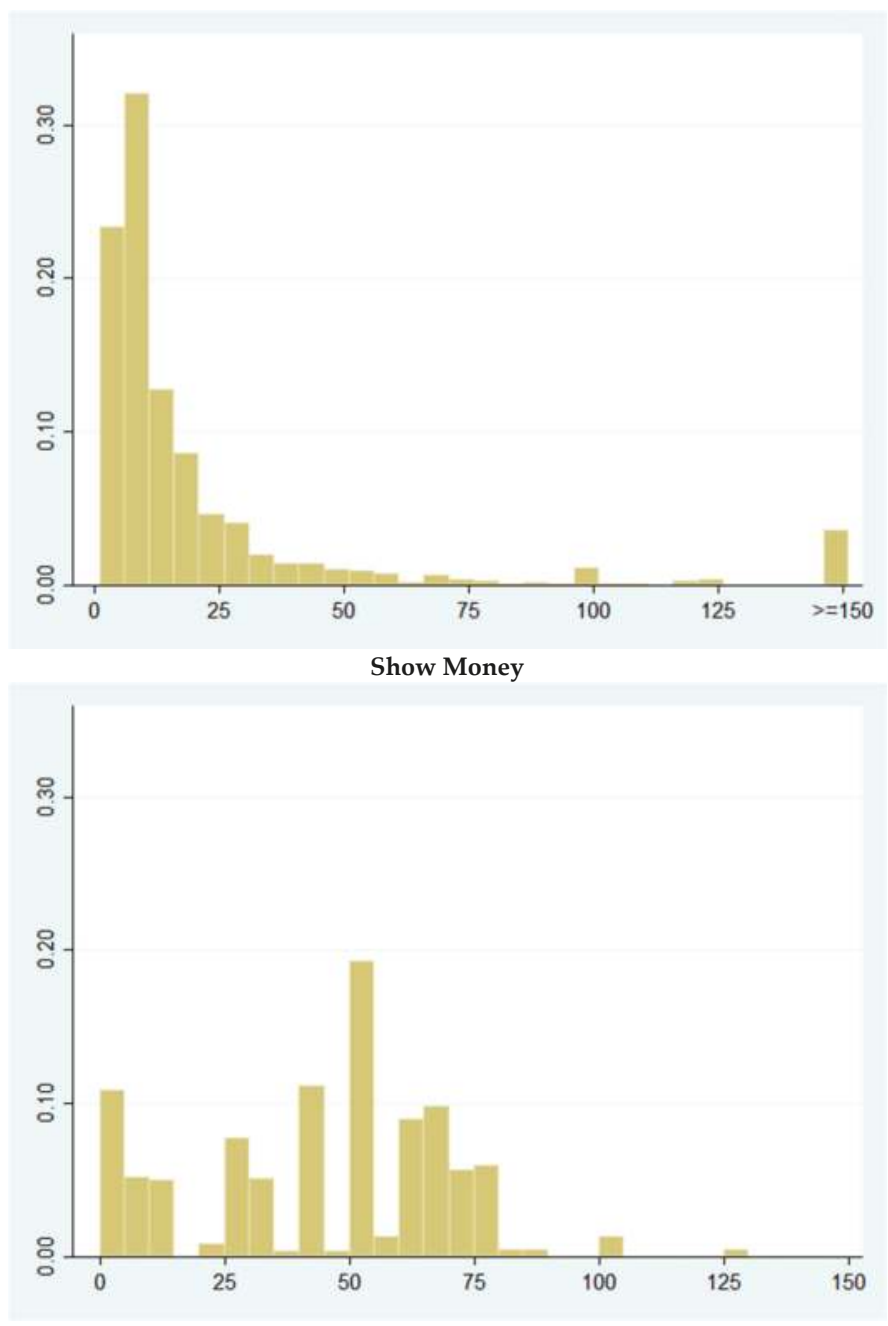

Fight Night Bonuses

Figure 5. Distribution of fighter show money and fight night bonuses. Note: UFC and WEC combined. Data in thousands of dollars.

In Berri et al. (2015) study of salary determination in the presence of fixed revenues, they found evidence that players in the Big 4 sports leagues were substantially overpaid by the logic of the traditional model of wage determination. They noted that owners were unlikely to systematically make errors of such magnitudes and argued that salaries reflect a combination of expected performance and bargaining power. With respect to the present study, if the sole purpose of fight night bonuses were to ex ante incentivize fighter performance, it seems unlikely UFC management would continue such a practice with a benign effect, especially considering that the next-largest competitor, Bellator MMA, does not utilize bonuses. 
One possibility is that fight night bonuses serve as an additional form of compensation via lottery and Zuffa's fighters exhibit risk seeking behavior. Optimism bias can lead to the overweighting of small probabilities and give rise to risk seeking (Kahneman and Tversky 1982). Bleichrodt et al. (2018) studied field hockey players and found that professional players were more optimistic and over weighted their probability of winning relative to a recreational group. McCann (2006) documented potential optimism bias in incentive-laden athlete contract negotiations. In the UFC, an anecdote is suggestive that fighters may prefer a portion of their compensation via lottery. In 2013, following a large amount of complaints about fighter pay, UFC President Dana White suggested the promotion could raise the pay of fighters on the lower end of the pay scale and eliminate fight night and locker room bonuses. Not long after, White stated, "I got a lot of feedback. The fighters want the (fight-night) bonuses and they want the discretionary bonuses to stay the same. So that's that" (Erickson 2013). Thus, while fight night bonuses do not appear to influence in-cage fighter performance, they may serve as a preferred method of additional compensation for fighters with optimism bias regarding their chances of winning such awards.

\section{Conclusions}

Fight night bonuses can be a powerful means to supplement living and training expenses, especially for a UFC fighter earning $\$ 8000$ to show and $\$ 8000$ to win by the end of the sample period. Yet even with these seemingly strong incentives and bonuses on average 269 percent larger than guaranteed show money pay, I find no evidence to suggest that fighters are meaningfully influenced by bonus levels within the observed range. Fighter perceptions regarding marginal changes in effort and conflicting incentives to move up in rankings, obtain a win bonus, and maintain one's Zuffa roster spot may offer plausible explanations. Fight night bonuses instead appear to serve as a lottery compensation mechanism to ex post reward performances consistent with an MMA promotion's desires rather than ex ante incentivize such performances and may be a preferred method of compensation for fighters with optimism bias.

Acknowledgments: I am grateful for helpful comments and suggestions from Rami Genauer, Michael Gift, seminar participants at Pepperdine University, conference participants at the Western Economic Association, and excellent research assistance from Willis Clow and Dai Shiheng. I would like to thank Rami Genauer and FightMetric LLC for providing the fighter performance data. Any remaining errors are my own.

Conflicts of Interest: The author declares no conflict of interest.

\section{References}

Becker, Brian, and Mark Huselid. 1992. The incentive effects of tournament compensation systems. Administrative Science Quarterly 37: 336-50. [CrossRef]

Berri, David, Michael Leeds, and Peter von Allmen. 2015. Salary determination in the presence of fixed revenues. International Journal of Sport Finance 10: 5-25.

Bieler, Des. 2016. New York Becomes Final State to Legalize MMA Events. Washingtonpost.com. Available online: https:/ /www.washingtonpost.com/news/early-lead/wp/2016/03/22/new-york-becomes-finalstate-to-legalize-mma-events (accessed on 12 February 2018).

Bleichrodt, Han, Olivier L'Haridon, and David Van Ass. 2018. The risk attitudes of professional athletes: Optimism and success are related. Decision 5: 95-118. [CrossRef]

Collier, Trevor, Andrew L. Johnson, and John Ruggiero. 2012. Aggression in mixed martial arts: An analysis of the likelihood of winning a decision. In Violence and Aggression in Sporting Contests: Economics, History, and Policy. Edited by R. Todd Jewell. New York: Springer, pp. 97-109.

Ehrenberg, Ronald, and Michael Bognanno. 1990a. Do tournaments have incentive effects? Journal of Political Economy 98: 1307-24. [CrossRef]

Ehrenberg, Ronald, and Michael Bognanno. 1990b. The incentive effects of tournaments revisited: Evidence from the European PGA tour. Industrial \& Labor Relations Review 43: 74S-88S. 
Erickson, Matt. 2013. Dana White Makes It Official: UFC Fight-Night Bonuses Staying. Mmajunkie.com. Available online: https:/ / mmajunkie.com/2013/07/dana-white-makes-it-official-ufc-fight-night-bonuses-staying (accessed on 12 May 2018).

Genauer, Rami. 2013. Interviewed by Paul Gift, Los Angeles, CA, January.

Gift, Paul. 2018. Moving the Needle in MMA: On the Marginal Revenue Product of UFC Fighters. Manuscript submitted for publication.

Kahneman, Daniel, and Amos Tversky. 1982. The psychology of preferences. Scientific American 246: 160-73. [CrossRef]

Lazear, Edward, and Paul Oyer. 2012. Personnel economics. In The Handbook of Organizational Economics. Edited by Robert Gibbons and John Roberts. Princeton: Princeton University Press, pp. 479-519.

Le, Cung, Nathan Quarry, Jon Fitch, Brandon Vera, Luis Javier Vazquez, Kyle Kingsbury, and Zuffa, LLC. 2018. Case No. 2:15-cv-01045-RFB-PAL. Zuffa, LLC's Opposition to Plaintiffs' Motion for Class Certification. ECF No. 540, Exhibit 92 (D. Nev. April 6, 2018).

Lynch, James, and Jeffrey Zax. 2000. The rewards to running. Journal of Sports Economics 1: 323-40. [CrossRef]

Maloney, Michael, and Robert McCormick. 2000. The response of workers to wages in tournaments: Evidence from foot races. Journal of Sports Economics 1: 99-123. [CrossRef]

Marrocco, Steven. 2013. Bryan Caraway Haggles for Bigger Fight-Night Bonuses at UFC 159. Mmajunkie.com. Available online: http:/ / mmajunkie.com/2013/04/bryan-caraway-haggles-for-bigger-fight-night-bonusesat-ufc-159 (accessed on 15 May 2018).

McCann, Michael. 2006. It's not about the money: The role of preferences, cognitive biases and heuristics among professional athletes. Brooklyn Law Review 71: 1459-528.

MMA Junkie Staff. 2013. All UFC Fight-Night Bonuses Now Capped at $\$ 50,000$. Mmajunkie.com. Available online: http:/ / mmajunkie.com/2013/03/all-ufc-fight-night-bonuses-now-capped-at-50000 (accessed on 15 May 2018).

Reams, Lamar, and Stephen Shapiro. 2017. Who's the main attraction? Star power as a determinant of Ultimate Fighting Championship pay-per-view demand. European Sport Management Quarterly 17: 132-51. [CrossRef]

Sauer, Raymond D. 2005. The state of research on markets for sports betting and suggested future directions. Journal of Economics and Finance 29: 416-26. [CrossRef]

Snowden, Jonathan. 2013. The Business of Fighting: A Look inside the UFC's Top-Secret Fighter Contract. Bleacherreport.com. Available online: https://bleacherreport.com/articles/1516575-the-business-offighting-a-look-inside-the-ufcs-top-secret-fighter-contract (accessed on 15 May 2018).

Tainsky, Scott, Steven Salaga, and Carla Almeida Santos. 2012. Estimating attendance for the Ultimate Fighting Championship: A demand theory approach. International Journal of Sport Management and Marketing 11: 206-24. [CrossRef]

Tainsky, Scott, Steven Salaga, and Carla Almeida Santos. 2013. Determinants of pay-per-view broadcast viewership in sports: The case of the Ultimate Fighting Championship. Journal of Sport Management 27: 43-58. [CrossRef]

Tenorio, Rafael. 2000. The economics of professional boxing contracts. Journal of Sports Economics 1: 363-84. [CrossRef]

UFC. 2014. UFC Statement on Fight Night Bonuses. Ufc.com. Available online: http://www.ufc.com/news/UFCStatement-on-Fight-Night-Bonuses (accessed on 19 May 2018).

UFC. 2019. About UFC. Ufc.com. Available online: https:/ /www.ufc.com/about (accessed on 9 January 2019).

U.S. House of Representatives Committee on Energy and Commerce. 2017. Perspectives on Mixed Martial Arts: Background Memo. House.gov. Available online: https:/ / docs.house.gov/meetings/IF/IF17/20171109/ 106604/HHRG-115-IF17-20171109-SD003.pdf (accessed on 15 December 2017).

Watanabe, Nicholas. 2012. Demand for pay-per-view consumption of Ultimate Fighting Championship events. International Journal of Sport Management and Marketing 11: 225-38. [CrossRef]

Watanabe, Nicholas. 2015. Sources of direct demand: An examination of demand for the Ultimate Fighting Championship. International Journal of Sport Finance 10: 26-41.

(C) 2019 by the author. Licensee MDPI, Basel, Switzerland. This article is an open access article distributed under the terms and conditions of the Creative Commons Attribution (CC BY) license (http:/ / creativecommons.org/licenses/by/4.0/). 
MDPI

St. Alban-Anlage 66

4052 Basel

Switzerland

Tel. +41616837734

Fax +41 613028918

www.mdpi.com

International Journal of Financial Studies Editorial Office

E-mail: ijfs@mdpi.com

www.mdpi.com/journal/ijfs

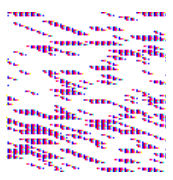



MDPI

St. Alban-Anlage 66

4052 Basel

Switzerland

Tel: +41 616837734

Fax: +41 613028918

www.mdpi.com 